


\section{Clean Energy Systems and Experiences}

edited by

Kei Eguchi 


\section{Clean Energy Systems and Experiences}

http://dx.doi.org/10.5772/246

Edited by Kei Eguchi

\section{(c) The Editor(s) and the Author(s) 2010}

The moral rights of the and the author(s) have been asserted.

All rights to the book as a whole are reserved by INTECH. The book as a whole (compilation) cannot be reproduced, distributed or used for commercial or non-commercial purposes without INTECH's written permission.

Enquiries concerning the use of the book should be directed to INTECH rights and permissions department (permissions@intechopen.com).

Violations are liable to prosecution under the governing Copyright Law.

\section{(cc) BY}

Individual chapters of this publication are distributed under the terms of the Creative Commons Attribution 3.0 Unported License which permits commercial use, distribution and reproduction of the individual chapters, provided the original author(s) and source publication are appropriately acknowledged. If so indicated, certain images may not be included under the Creative Commons license. In such cases users will need to obtain permission from the license holder to reproduce the material. More details and guidelines concerning content reuse and adaptation can be foundat http://www.intechopen.com/copyright-policy.html.

\section{Notice}

Statements and opinions expressed in the chapters are these of the individual contributors and not necessarily those of the editors or publisher. No responsibility is accepted for the accuracy of information contained in the published chapters. The publisher assumes no responsibility for any damage or injury to persons or property arising out of the use of any materials, instructions, methods or ideas contained in the book.

First published in Croatia, 2010 by INTECH d.o.o.

eBook (PDF) Published by IN TECH d.o.o.

Place and year of publication of eBook (PDF): Rijeka, 2019.

IntechOpen is the global imprint of IN TECH d.o.o.

Printed in Croatia

Legal deposit, Croatia: National and University Library in Zagreb

Additional hard and PDF copies can be obtained from orders@intechopen.com

Clean Energy Systems and Experiences

Edited by Kei Eguchi

p. cm.

ISBN 978-953-307-147-3

eBook (PDF) ISBN 978-953-51-5926-1 


\section{We are IntechOpen, \\ the world's leading publisher of Open Access books}

\section{Built by scientists, for scientists}

\section{$4,200+$}

Open access books available

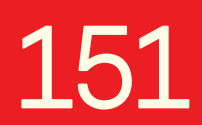

Countries delivered to

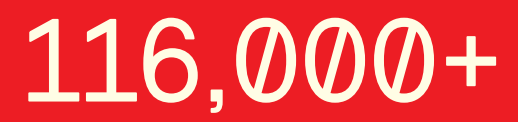

International authors and editors

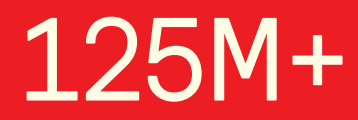

Downloads

Our authors are among the

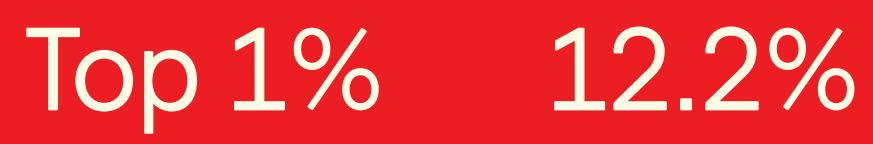

most cited scientists

Contributors from top 500 universities

\section{Interested in publishing with us? \\ Contact book.department@intechopen.com}

Numbers displayed above are based on latest data collected.

For more information visit www.intechopen.com 



\section{Meet the editor}

Kei Eguchi was born in Saga, Japan in 1972. He received the B.Eng., the M.Eng., and the D.Eng. degree from Kumamoto University, Kumamoto, Japan in 1994, 1996, and 1999, respectively. His research interests include nonlinear dynamical systems, intelligent circuits and systems, and low-voltage analog integrated circuits. From 1999 to 2006, he was an Associate Professor and a Lecturer in Kumamoto National College of Technology. From 2006 to 2012, he was an Associate Professor in Shizuoka University. In 2012, he joined the faculty of Fukuoka Institute of Technology, where he is now a Professor. Prof. Dr. Eguchi received ICICIC2017 Best Paper Award, 2016 Institute of Industrial Applications Engineers Award, 2016 Contribution Award of Japan Society of Technology Education, ICICIC2016 Best Paper Award, ICEEI2016 Excellent Oral Presentation Award, ICEESE2016 Best Presenter Award, Best Presentation Award in ICIAE2016, ICSGC2015 Excellent Oral Presentation Award, ICACTE2015 Excellent Paper Award, ICIC International Contribution Award, ICIAE2015 Best Presentation Award, Session Best Paper in IPECE15, Session Best Paper in ICEECE2015, ICPEE2014 Excellent Oral Presentation Award, iCABSE2014 Excellent Paper Award, KKU-IENC2014 Outstanding Paper Award, ICEEN2014 Excellent Paper Award, JTL-AEME2013 Best Paper Award, ICTEEP2013 Best Session Paper Award, 2010 Takayanagi Research Encourage Award, 2010 Paper Award of Japan Society of Technology Education, ICICIC2009 Best Paper Award, and ICINIS2009 Outstanding Contribution Award. He is a president of the Intelligent Networks and Systems Society and a senior member of IEEJ, IRED, EACEEE, SAISE, and APCBEES. 



\title{
Contents
}

\author{
Preface XI
}

Chapter 1 A DC/DC converter for clean-energy applications 1

Nimrod Vázquez, Claudia Hernández and Eslí Vázquez

Chapter 2 A dual-input DC-DC converter using clean energy power supplies Kei Eguchi

Chapter 3 Development of sustainable energy research and applications Abdeen Mustafa Omer

Chapter 4 The application of Ionic liquids in dissolution and separation of lignocellulose 71 Jianji Wang, Yong Zheng and Suojiang Zhang

Chapter 5 Decentralized production of hydrogen for residential PEM fuel cells from piped natural gas by low temperature steammethane reforming using sorption enhanced reaction concept 85 Michael G. Beaver and Shivaji Sircar

Chapter 6 Exergy analysis of low and high temperature water gas shift reactor with parabolic concentrating collector 107 Murat OZTURK

Chapter 7 Economic analysis of large-scale wind energy conversion systems in central anatolian Turkey 131 Mustafa Serdar GENÇ

Chapter 8 Energy systems comparison and clean high tech evolution 155 Gustav R. Grob

Chapter 9 Zero emissions future city $\mathbf{1 6 5}$ Jan Gorski and Evgeny Yantovsky 



\section{Preface}

Renewable energy sources such as solar power, wind power, hydroelectric power, geothermal power, and so on have attracted much attention as alternatives to fossil fuels, because toxins and pollutants are not produced by these sources. For this reason, these energy sources have come to be known as clean energy.

Currently, the introduction of clean energy is inferior to energy conservation in respect of cost. Although clean energy technologies are still under development, they are expected to play a prominent role in the achievement of world energy security and the realization of a sustainable society. Furthermore, clean energy technologies can provide opportunities for reducing greenhouse gases. For this reason, in order to realize a sustainable society through efforts to protect the environment, it is necessary to increase the amount of clean energy as a proportion of total global energy consumption. Therefore, it is a pressing need to develop outstanding clean energy technology.

This book reports the latest developments and trends in "clean energy systems and experiences". Discussions of new theory and novel applications of clean energy systems by a number of innovative researchers have been organized into nine chapters. The information in this book focuses particularly on: (1) Power converters for clean energy applications (Chapters 1 and 2); (2) Renewable energy sources for clean energy applications (Chapters 3 - 5); and (3) Analyses and comparisons of energy systems (Chapters 6 - 9). As a whole, the studies presented here reveal important new directions toward the realization of a sustainable society. The contributors to each chapter are energy scientists and engineers with strong expertise in their respective fields. This book offers a forum for exchanging state of the art scientific information and knowledge. We hope that this work will be used by scientists and engineers working in the area of clean energy and by industry researchers. If any technical errors exist in this book, the authors deeply appreciate readers' constructive comments for correction and improvement of future editions.

Editor

Kei Eguchi

Department of Technology Education

Shizuoka University

Japan 



\title{
A DC/DC converter for clean-energy applications
}

\author{
Nimrod Vázquez, Claudia Hernández and Eslí Vázquez \\ Instituto Tecnológico de Celaya \\ México
}

\section{Introduction}

Fossil fuels are depleting day by day, therefore it is imperative to find out alternative methods in order to fulfill the energy demand of the world. Renewable energy is becoming more important nowadays. There exist applications of renewable energy which employ hundred of MW (high power) and there are also those which uses hundred of W (low power). Applications can also be classified depending if they are connected to the grid or not, as well known as cogeneration and stand alone systems. This last one is a low power application, specially employed in remote places, where electricity is not available.

Usually photovoltaic and wind systems are the source of energy in stand alone systems. Efficient use of energy is very important, since there is no utility line; a battery set becomes essential because energy power is provided in an irregular way from the renewable source; leaving aside this issue a power conversion stage is required in order to make sure a good output power quality.

The operation of a dc/dc converter applicable in stand alone systems is discussed in this chapter, which is for using clean energy as it could be a photovoltaic panel or a wind turbine. The system optimizes delivered energy in a smart way, but assuring its availability in the best possible way.

Chapter is organized as follows: stand alone systems are described first, later on some converters reported in literature are discussed, and finally operation, energy administration and results of a dc/dc converter for clean-energy applications are presented.

\section{Stand alone systems and renewable sources}

Energy is not provided from the utility line for the stand alone systems but from renewable source, which depends on weather conditions. So that, in order to make sure there will exist availability of energy, when load required it, a battery set is traditionally considered. Power consumption is restricted to a maximum limit and it also is a finite measurable quantity, to deliver the more amount of energy its use has to be optimized.

A block diagram for stand alone systems is shown in Figure 1. Photovoltaic panel, wind turbine system or both can be used as renewable source of energy; reliable energy is provided by a power converter, which is fed from the renewable source and the battery set, it focus mainly to deliver a regulated voltage to the load. 
Certainly weather conditions restrict the renewable sources, but output power not only depends on wind speed or solar irradiance when it is employed a turbine system or a photovoltaic panel, also depend on the load. System behaviour for constant weather conditions is shown in Figure 2; traditionally the output power is plotted against its output voltage, but particularly for this graph the load is been changed, because the system depends on it. For different weather conditions similar graph can be obtained but the power varies according it.

When a renewable source is connected to a load not necessarily the maximum output power is consumed, as it is shown between A and B points in Figure 2. A maximum power point tracker (MPPT, point $\mathrm{B}$ ) is employed in order to optimize the obtained energy; however this is not completely required in stand alone application, due to the load is fixed or bounded and the power system requirements could be lower than the maximum obtainable from the renewable source.

When considering a photovoltaic system and a specific load connected to the stand alone system, there exist two different possibilities: first one occurs if the maximum energy obtained from the panel is lower than the output power (point $\mathrm{C}$ ) then it is necessary to use a battery in order to deliver the required amount of energy to the load; secondly, it may happen that the maximum energy obtained from the panel is higher or equal than the output power (a point between A and B) then no battery is needed.

A power converter must take into account these two scenarios in its operation form in order to provide a constant regulated output voltage no matter weather conditions. Obviously the amount of energy is finite and depends on the battery set and the climatic conditions.

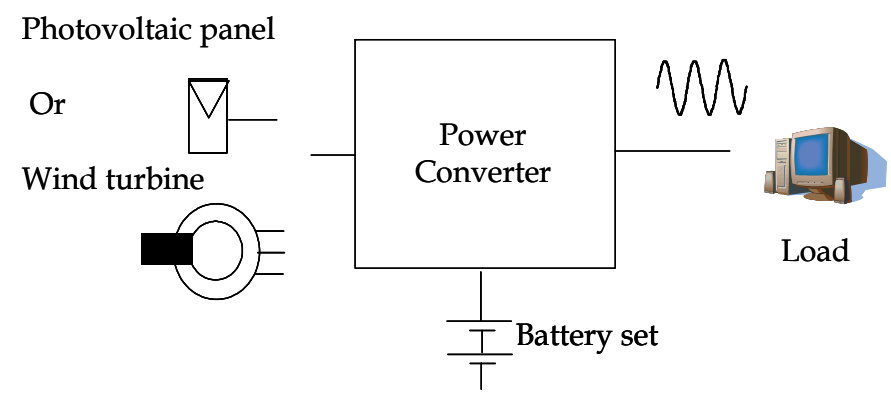

Fig. 1. Block diagram for stand-alone systems

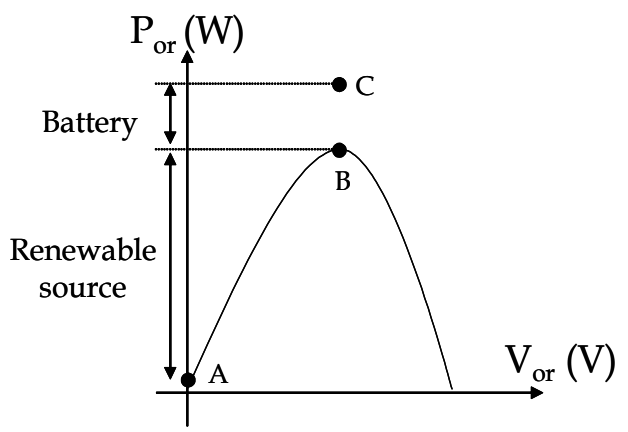

Fig. 2. Characteristic waveforms of renewable sources 


\section{State of the art in power conversion for renewable systems}

Power converters normally reported in literature (Carrasco et al., 2006) consider not only different power stages, but also different ways of operation. Some of them are connected to the grid but some others are stand alone systems. Fortunately, two types of converters are typically used no matter configuration: a dc/dc converter and a $\mathrm{dc} / \mathrm{ac}$ converter. This section describes some topologies reported in literature for renewable systems dealing with photovoltaic and wind systems.

\subsection{Grid connected systems}

Grid connected systems deliver the maximum obtainable power to the ac mains from the photovoltaic (PV) and/or wind system (Carrasco et al., 2006); since the provided energy is variable and dependent on weather conditions, the possible released energy is also variable. Algorithms like improved perturbation and observation method (Femia et al., 2009), sliding mode observer technique (Kim et al., 2006), or some others (Park et al., 2006; Kwon et al., 2006) are used to track the maximum power point (MPP).

In order to increase the system efficiency is preferred to have low voltage with the solar cell array (Ertl et al., 2002), and also some wind systems generate relatively low voltage. Therefore, converter in these application require boosting type converters, Figure 3 shows different topologies which provide current to the ac-mains.

Figure 3(a) shows a topology which considers two stages: a dc/dc boost converter and a $\mathrm{dc} / \mathrm{ac}$ converter (Kwon et al., 2006). Dc/dc is used for increasing the output voltage at a constant level allowing interaction to ac mains on the inverter stage, which is employed in order to perform the MPPT and deliver a sinusoidal current to the utility line. Converter illustrated in Figure 3(b) has also two stages: multiple isolated dc/dc converters and a multilevel inverter (Ertl et al., 2002); first stage is mainly used for isolation purposes and the next one to provide sinusoidal current to the ac mains.

It is normally found in literature systems which combine the power from two or more sources. Kobayashi et al. (2006) suggested a converter which is able to obtain energy from a PV array and the utility mains for telecommunication applications. Particularly for this case there are not energy injected to the ac mains. Walker \& Sernia (2004) proposed a cascade connection of dc/dc converter when multiple photovoltaic panels are employed, a single converter for each panel, also different dc/dc converters can be taken into account. Chen at al. (2007) presented a system which uses photovoltaic panels and a wind turbine as main inputs, the photovoltaic voltage is higher than the output voltage and the wind turbine voltage is lower than the output voltage.

Figure 4 shows converters which are able to handle photovoltaic arrays and/or wind systems. They are multiple input dc/dc converters, they have the purpose to increase the output power or deliver energy from different renewable sources. Figure 4(a) shows how buck and buck-boost dc/dc converters are integrated to produce a single output voltage (Chen et al., 2006). Specially for this topology one input has to have high voltage (or at least higher than the desired output voltage) and the other one could have a low voltage; the energy can be delivered independently from both inputs. 


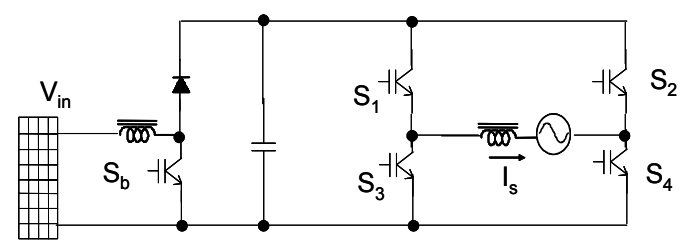

(a) Dc/dc converter and inverter
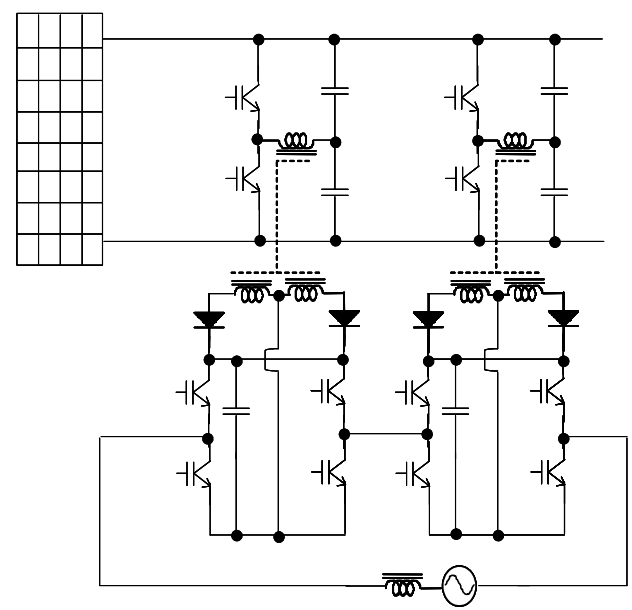

(b) Multiple dc/dc converters and multilevel inverter

Fig. 3. Topologies to inject current to the ac mains

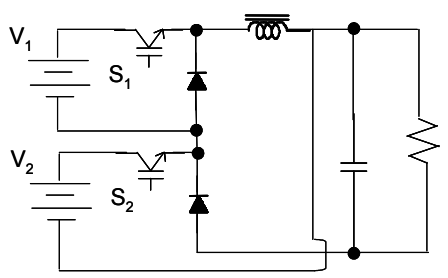

(a) Buck converter and buck-boost converter

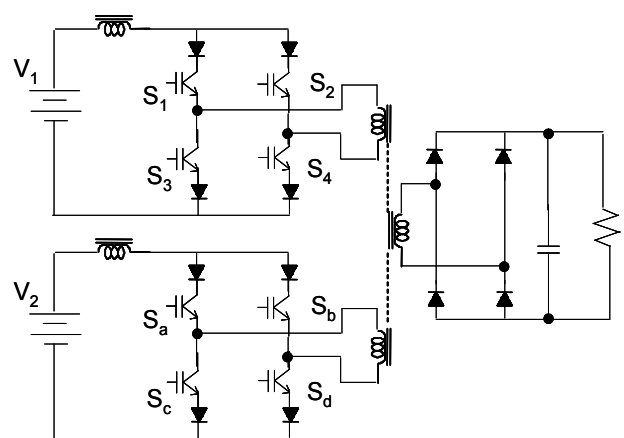

(b) Isolated converter

Fig. 4. Multi-input converters

Figure 4(b) illustrates an isolated converter (Chen et al., 2002), two inputs are magnetically coupled by a current fed transformer, for this case the two inputs may have different input voltage range, this is due to the transformer ratio which can be used to increase or decrease the voltage, however semiconductor counts is its major disadvantage. 


\subsection{Stand alone systems}

Stand alone systems are not connected to utility line, for this type of systems is compulsory to use a battery set in order to provide energy due to weather conditions. Energy is stored in the battery set and when it is completely charged then is ready to feed the load. Traditionally at this time the energy available from PV system is not used until the battery set is charged again.

Figure 5(a) shows a converter, which consist of two stages, proposed by Song and Enjeti (2004). The first stage is a dc/dc boost converter that increases the input voltage, but also charges the battery set. The second stage is a dc/ac converter based on an inverter plus an ac/ac converter, which is fed in straight way by the battery set, this feature turns out to be its major disadvantage because the battery is charged continuously and deteriorates its useful life.

Figure 5(b) illustrates a dc/dc converter for stand alone applications based on the integration of different dc/dc converters. Energy, which can be administrated by having control on the switches, is delivered in three modes: the first one feeds the load and charge the battery set simultaneously from the renewable source, the second one delivers energy from the sources to the load, and finally, the last one when the battery set provides all the energy to the load. However, it is not possible to deliver energy only from the renewable source for this topology, so that the battery set is always involved, which deteriorate its useful life.

A converter, which is able to deliver energy from the renewable source without the use of the battery set, is suggested in next sections. Not only an optimum use of the renewable source and the battery set is achieved with the proposed topology but also similar operating modes are allowed as those proposed by Pacheco et al. (2002). Energy may be delivered by the battery set or the renewable source independently and also simultaneously from both sources with the aid of a smart use of the energy available from the renewable source.

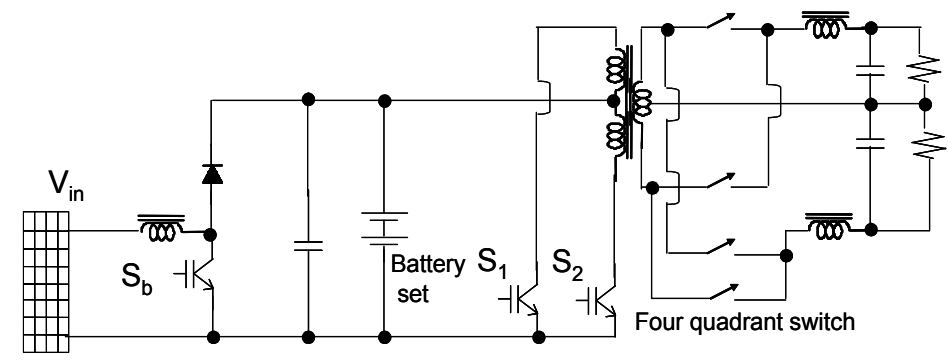

(a) Isolated converter

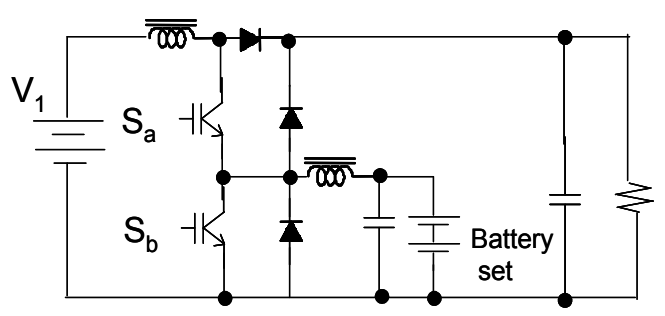

(b) Integrated converter

Fig. 5. Converters for stand alone systems 


\section{A dc/dc converter applicable in renewable systems}

It is analyzed a topology based on a step-up converter, which also accepts two input voltages (as shown in Figure 6(a)). Output for this converter can be connected to DC loads or an inverter for AC loads. The system is composed by a dc/dc boost converter and two input sources are located with the aid of some extra components, as it is shown in same figure. An input could be a photovoltaic or wind system, and the other one is a battery set. Converter is capable of being operated in four modes, first and second modes occur when the power becomes just from one input, the third one happens when no energy is available from both sources and finally the last one when energy is demanded from both inputs. These operating modes are employed to feed the load by having an optimization of the energy obtained from the renewable source.

Energy is provided completely from the renewable system, if is able to do it, depending on weather circumstances and without using the battery set. Also if there is not enough power, an energy complement may be delivered from the battery set, just in case it is required to do so, then energy is taken from both voltage sources in a complementary way. Finally if there is no available power from the wind system then energy is provided from the battery set only. Operating this way allows optimizing the use of the battery set and also obtainable energy from the photovoltaic/wind system.

\subsection{Operation modes of the converter}

Converter is operated in different established modes by switching states of semiconductors involved $\left(S_{1}, S_{2}\right.$ and $\left.S_{m}\right)$, as described next:

- $\quad$ Power delivered from one of the voltage source.

There exist two possibilities for this operating form. Figure 6(b) and (c) shows the equivalent circuits. If energy is just delivered by wind system, then the auxiliary switch $S_{1}$ is turned off and the switch $S_{2}$ is on, as illustrate in Figure $6(b)$. When the wind system cannot provide the required energy to the load, then the auxiliary switch $S_{2}$ is turned off and the switch $S_{1}$ is turned on, in this case the energy is delivered only by the battery set as shown in Figure $6(\mathrm{c})$. Semiconductor $S_{\mathrm{m}}$ is switching to regulate the output voltage independently of the source used.

- Not energy available from the voltage sources

It is possible not to have energy due to weather conditions and the battery set may be discharged. The two auxiliary switches $\left(S_{1}\right.$ and $\left.S_{2}\right)$ are turned off as shown in Figure 6(d). As a consequence there is not energy available to regulate the output voltage so that the remaining energy is delivered by the free wheeling diodes.

- $\quad$ Power delivered from both voltages sources

When wind/photovoltaic system cannot provide all required energy by the load, but still there is available energy, then the system could be operated to demand energy from both sources: the wind/photovoltaic system and the battery set. This mode occurs if $S_{1}$ and $S_{2}$ are turned on simultaneously or if they are alternated at different times. This last switching state was used in the converter as illustrated in Figure 7. 


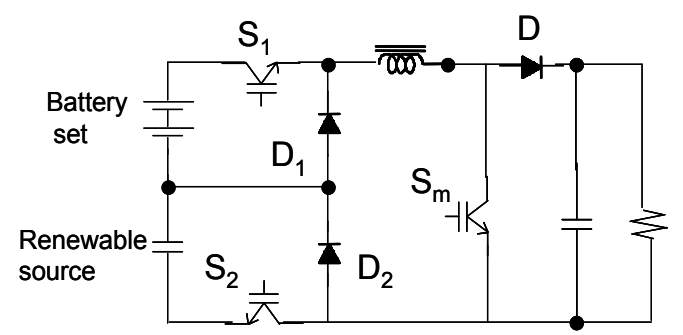

(a) Analyzed converter

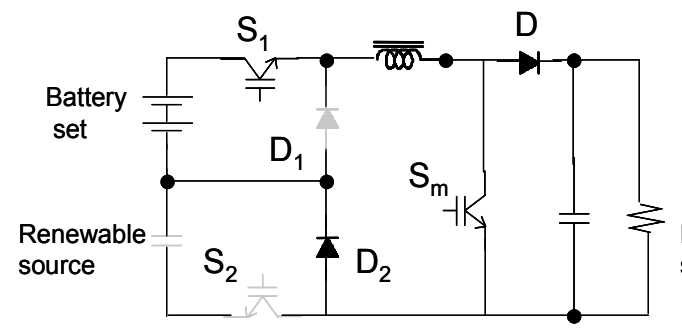

(c) Circuit when $S_{1}$ is on

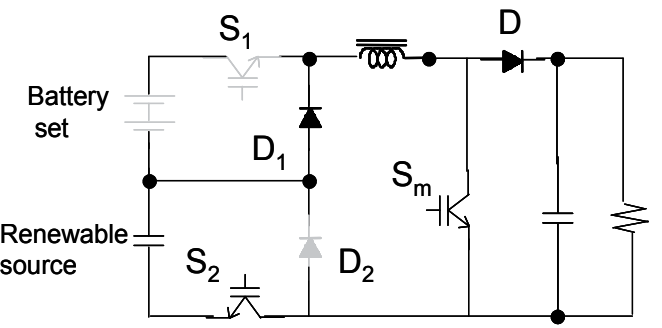

(b) Circuit when $S_{2}$ is on

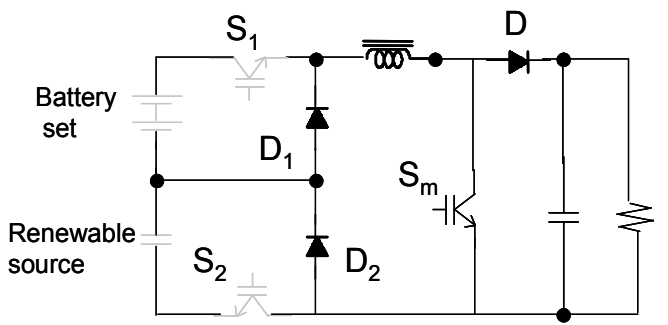

(d) Circuit when $S_{1}$ and $S_{2}$ are off

Fig. 6. The dc/dc converter and its different stages

Figure 7 shows control signals of the semiconductors in order to deliver energy from both voltage sources, a low constant switching frequency is considered; control signals $S_{1}$ and $S_{2}$ are complementary, the duty cycle is used for controlling the amount of energy given by each source. A constant output power to the load is provided by switching the main semiconductor $S_{m}$, which guarantied the appropriate output voltage, however in order to be able to increase the efficiency the auxiliary switches are turned on and off in a complementary way at low switching frequency.

\subsection{Energy administration}

Since the converter is designed for stand alone applications, the load is only fed by the renewable source and the stored energy in the battery set. System gives priority to the power obtained from the renewable source for optimizing the energy use, this means: energy from the battery is taken into account just when is really needed due to weather conditions and/or output power.

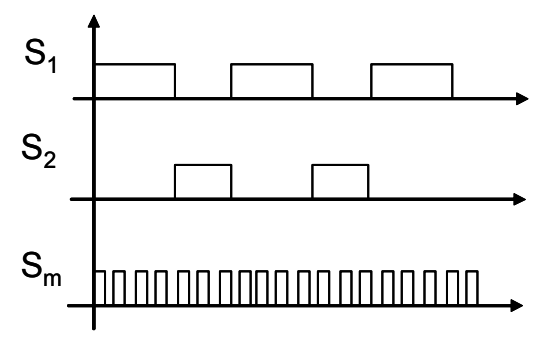

Fig. 7. Control signals. 
Output power, which depends on the load, is not only constant for certain specific conditions but also is bounded, so that the boost converter must be controlled in order to regulate the output voltage and makes sure to maintain the required output voltage at the load. All this is made by using a sliding mode controller in order to introduce a good dynamic response to the system (Sira-Ramirez \& Rios-Bolivar, 1994). The sliding surface considered allows avoiding the use of current sensors (Vazquez et al., 2003).

In spite of weather conditions, output power must be maintained, so that the system takes in consideration the battery set in order to supply the required energy which allows feed the load properly. Auxiliary switches are turned on and off depending on the availability of the renewable source, in order to be able to do this a modified MPPT algorithm, which is performed with a microcontroller, is considered.

Modified MPPT not only defines the maximum power point (MPP) for the renewable source but also established when the energy must be taken either from the two voltage sources or just from a single one. Algorithm determines when the renewable source delivers the possible maximum power in order to optimise its use and the battery set provides the complement. Sometimes when the required load power is lower than the maximum and the demanded energy can be obtained from the renewable source, the maximum point is not tracked.

The system is turned off for safety purposes when energy is not enough to maintain the system operation because the battery set is discharged.

\section{(a) Modified MPPT algorithm}

Figure 2 shows the renewable source behaviour for certain weather conditions, the output power may be different depending on the load. The figure illustrates three points, where each point represents a specific load power. If load requires power between points A and B, then the photovoltaic/wind system is able to provide the total load power, this leads that the system must be inside the curve behaviour of the renewable system and the maximum point is not tracked. However, if load demands a power higher than the possible provided from point $B$, as well it could be point $C$, then the battery provides the rest of power in order to reach the total load power, especially at this point the renewable system must be operated to track the MPP.

Operation mentioned before is achieved with aid of a modified MPPT algorithm; Figure 8 shows the flow chart. The method is based on the perturbation and observation technique, voltage and power of the renewable source are used as inputs. Depending on system conditions the duty cycle of auxiliary switch $S_{2}$ must be increased or decreased, it should be notice that the other auxiliary switch $\left(\mathrm{S}_{1}\right)$ has a complement operation in order to demand the complement power from the battery set. 


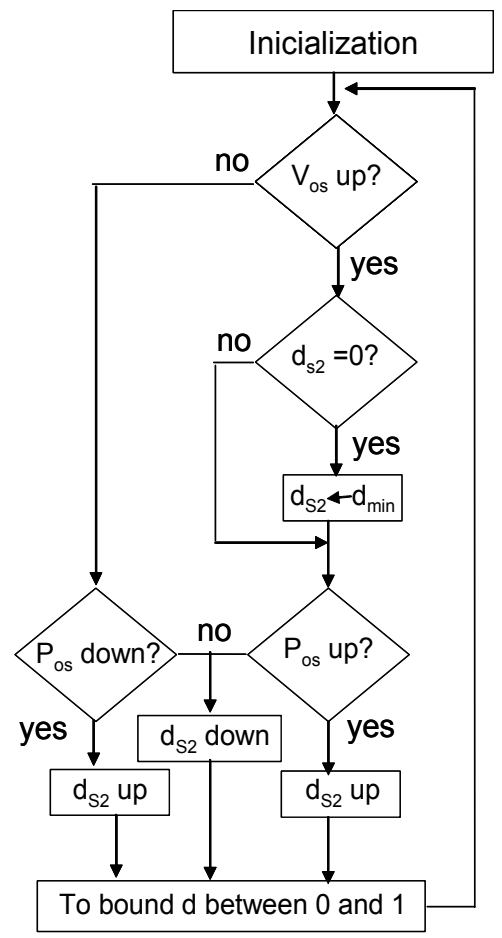

Fig. 8. Flow diagram of the modified MPPT algorithm.

It is an important part of algorithm that duty cycle, due to its natural values, must be bounded to a maximum and minimum value ( 1 and 0$)$. Particularly when the duty cycle is limited to a unity, the system is not tracking the MPP, then it operates inside the curve behaviour (between points A and B). While algorithm is continuously sensing the voltage and power, the duty cycle is set to the working condition.

For the case when the duty cycle is zero and a voltage variation is detected at the renewable system, the duty cycle of $S_{2}$ is set to minimum value, to permit the operation of the system.

\subsection{Controlling the dc/dc boost converter}

A sliding mode controller is employed for controlling the $\mathrm{dc} / \mathrm{dc}$ boost converter, the main switch $\left(\mathrm{S}_{\mathrm{m}}\right)$ is used for this purpose and the output voltage is tighly regulated. The sliding mode control offers good characteristics to the system: fast regulation and robustness under input voltage and load variations (Sira-Ramirez and Rios-Bolivar ,1994). The following sliding surface and control law are used:

$$
\begin{gathered}
\sigma=s_{1} e_{x}+k_{p} e_{y}+k_{i} e_{z}=0 \\
u= \begin{cases}1 & \text { If } \sigma<0 \\
0 & \text { If } \sigma>0\end{cases}
\end{gathered}
$$


Where:

$$
\begin{aligned}
& \dot{e}_{x}=f(t)-k_{i} e_{x}, \\
& e_{y}=x_{2}-x_{2 r}, \\
& \dot{e}_{z}=x_{2}-x_{2 r} \\
& f(t)=a-w_{o} x_{2}(1-u), \\
& s_{1}, k_{c} \text { and } k_{i} \text { are the controller parameters }
\end{aligned}
$$

The dc/dc boost converter model is:

$$
\begin{gathered}
\dot{x}_{1}=a-w_{0} x_{2}(1-u) \\
\dot{x}_{2}=-b+w_{0} x_{1}(1-u)
\end{gathered}
$$

Where:

$$
\begin{aligned}
& u= \begin{cases}1 & S_{m} \text { turn on } \\
0 & S_{m} \text { turn off }\end{cases} \\
& x_{1}=i_{L} \sqrt{L}, x_{2}=v_{o} \sqrt{C}, \\
& w_{o}=1 / \sqrt{L C}, a=V_{\text {in }} / \sqrt{L}, b=i_{o} / \sqrt{C} \\
& V_{\text {in }}=u_{2} * V_{\text {wind }}+u_{1} * V_{b a t},
\end{aligned}
$$

$u_{2}$ and $u_{1}$ are the control signals of the auxiliary switches

In order to make sure that operation of the sliding mode controller, an existance of the sliding mode and an stability analysis must be done.

(a) The sliding mode existance

In order to verify the existance condition the following condition must be fulfilled (SiraRamirez \& Rios-Bolivar ,1994):

$$
\sigma \dot{\sigma}<0
$$

This last expression must be fulfilled, therefore control law values of (2) are taken into account together with (3), and it is obtained next:

$$
\begin{aligned}
& \text { If } u=+1 \rightarrow \sigma<0 \text {; then } \dot{\sigma}>0 \\
& \text { If } u=-1 \rightarrow \sigma>0 \text {; then } \dot{\sigma}<0
\end{aligned}
$$

Using equations (1), (3) and (5) is obtained:

$$
\dot{\sigma}=-\frac{w_{0}}{2}\left\{s_{1} x_{2}-x_{1}\right\}(1-u)+s_{1} a-b+k_{i}\left(x_{2}-x_{2 r}\right)=0
$$

With expressions (5) and (6) existence conditions are:

$$
\begin{gathered}
r>0 \\
-w_{0}\left\{s_{1} x_{2}-x_{1}\right\}+r<0
\end{gathered}
$$


Where: $r=s_{1} a-b+k_{i} e x_{2}-\dot{x}_{2 r}$

(b) The stability analysis

The analysis of stability for the controller is made with the equivalent control; which is substituted into the system model, and is verified under that condition.

The equivalent control is the control law when the system is into the sliding surface, and it is obtained from $\sigma=0$, however changing the control law $(u)$ for the equivalent control $u_{e q}$ is obtained:

$$
u_{e q}=1-\frac{s_{1} a-b+k_{i}\left(x_{2}-x_{2 r}\right)}{\frac{w_{0}}{2}\left\{s_{1} x_{2}-x_{1}\right\}}
$$

This analysis is beyond purposes for this communication, so it is not included, but the result has to fulfill the following inequality:

$$
0<k_{i}<s_{1} \omega_{1}
$$

The inequality (9) is an approximation, but establishes a region where system is stable.

(c) The implemented circuit

Figure 9 shows the circuit for implementing expressions (1) and (2). There are four important parts represented in blocks. Block $A$ is used to obtain the funtion $f(t)$ which emulates the inductor current, block $\mathrm{B}$ determines the variable $e_{x}$, the circuit for implementing equations (1) and (2) is shown in the block $C$; an operational amplifier and a comparator are used. The operational amplifier is employed for proportional and integral operation of voltage error and comparator in order to obtain the control law. A soft start was performed with a capacitor, this allows to the reference initiate in zero voltage condition at the start up.

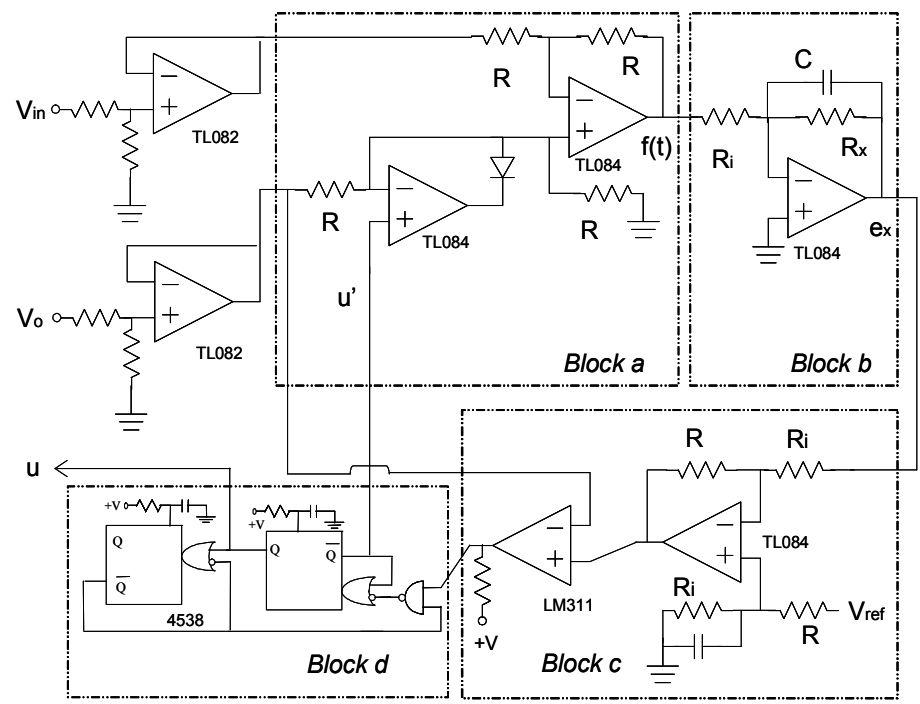

Fig. 9. Implemented controller for the dc/dc boost converter. 


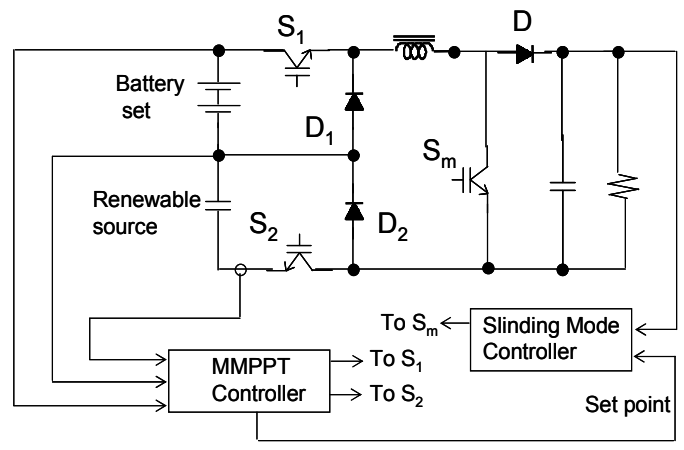

Fig. 10. Block diagram of the implemented system.

Since the ideal sliding mode controller has an infinite switching frequency, a circuit to limit is employed. For this purpose the block D is employed. Two CMOS logic circuits are used, the timer 4538 and the NAND gate 4011.

An important part for the implementation is block A, for the $f(t)$ term. A multiplying factor is involved in the expression, however it is also easy to implement. Actually the control law operates as if it was an analogue gate, which allows voltage appears or disappears with control law. For implementing this part, two operational amplifiers and a diode are employed; the diode with an operational amplifier makes same function as an analogue gate.

Summarizing, five integrated circuits are used; six operational amplifiers build it up into the TL084 and TL082, a comparator (LM311), and two CMOS logic circuits 4538 and 4011.

\subsection{The complete system}

A block diagram for the implemented control system and the dc/dc converter analyzed is shown in Figure 10. A microcontrolloer is used for performing the modified MPPT algorithm, voltage and current of the renewable source are measured; additionally a sliding mode controller is considered for regulating the output voltage of the $\mathrm{dc} / \mathrm{dc}$ boost converter.

\subsection{Simulation and experimental evaluation}

System functionality was not only mathematically simulated but also an experimental prototype was built, so that converter operation was validated. Battery set voltage was $48 \mathrm{~V}$, and a low power wind system is considered, the dc/dc converter output voltage was $250 \mathrm{~V}$, the output power was $300 \mathrm{~V}$. Figures 11 through 15 shows some simulation and experimental results.

Figure 11 illustrates operation when wind system proportionate all the energy. Inductor current, output voltage and also control signal for the main switch are shown.

Figure 12 shows opertation when energy is provided from both input voltages. Inductor current, output voltage, control signal for the main switch and control signal of the auxiliary switches are also shown. It should be noticed that the auxiliary switches are operating at low frequency and the main switch at high frequency. 


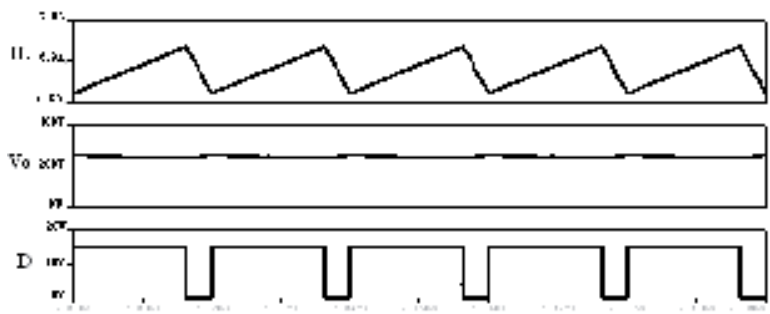

Fig. 11. Simulated waveforms when only one input voltage is available: the inductor current $\left(\mathrm{I}_{\mathrm{L}}\right)$, output voltage $\left(\mathrm{V}_{\mathrm{o}}\right)$ and duty cycle $(\mathrm{D})$. (From top to bottom).

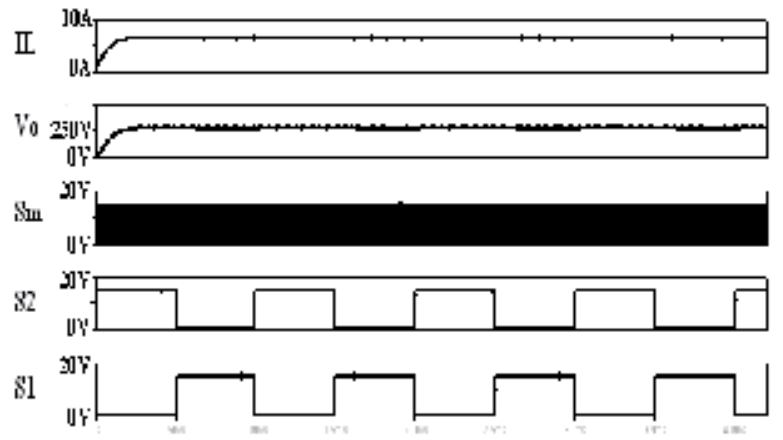

Fig. 12. Simulated waveforms when two inputs are in use: inductor current $\left(\mathrm{I}_{\mathrm{L}}\right)$, output voltage $\left(\mathrm{V}_{\mathrm{o}}\right)$, control signal of the main switch $\left(\mathrm{S}_{\mathrm{m}}\right)$ and control signals of the auxiliary switches $\left(S_{2}, S_{1}\right)$. (From top to bottom).

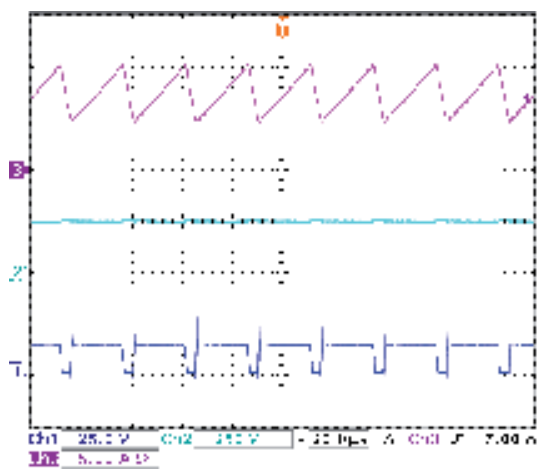

Fig. 13. Experimental waveforms when the wind system is only operating: the inductor current $\left(\mathrm{I}_{\mathrm{L}}\right)$, output voltage $\left(\mathrm{V}_{\mathrm{o}}\right)$ and duty cycle $(\mathrm{D})$. (From top to bottom).

Figure 13 shows experimental results when wind system deliver all the energy to the load. The inductor current, output voltage and also control signal for the main switch are shown. Figure 14 illustrates operation when energy is taken from both voltage sources. Output voltage, inductor current, and also auxiliary swithces are shown.

Figure 15 shows a test when wind turbine changes its MPP due to a variation on weather conditions, it is easily seen how the system is being automatically adapted. Energy delivered 
to the load from the emulated renewable source is higher than energy available before variation, particularly for this case the battery set is providing energy too.

(a) Testing the modified MPPT algorithm

In spite of the waveform shown in Figure 15, system performance was evaluated with other circuit with a known MPP. Mainly the reason for doing this is explained because in a wind turbine or photovoltaic panel the MPP cannot be determined accurately under real performance.

System behaviour in a real situation is relatively difficult to verify because depends on weather conditions. In order to avoid this situation a simple laboratory emulator was implemented, as shown in Figure 16. Emulator circuits consists of a voltage source with an inductace and resistance in series with it, and a capacitor, where inductor and capacitor are included for filtering purpose. In steady state the output power is determined by:

$$
P_{o s}=\frac{-v_{o s}^{2}+v_{o s} V_{s}}{R_{s}}
$$

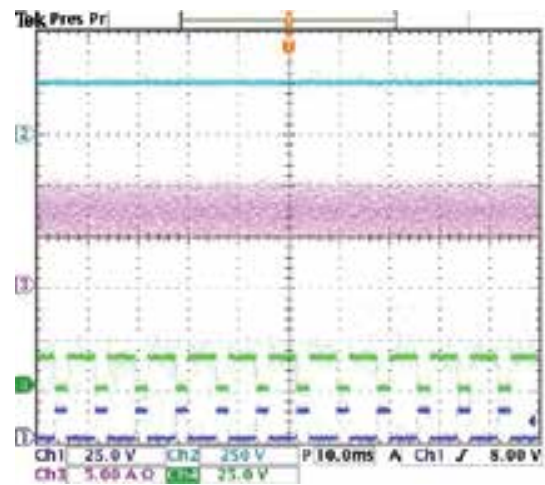

Fig. 14. Experimental waveforms when two inputs are in use: output voltage $\left(\mathrm{V}_{\mathrm{o}}\right)$, inductor current $\left(\mathrm{I}_{\mathrm{L}}\right)$, and control signal of the auxiliary switches. (From top to bottom).

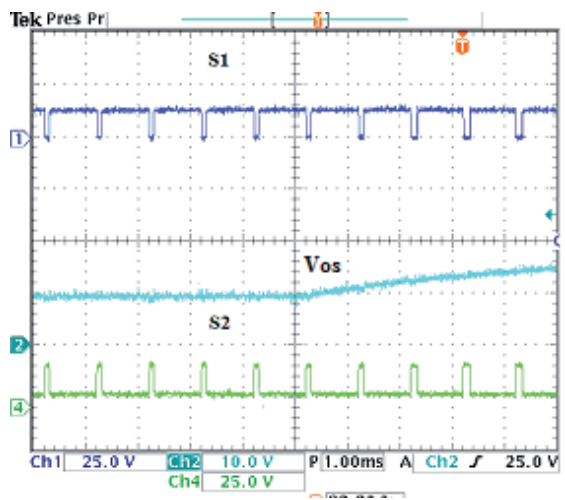

Fig. 15. Experimental waveforms under variation of climatic conditions: Auxiliary signal $\mathrm{S}_{1}$, output of the renewable source, and auxiliary signal $S_{2}$. (From top to bottom). 


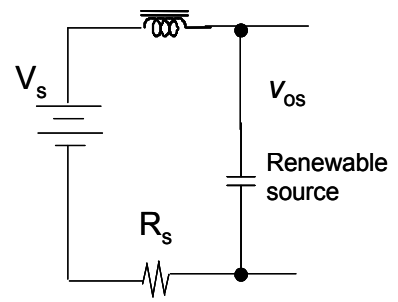

Fig. 16. Emulator as renewable source.

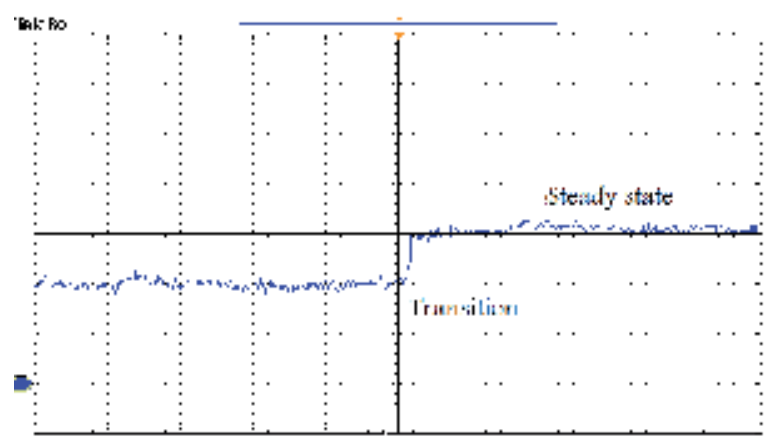

Fig. 17. Experimental waveforms under simulated variation of climatic conditions: output of the renewable source.

Where: $v_{o s}$ is the emulated output voltage,

$V_{s}$ is the input voltage, $R_{s}$ is the series resistance

Maximum power point occurs at the half of $\mathrm{V}_{\mathrm{s}}$, and the power is:

$$
P_{M P P}=\frac{V_{s}^{2}}{4 R_{s}}
$$

When a different maximum power point is required to evaluate the performance, it is just necessary to change the series resistance or the input voltage $\left(V_{s}\right)$. Then the system can be tested under controlled circumstances and with a known MPP.

Figure 17 shows converter operation when the emulated renewable source is not providing all the energy to the load and suddenly a variation is made. The system is adapted to the new condition, as the MPP are known in each case and the system reach them, then its reliability was verified. 


\section{References}

Carrasco, J.M.; Garcia, L.; Bialasiewicz, J. T.; Galván, E.; Portillo, R. C.; Martín, Ma. A.; León, J. I. \& Moreno-Alfonso N. (2006). Power-Electronic Systems for the Grid Integration of Renewable Energy Sources: A Survey, IEEE Transactions on Industrial Electronics, Vol. 53, No. 4, August, 2006, pp 1002-1016, ISSN 0278-0046

Chen, Y.M.; Liu, Y.C. \& YuWu, F. (2002). Multi- Input DC/DC Converter Based on the Multiwinding Transformer for Renewable Energy Applications, IEEE transactions on industry applications, Vol. 38, No. 4, July/August, 2002, pp 1096-1104, ISSN 00939994

Chen, Y.M.; Liu, Y.C. \& Lin, S.H. (2006). Double-Input PWM DC/DC Converter for High/Low-Voltage Sources, IEEE Transactions on Industrial Electronics, Vol. 53, No. 5, October, 2006, pp 1538-1545, ISSN 0278-0046

Chen, Y.M.; Liu, Y.C.; Hung, S.C. \& Cheng, C.S. (2007). Multi-Input Inverter for Grid Connected Hybrid PV/Wind Power System, IEEE transactions on power electronics, Vol. 22, No. 3, May, 2007, pp. 1070-1077, ISSN 0885-8933

Ertl, H.; Kolar, J. W. \& Zach, F.C. (2002). A Novel Multicell DC-AC Converter for Applications in Renewable Energy Systems, IEEE Transactions on industrial Electronics, Vol. 49, No. 5, October, 2002, pp 1048-1057, ISSN 0278-0046

Femia, N.; Petrone, G.; Spagnuolo, G. \& Vitelli, M. (2009). A Technique for Improving P\&O MPPT Performances of Double-Stage Grid-Connected Photovoltaic Systems, IEEE Transactions on Industrial Electronics, Vol. 56, No. 11, November, 2009, pp 4473-4482, ISSN 0278-0046

Kim, I.S.; Kim, M.B. \& Youn, M.J. (2006). New Maximum Power Point Tracker Using Sliding-Mode Observer for Estimation of Solar Array Current in the GridConnected Photovoltaic System, IEEE Transactions on Industrial Electronics, Vol. 53, No. 4, August, 2006, pp 1027-1035, ISSN 0278-0046

Kobayashi, K.; Matsuo, H. \& Sekine, Y. (2006). Novel Solar-Cell Power Supply System Using a Multiple-Input DC-DC Converter, IEEE Transactions on Industrial Electronics, Vol.53, No. 1, February, 2006, pp 281-286, ISSN 0278-0046

Kwon, J.M.; Nam, K.H. \& Kwon, B.H. (2006). Photovoltaic Power Conditioning System with Line Connection, IEEE Transactions on Industrial Electronics, Vol. 53, No. 4, August, 2006, pp 1048-1054, ISSN 0278-0046

Pacheco, V. M.; Freitas, L. C.; Vieira Jr., J.B.; Coelho, E.A.A. \& Farias, V.J. (2002). A DC-DC Converter Adequate for Alternative Supply System Applications, Proceedings of IEEE Applied Power Electronics Conference and Exposition, pp. 1074-1080, ISBN 0-78037404-5, USA, March 2002, IEEE, Dallas

Park, J.H.; Ahn, J.Y.; Cho, B.H. \& Yu, G.J. (2006). Dual-Module-Based Maximum Power Point Tracking Control of Photovoltaic Systems, IEEE Transactions on Industrial Electronics, Vol. 53, No. 4, August, 2006, pp 1036-1047, ISSN 0278-0046

Sira-Ramirez, H. \& Rios-Bolivar, M. (1994). Sliding Mode Control of DC-to-DC Power Converters via Extended Linearization, IEEE Transactions on Circuits and Systems Part I: Fundamental Theory and Applications, Vol. 41, No. 10, October, 1994, pp. 652661, ISSN 1057-7122

Song, Y.J. \& Enjeti, P.N. (2004). A High Frequency Link Direct DC-AC Converter for Residential Fuel Cell Power Systems, Proceedings of IEEE Power Electronics Specialists Conference, pp. 4755-4761, ISBN 0-7803-8399-0, Germany, June 2004, IEEE, Aachen 
Vazquez, N.; Hernandez, C.; Alvarez, J. \& Arau, J. (2003). Sliding Mode Control for DC/DC Converters: A new Sliding Surface, Proceedings of IEEE International Symposium on Industrial Electronics, pp. 422-426, ISBN 0-7803-7912-8, Brasil, June 2003, IEEE, Rio de Janeiro

Walker, G.R. \& Sernia, P.C. (2004). Cascaded DC-DC Converter Connection of Photovoltaic Modules, IEEE Transactions on Power Electronics, Vol. 19, No. 4, July, 2004, pp 11301139, ISSN 0885-8933 


\title{
A dual-input DC-DC converter using clean energy power supplies
}

\author{
Kei Eguchi \\ Shizuoka University \\ Japan
}

\section{Introduction}

For small color displays in portable devices, white LEDs have been used to provide one of the most ideal back-light solutions. To drive white LEDs in portable devices, switchedcapacitor (SC) DC-DC converters (Bong (2009); Chung (2009); Doms (2009); Eguchi (2009a; 2010a;b); Gregoire (2006); Min (2002); Myono (2001); Park (2009); Starzyk (2001); Tanzawa (1997); Wei (2008); Yamada (2004); Yamakawa (2008)) have been used, because the capacitorbased converter can be designed without a magnetic element. Although the power efficiency of capacitor-based converters is inferior to that of inductor-based converters such as buck converters, boost converters, etc., inductor-less design enables capacitor-based converters to realize thin circuit composition, light-weight, no flux of magnetic induction, and so on.

In previous studies, single-input SC converters realizing step-up conversion (Chung (2009); Eguchi (2010b); Min (2002); Myono (2001); Park (2009); Starzyk (2001); Tanzawa (1997); Wei (2008)) have been used as a driver circuit of white LEDs. However, the single-input SC power converter is difficult to improve power efficiency by adjusting a voltage conversion ratio ${ }^{1}$, because the ratio of voltage conversion is predetermined by circuit structure. Therefore, the single-input SC converter is difficult to realize long battery runtime.

To solve this problem, multiple-input parallel converters (Eguchi (2009b); Ishikawa (2007); Kabe (2007); Qiu (2006)) using battery power supplies and clean energy power supplies have been proposed, where solar energy is usually used in mobile devices as a clean energy source. By converting solar energy, the multiple-input parallel converter can achieve long battery runtime. However, the hardware-cost of the parallel converter increases in proportion to the number of converter blocks although the parallel converter can be designed easily by connecting single SC DC-DC converters. Moreover, the parallel converter which consists of same converter blocks is difficult to achieve the wide range of clean energy inputs, because the ratio of the voltage conversion is predetermined by circuit structure although the value of input voltages from solar-cells changes depending on the weather conditions. To utilize solar energy for back-lighting applications effectively, the SC DC-DC converter which can realize not only small hardware-cost but also wide input-range is required.

In this chapter, a switched-capacitor-based serial DC-DC converter is proposed. The converter consists of 2 converter blocks, where the Block-1 is the step-up/step-down SC DC-DC

\footnotetext{
${ }^{1}$ To adjust the output voltage, pulse width modulation (PWM) scheme or on-resistance control scheme is usually employed in the SC DC-DC converter.
} 


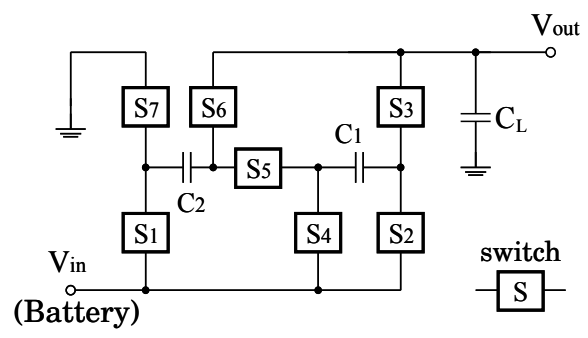

Fig. 1. Conventional single-input converter

\begin{tabular}{|c|c|c|c|}
\hline Ratio & Phase & On & Off \\
\hline \hline \multirow{2}{*}{$2 \times$} & Charging & $S_{3}, S_{4}, S_{5}, S_{7}$ & $S_{1}, S_{2}, S_{6}$ \\
\cline { 2 - 4 } & Transfer & $S_{1}, S_{3}, S_{4}, S_{6}$ & $S_{2}, S_{5}, S_{7}$ \\
\hline \multirow{2}{*}{$1.5 \times$} & Charging & $S_{2}, S_{5}, S_{7}$ & $S_{1}, S_{3}, S_{4}, S_{6}$ \\
\cline { 2 - 4 } & Transfer & $S_{1}, S_{3}, S_{4}, S_{6}$ & $S_{2}, S_{5}, S_{7}$ \\
\hline
\end{tabular}

Table 1. Setting of clock pulses

converter using battery energy and the Block-2 is a quasi-switched-capacitor cell (Pan (2007)) using solar energy. The hardware-cost of the quasi-SC cell (Pan (2007)) is much smaller than that of the conventional single-input converter (Chung (2009); Eguchi (2010b); Min (2002); Myono (2001); Park (2009); Starzyk (2001); Tanzawa (1997); Wei (2008)). Therefore, the proposed converter can realize small hardware-cost. Furthermore, unlike conventional SC DC-DC converters, the output voltage of the proposed converter is generated by adding the output voltage of the SC-based circuit to the voltage of solar-cells. In the Block-1, the voltage conversion ratio is controlled according to the variation of the voltage of solar cells. Therefore, the proposed converter can realize wide input-range.

Concerning the proposed serial converter, theoretical analyses and SPICE simulations are performed to investigate the circuit characteristics. Furthermore, to confirm the validity of circuit design, experiments are performed concerning the experimental circuit fabricated with commercially available transistors on a bread board.

\section{Circuit Structure}

\subsection{Single-Input Converter}

Figure 1 shows an example of the single-input converter. The converter of figure 1 is one of the most famous converters and is adopted for MAX1910, MAX1912 ${ }^{2}$, and so on. According to the control rule shown in Table 1, power switches $S_{1} \sim S_{7}$ in figure 1 are driven by 2-phase clock pulses, synchronously. By controlling $S_{1} \sim S_{7}$, the conventional converter shown in figure 1 generates $1.5 \times / 2 \times$ stepped-up voltages. However, as Table 1 shows, the single-input converter is difficult to improve power efficiency further by adjusting a voltage conversion

\footnotetext{
${ }^{2}$ MAX1910 and MAX1912 are $1.5 \times / 2 \times$ step-up converters produced by Maxim Integrated Products. In mobile back-lighting applications, the stepped-up voltage such as $4.75 \sim 6.5 \mathrm{~V}$ (Typ. $=5 \mathrm{~V}$ ) is required to drive some LEDs from the voltage of a lithium battery. The typical voltage of the lithium battery used in the mobile equipments is about $3.7 \mathrm{~V}$.
} 


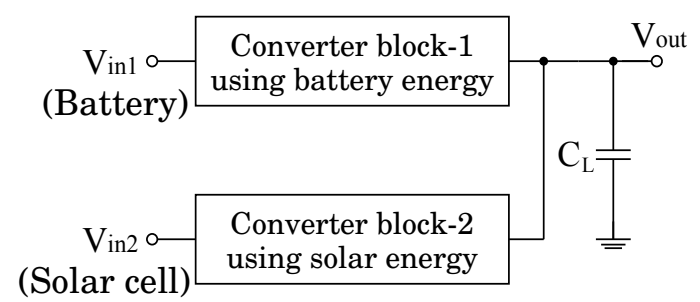

(a) Block diagram

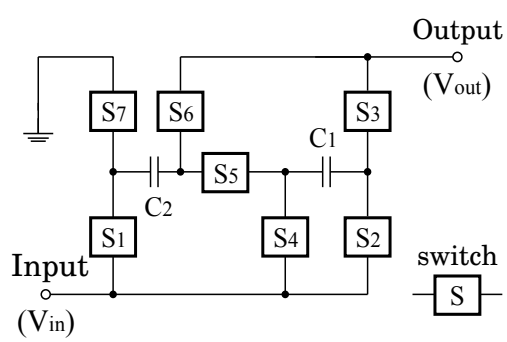

(b) Converter block

Fig. 2. Conventional multiple-input parallel converter

ratio, because the ratio of the voltage conversion is predetermined by circuit structure. Therefore, since the single-input converter only consumes energy stored in the battery, it is difficult for the single-input converter to realize long battery runtime.

\subsection{Parallel-Connected Converter}

To realize long battery runtime, the multiple-input converter has been proposed (Ishikawa (2007); Kabe (2007); Qiu (2006)). As described in (Ishikawa (2007); Kabe (2007); Qiu (2006)), the multiple-input converter can be designed easily by connecting single-input DC-DC converters in parallel.

Figure 2 shows an example of the multiple-input parallel converter designed by using switched-capacitor (SC) techniques, where battery energy and solar energy are used as input energy sources. The multiple-input converter can realize long battery runtime, because the consumption of battery energy is suppressed by converting solar energy. However, the hardware-cost of the parallel converter increases in proportion to the number of converter blocks. Furthermore, the parallel converter which consists of same converter blocks is difficult to realize the wide range ${ }^{3}$ of clean energy inputs, because the ratio of the voltage conversion is predetermined by the circuit structure of converter blocks although the voltage of solar-cells changes depending on the weather conditions.

Of course, the parallel converters can achieve the wide input range by connecting different kinds of converters according to input sources. However, although the wide input range is realized by using different kinds of converters, the problem of hardware-cost cannot be solved. To make matters worse, this approach not only causes the complexity of circuit control but also ruins the simplicity of circuitry. To utilize solar energy effectively, the SC DC-DC converter which can realize not only small hardware-cost but also wide input-range is required.

\subsection{Proposed Converter}

Figure 3 shows the proposed serial DC-DC converter. The converter consists of 2 converter blocks, where the Block-1 is the step-up/step-down SC DC-DC converter using battery energy and the Block-2 is a switched-capacitor-based converter using solar energy. Unlike conventional converters, the output voltage of the proposed converter is generated by adding the

\footnotetext{
${ }^{3}$ Only when $V_{\text {in } 2} \geq V_{t a g} / 2$, the conventional converter of figure 2 can offer the stepped-up voltage $V_{t a g}$ to drive some LEDs from clean energy power supplies. Concretely, the voltage from solar-cells, $V_{\text {in2 }}$, must be more than $2.5 \mathrm{~V}$ when target output voltage $V_{\text {tag }}$ is $5 \mathrm{~V}$.
} 


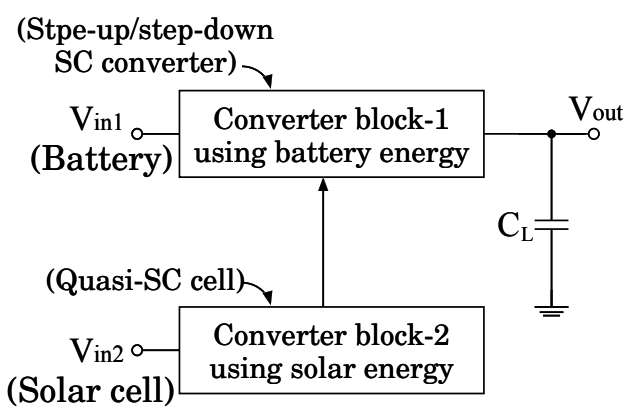

(a) Block diagram

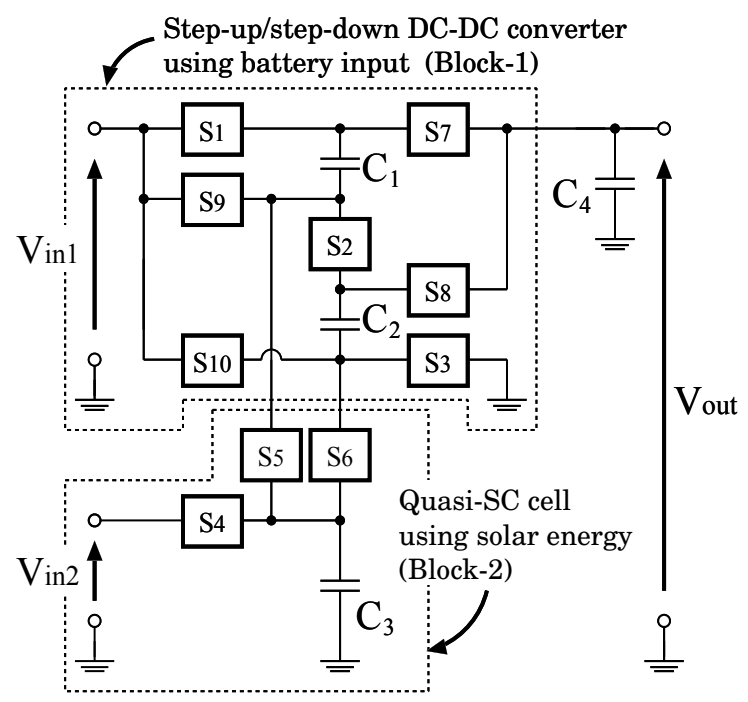

(b) Circuit structure

Fig. 3. Proposed dual-input serial converter

output voltage of an SC-based circuit to the voltage of solar-cells. According to the voltage of solar-cells, the proposed converter changes the operation modes as shown in Table 2, where $V_{\text {tag }}$ (Typ. $\left.=5 \mathrm{~V}\right)$ denotes the target output voltage $\left(\simeq 3 V_{i n 1} / 2\right)$ to drive LEDs.

To realize the operation modes shown in Table 2, power switches $S_{1} \sim S_{10}$ in figure 3 are driven by 2-phase clock pulses, synchronously. By controlling $S_{1} \sim S_{10}$, the proposed converter performs a step-up DC-DC conversion. Table 3 shows the setting of clock pulses. In Table 3, the interval of Charging (=State $-T 1)$ and Transfer (=State - T2) is set to

$$
\begin{array}{ll} 
& T=T 1+T 2, \\
& T 1=D T, \\
\text { and } \quad & T 2=(1-D) T,
\end{array}
$$

where $D$ and $T$ denote the duty factor and the period of the clock pulses, respectively. 


\begin{tabular}{|c||c|c|c|}
\hline & \multirow{2}{*}{ Input voltage $V_{\text {in } 2}$} & \multicolumn{2}{c|}{ Conversion ration } \\
\cline { 3 - 4 } & & Block-1 & Block-2 \\
\hline \hline Mode-1 & $\frac{2 V_{\text {tag }}}{3} \leq V_{\text {in } 2}$ & $\frac{1}{2} \times$ & $1 \times$ \\
\hline Mode-2 & $\frac{V_{t a g}}{3} \leq V_{\text {in } 2}<\frac{2 V_{\text {tag }}}{3}$ & $1 \times$ & $1 \times$ \\
\hline Mode-3 & $V_{i n 2}<\frac{V_{t a g}}{3}$ & $\frac{3}{2} \times$ & $0 \times$ \\
\hline
\end{tabular}

Table 2. Setting of conversion ratio

\begin{tabular}{|l|l|c|c|}
\hline & Phase & On & Off \\
\hline \hline \multirow{2}{*}{ Mode-1 } & Charging (State - T1) & $S_{1}, S_{2}, S_{3}, S_{4}$ & $S_{5}, S_{6}, S_{7}, S_{8}, S_{9}, S_{10}$ \\
\cline { 2 - 4 } & Transfer (State - T2) & $S_{5}, S_{6}, S_{7}, S_{8}$ & $S_{1}, S_{2}, S_{3}, S_{4}, S_{9}, S_{10}$ \\
\hline \multirow{2}{*}{ Mode-2 } & Charging (State - T1) & $S_{1}, S_{2}, S_{3}, S_{4}$ & $S_{5}, S_{6}, S_{7}, S_{8}, S_{9}, S_{10}$ \\
\cline { 2 - 4 } & Transfer (State - T2) & $S_{2}, S_{6}, S_{7}$ & $S_{1}, S_{3}, S_{4}, S_{5}, S_{8}, S_{9}, S_{10}$ \\
\hline \multirow{2}{*}{ Mode-3 } & Charging (State - T1) & $S_{1}, S_{2}, S_{3}$ & $S_{4}, S_{5}, S_{6}, S_{7}, S_{8}, S_{9}, S_{10}$ \\
\cline { 2 - 4 } & Transfer (State - T2) & $S_{7}, S_{8}, S_{9}, S_{10}$ & $S_{1}, S_{2}, S_{3}, S_{4}, S_{5}, S_{6}$ \\
\hline
\end{tabular}

Table 3. Setting of clock pulses

Figure 4 shows the comparison concerning the input range of figures 2 and 3 . As figure 4 shows, the proposed converter can extend the input range of $V_{\text {in } 2}$ from $V_{\text {in } 2} \geq V_{\text {tag }} / 2$ to $V_{\text {in } 2} \geq V_{\text {tag }} / 3$. Concretely, in comparison with the conventional parallel converter using $1.5 \times$ step-up converters, the proposed converter can achieve 16\% extension of input range.

Furthermore, the proposed converter can realize small hardware-cost. Table 4 shows the comparison concerning the hardware-cost of figures 2 and 3. As Table 4 shows, the hardware-cost of the proposed converter is less than $80 \%$ of that of the conventional converter.

The circuit properties of the proposed serial converter will be described in the following section.

\section{Theoretical Analysis}

First, the equivalent circuit of the proposed converter is analyzed. To save space, only the analysis for Mode- 1 is described in this section ${ }^{4}$. In the theoretical analysis, we assume that 1. parasitic elements are negligibly small and 2 . time constant is much larger than the period of clock pulses.

Figure 5 shows instantaneous equivalent circuits of the proposed converter. In figure $5, R_{o n}{ }^{5}$ denotes the on-resistance of power switches.

\footnotetext{
4 The theoretical analysis for Mode- 2 and Mode- 3 will be described in Appendix.

${ }^{5}$ SC power converters are known as an implementable converter, because they do not require magnetic elements. In the converter block implemented into a chip, the direction of fluctuation in on-resistances is almost the same. Therefore, to simplify the theoretical analysis, we assume that all the power switches have the same on-resistances.
} 


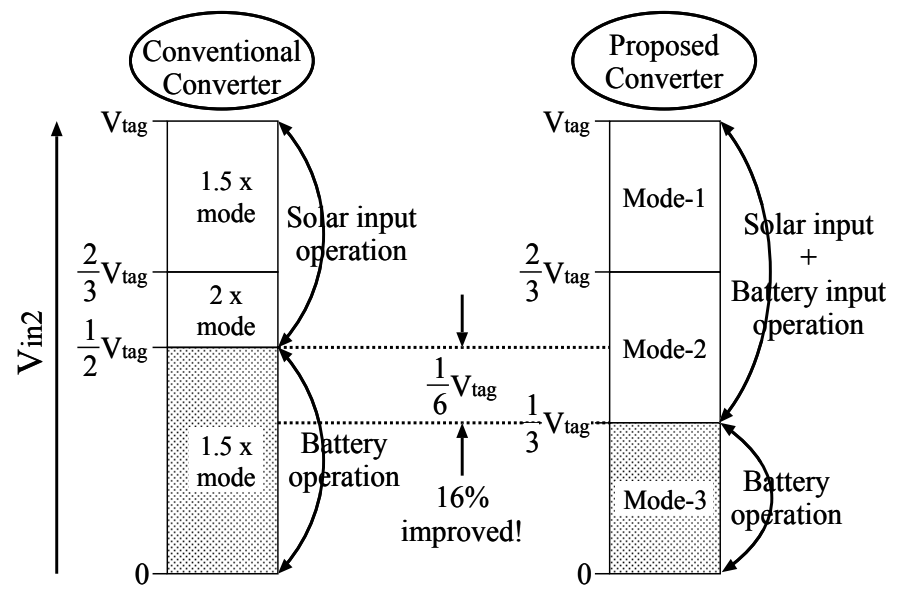

Fig. 4. Comparison concerning input range of $V_{i n 2}$

\begin{tabular}{|c||c|c|}
\hline & $\begin{array}{c}\text { Number of } \\
\text { switches }\end{array}$ & $\begin{array}{c}\text { Number of } \\
\text { capacitors }\end{array}$ \\
\hline \hline $\begin{array}{c}\text { Conventional } \\
\text { converter }\end{array}$ & 14 & 5 \\
\hline $\begin{array}{c}\text { Proposed } \\
\text { converter }\end{array}$ & $\begin{array}{c}10 \\
(71 \%)\end{array}$ & $\begin{array}{c}4 \\
(80 \%)\end{array}$ \\
\hline
\end{tabular}

Table 4. Comparison concerning hardware cost

In the steady state of figure 5 , differential values of the electric charges in $C_{k}(k=\{1,2,3,4\})$ satisfy

$$
\Delta q_{T 1}^{k}+\Delta q_{T 2}^{k}=0
$$

where $\Delta q_{T 1}^{k}$ and $\Delta q_{T 2}^{k}$ denote electric charges when State - T1 and State - T2, respectively. In the case of State - T1, differential values of the electric charges in the input and the output terminals, $\Delta q_{T 1, V_{i n 1}}, \Delta q_{T 1, V_{\text {in } 2}}$, and $\Delta q_{T 1, V_{\text {out }}}$, are given by

$$
\begin{aligned}
& \Delta q_{T 1, V_{\text {in } 1}}=\Delta q_{T 1}^{1}=\Delta q_{T 1}^{2}, \\
& \Delta q_{T 1, V_{\text {in } 2}}=\Delta q_{T 1}^{3}, \\
\text { and } \quad & \Delta q_{T 1, V_{\text {out }}}=\Delta q_{T 1}^{4} .
\end{aligned}
$$

On the other hand, in the case of State - T2, differential values of the electric charges in the input and the output terminals, $\Delta q_{T 2, V_{\text {in1 }}}, \Delta q_{T 2, V_{\text {in2 }}}$, and $\Delta q_{T 2, V_{\text {out }}}$, are given by

$$
\begin{aligned}
& \Delta q_{T 2, V_{\text {in } 1}}=0, \\
& \Delta q_{T 2, V_{\text {in } 2}}=0, \\
& \text { and } \quad \Delta q_{T 2, V_{\text {out }}}=\Delta q_{T 2}^{1}+\Delta q_{T 2}^{2}+\Delta q_{T 2}^{4} .
\end{aligned}
$$




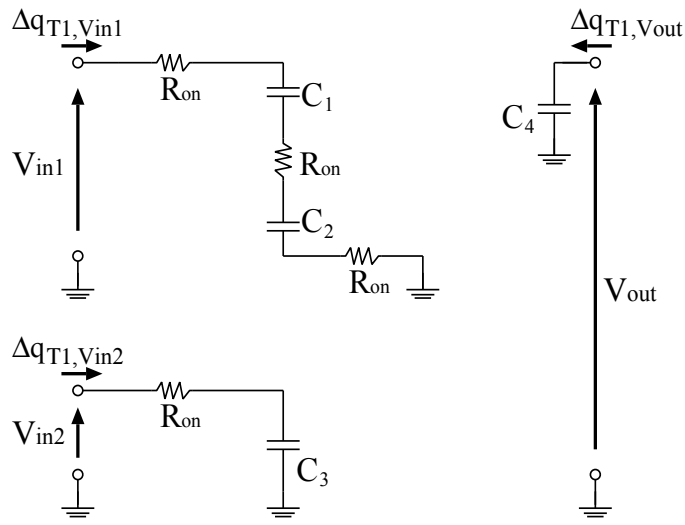

(a) State - T1

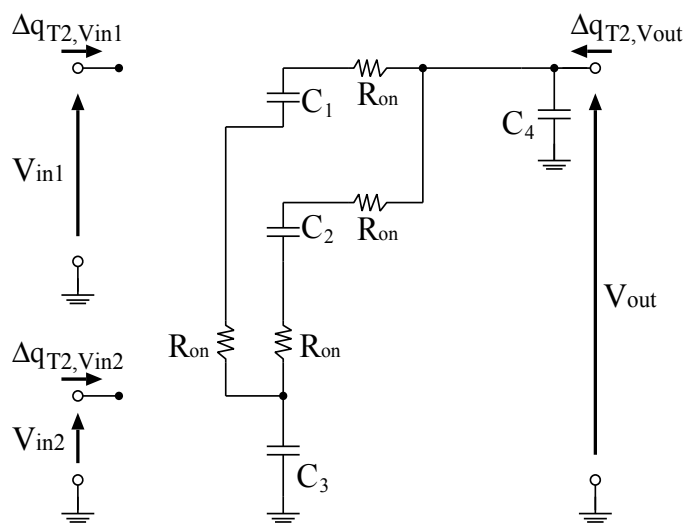

(b) State - T2

Fig. 5. Instantaneous equivalent circuits when $2 V_{\text {tag }} / 3 \leq V_{\text {in } 2}$

Furthermore, in figure 5, the following condition is satisfied:

$$
\Delta q_{T 2}^{3}=\Delta q_{T 2}^{1}+\Delta q_{T 2}^{2}
$$

Here, average currents of the inputs and the output are given by

$$
\begin{aligned}
\overline{I_{\text {in } 1}} & =\left(\Delta q_{T 1, V_{\text {in } 1}}+\Delta q_{T 2, V_{\text {in1 }}}\right) / T \\
& \equiv \Delta q_{V_{\text {in } 1}} / T, \\
\overline{I_{\text {in } 2}} & =\left(\Delta q_{T 1, V_{\text {in } 2}}+\Delta q_{T 2, V_{\text {in } 2}}\right) / T \\
& \equiv \Delta q_{V_{\text {in } 2}} / T, \\
\text { and } \quad \overline{I_{\text {out }}} & =\left(\Delta q_{T 1, V_{\text {out }}}+\Delta q_{T 2, V_{\text {out }}}\right) / T \\
& \equiv \Delta q_{V_{\text {out }}} / T,
\end{aligned}
$$

where $\Delta q_{V_{\text {in } 1}}, \Delta q_{V_{\text {in } 2}}$, and $\Delta q_{V_{\text {out }}}$ are electric charges in the input terminal-1, the input terminal2 , and the output terminal, respectively. From equations $(2) \sim(6)$, the relation between the 


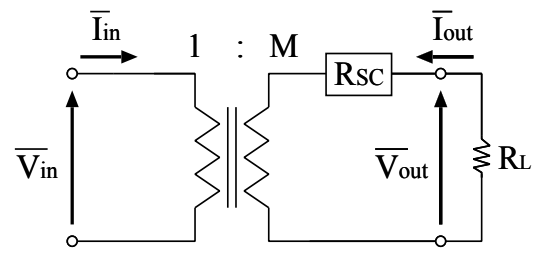

Fig. 6. General form of equivalent circuit

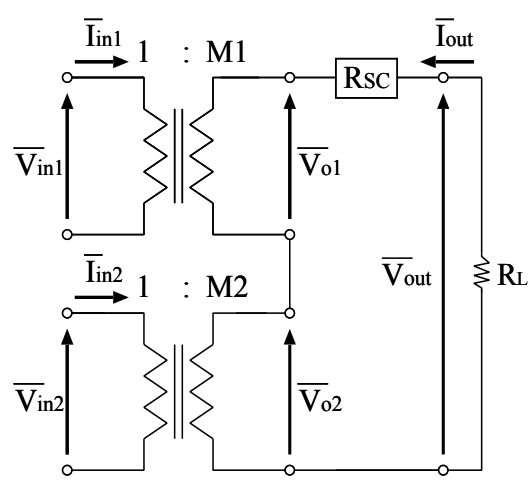

Fig. 7. Equivalent circuit of proposed converter

input currents and the output current are derived:

$$
\text { and } \quad \begin{aligned}
\overline{I_{i n 1}} & =-\frac{1}{2} \overline{I_{\text {out }}} \\
\overline{I_{\text {in } 2}} & =-\overline{I_{\text {out }} .}
\end{aligned}
$$

In figure 5 , the energy consumed by resistors in one period, $W_{T}$, can be expressed as

$$
W_{T}=W_{T 1}+W_{T 2}
$$

where

$$
\begin{aligned}
W_{T 1} & =\frac{3 R_{o n}}{T 1}\left(\Delta q_{T 1}^{1}\right)^{2}+\frac{R_{o n}}{T 1}\left(\Delta q_{T 1}^{3}\right)^{2} \\
\text { and } \quad W_{T 2} & =\frac{2 R_{o n}}{T 2}\left(\Delta q_{T 2}^{1}\right)^{2}+\frac{2 R_{o n}}{T 2}\left(\Delta q_{T 2}^{2}\right)^{2} .
\end{aligned}
$$

From equations $(2) \sim(7)$, equations (9) and (10) can be rewritten as

$$
\begin{aligned}
W_{T 1} & =\frac{7 R_{\text {on }}}{4 D T}\left(\Delta q_{V_{\text {out }}}\right)^{2} \\
\text { and } \quad W_{T 2} & =\frac{R_{\text {on }}}{(1-D) T}\left(\Delta q_{V_{\text {out }}}\right)^{2} .
\end{aligned}
$$




\begin{tabular}{|c|c|c|c|}
\hline Input voltage $V_{\text {in } 2}$ & $R_{S C}$ & $M 1$ & $M 2$ \\
\hline \hline$\frac{2 V_{\text {tag }}}{3} \leq V_{\text {in } 2}$ & $\frac{(7-3 D) R_{\text {on }}}{4 D(1-D)}$ & $\frac{1}{2}$ & 1 \\
\hline$\frac{V_{\text {tag }}}{3} \leq V_{\text {in } 2}<\frac{2 V_{\text {tag }}}{3}$ & $\frac{(4-D) R_{\text {on }}}{D(1-D)}$ & 1 & 1 \\
\hline$V_{\text {in } 2}<\frac{V_{\text {tag }}}{3}$ & $\frac{(3+D) R_{\text {on }}}{4 D(1-D)}$ & $\frac{3}{2}$ & 0 \\
\hline
\end{tabular}

Table 5. Theoretical results of other conversion ratios

Here, a general equivalent circuit of SC power converters (Eguchi (2009a;b; 2010a;b)) can be given by the circuit shown in figure 6 , where $R_{S C}$ is called the SC resistance, $M$ is the ratio of an ideal transformer, and $\overline{V_{i n}}$ and $\overline{V_{\text {out }}}$ denote the averaged input voltage and the averaged output voltage, respectively. The consumed energy $W_{T}$ in figure 6 can be defined by

$$
\begin{aligned}
W_{T} & =W_{T 1}+W_{T 2} \\
& \equiv\left(\frac{\Delta q_{V_{\text {out }}}}{T}\right)^{2} \cdot R_{S C} \cdot T .
\end{aligned}
$$

By substituting equations (11) and (12) into equation (13), SC resistance $R_{S C}$ for Mode- 1 is given by

$$
R_{S C}=\frac{7-3 D}{4 D(1-D)} \cdot R_{o n}
$$

The equivalent circuit shown in figure 6 can be expressed by the determinant using the Kettenmatrix. Therefore, by using equations (7) and (14), the equivalent circuit of the proposed step-up converter can be given by the circuit shown in figure 7 and the following determinants:

$$
\begin{aligned}
& {\left[\begin{array}{l}
\overline{V_{\text {in } 1}} \\
I_{\text {in } 1}
\end{array}\right]=\left[\begin{array}{cc}
1 / M 1 & 0 \\
0 & M 1
\end{array}\right]\left[\begin{array}{l}
\overline{V_{o 1}} \\
\overline{I_{\text {out }}}
\end{array}\right],} \\
& {\left[\begin{array}{c}
\overline{V_{\text {in } 2}} \\
\bar{I}_{\text {in } 2}
\end{array}\right]=\left[\begin{array}{cc}
1 / \mathrm{M} 2 & 0 \\
0 & \mathrm{M} 2
\end{array}\right]\left[\begin{array}{c}
\overline{V_{o 2}} \\
\overline{I_{\text {out }}}
\end{array}\right] \text {, }}
\end{aligned}
$$

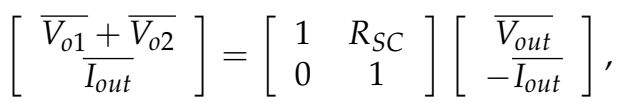

where $M 1=1 / 2$ and $M 2=1$. To save space, only the conversion mode in the case of $2 V_{\text {tag }} / 3 \leq V_{\text {in } 2}$ was discussed in this section. However, other cases can also be analyzed by the same method. Table 5 shows parameters $M 1, M 2$, and $R_{S C}$ of other modes.

By using equations (15) (17) and figure 7, power efficiency $\eta^{6}$ can be expressed by

$$
\begin{aligned}
\eta & =\frac{R_{L}\left(\overline{I_{\text {out }}}\right)^{2}}{R_{L}\left(\overline{I_{\text {out }}}\right)^{2}+R_{S C}\left(\overline{I_{\text {out }}}\right)^{2}} \\
& =\frac{R_{L}}{R_{L}+R_{S C}}
\end{aligned}
$$

\footnotetext{
${ }^{6}$ Of course, the consumed energy of peripheral circuits such as pulse generators, comparators, etc. is disregarded in the power efficiency of equation (18).
} 


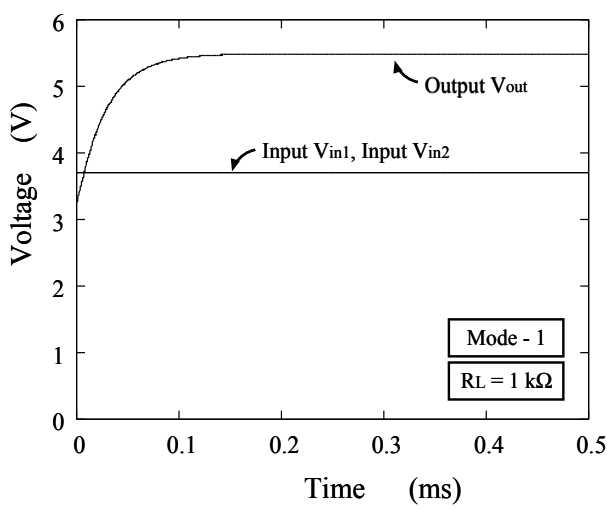

(a) Mode-1

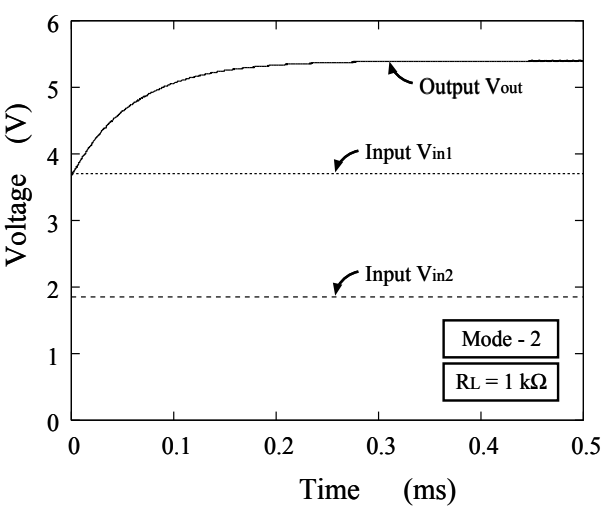

(b) Mode-2

Fig. 8. Output voltage of proposed converter

where the optimal value of parameter $D$ is obtained when

$$
\frac{d R_{S C}}{d D}=0 \quad \text { and } \quad 0<D<1 .
$$

Concretely, from equations (14) and (19), the optimal duty factor is $D \simeq 0.57$ for Mode- 1 .

\section{Simulation}

To confirm the validity of the theoretical analysis, SPICE simulations were performed under conditions where where $V_{i n 1}=3.7 \mathrm{~V}, C_{1} \sim C_{4}=2 \mu \mathrm{F}, T=1 \mu \mathrm{s}, D=0.5$, and $R_{o n}=2 \mathrm{ohm}$. Figure 8 shows the output voltage of the proposed converter, where the output voltage was not regulated. In figure 8, input voltage $V_{i n 2}$ for Mode- 1 and Mode-2 was set to $V_{i n 2}=V_{i n 1}$ and $V_{i n 2}=V_{i n 1} / 2$, respectively. As figure 8 shows, in spite of the change in $V_{i n 2}$, the proposed converter can generate the stepped-up output voltage. In other words, the proposed converter can realize wide input-range of $V_{\text {in } 2}$.

Figure 9 shows the power efficiency of the proposed converter as a function of output load $R_{L}$. In figure 9, input voltage $V_{i n 2}$ for Mode- 1 and Mode- 2 was set to $V_{i n 2}=V_{i n 1}$ and $V_{i n 2}=V_{i n 1} / 2$, respectively. As figure 9 shows, theoretical results correspond well with simulated results. For this reason, the derived theoretical formulas will be helpful to design the series converter. Of course, the power efficiency can be improved by using power-switches with small onresistance.

\section{Experiment}

To confirm the validity of circuit design, experiments were performed regarding to the proposed converter shown in figure 3. The experimental circuit was built with commercially available transistors on a bread board.

Figures 10, 11, and 12 show the experimental results of the bread board circuit, where input voltages capacitors $V_{i n 1}=3.7 \mathrm{~V}, C_{1} \sim C_{4}=3.3 \mu \mathrm{F}, R_{L}=10 \mathrm{kohm}, T=100 \mu \mathrm{s}$, and $D=0.5$. In figures 10,11 , and 12 , input voltage $V_{i n 2}$ was set to about $3.7 \mathrm{~V}, 1.8 \mathrm{~V}$, and $0 \mathrm{~V}$, respectively. 


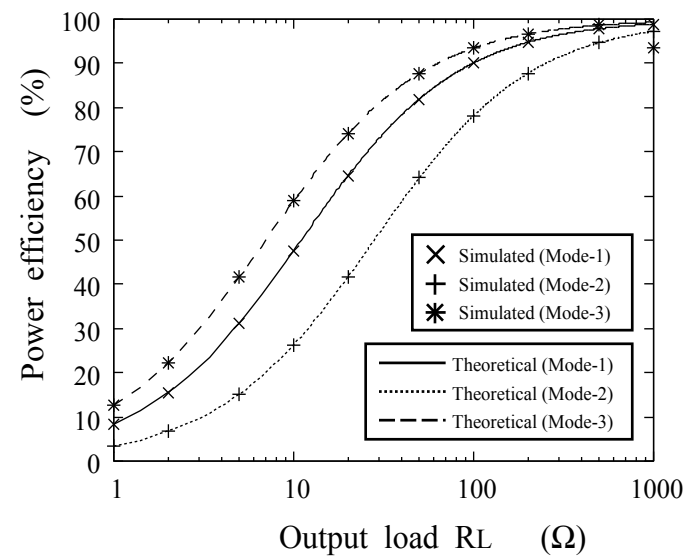

Fig. 9. Power efficiency as function of output load $R_{L}$

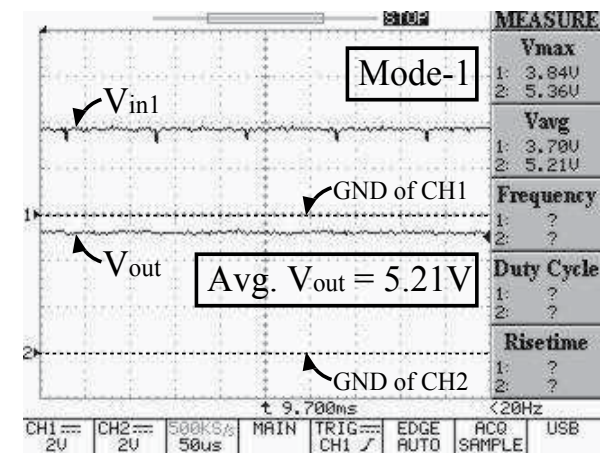

(a) $V_{\text {out }}$ vs. $V_{\text {in } 1}$

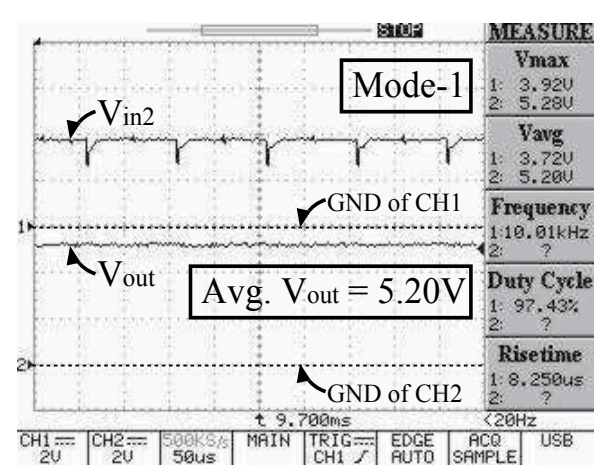

(b) $V_{\text {out }}$ vs. $V_{\text {in } 2}$

Fig. 10. Measured output voltages for Mode-1

As these figures show, the circuit design of the proposed converter is appropriate, because the stepped-up voltage about $5 \mathrm{~V}$ can be generated ${ }^{7}$.

\section{Conclusion}

In this chapter, a serial SC DC-DC converter using clean energy power supplies has been proposed.

The validity of the circuit design was confirmed by theoretical analyses, SPICE simulations, and experiments. The proposed converter can realize not only long battery runtime but also small hardware-cost and wide input-range. Concretely, in comparison with the conventional parallel converter using $1.5 \times$ step-up SC converters, the proposed converter can achieve $20 \%$

\footnotetext{
${ }^{7}$ In the experiment, the circuit properties such as power efficiency, ripple noise, etc. were not examined, because the experimental circuit was built with commercially available transistors on the bread board. Only the circuit design was verified through the experiments, because the parasitic resistance of the bread board is very large unlike an IC chip.
} 


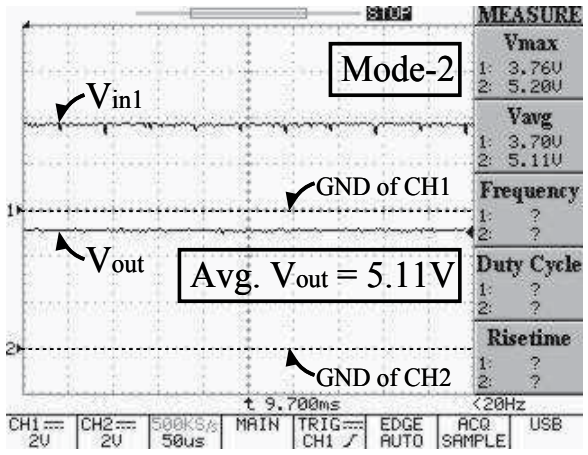

(a) $V_{\text {out }}$ vs. $V_{\text {in } 1}$

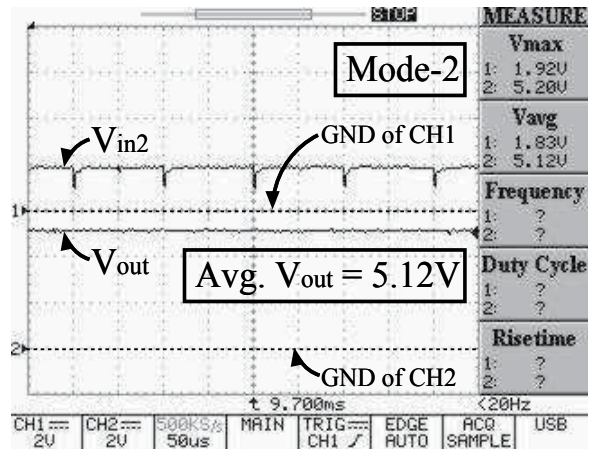

(b) $V_{\text {out }}$ vs. $V_{\text {in } 2}$

Fig. 11. Measured output voltages for Mode-2

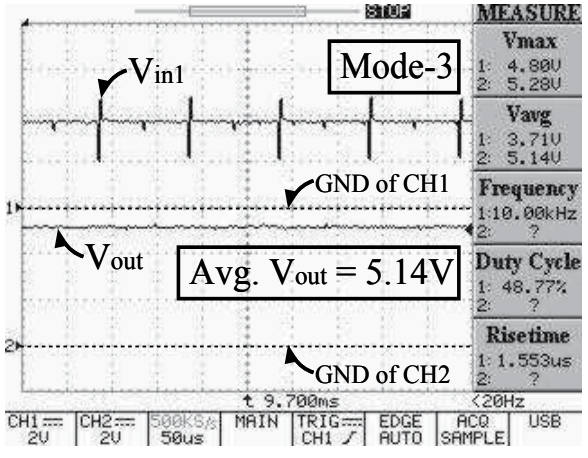

(a) $V_{\text {out }}$ vs. $V_{\text {in } 1}$

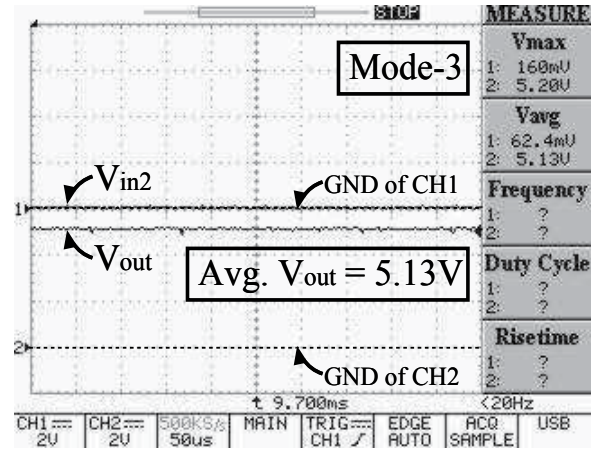

(b) $V_{\text {out }}$ vs. $V_{\text {in } 2}$

Fig. 12. Measured output voltages for Mode-3

reduction of hardware cost and 16\% extension of input range. Furthermore, the derived theoretical formulas can provide basic information to design serial SC DC-DC converters, because theoretical results corresponded well with SPICE simulation results. The proposed converter will be useful as a driver circuit of white LEDs for display back-lighting.

The IC implementation and experiments are left to a future study.

\section{Appendix}

\section{Theoretical analysis for Mode-2}

In this section, the characteristics of the proposed converter for $V_{t a g} / 3 \leq V_{\text {in } 2}<2 V_{t a g} / 3$ is analyzed theoretically. The conditions of this theoretical analysis are the same as that shown in section 3.

Figure 13 shows the instantaneous equivalent circuits for Mode-2. In the steady state, the differential value of electric charges in $C_{k}(k=\{1,2,3,4\})$ satisfies equation (2). In the case of State - T1, differential values of electric charges in the input terminals and the output 


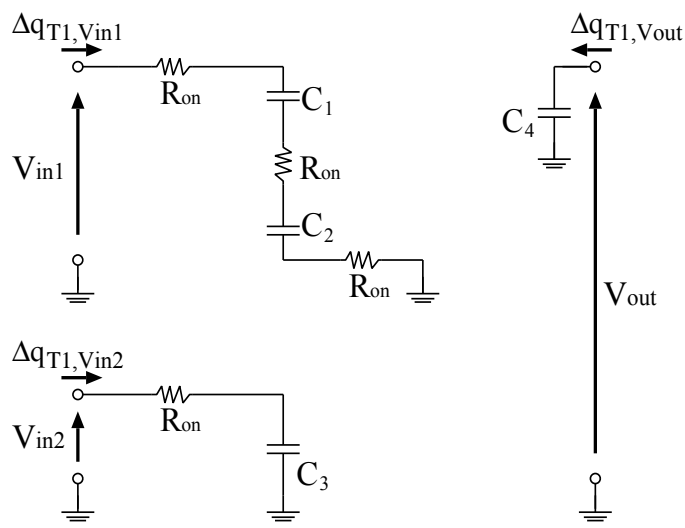

(a) State $-T 1$

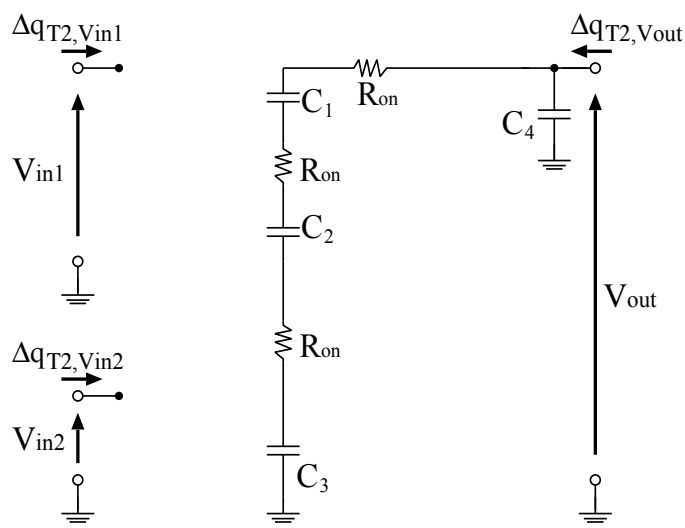

(b) State - T2

Fig. 13. Instantaneous equivalent circuits when $V_{\text {tag }} / 3 \leq V_{\text {in } 2}<2 V_{\text {tag }} / 3$

terminal, $\Delta q_{T 1, V_{i n 1}}, \Delta q_{T 1, V_{i n 2}}$, and $\Delta q_{T 1, V_{\text {out }}}$, are given by

$$
\text { and } \begin{aligned}
\Delta q_{T 1, V_{\text {in } 1}} & =\Delta q_{T 1}^{1}-\Delta q_{T 1}^{2}, \\
\Delta q_{T 1, V_{\text {in } 2}} & =\Delta q_{T 1}^{3}, \\
\Delta q_{T 1, V_{\text {out }}} & =\Delta q_{T 1}^{4} .
\end{aligned}
$$

In the case of State - T2, differential values of electric charges in the input terminals and the output terminal, $\Delta q_{T 2, V_{\text {in } 1}}, \Delta q_{T 2, V_{\text {in } 2}}$, and $\Delta q_{T 2, V_{\text {out }}}$, are given by

$$
\text { and } \quad \begin{aligned}
\Delta q_{T 2, V_{\text {in } 1}} & =0, \\
\Delta q_{T 2, V_{\text {in } 2}} & =0, \\
\Delta q_{T 2, V_{\text {out }}} & =\Delta q_{T 2}^{1}+\Delta q_{T 2}^{4}=\Delta q_{T 2}^{2}+\Delta q_{T 2}^{4}=\Delta q_{T 2}^{3}+\Delta q_{T 2}^{4} .
\end{aligned}
$$


By substituting equations (2), (20), and (21) into equation (6), the following equations are derived:

$$
\overline{I_{\text {in } 1}}=-\overline{I_{\text {out }}} \quad \text { and } \quad \overline{I_{\text {in } 2}}=-\overline{I_{\text {out }}} .
$$

In figure 13 , the energy consumed by resistors in one period, $W_{T}$, can be expressed as

$$
W_{T}=W_{T 1}+W_{T 2}
$$

where

$$
\begin{aligned}
W_{T 1} & =\frac{3 R_{o n}}{T_{1}}\left(\Delta q_{T 1}^{1}\right)^{2}+\frac{R_{o n}}{T_{1}}\left(\Delta q_{T 1}^{3}\right)^{2} \\
\text { and } \quad W_{T 2} & =\frac{3 R_{o n}}{T_{2}}\left(\Delta q_{T 2}^{1}\right)^{2} .
\end{aligned}
$$

From equations (2), (20), and (21), equation (23) can be rewritten as

$$
W_{T}=\frac{4 R_{\text {on }}}{D T}\left(\Delta q_{V_{\text {out }}}\right)^{2}+\frac{3 R_{\text {on }}}{(1-D) T}\left(\Delta q_{V_{\text {out }}}\right)^{2} .
$$

Thus, from equations (13) and (24), the SC resistance $R_{S C}$ is given by

$$
R_{S C}=\frac{(4-D) R_{o n}}{D(1-D)}
$$

Therefore, by using equations (22) and (25), the equivalent circuit can be expressed by the circuit shown in figure 7 and equations (15) $\sim(17)$, where $M 1=1$ and $M 2=1$. The power efficiency can also be obtained by equation (18), where the optimal duty factor is $D \simeq 0.67$ when $V_{\text {tag }} / 3 \leq V_{\text {in } 2}<2 V_{\text {tag }} / 3$.

\section{Theoretical analysis for Mode-3}

Next, the characteristics of the proposed converter for $2 V_{t a g} / 3 \leq V_{i n 2}$ is analyzed theoretically. Figure 14 shows the instantaneous equivalent circuits when Mode-3. In the steady state, the differential value of electric charges in $C_{k}(k=\{1,2,3,4\})$ satisfies equation (2). In the case of State $-T 1, \Delta q_{T 1, V_{\text {in } 1}}, \Delta q_{T 1, V_{\text {in } 2}}$, and $\Delta q_{T 1, V_{\text {out }}}$, are given by

$$
\text { and } \quad \begin{aligned}
\Delta q_{T 1, V_{\text {in } 1}} & =\Delta q_{T 1}^{1}=\Delta q_{T 1}^{2}, \\
\Delta q_{T 1, V_{\text {in } 2}} & =0, \\
\Delta q_{T 1, V_{\text {out }}} & =\Delta q_{T 1}^{4} .
\end{aligned}
$$

On the other hand, in the case of State $-T 2, \Delta q_{T 2, V_{i n 1}}, \Delta q_{T 2, V_{i n 2}}$, and $\Delta q_{T 2, V_{\text {out }}}$, are given by

$$
\begin{aligned}
& \Delta q_{T 2, V_{i n 1}}=-\Delta q_{T 1}^{2}-\Delta q_{T 2}^{2}, \\
\Delta q_{T 2, V_{i n 2}} & =0, \\
\text { and } \quad \Delta q_{T 2, V_{\text {out }}} & =\Delta q_{T 2}^{1}+\Delta q_{T 2}^{2}+\Delta q_{T 2}^{4} .
\end{aligned}
$$

By substituting equations (2), (26), and (27) into equation (6), the following equation is derived:

$$
\overline{I_{\text {in } 1}}=-\frac{3}{2} \overline{I_{o u t}} \quad \text { and } \quad \overline{I_{\text {in } 2}}=0
$$




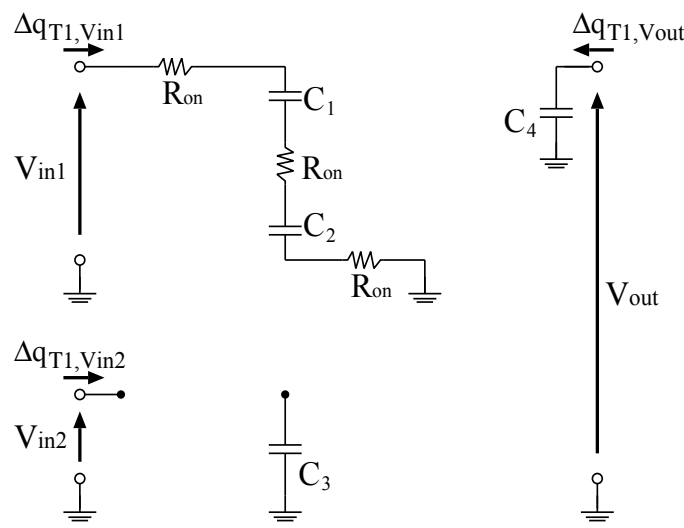

(a) State - T1

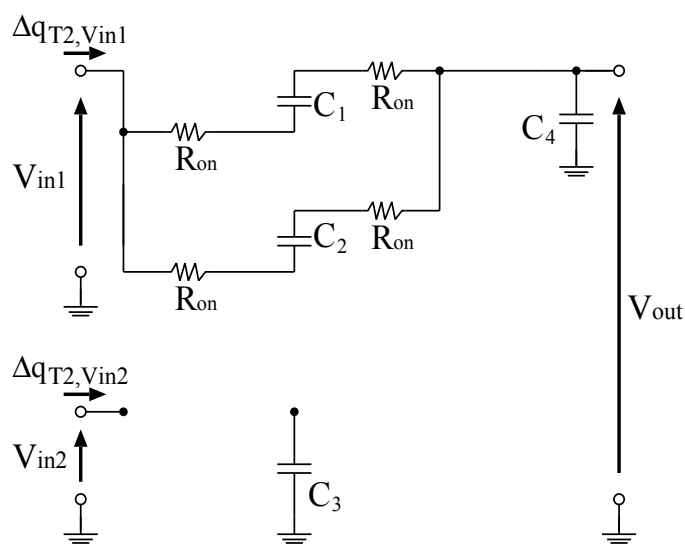

(b) State - T2

Fig. 14. Instantaneous equivalent circuits when $2 V_{t a g} / 3 \leq V_{i n 2}$

In figure 14 , the energy consumed by resistors in one period, $W_{T}$, can be expressed as

$$
W_{T}=W_{T 1}+W_{T 2},
$$

where

$$
\begin{aligned}
W_{T 1} & =\frac{3 R_{o n}}{T_{1}}\left(\Delta q_{T 1}^{1}\right)^{2} \\
\text { and } \quad W_{T 2} & =\frac{2 R_{o n}}{T_{2}}\left(\Delta q_{T 2}^{1}\right)^{2}+\frac{2 R_{o n}}{T_{2}}\left(\Delta q_{T 2}^{2}\right)^{2} .
\end{aligned}
$$

From equations (2), (26), and (27), equation (29) can be rewritten as

$$
W_{T}=\frac{3 R_{\text {on }}}{4 D T}\left(\Delta q_{V_{\text {out }}}\right)^{2}+\frac{R_{\text {on }}}{(1-D) T}\left(\Delta q_{V_{\text {out }}}\right)^{2} .
$$


Thus, from equations (13) and (30), the SC resistance $R_{S C}$ is given by

$$
R_{S C}=\frac{(3+D) R_{o n}}{4 D(1-D)}
$$

Therefore, by using equations (28) and (31), the equivalent circuit can be expressed by the circuit shown in figure 7 and equations (15) (17), where $M 1=3 / 2$ and $M 2=0$. The power efficiency can also be obtained by equation (18), where the optimal duty factor is $D \simeq 0.46$ when $2 V_{\text {tag }} / 3 \leq V_{\text {in } 2}$.

\section{References}

Bong, J.H.; Kwon, Y.J.; Kim, D. \& Min,K.S. (2009). Negative charge pump circuit with large output current and high power efficiency. IEICE Electronics EXpress, Vol.6 (No.6): 304309. ISSN 1349-2543

Chung, I.Y. \& Shin, J. (2009). New charge pump circuits for high output voltage and large current drivability. IEICE Electronics EXpress, Vol.6 (No.12): 800-805. ISSN 1349-2543

Doms, I.; Merken, P.; Hoof, C.V. \& Mertens, R.P. (2009). Capacitive power management circuit for micropower thermoelectric generators with a 1.4 $\mu \mathrm{A}$ controller. IEEE, J. Solid-State Circuits, Vol.44 (No.10): 2824-2833. ISSN 0018-9200

Eguchi, K.; Oota, I.; Terada, S. \& Inoue, T. (2009). A design method of switched-capacitor power converters by employing a ring-type power converter. Int. J. of Innovative Computing, Information and Control, Vol.5 (No.10 (A)): 2927-2938. ISSN 1349-4198

Eguchi, K.; Pongswatd, S.; Tirasesth, K. \& Sasaki, H. (2009). Synthesis and analysis of a multiple-input parallel SC DC-DC converter. Proceedings of the 2009 ECTI International Conference, pp.306-309, ISBN 978-1-4244-3388-9, Thailand, May 2009, the Institute of Electrical and Electronics Engineers, Piscataway

Eguchi, K.; Pongswatd, S.; Tirasesth, K.; Sasaki, H. \& Inoue, T. (2010). Optimal design of a single-input parallel DC-DC converter designed by switched capacitor techniques. Int. J. of Innovative Computing, Information and Control, Vol.6 (No.1 (A)): 215-227. ISSN 1349-4198

Eguchi, K.; Pongswatd, S.; Julsereewong, A.; Tirasesth, K.; Sasaki, H. \& Inoue, T. (2010). Design of a multiple-input SC DC-DC converter realizing long battery runtime. IEICE, Fundamentals, Vol.E93-A (No.5): 985-988. ISSN 1745-1337

Gregoire, B.R. (2006). A compact switched-capacitor regulated charge pump power supply. IEEE, J. Solid-State Circuits, Vol.41 (No.8): 1944-1953. ISSN 0018-9200

Ishikawa, Y. \& Saito, T. (2007). Synchronization and chaos in multiple-input parallel DC-DC converters with WTA switching. IEICE, Fundamentals, Vol.E90-A (No.6): 1162-1169. ISSN 1745-1337

Kabe, T.; Parui, S.; Torikai, H.; Banerjee, S. \& Saito, T. (2007). Analysis of current mode controlled DC-DC converters through piecewise linear models. IEICE, Fundamentals, Vol.E90-A (No.2): 448-456. ISSN 1745-1337

Min, K. \& Ahn, J. (2002). CMOS charge pumps using cross-coupled charge transfer switches with improved voltage pumping gain and low gate-oxide stress for low-voltage memory circuits. IEICE, Electronics, Vol.E85-C (No.1): 225-229. ISSN 1745-1353

Myono, T.; Uemoto, A.; Kawai, S.; Nishibe, E.; Kikuchi, S.; Iijima, T. \& Kobayashi,H. (2001). High-efficiency charge-pump circuits with large current output for mobile equipment applications. IEICE, Electronics, Vol.E84-C (No.10): 1602-1611. ISSN 1745-1353 
Pan, J.; Inoue, Y. \& Liang, Z. (2007) An energy management circuit for self-powered ubiquitous sensor modules using vibration-based energy, IEICE, Fundamentals, Vol.E90-A (No.10): 2116-2123. ISSN 1745-1337

Park, S.J.; Kang, Y.G.; Kim, J.Y.; Han, T.H.; Jun, Y.H.; Lee, C. \& Kong, B.S. (2009). CMOS crosscoupled charge pump with improved latch-up immunity. IEICE Electronics EXpress, Vol.6 (No.11): 736-742. ISSN 1349-2543

Qiu, Y.; Xu, M.; Yao, K.; Sun, J. \& Lee, F.C. (2006). Multifrequency small signal model for buck and multiphase buck converters. IEEE, Power Electronics, Vol.21 (No.5): 1185-1192. ISSN 0885-8993

Starzyk, J.A.; Jan, T.W. \& Qiu, F. (2001). A DC-DC charge pump design based on voltage doublers. IEEE Trans. Circuit \& Syst.-I, Vol.48 (No.3): 350-359. ISSN 1057-7122

Tanzawa, T. \& Tanaka, T. (1997). A dynamic analysis of the Dickson charge pump circuit. IEEE, J. Solid-State Circuits, Vol.32 (No.8): 1237-1240. ISSN 0018-9200

Wei, C.L.; Wu, L.Y.; Yang, H.H.; Tsai, C.H.; Liu,B.D. \& Chang, S.J. (2008). A versatile step-up/step-down switched-capacitor-based DC-DC converter, IEICE, Electronics, Vol.E91-C (No.5): 809-812. ISSN 1745-1353

Yamada, K.; Fujii, N. \& Takagi, S. (2004). Capacitance value free switched capacitor DC-DC voltage converter realizing arbitrary rational conversion ratio. IEICE, Fundamentals, Vol.E87-A (No.2): 344-349. ISSN 1745-1337

Yamakawa, T.; Inoue, T. \& Tsuneda, A. (2008). Design and experiments of a novel low-ripple Cockcroft-Walton AC-to-DC converter for a coil-coupled passive RFID tag. IEICE, Fundamentals, Vol.E91-A (No.2): 513-520. ISSN 1745-1337 


\title{
Development of sustainable energy research and applications
}

\author{
Abdeen Mustafa Omer \\ Energy Research Institute (ERI), Sudan
}

\begin{abstract}
People relay upon oil for primary energy and this for a few more decades. Other orthodox sources may be more enduring, but are not without serious disadvantages. Power from natural resources has always had great appeal. Coal is plentiful, though there is concern about despoliation in winning it and pollution in burning it. Nuclear power has been developed with remarkable timeliness, but is not universally welcomed, construction of the plant is energy-intensive and there is concern about the disposal of its long-lived active wastes. Barrels of oil, lumps of coal, even uranium come from nature but the possibilities of almost limitless power from the atmosphere and the oceans seem to have special attraction. The wind machine provided an early way of developing motive power. The massive increases in fuel prices over the last years have however, made any scheme not requiring fuel appear to be more attractive and to be worth reinvestigation. In considering the atmosphere and the oceans as energy sources the four main contenders are wind power, wave power, tidal and power from ocean thermal gradients. The renewable energy resources are particularly suited for the provision of rural power supplies and a major advantage is that equipment such as flat plate solar driers, wind machines, etc., can be constructed using local resources and without the advantage results from the feasibility of local maintenance and the general encouragement such local manufacture gives to the build up of small-scale rural based industry. This article gives some examples of small-scale energy converters, nevertheless it should be noted that small conventional, i.e., engines are currently the major source of power in rural areas and will continue to be so for a long time to come. There is a need for some further development to suit local conditions, to minimise spares holdings, to maximise interchangeability both of engine parts and of the engine application. Emphasis should be placed on full local manufacture.
\end{abstract}

Keywords: Renewable energy technologies, energy efficiency, sustainable development, emissions, environment.

\section{Introduction}

This chapter comprises a comprehensive review of energy sources, the environment and sustainable development. It includes the renewable energy technologies, energy efficiency 
systems, energy conservation scenarios, energy savings in greenhouses environment and other mitigation measures necessary to reduce climate change.

The sources to alleviate the energy situation in the world are sufficient to supply all foreseeable needs. Conservation of energy and rationing in some form will however have to be practised by most countries, to reduce oil imports and redress balance of payments positions. Meanwhile development and application of nuclear power and some of the traditional solar, wind and water energy alternatives must be set in hand to supplement what remains of the fossil fuels.

The encouragement of greater energy use is an essential component of development. In the short-term it requires mechanisms to enable the rapid increase in energy/capita, and in the long-term we should be working towards a way of life, which makes use of energy efficiency and without the impairment of the environment or of causing safety problems. Such a programme should as far as possible be based on renewable energy resources.

Large-scale, conventional, power plant such as hydropower, has an important part to play in development. It does not, however, provide a complete solution. There is an important complementary role for the greater use of small-scale, rural based, power plant. Such plant can be used to assist development since it can be made locally using local resources, enabling a rapid built-up in total equipment to be made without a corresponding and unacceptably large demand on central funds. Renewable resources are particularly suitable for providing the energy for such equipment and its use is also compatible with the longterm aims. It is possible with relatively simple flat plate solar collectors (Figure 1) to provide warmed water and enable some space heating for homes and offices which is particularly useful when the buildings are well insulated and thermal capacity sufficient for the carry over of energy from day to night is arranged.

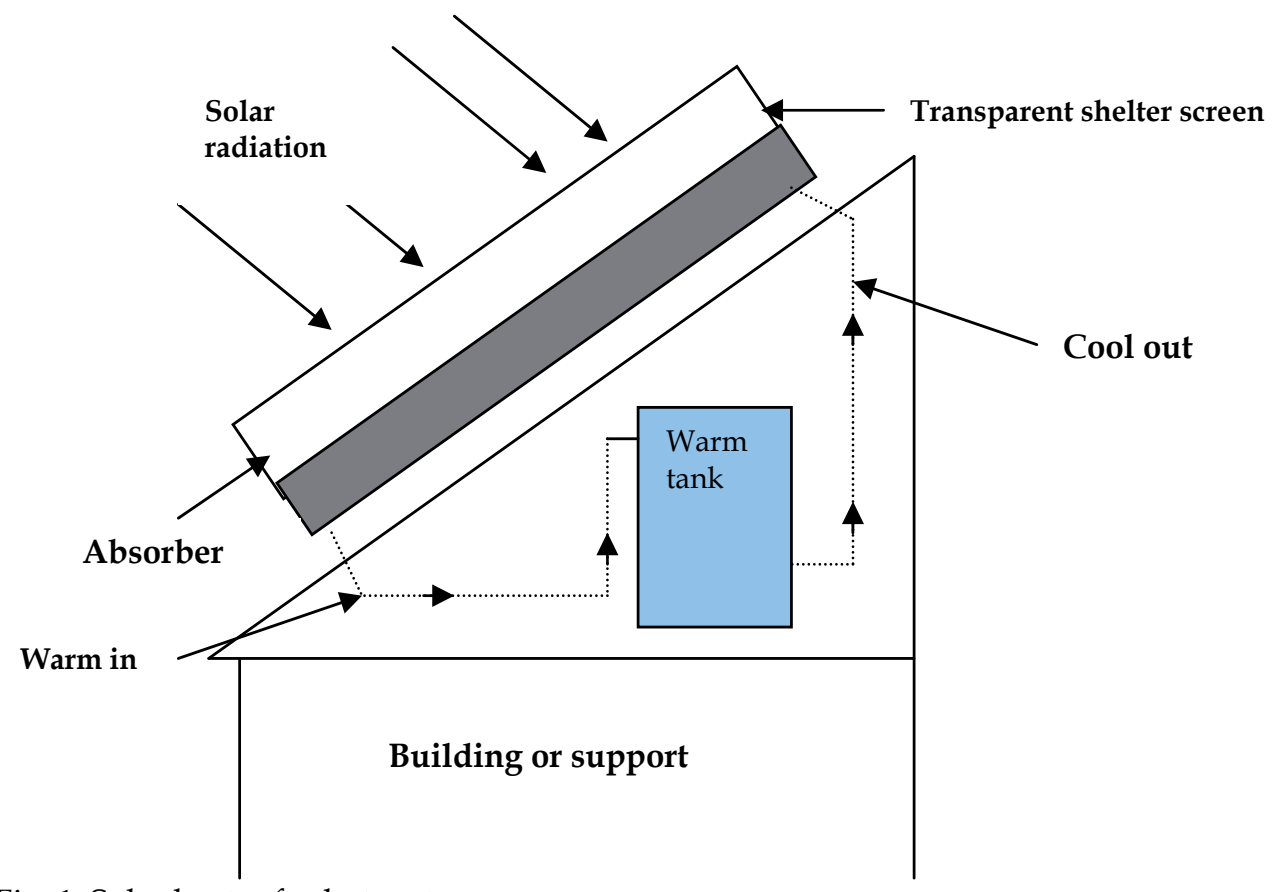

Fig. 1. Solar heater for hot water 
In compiling energy consumption data one can categorise usage according to a number of different schemes:

- Traditional sector- industrial, transportation, etc.

- End-use- space heating, process steam, etc.

- Final demand- total energy consumption related to automobiles, to food, etc.

- Energy source- oil, coal, etc.

- Energy form at point of use- electric drive, low temperature heat, etc.

\section{Renewable energy}

The renewable energy resources are particularly suited for the provision of rural power supplies and a major advantage is that equipment such as flat plate solar driers, wind machines, etc., can be constructed using local resources and without the high capital cost of more conventional equipment. Further advantage results from the feasibility of local maintenance and the general encouragement such local manufacture gives to the build up of small scale rural based industry. Table 1 lists the energy sources available.

Globally, buildings are responsible for approximately $40 \%$ of the total world annual energy consumption. Most of this energy is for the provision of lighting, heating, cooling, and air conditioning. Increasing awareness of the environmental impact of $\mathrm{CO}_{2}$ and $\mathrm{NO}_{x}, \mathrm{CFCs}$ emissions and triggered a renewed interest in environmentally friendly cooling, and heating technologies. Under the 1997 Montreal Protocol, governments agreed to phase out chemicals used as refrigerants that have the potential to destroy stratospheric ozone. It was therefore considered desirable to reduce energy consumption and decrease the rate of depletion of world energy reserves and pollution of the environment.

\begin{tabular}{|l|l|l|}
\hline Energy source & Energy carrier & Energy end-use \\
\hline Vegetation & Fuel-wood & $\begin{array}{l}\text { Cooking } \\
\text { Water heating } \\
\text { Building materials } \\
\text { Animal fodder preparation }\end{array}$ \\
\hline Oil & Kerosene & $\begin{array}{l}\text { Lighting } \\
\text { Ignition fires }\end{array}$ \\
\hline Dry cells & Dry cell batteries & $\begin{array}{l}\text { Lighting } \\
\text { Small appliances }\end{array}$ \\
\hline Muscle power & Animal power & $\begin{array}{l}\text { Transport } \\
\text { Land preparation for farming } \\
\text { Food preparation (threshing) }\end{array}$ \\
\hline Muscle power & Human power & $\begin{array}{l}\text { Transport } \\
\text { Land preparation for farming } \\
\text { Food preparation (threshing) }\end{array}$ \\
\hline
\end{tabular}

Table 1. Sources of energy 
Currently the 'non-commercial' fuels wood, crop residues and animal dung are used in large amounts in the rural areas of developing countries, principally for heating and cooking; the method of use is highly inefficient. Table 2 presented some renewable applications.

\begin{tabular}{|l|l|}
\hline \multicolumn{1}{|c|}{ Systems } & \multicolumn{1}{c|}{ Applications } \\
\hline Water supply & Rain collection, purification, storage and recycling \\
Wastes disposal & Anaerobic digestion $\left(\mathrm{CH}_{4}\right)$ \\
Cooking & Methane \\
Food & Cultivate the 1 hectare plot and greenhouse for four people \\
Electrical demands & Wind generator \\
Space heating & Solar collectors \\
Water heating & Solar collectors and excess wind energy \\
Control system & Ultimately hardware \\
Building fabric & Integration of subsystems to cut costs \\
\hline
\end{tabular}

Table 2. Renewable applications

Table 3 lists the most important of energy needs.

Considerations when selecting power plant include the following:

- Power level- whether continuous or discontinuous.

- Cost- initial cost, total running cost including fuel, maintenance and capital amortised over life.

- Complexity of operation.

- Maintenance and availability of spares.

- $\quad$ Life.

- Suitability for local manufacture.

Table 4 listed methods of energy conversion.

Transport e.g., small vehicles and boats

Agricultural machinery e.g., two-wheeled tractors

Crop processing e.g., milling

Water pumping

Small industries e.g., workshop equipment

Electricity generation e.g., hospitals and schools

Domestic e.g., cooking, heating, lighting

Water supply e.g., rain collection, purification, storage and recycling

Building fabric e.g., integration of subsystems to cut costs

Wastes disposal e.g., anaerobic digestion $\left(\mathrm{CH}_{4}\right)$

Table 3. energy needs in rural areas 


\begin{tabular}{|l|l|}
\hline $\begin{array}{l}\text { Muscle power } \\
\text { Internal combustion engines }\end{array}$ & Man, animals \\
Reciprocating & $\begin{array}{l}\text { Petrol- spark ignition } \\
\text { Diesel- compression ignition } \\
\text { Humphrey water piston }\end{array}$ \\
Rotating & Gas turbines \\
Heat engines & \\
Vapour (Rankine) & Steam engine \\
Reciprocating & Steam turbine \\
Rotating & Steam engine \\
Gas Stirling (Reciprocating) & Steam turbine \\
Gas Brayton (Rotating) & Thermionic, thermoelectric \\
Electron gas & Photo devices \\
Electromagnetic radiation & Wheels, screws, buckets, turbines \\
Hydraulic engines & Vertical axis, horizontal axis \\
Wind engines (wind machines) & Dynamo/alternator, motor \\
Electrical/mechanical & \\
\hline
\end{tabular}

Table 4. Methods of energy conversion

The human wastes (four people) would provide about $280 \mathrm{kWh} / \mathrm{a}$ of methane, but with the addition of vegetable wastes from 0.2 ha or wastes from 1 ha growing a complete diet, about $1500 \mathrm{kWh} /$ a may be obtained by anaerobic digestion. The sludge from the digester may be returned to the land. In hotter climates, this efficient could be used to set up a more productive cycle (Figure 2).

There is a need for greater attention to be devoted to this field in the development of new designs, the dissemination of information and the encouragement of its use. International and government bodies and independent organisations all have a role to play in renewable energy technologies.

Society and industry in Europe and elsewhere are increasingly dependent on the availability of electricity supply and on the efficient operation of electricity systems. In the European Union (EU), the average rate of growth of electricity demand has been about $1.8 \%$ per year since 1990 and is projected to be at least $1.5 \%$ yearly up to 2030 . Currently, distribution networks generally differ greatly from transmission networks, mainly in terms of role, structure (radial against meshed) and consequent planning and operation philosophies (Robinson, 2007).

\section{Energy use}

Energy use is one of several essential components for developing countries:

- The overall situation and the implications of increased energy use in the future.

- The problem of the provision of power in rural areas, including the consideration of energy resources and energy conversion.

In addition to the drain on resources, such an increase in consumption consequences, together with the increased hazards of pollution and the safety problems associated with a large nuclear fission programmes. This is a disturbing prospect. It would be equally 
unacceptable to suggest that the difference in energy between the developed and developing countries and prudent for the developed countries to move towards a way of life which, whilst maintaining or even increasing quality of life, reduce significantly the energy consumption per capita. Such savings can be achieved in a number of ways:

- Improved efficiency of energy use, for example better thermal insulation, energy recovery, and total energy.

- Conservation of energy resources by design for long life and recycling rather than the short life throwaway product.

- Systematic replanning of our way of life, for example in the field of transport.

Energy ratio is defined as the ratio of:

Energy content of the food product/Energy input to produce the food

A review of the potential range of recyclables is presented in Table 5.

Currently the non-commercial fuels wood, crop residues and animal dung are used in large amounts in the rural areas of developing countries, principally for heating and cooking, the method of use is highly inefficient. As in the developed countries, the fossil fuels are currently of great importance in the developing countries. Geothermal and tidal energy are less important though, of course, will have local significance where conditions are suitable. Nuclear energy sources are included for completeness, but are not likely to make any effective contribution in the rural areas.

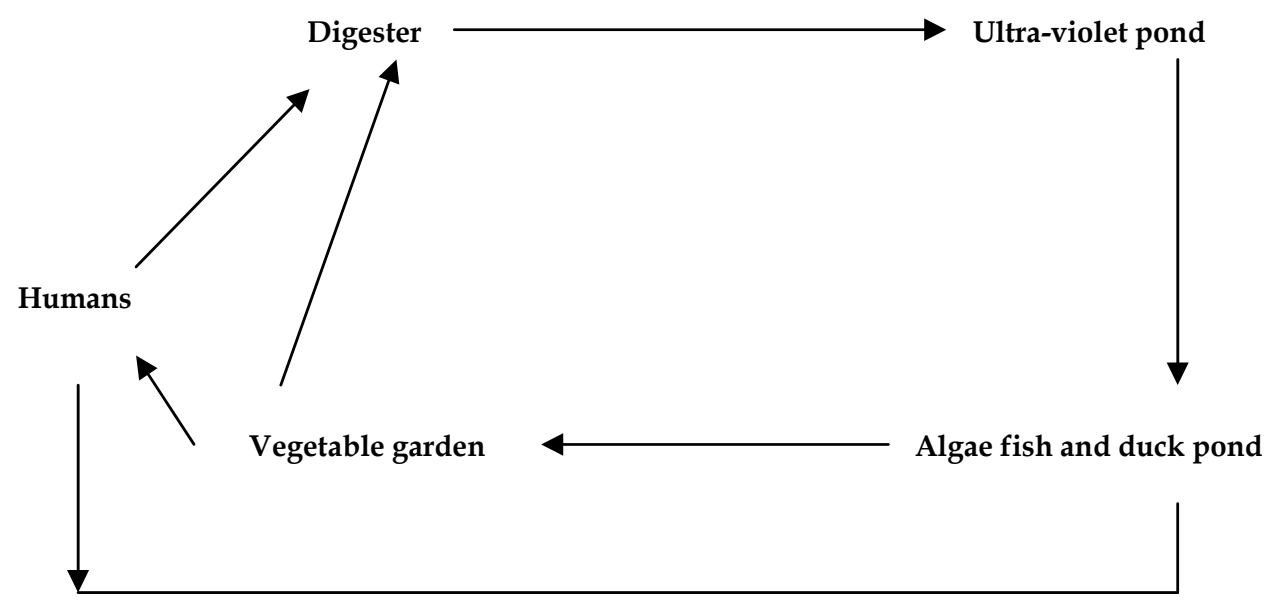

Fig. 2. Biomass energy utilisation cycle

\section{Biogas}

Biogas is a generic term for gases generated from the decomposition of organic material. As the material breaks down, methane $\left(\mathrm{CH}_{4}\right)$ is produced as shown in Figure 3. Sources that 
generate biogas are numerous and varied. These include landfill sites, wastewater treatment plants and anaerobic digesters. Landfills and wastewater treatment plants emit biogas from decaying waste. To date, the waste industry has focused on controlling these emissions to our environment and in some cases, tapping this potential source of fuel to power gas turbines, thus generating electricity. The primary components of landfill gas are methane $\left(\mathrm{CH}_{4}\right)$, carbon dioxide $\left(\mathrm{CO}_{2}\right)$, and nitrogen $\left(\mathrm{N}_{2}\right)$. The average concentration of methane is $\sim 45 \%, \mathrm{CO}_{2}$ is $\sim 36 \%$ and nitrogen is $\sim 18 \%$ (Omer, and Yemen, 2001). Other components in the gas are oxygen $\left(\mathrm{O}_{2}\right)$, water vapour and trace amounts of a wide range of non-methane organic compounds (NMOCs). Landfill gas-to-cogeneration projects present a win-win-win situation. Emissions of particularly damaging pollutant are avoided, electricity is generated from a free fuel and heat is available for use locally.

\begin{tabular}{|c|c|c|}
\hline $\begin{array}{l}\text { Construction and } \\
\text { demolition } \\
\text { material }\end{array}$ & Recycling technology options & Recycling product \\
\hline Asphalt & $\begin{array}{l}\text { Cold recycling: heat generation; } \\
\text { Minnesota process; parallel dnum } \\
\text { proces5; elongated drum; microwave } \\
\text { asphalt recycling system; finfalt; } \\
\text { surface regeneration }\end{array}$ & Recycling asphalt; asphalt aggregate \\
\hline Brick & Bun to ash, crush into aggregate & Slime burn ash; filling material; hardcore \\
\hline Concrete & Crush into aggregate & $\begin{array}{l}\text { Recycling aggregate; cement replacement; } \\
\text { protection of levee; backfilling; filter }\end{array}$ \\
\hline Ferrous metal & Melt; reuse directly & Recycled steel scrap \\
\hline Glass & $\begin{array}{l}\text { Reuse directly; grind to powder; } \\
\text { polishing; crush into aggregate; burn } \\
\text { to ash }\end{array}$ & $\begin{array}{l}\text { Recycled window unit; glass fibre; filling } \\
\text { material; tile; paving block; asphalt; } \\
\text { recycled aggregate; cement replacement; } \\
\text { mammade soil }\end{array}$ \\
\hline Masoury & $\begin{array}{l}\text { Crush into aggregate; heat to } 900^{\circ} \mathrm{C} \text { to } \\
\text { ash }\end{array}$ & $\begin{array}{l}\text { Thermal insulating coucrete; traditional } \\
\text { clay }\end{array}$ \\
\hline Non-ferrous metal & Melt & Recycled metal \\
\hline $\begin{array}{l}\text { Paper and } \\
\text { cardboard }\end{array}$ & Purification & Recycled paper \\
\hline Plastic & $\begin{array}{l}\text { Convert to powder by cryogenic } \\
\text { milling; clopping; crush into } \\
\text { aggregate; burn to ash }\end{array}$ & $\begin{array}{l}\text { Panel; recycled plastic; plastic lumber; } \\
\text { recycled aggregate; landfill drainage; } \\
\text { asphalt; manmade soil }\end{array}$ \\
\hline Timber & $\begin{array}{l}\text { Reuse directly; cut into aggregate; } \\
\text { blast funnace deoxidisation; } \\
\text { gasification or pyrolysis; chipping; } \\
\text { moulding by pressurising timber chip } \\
\text { under steam and water }\end{array}$ & $\begin{array}{l}\text { Whole timber; furniture and kitchen } \\
\text { utensils; lightweight recycled aggregate; } \\
\text { source of energy; chemical production; } \\
\text { wood-based panel; plastic lumber; } \\
\text { geofibre; insulation board }\end{array}$ \\
\hline
\end{tabular}

Table 5. Summary of material recycling practices in construction sector

In the past two decades the world has become increasingly aware of the depletion of fossil fuel reserves and the indications of climatic changes based on carbon dioxide emissions. Therefore extending the use of renewable resources, efficient energy production and the reduction of energy consumption are the main goals to reach a sustainable energy supply. Renewable energy sources include water and wind power, solar and geothermal energy, as 
well as energy from biomass. The technical achievability and the actual usage of these energy sources are different around Europe, but biomass is seen to have a great potential in many of them. An efficient method for the conversion of biomass to energy, is the production of biogas by microbial degradation of organic matter under the absence of oxygen (anaerobic digestion). It is now possible to produce biogas at rural installation, upgrade it to bio-methane, feed it into the gas grid, use it in a heat demand-controlled $\mathrm{CHP}$ and to receive revenues. Biogas is a mixture containing predominantly methane $(50-65 \%$ by volume) and carbon dioxide and in a natural setting it is formed in swamps and anaerobic sediments, etc., due due to its high methane concentration, biogas is a valuable fuel. Wet (40-95\%) organic materials with low lignin and cellulose content are generally suitable for anaerobic digestion. The imporatance and role of biogases in energy production is growing. Nowadays, a lot of countries in Europe promote utilisation of renewable energies by guaranteed refund prices or emission trading systems.

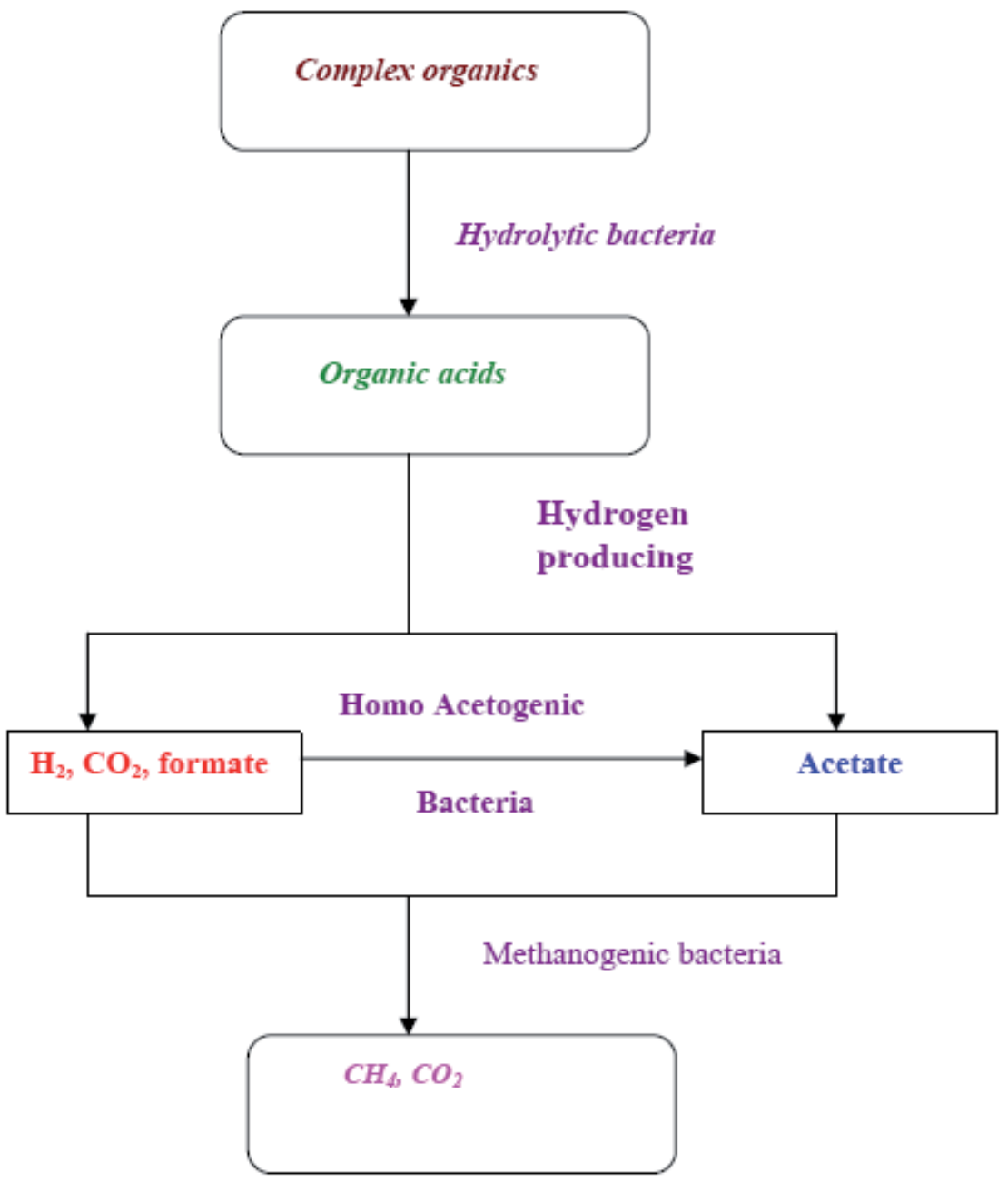

Fig. 3. Biogas production process 


\section{Wave power conversion devices}

The patent literature is full of devices for extracting energy from waves, i.e., floats, ramps, and flaps, covering channels. Small generators driven from air trapped by the rising and falling water in the chamber of a buoy are in use around the world (Swift-Hook, et al, 2007). Wave power is one possibility that has been selected. Figure 4 shows the many other aspects that will need to be covered. A wave power programme would make a significant contribution to energy resources within a relatively short time and with existing technology. Wave energy has also been in the news recently. There is about 140 megawatts per mile available round British coasts. It could make a useful contribution people needs, about twice that of the UK generating system is available provided. Although very large amounts of power are available in the waves, it is important to consider how much power can be extracted. A few years ago only a few percent efficiency had been achieved. Recently, however, several devices have been studied which have very high efficiencies. Some form of storage will be essential on a second-to-second and minute-to-minute basis to smooth the fluctuations of individual waves and wave's packets but storage from one day to the next will certainly not be economic. This is why provision must be made for adequate standby capacity.

The increased availability of reliable and efficient energy services stimulates new development alternatives. This article discusses the potential for such integrated systems in the stationary and portable power market in response to the critical need for a cleaner energy technology. Anticipated patterns of future energy use and consequent environmental impacts (acid precipitation, ozone depletion and the greenhouse effect or global warming) are comprehensively discussed in this paper. Throughout the theme several issues relating to renewable energies, environment and sustainable development are examined from both current and future perspectives. It is concluded that renewable environmentally friendly energy must be encouraged, promoted, implemented and demonstrated by full-scale plan especially for use in remote rural areas.

Globally, buildings are responsible for approximately $40 \%$ of the total world annual energy consumption. Most of this energy is for the provision of lighting, heating, cooling, and air conditioning. Increasing awareness of the environmental impact of $\mathrm{CO}_{2}$ and $\mathrm{NO}_{x}$ emissions and CFCs triggered a renewed interest in environmentally friendly cooling, and heating technologies. Under the 1997 Montreal Protocol, governments agreed to phase out chemicals used as refrigerants that have the potential to destroy stratospheric ozone. It was therefore considered desirable to reduce energy consumption and decrease the rate of depletion of world energy reserves and pollution of the environment. One way of reducing building energy consumption is to design buildings, which are more economical in their use of energy for heating, lighting, cooling, ventilation and hot water supply. Passive measures, particularly natural or hybrid ventilation rather than air-conditioning, can dramatically reduce primary energy consumption. However, exploitation of renewable energy in buildings and agricultural greenhouses can, also, significantly contribute towards reducing dependency on fossil fuels. Therefore, promoting innovative renewable applications and reinforcing the renewable energy market will contribute to preservation of the ecosystem by reducing emissions at local and global levels. This will also contribute to the amelioration of environmental conditions by replacing conventional fuels with renewable energies that produce no air pollution or greenhouse gases. The provision of good indoor environmental quality while achieving energy and cost efficient operation of the heating, ventilating and 
air-conditioning (HVAC) plants in buildings represents a multi variant problem. The comfort of building occupants is dependent on many environmental parameters including air speed, temperature, relative humidity and quality in addition to lighting and noise. The overall objective is to provide a high level of building performance (BP), which can be defined as indoor environmental quality (IEQ), energy efficiency (EE) and cost efficiency (CE).

\section{Ethanol production}

Alternative fuels were defined as methanol, ethanol, natural gas, propane, hydrogen, coalderived liquids, biological material and electricity. The fuel pathways currently under development for alcohol fuels are shown in Figure 5. The production of agricultural biomass and its exploitation for energy purposes can contribute to alleviate several problems, such as the dependence on import of energy products, the production of food surpluses, the pollution provoked by the use of fossil fuels, the abandonment of land by farmers and the connected urbanisation. Biomass is not at the moment competitive with mineral oil, but, taking into account also indirect costs and giving a value to the aforementioned advantages, public authorities at national and international level can spur its production and use by incentives of different nature. In order to address the problem of inefficiency, research centres around the world have investigated the viability of converting the resource to a more useful form, namely solid briquettes and fuel gas (Figure 6).

The main advantages are related to energy, agriculture and environment problems, are foreseeable both at regional level and at worldwide level and can be summarised as follows:

- Reduction of dependence on import of energy and related products.

- Reduction of environmental impact of energy production (greenhouse effect, air pollution, and waste degradation).

- Substitution of food crops and reduction of food surpluses and of related economic burdens, and utilisation of marginal lands and of set aside lands.

- Reduction of related socio-economic and environmental problems (soil erosion, urbanisation, landscape deterioration, etc.).

- Development of new know-how and production of technological innovation.

The convention on Biological Diversity set conservation of biodiversity on the world agenda. Gaps in knowledge need to be addressed for actions to be effective and sustainable. Gaps include: species diversity, microorganisms and their ecological roles, ecological and geographical status of species, human capacity to access and forecast bio-ecological degradation. Requirements for global inventories call for worldwide collaboration. Criteria for setting priorities need to be formulated and agreed. Global inventorying needs a collaborative international effort, perhaps under the aegis of the Convention on Biological Diversity. The recently formulated global taxonomy initiatives are a step in the right direction. 


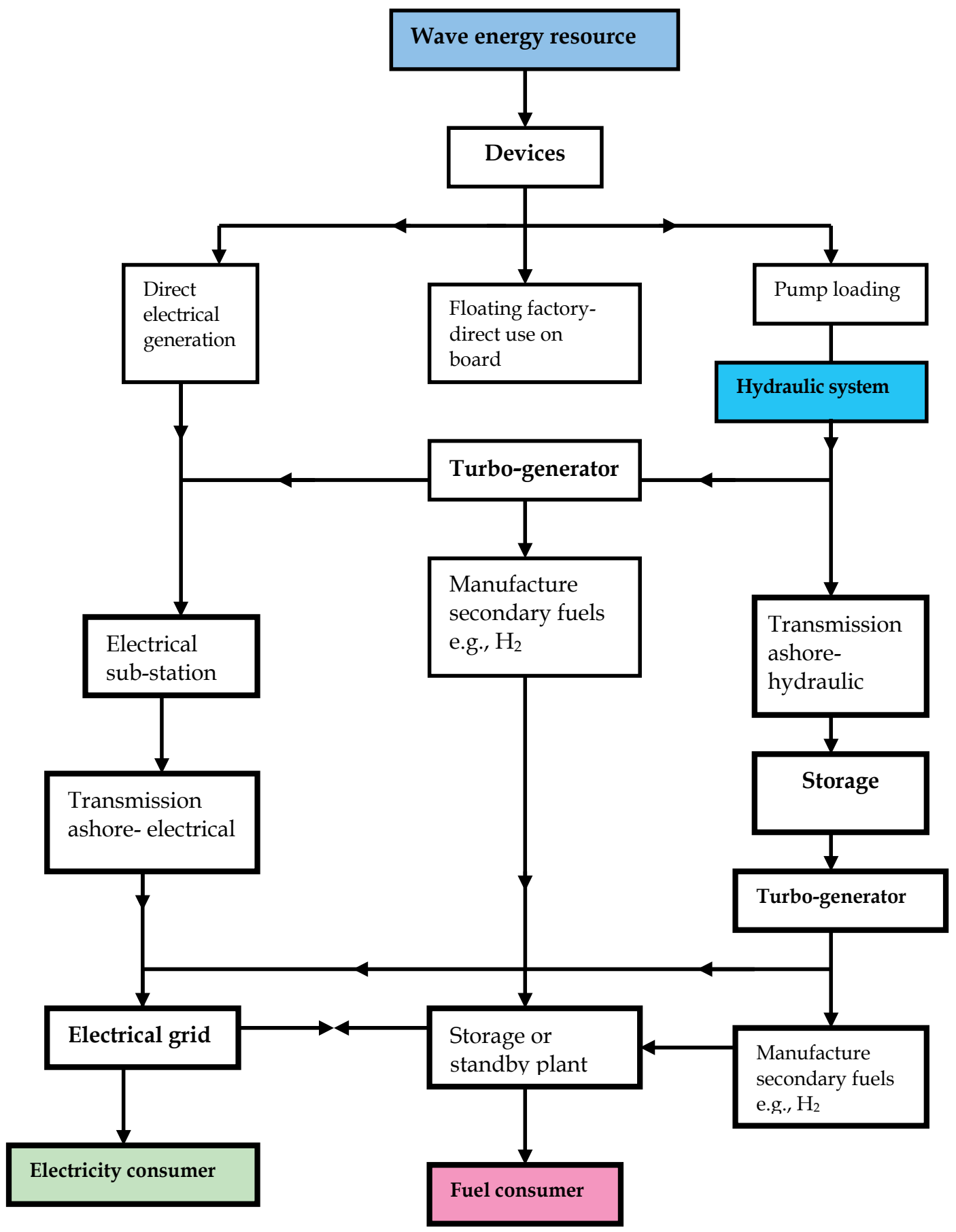

Fig. 4. Possible systems for exploiting wave power, each element represents an essential link in the chain from sea waves to consumer 
The debate over an international climate change regime has thus far focused primarily on efficiency concerns in developed countries. In the international negotiations over the control of climate change, the developing countries so far have assumed few obligations. At present, this debate has not progressed very far. There are several reasons for this impasse. First, there is a distinction between cost effectiveness (where in the world should the control be undertaken in order to minimise the global costs of control) and equity (who should bear the costs of mitigation and abatement resulting from climate change) that has not been adequately clarified and agreed upon by the parties to the Protocol. Second, the global control or anthropogenic climate change will require complex cooperative efforts among a large number of individual nations. This cooperative effort will have to be based on a thorough understanding of how the various participating nations contribute to the process of global climate change, and how that process affects them. One of the fundamental principles of environmental policy is that the polluter pays for using the environment and the use of natural resources. This is one way of imposing responsibility for environmental consequences on the party causing the environmental damage. In the context of environmental taxes, it is the polluter who pays, which is one reason why taxes are as suitable as an instrument for environmental policy.

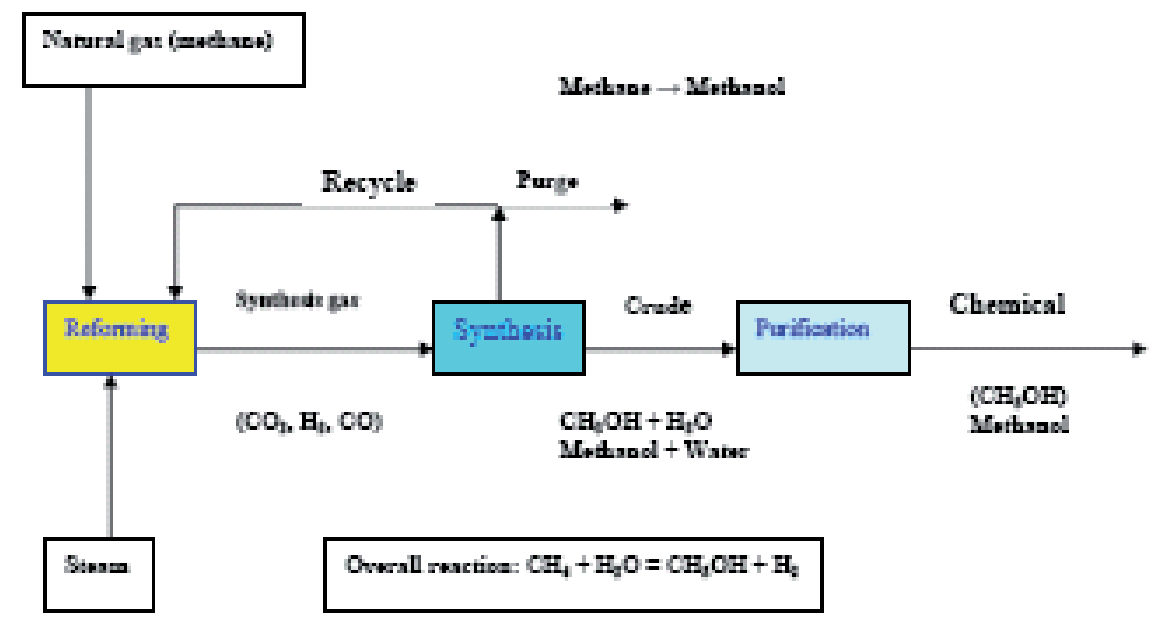

Fig. 5. Schematic process flowsheet

Biomass resources play a significant role in energy supply in all developing countries. Biomass resources should be divided into residues or dedicated resources, the latter including firewood and charcoal can also be produced from forest residues. Ozone $\left(\mathrm{O}_{3}\right)$ is a naturally occurring molecule that consists of three oxygen atoms held together by the bonding of the oxygen atoms to each other. The effects of the chlorofluorocarbons (CFCs) molecule can last for over a century. This reaction is shown in Figure 7.

It is a common misconception that the reason for recycling old fridge is to recover the liquid from the cooling circuit at the back of the unit. The insulating foams used inside some fridges act as sinks of CFCs- the gases having been used as blowing agents to expand the 
foam during fridge manufacture. Although the use of ozone depleting chemicals in the foam in fridges has declined in the West, recyclers must consider which strategy to adopt to deal with the disposal problem they still present each year. It is common practice to dispose of this waste wood in landfill where it slowly degraded and takes up valuable void space. This wood is a good source of energy and is an alternative to energy crops. Agricultural wastes are abundantly available globally and can be converted to energy and useful chemicals by a number of microorganisms. The success of promoting any technology depends on careful planning, management, implementation, training and monitoring. Main features of gasification project are:

- Networking and institutional development/strengthening.

- Promotion and extension.

- Construction of demonstration projects.

- $\quad$ Research and development; and training and monitoring.

\section{Biomass CHP}

Combined heat and power (CHP) installations are quite common in greenhouses, which grow high-energy, input crops (e.g., salad vegetables, pot plants, etc.). Scientific assumptions for a short-term energy strategy suggest that the most economically efficient way to replace the thermal plants is to modernise existing power plants to increase their energy efficiency and to improve their environmental performance. However, utilisation of wind power and the conversion of gas-fired CHP plants to biomass would significantly reduce the dependence on imported fossil fuels. Although a lack of generating capacity is forecasted in the long-term, utilisation of the existing renewable energy potential and the huge possibilities for increasing energy efficiency are sufficient to meet future energy demands in the short-term.

A total shift towards a sustainable energy system is a complex and long process, but is one that can be achieved within a period of about 20 years. Implementation will require initial investment, long-term national strategies and action plans. However, the changes will have a number of benefits including: a more stable energy supply than at present, and major improvement in the environmental performance of the energy sector, and certain social benefits. A vision used a methodology and calculations based on computer modelling that utilised:

- Data from existing governmental programmes.

- Potential renewable energy sources and energy efficiency improvements.

- Assumptions for future economy growth.

- Information from studies and surveys on the recent situation in the energy sector.

In addition to realising the economic potential identified by the National Energy Savings Programme, a long-term effort leading to a $3 \%$ reduction in specific electricity demand per year after 2020 is proposed. This will require further improvements in building codes, and continued information on energy efficiency (IEA, 2007). 


\section{Biomass}

resource

Industry

Agriculture

Forestry

Waste

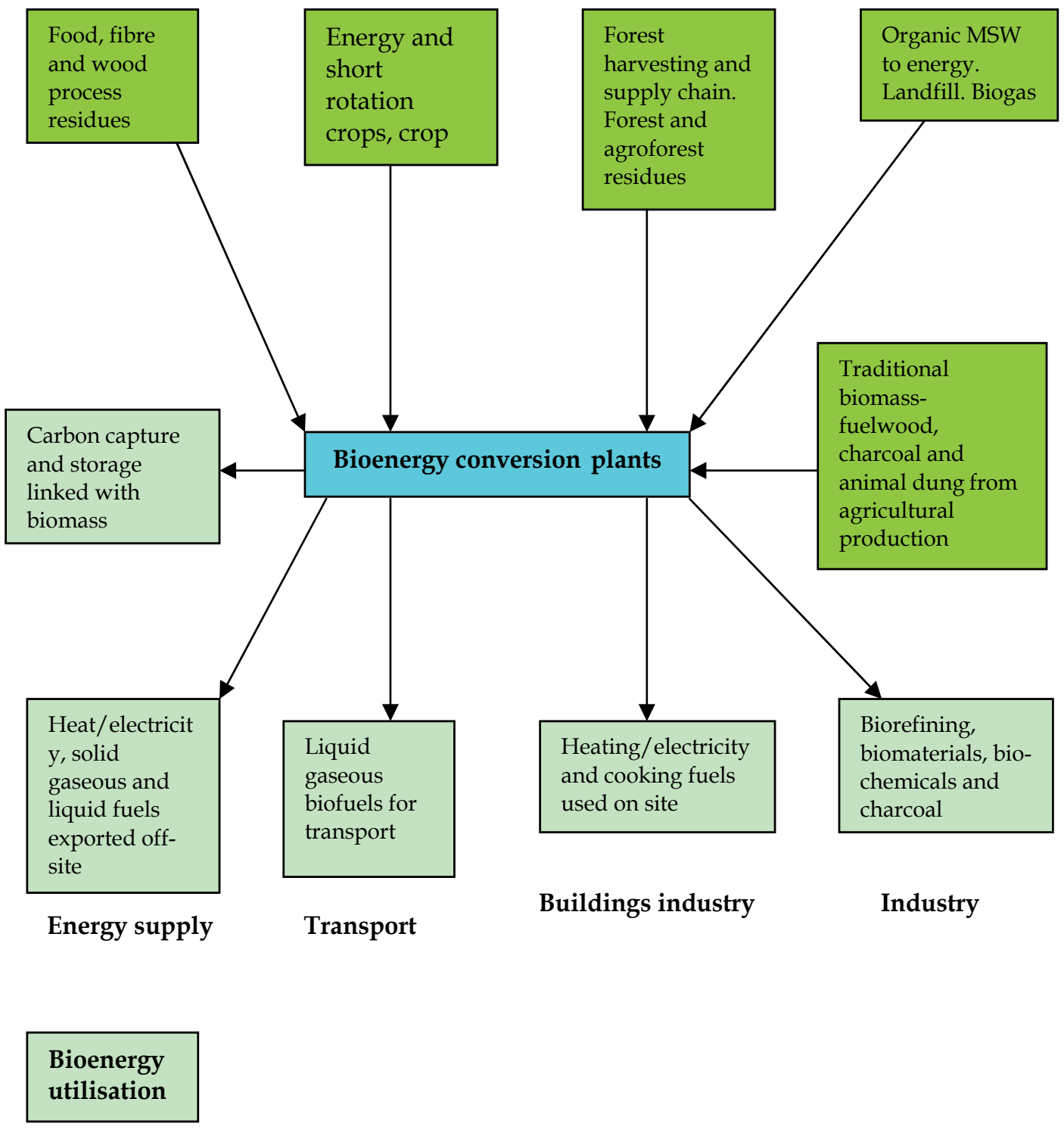

Fig. 6. Biomass resources from several sources is converted into a range of products for use by transport, industry and building sectors 


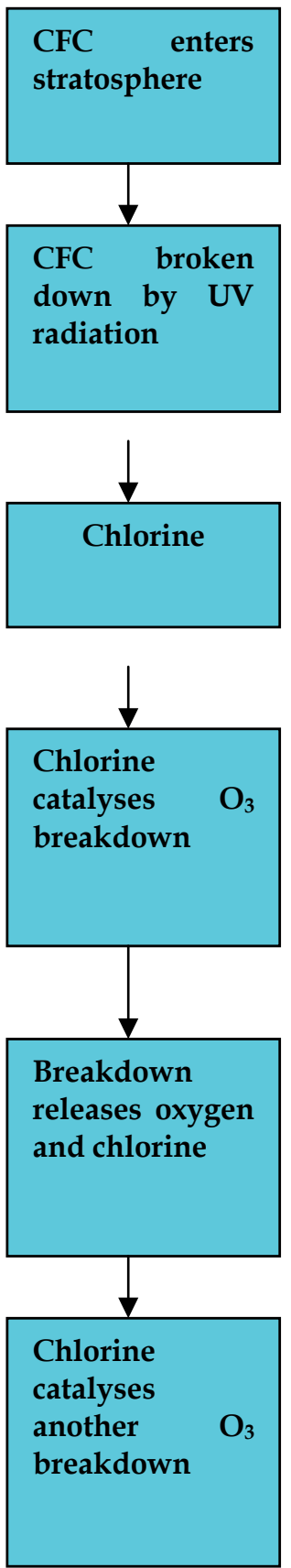

Fig. 7. The process of ozone depletion (Trevor, 2007) 
The environmental Non Governmental Organisations (NGOs) are urging the government to adopt sustainable development of the energy sector by:

- Diversifying of primary energy sources to increase the contribution of renewable and local energy resources in the total energy balance.

- Implementing measures for energy efficiency increase at the demand side and in the energy transformation sector.

The price of natural gas is set by a number of market and regulatory factors that include:

Supply and demand balance and market fundamentals, weather, pipeline availability and deliverability, storage inventory, new supply sources, prices of other energy alternatives and regulatory issues and uncertainty.

Classic management approaches to risk are well documented and used in many industries. This includes the following four broad approaches to risk:

- Avoidance includes not performing an activity that could carry risk. Avoidance may seem the answer to all risks, but avoiding risks also means losing out on potential gain.

- Mitigation/reduction involves methods that reduce the severity of potential loss.

- Retention/acceptance involves accepting the loss when it occurs. Risk retention is a viable strategy for small risks. All risks that are not avoided or transferred are retained by default.

- Transfer means causing another party to accept the risk, typically by contract.

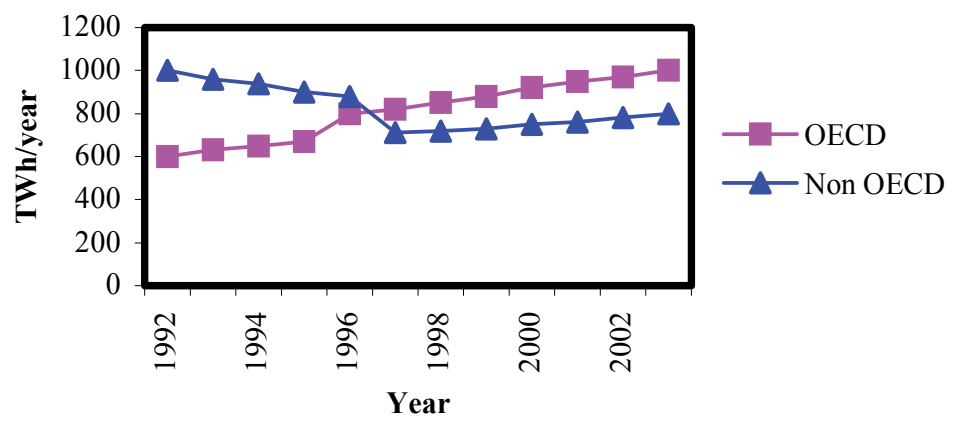

Fig. 8. Global CHP trends from 1992-2003

Methane is a primary constituent of landfill gas (LFG) and a potent greenhouse gas (GHG) when released into the atmosphere. Globally, landfills are the third largest anthropogenic emission source, accounting for about $13 \%$ of methane emissions or over 818 million tones of carbon dioxide equivalent $\left(\mathrm{MMTCO}_{2} \mathrm{e}\right)$ (Brain, and Mark, 2007) as shown in Figures 8-10. 


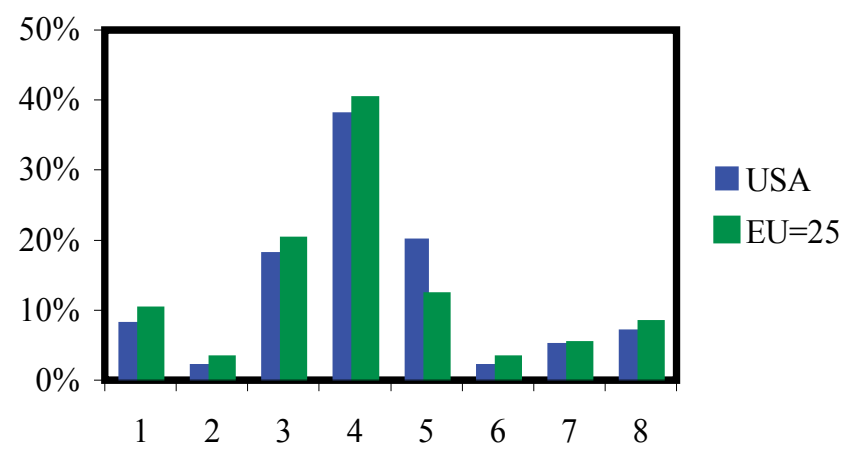

Fig. 9. Distribution of industrial CHP capacity in the EU and USA

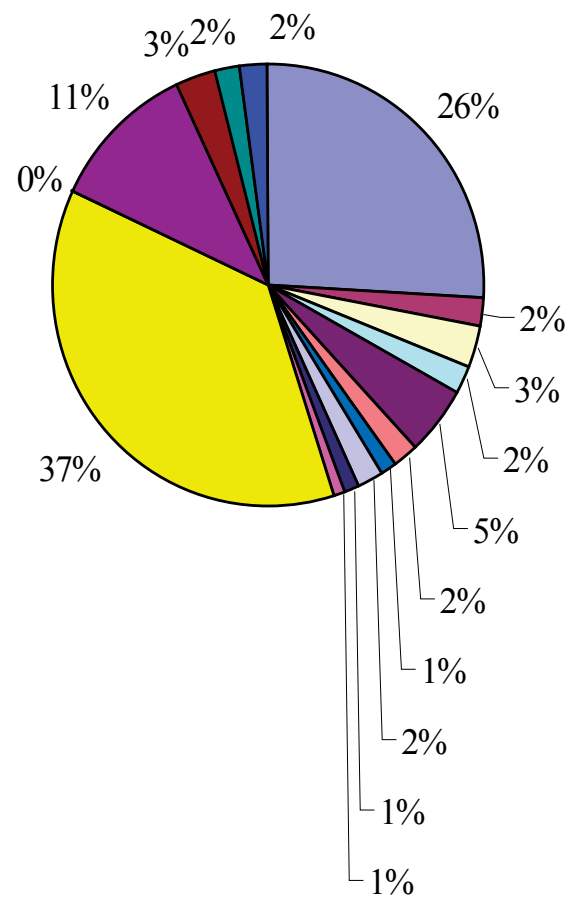

$\begin{array}{llll}\square \text { USA } & \square \text { UK } & \square \text { Ukraine } & \square \text { South Africa } \\ \square \text { Russia } & \square \text { Poland } & \square \text { Nigeria } & \square \text { Mexico } \\ \square \text { Japan } & \square \text { Italy } & \square \text { Others } & \square \text { Colombia } \\ \square \text { China } & \square \text { Canada } & \square \text { Brazil } & \square \text { Australia }\end{array}$

Fig. 10. World landfill methane emissions $\left(\mathrm{MMTCO}_{2} \mathrm{e}\right)$ 


\section{Geothermal energy}

Geothermal steam has been used in volcanic regions in many countries to generate electricity. The use of geothermal energy involves the extraction of heat from rocks in the outer part of the earth. It is relatively unusual for the rocks to be sufficiently hot at shallow depth for this to be economically attractive. Virtually all the areas of present geothermal interest are concentrated along the margins of the major tectonic plates, which form the surface of the earth. Heat is conventionally extracted by the forced or natural circulation of water through permeable hot rock.

There are various practical difficulties and disadvantages associated with the use of geothermal power:

Transmission: geothermal power has to be used where it is found. In Iceland it has proved feasible to pipe hot water $20 \mathrm{~km}$ in insulated pipes but much shorter distances are preferred.

Environmental problems: these are somewhat variable and are usually not great. Perhaps the most serious is the disposal of warm high salinity water where it cannot be reinjected or purified. Dry steam plants tend to be very noisy and there is releases of small amounts of methane, hydrogen, nitrogen, amonia and hydrogen sulphide and of these the latter presents the main problem.

The geothermal fluid is often highly chemically corrosive or physically abrassive as the result of the entrained solid matter it carries. This may entail special plant design problems and unusually short operational lives for both the holes and the installations they serve.

Because the useful rate of heat extraction from a geothermal field is in nearly all cases much higher than the rate of conduction into the field from the underlying rocks, the mean temperatures of the field is likely to fall during exploitation. In some low rainfall areas there may also be a problem of fluid depletion. Ideally, as much as possible of the geothermal fluid should be reinjected into the field. However, this may involve the heavy capital costs of large condensation installations. Occasionally, the salinity of the fluid available for reinjection may be so high (as a result of concentration by boiling) that is unsuitable for reinjection into ground. Ocasionally, the impurities can be precipitated and used but this has not generally proved commercially attractive.

World capacity of geothermal energy is growing at a rate of $2.5 \%$ per year from a 2005 level of $28.3 \mathrm{GW}$. The GSHPs account for approximately $54 \%$ of this capacity almost all of it in the North America and Europe (Rawlings, 1999). The involvement of the UK is minimal with less than $0.04 \%$ of world capacity and yet is committed to substantial reduction in carbon emission beyond the $12.5 \%$ Kyoto obligation to be achieved by 2012. The GSHPs offer a significant potential for carbon reduction and it is therefore expected that the market for these systems will rise sharply in the UK in the immediate years ahead given to low capacity base at present.

There are numerous ways of harnessing low-grade heat from the ground for use as a heat pump source or air conditioning sink. For small applications (residences and small commercial buildings) horizontal ground loop heat exchangers buried typically at between $1 \mathrm{~m}$ and $1.8 \mathrm{~m}$ below the surface can be used provided that a significant availability of land surrounding the building can be exploited which tends to limit these applications to rural settings. 
Heat generation within the earth is approximately $2700 \mathrm{GW}$, roughly an order of magnitude greater than the energy associated with the tides but about four orders less than that received by the earth from the sun (Oxburgh, 1975).

Temperature distributions within the earth depend on:

- The abundance and distribution of heat producing elements within the earth.

- The mean surface temperature (which is controlled by the ocean/atmosphere system).

- The thermal properties of the earth's interior and their lateral and radial variation.

- Any movements of fluid or solid rock materials occurring at rates of more than a few millimetres per year.

Of these four factors the first two are of less importance from the point of view of geothermal energy. Mean surface temperatures range between $0-30^{\circ} \mathrm{C}$ and this variation has a small effect on the useable enthalpy of any flows of hot water. Although radiogenic heat production in rocks may vary by three orders of magnitude, there is much less variation from place to place in the integrated heat production with depth. The latter factors, however, are of great importance and show a wide range of variation. Their importance is clear from the relationship:

$$
\beta=q / k
$$

Where:

$\beta$ is the thermal gradient for a steady state $\left({ }^{\circ} \mathrm{C} / \mathrm{km}\right), \mathrm{q}$ is the heat flux $\left(10^{-6} \mathrm{cal} \mathrm{cm}^{-2} \mathrm{sec}^{-1}\right)$ and $\mathrm{k}$ is the thermal conductivity ( $\left.\mathrm{cal} \mathrm{cm}^{-1} \mathrm{sec}^{-1} \mathrm{o}^{-1}\right)$.

The first requirement of any potential geothermal source region is that $\beta$ being large, i.e., that high rock temperatures occur at shallow depth. Beta will be large if either $\mathrm{q}$ is large or $\mathrm{k}$ is small or both. By comparison with most everyday materials, rocks are poor conductors of heat and values of conductivity may vary from $2 \times 10^{-3}$ to $10^{-2} \mathrm{cal} \mathrm{cm}^{-1} \mathrm{sec}^{-1} \mathrm{oC}^{-1}$. The mean surface heat flux from the earth is about 1.5 heat flow units $\left(1 \mathrm{HFU}=10^{-6} \mathrm{cal} \mathrm{cm}^{-2} \mathrm{sec}^{-1}\right)$. Rocks are also very slow respond to any temperature change to which they are exposed, i.e., they have a low thermal diffusivity:

$$
\mathrm{K}=\mathrm{k} / \rho \mathrm{C}_{\mathrm{p}}
$$

Where:

$\mathrm{K}$ is thermal diffusivity; $\rho$ and $\mathrm{C}_{\mathrm{p}}$ are density and specific heat respectively.

These values are simple intended to give a general idea of the normal range of geothermal parameters (Table 6). In volcanic regions, in particular, both $\mathrm{q}$ and $\beta$ can vary considerably and the upper values given are somewhat nominal.

\begin{tabular}{|l|l|l|l|}
\hline Parameter & Lower & Average & Upper \\
\hline $\mathrm{q}(\mathrm{HFU})$ & 0.8 & 1.5 & $3.0($ non volcanic) $\approx 100$ (volcanic) \\
$\mathrm{k}=\mathrm{cal} \mathrm{cm}^{-2} \mathrm{sec}^{-1} \mathrm{oC}^{-1}=$ & $2 \times 10^{-3}$ & $6 \times 10^{-3}$ & $12 \times 10^{-3}$ \\
$\beta={ }^{\circ} \mathrm{C} / \mathrm{km}$ & 8 & 20 & 60 (non volcanic) $\approx 300$ (volcanic) \\
\hline
\end{tabular}

Table 6. Values of geothermal parameters 


\section{Landfill gas}

Landfill gas (LFG) is currently extracted at over 1200 landfills worldwide for a variety of energy purposes (Table 7), such as:

- Creating pipeline quality gas or an alternative fuel for vehicles.

- Processing the LFG to make it available as an alternative fuel to local industrial or commercial customers.

- Generation of electricity with engines, turbines, micro-turbines and other emerging technologies.

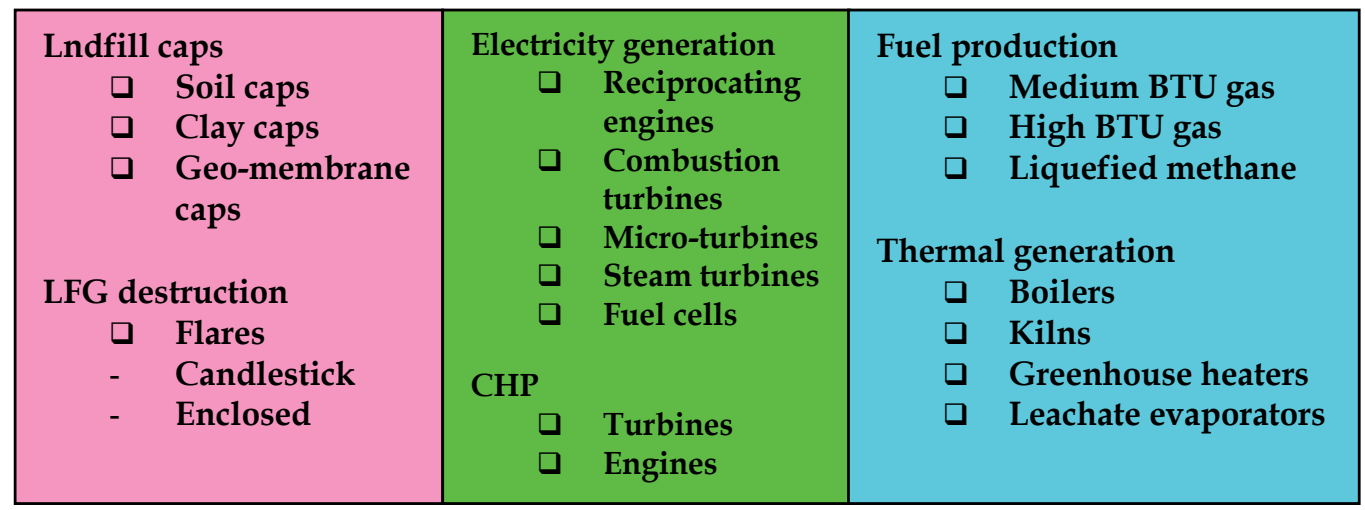

Table 7. Types of LFG implemented recently worldwide

In terms of solid waste management policy, many NGOs have changed drastically in the past ten years from a mass production and mass consumption society to 'material-cycle society'. In addition to national legislation, municipalities are legally obliged to develop a plan for handling the municipal solid waste (MSW) generated in administrative areas. Such plans contain:

- Estimates of future waste volume.

- Measures to reduce waste.

- Measures to encourage source separation.

- A framework for solid waste disposal and the construction and management of solid waste management facilities.

Landfilling is in the least referred tier of the hierarchy of waste management options: Waste minimisation, reuse and recycling, incineration with energy recovery, and optimised final disposal. The key elements are as follows: construction impacts, atmospheric emissions, noise, water quality, landscape, visual impacts, socio economics, ecological impacts, traffic, solid waste disposal and cultural heritage. 


\section{Energy efficiency}

Energy efficiency is the most cost-effective way of cutting carbon dioxide emissions and improvements to households and businesses. It can also have many other additional social, economic and health benefits, such as warmer and healthier homes, lower fuel bills and company running costs and, indirectly, jobs. Britain wastes 20 per cent of its fossil fuel and electricity use. This implies that it would be cost-effective to cut $£ 10$ billion a year off the collective fuel bill and reduce $\mathrm{CO}_{2}$ emissions by some 120 million tones. Yet, due to lack of good information and advice on energy saving, along with the capital to finance energy efficiency improvements, this huge potential for reducing energy demand is not being realised. Traditionally, energy utilities have been essentially fuel providers and the industry has pursued profits from increased volume of sales. Institutional and market arrangements have favoured energy consumption rather than conservation. However, energy is at the centre of the sustainable development paradigm as few activities affect the environment as much as the continually increasing use of energy. Most of the used energy depends on finite resources, such as coal, oil, gas and uranium. In addition, more than three quarters of the world's consumption of these fuels is used, often inefficiently, by only one quarter of the world's population. Without even addressing these inequities or the precious, finite nature of these resources, the scale of environmental damage will force the reduction of the usage of these fuels long before they run out.

Throughout the energy generation process there are impacts on the environment on local, national and international levels, from opencast mining and oil exploration to emissions of the potent greenhouse gas carbon dioxide in ever increasing concentration. Recently, the world's leading climate scientists reached an agreement that human activities, such as burning fossil fuels for energy and transport, are causing the world's temperature to rise. The Intergovernmental Panel on Climate Change has concluded that "the balance of evidence suggests a discernible human influence on global climate". It predicts a rate of warming greater than any one seen in the last 10,000 years, in other words, throughout human history. The exact impact of climate change is difficult to predict and will vary regionally. It could, however, include sea level rise, disrupted agriculture and food supplies and the possibility of more freak weather events such as hurricanes and droughts. Indeed, people already are waking up to the financial and social, as well as the environmental, risks of unsustainable energy generation methods that represent the costs of the impacts of climate change, acid rain and oil spills. The insurance industry, for example, concerned about the billion dollar costs of hurricanes and floods, has joined sides with environmentalists to lobby for greenhouse gas emissions reduction. Friends of the earth are campaigning for a more sustainable energy policy, guided by the principal of environmental protection and with the objectives of sound natural resource management and long-term energy security. The key priorities of such an energy policy must be to reduce fossil fuel use, move away from nuclear power, improve the efficiency with which energy is used and increase the amount of energy obtainable from sustainable, and energy sources. Efficient energy use has never been more crucial than it is today, particularly with the prospect of the imminent introduction of the climate change levy (CCL). Establishing an energy use action plan is the essential foundation to the elimination of energy waste. A logical starting point is to carry out an energy audit that enables the assessment of the energy use and determine what actions to take. The actions are best categorised by splitting measures into the following three general groups: 
(1) High priority/low cost:

These are normally measures, which require minimal investment and can be implemented quickly. The followings are some examples of such measures:

- Good housekeeping, monitoring energy use and targeting waste-fuel practices.

- Adjusting controls to match requirements.

- Improved greenhouse space utilisation.

- Small capital item time switches, thermostats, etc.

- Carrying out minor maintenance and repairs.

- Staff education and training.

- Ensuring that energy is being purchased through the most suitable tariff or contract arrangements.

(2) Medium priority/medium cost:

Measures, which, although involve little or no design, involve greater expenditure and can take longer to implement. Examples of such measures are listed below:

- New or replacement controls.

- Greenhouse component alteration, e.g., insulation, sealing glass joints, etc.

- Alternative equipment components, e.g., energy efficient lamps in light fittings, etc.

(3) Long term/high cost:

These measures require detailed study and design. They can be best represented by the followings:

- $\quad$ Replacing or upgrading of plant and equipment.

- Fundamental redesign of systems, e.g., CHP installations.

This process can often be a complex experience and therefore the most cost-effective approach is to employ an energy specialist to help.

\section{Policy recommendations for a sustainable energy future}

Sustainability is regarded as a major consideration for both urban and rural development. People have been exploiting the natural resources with no consideration to the effects, both short-term (environmental) and long-term (resources crunch). It is also felt that knowledge and technology have not been used effectively in utilising energy resources. Energy is the vital input for economic and social development of any country. Its sustainability is an important factor to be considered. The urban areas depend, to a large extent, on commercial energy sources. The rural areas use non-commercial sources like firewood and agricultural wastes. With the present day trends for improving the quality of life and sustenance of mankind, environmental issues are considered highly important. In this context, the term energy loss has no significant technical meaning. Instead, the exergy loss has to be considered, as destruction of exergy is possible. Hence, exergy loss minimisation will help in sustainability.

The development of a renewable energy in a country depends on many factors. Those important to success are listed below: 
(1) Motivation of the population

The population should be motivated towards awareness of high environmental issues, rational use of energy in order to reduce cost. Subsidy programme should be implemented as incentives to install biomass energy plants. In addition, image campaigns to raise awareness of renewable technology.

(2) Technical product development

To achieve technical development of biomass energy technologies the following should be addressed:

- Increasing the longevity and reliability of renewable technology.

- Adapting renewable technology to household technology (hot water supply).

- Integration of renewable technology in heating technology.

- Integration of renewable technology in architecture, e.g., in the roof or façade.

- Development of new applications, e.g., solar cooling.

- Cost reduction.

(3) Distribution and sales

Commercialisation of biomass energy technology requires:

- Inclusion of renewable technology in the product range of heating trades at all levels of the distribution process (wholesale, retail, etc.).

- $\quad$ Building distribution nets for renewable technology.

- Training of personnel in distribution and sales.

- Training of field sales force.

(4) Consumer consultation and installation

To encourage all sectors of the population to participate in adoption of biomass energy technologies, the following has to be realised:

- Acceptance by craftspeople, marketing by them.

- Technical training of craftspeople, initial and follow-up training programmes.

- Sales training for craftspeople.

- Information material to be made available to craftspeople for consumer consultation.

(5) Projecting and planning

Successful application of biomass technologies also require:

- Acceptance by decision makers in the building sector (architects, house technology planners, etc.).

- Integration of renewable technology in training.

- Demonstration projects/architecture competitions.

- Biomass energy project developers should prepare to participate in the carbon market by: 
- Ensuring that renewable energy projects comply with Kyoto Protocol requirements.

- Quantifying the expected avoided emissions.

- Registering the project with the required offices.

- Contractually allocating the right to this revenue stream.

- Other ecological measures employed on the development include:

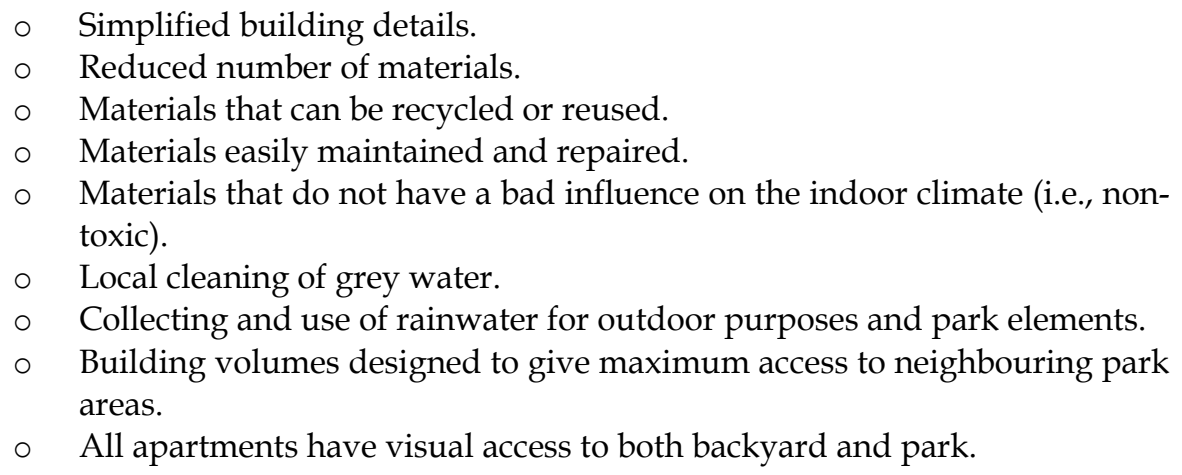

(6) Energy saving measures

The following energy saving measures should also be considered:

- Building integrated solar PV system.

- Day-lighting.

- Ecological insulation materials.

- Natural/hybrid ventilation.

- Passive cooling.

- Passive solar heating.

- Solar heating of domestic hot water.

- Utilisation of rainwater for flushing.

Improving access for rural and urban low-income areas in developing countries must be through energy efficiency and renewable energies. Sustainable energy is a prerequisite for development. Energy-based living standards in developing countries, however, are clearly below standards in developed countries. Low levels of access to affordable and environmentally sound energy in both rural and urban low-income areas are therefore a predominant issue in developing countries. In recent years many programmes for development aid or technical assistance have been focusing on improving access to sustainable energy, many of them with impressive results.

Apart from success stories, however, experience also shows that positive appraisals of many projects evaporate after completion and vanishing of the implementation expert team. Altogether, the diffusion of sustainable technologies such as energy efficiency and renewable energies for cooking, heating, lighting, electrical appliances and building insulation in developing countries has been slow. 
Energy efficiency and renewable energy programmes could be more sustainable and pilot studies more effective and pulse releasing if the entire policy and implementation process was considered and redesigned from the outset. New financing and implementation processes are needed which allow reallocating financial resources and thus enabling countries themselves to achieve a sustainable energy infrastructure. The links between the energy policy framework, financing and implementation of renewable energy and energy efficiency projects have to be strengthened and capacity building efforts are required.

\section{Environmental aspects of energy conversion and use}

Environment has no prcise limits because it is in fact a part of everything. Indeed, environment is, as anyone probably already knows, not only flowers blossoming or birds singing in the spring, or a lake surrounded by beautiful mountains. It is also human settlements, the places where people live, work, rest, the quality of the food they eat, the noise or silence of the street they live in. environment is not only the fact that our cars consume a good deal of energy and pollute the air, but also, that we often need them to go to work and for hoildays. Obviously man uses energy just as plants, bactria, mishrooms, bees, fish and rats do. Man largely uses solar energy- food, hydropower, wood- and thus participates harmoniously in the natural flow of energy through the environment. But man also uses oil, gas, coal and nuclear power. By using such sources of energy, man is thus modifying his environment.

The atmospheric emissions of fossil fuelled installations are mosty aldehydes, carbon monoxide, nitrogen oxides, sulpher oxides and particles (i.e., ash) as well as carbon dioxide. Table 8 shows estimates include not only the releases occuring at the power plant itself but also cover fuel extraction and treatment, as well as the storage of wastes and the aea of land required for operations. Table 9 shows energy consumption in different regions of the world.

\begin{tabular}{|l|c|c|c|c|}
\hline \multirow{2}{*}{$\begin{array}{l}\text { Primary source } \\
\text { of energy }\end{array}$} & \multicolumn{2}{|c|}{ Emissions } & Waste $\left(\times 10^{3}\right.$ metric & Area $\left(\mathrm{km}^{2}\right)$ \\
\cline { 2 - 3 } tons $)$ & Atmosphere & Water & $60-3000$ & \\
\hline Coal & 380 & $7-41$ & negligible & 720 \\
Oil & $70-160$ & $3-6$ & - & 84 \\
Gas & 24 & 1 & 2600 & 77 \\
Nuclear & 6 & 21 & \\
\hline
\end{tabular}

Table 8. Annual greenhouse emissions from different sources of power plants

\begin{tabular}{|l|c|c|}
\hline Region & Population (millions) & Energy $\left(\right.$ Watt $\left./ \mathrm{m}^{2}\right)$ \\
\hline Africa & 820 & 0.54 \\
Asia & 3780 & 2.74 \\
Central America & 180 & 1.44 \\
North America & 335 & 0.34 \\
South America & 475 & 0.52 \\
Western Europe & 445 & 2.24 \\
Eastern Europe & 130 & 2.57 \\
Oceania & 35 & 0.08 \\
Russia & 330 & 0.29 \\
\hline
\end{tabular}

Table 9. Energy consumption in different continents 


\section{Greenhouses environment}

Greenhouse cultivation is one of the most absorbing and rewarding forms of gardening for anyone who enjoys growing plants. The enthusiastic gardener can adapt the greenhouse climate to suit a particular group of plants, or raise flowers, fruit and vegetables out of their natural season. The greenhouse can also be used as an essential garden tool, enabling the keen amateur to expand the scope of plants grown in the garden, as well as save money by raising their own plants and vegetables. There was a decline in large private greenhouses during the two world wars due to a shortage of materials for their construction and fuel to heat them. However, in the 1950s mass-produced, small greenhouses became widely available at affordable prices and were used mainly for raising plants (John, 1993). Also, in recent years, the popularity of conservatories attached to the house has soared. Modern double-glazing panels can provide as much insulation as a brick wall to create a comfortable living space, as well as provide an ideal environment in which to grow and display tender plants.

The comfort in a greenhouse depends on many environmental parameters. These include temperature, relative humidity, air quality and lighting. Although greenhouse and conservatory originally both meant a place to house or conserve greens (variegated hollies, cirrus, myrtles and oleanders), a greenhouse today implies a place in which plants are raised while conservatory usually describes a glazed room where plants may or may not play a significant role. Indeed, a greenhouse can be used for so many different purposes. It is, therefore, difficult to decide how to group the information about the plants that can be grown inside it.

Throughout the world urban areas have increased in size during recent decades. About $50 \%$ of the world's population and approximately $76 \%$ in the more developed countries are urban dwellers. Even though there is an evidence to suggest that in many 'advanced' industrialised countries there has been a reversal in the rural-to-urban shift of populations, virtually all population growth expected between 2000 and 2030 will be concentrated in urban areas of the world. With an expected annual growth of $1.8 \%$, the world's urban population will double in 38 years. This represents a serious contributing to the potential problem of maintaining the required food supply. Inappropriate land use and management, often driven by intensification resulting from high population pressure and market forces, is also a threat to food availability for domestic, livestock and wildlife use. Conversion to cropland and urban-industrial establishments is threatening their integrity. Improved productivity of peri-urban agriculture can, therefore, make a very large contribution to meeting food security needs of cities as well as providing income to the peri-urban farmers. Hence, greenhouses agriculture can become an engine of pro-poor 'trickle-up' growth because of the synergistic effects of agricultural growth such as (UN, 2001):

- Increased productivity increases wealth.

- Intensification by small farmers raises the demand for wage labour more than by larger farmers.

- Intensification drives rural non-farm enterprise and employment.

- Alleviation of rural and peri-urban poverty is likely to have a knock-on decrease of urban poverty.

Despite arguments for continued large-scale collective schemes there is now an increasingly compelling argument in favour of individual technologies for the development of controlled 
greenhouses. The main points constituting this argument are summarised by (UN, 2001) as follows:

- Individual technologies enable the poorest of the poor to engage in intensified agricultural production and to reduce their vulnerability.

- Development is encouraged where it is needed most and reaches many more poor households more quickly and at a lower cost.

- Farmer-controlled greenhouses enable farmers to avoid the difficulties of joint management.

Such development brings the following challenges (UN, 2001):

- The need to provide farmers with ready access to these individual technologies, repair services and technical assistance.

- Access to markets with worthwhile commodity prices, so that sufficient profitability is realised.

- This type of technology could be a solution to food security problems. For example, in greenhouses, advances in biotechnology like the genetic engineering, tissue culture and market-aided selection have the potential to be applied for raising yields, reducing pesticide excesses and increasing the nutrient value of basic foods.

However, the overall goal is to improve the cities in accordance with the Brundtland Report and the investigation into how urban green could be protected. Indeed, greenhouses can improve the urban environment in multitude of ways. They shape the character of the town and its neighbourhoods, provide places for outdoor recreation, and have important environmental functions such as mitigating the heat island effect, reduce surface water runoff, and creating habitats for wildlife. Following analysis of social, cultural and ecological values of urban green, six criteria in order to evaluate the role of green urban in towns and cities were prescribed (WCED, 1987). These are as follows:

- Recreation, everyday life and public health.

- Maintenance of biodiversity - preserving diversity within species, between species, ecosystems, and of landscape types in the surrounding countryside.

- City structure - as an important element of urban structure and urban life.

- Cultural identity - enhancing awareness of the history of the city and its cultural traditions.

- Environmental quality of the urban sites - improvement of the local climate, air quality and noise reduction.

- Biological solutions to technical problems in urban areas - establishing close links between technical infrastructure and green-spaces of a city.

The main reasons why it is vital for greenhouses planners and designers to develop a better understanding of greenhouses in high-density housing can be summarised as follows (WCED, 1987):

- $\quad$ Pressures to return to a higher density form of housing.

- The requirement to provide more sustainable food.

- The urgent need to regenerate the existing, and often decaying, houses built in the higher density, high-rise form, much of which is now suffering from technical problems. 
The connection between technical change, economic policies and the environment is of primary importance as observed by most governments in developing countries, whose attempts to attain food self-sufficiency have led them to take the measures that provide incentives for adoption of the Green Revolution Technology (Herath, 1985). Since, the Green Revolution Technologies were introduced in many countries actively supported by irrigation development, subsidised credit, fertiliser programmes, self-sufficiency was found to be not economically efficient and often adopted for political reasons creating excessive damage to natural resources. Also, many developing countries governments provided direct assistance to farmers to adopt soil conservation measures. They found that high costs of establishment and maintenance and the loss of land to hedgerows are the major constraints to adoption (Herath, 1985). The soil erosion problem in developing countries reveals that a dynamic view of the problem is necessary to ensure that the important elements of the problem are understood for any remedial measures to be undertaken. The policy environment has, in the past, encouraged unsustainable use of land (Herath, 1985). In many regions, government policies such as provision of credit facilities, subsidies, price support for certain crops, subsidies for erosion control and tariff protection, have exacerbated the erosion problem. This is because technological approaches to control soil erosion have often been promoted to the exclusion of other effective approaches. However, adoption of conservation measures and the return to conservation depend on the specific agro-ecological conditions, the technologies used and the prices of inputs and outputs of production.

\section{Types of Greenhouses}

Choosing a greenhouse and setting it up are important, and often expensive, steps to take. Greenhouses are either freestanding or lean-to, that is, built against an existing wall. A freestanding greenhouse can be placed in the open, and, hence, take advantage of receiving the full sun throughout the day. It is, therefore, suitable for a wide range of plants. However, its main disadvantage when compared to a lean-to type is that more heat is lost through its larger surface area. This is mainly why lean-to greenhouses have long been used in the walled gardens of large country houses to grow Lapageria rosea and other plants requiring cool, constant temperature, such as half-hardly ferns. However, generally, good ventilation and shading in the spring and summer to prevent overheating are essential for any greenhouse. The high daytime temperatures will warm the back wall, which acts as a heat battery, releasing its accumulated heat at night. Therefore, plants in a greenhouse with this orientation will need the most attention, as they will dry out rapidly.

Also, greenhouses vary considerably in their shapes and internal dimensions. Traditional greenhouses have straight sides, which allow the maximum use of internal space, and are ideal for climbers. On the other hand, greenhouses with sloping sides have the advantage of allowing the greatest penetration of sunlight, even during winter. The low winter sun striking the glass at $90^{\circ} \mathrm{C}$ lets in the maximum amount of light. Where the sun strikes the glass at a greater or lesser angle, a proportion of the light is reflected away from greenhouse. Sloping sides, also, offer less wind resistance than straight sides and therefore, less likely to be damaged during windy weather. This type of greenhouse is most suitable for short winter crops, such as early spring lettuce, and flowering annuals from seed, which do not require much headroom. 
A typical greenhouse is shown schematically in Figure 11. However, there are several designs of greenhouses, based on dimensions, orientation and function. The following three options are the most widely used:

- A ready-made design

- A designed, which is constructed from a number of prefabricated modules

- A bespoke design

Of these, the prefabricated ready-made design, which is utilised to fit the site, is the cheapest greenhouses and gives flexibility. It is, also, the most popular option (WCED, 1987).

Specific examples of commercially available designs are numerous. Dutch light greenhouses, for example, have large panes of glass, which cast little shade on the plants inside. They are simple to erect, consisting of frames bolted together, which are supported on a steel framework for all but the smallest models. They are easy to move and extra sections can be added on to them, a useful attraction. Curvilinear greenhouses, on the other hand, are designed primarily to let in the maximum amount of light throughout the year by presenting at least one side perpendicular to the sun. This attractive style of greenhouse tends to be expensive because of the number of different angles, which require more engineering. Likewise, the uneven span greenhouses are designed for maximum light transmission on one side. These are generally taller than traditional greenhouses, making them suitable for tall, early season crops, such as cucumbers. Also, the polygonal greenhouses are designed more as garden features than as practical growing houses, and consequently, are expensive. Their internal space is somewhat limited and on smaller models over-heading can be a problem because of their small roof ventilations. They are suitable for growing smaller pot plants, such as pelargoniums and cacti. Another example is the solar greenhouses. These are designed primarily for areas with very cold winters and poor winter light. They take the form of lean-to structures facing the sun, are well insulated to conserve heat and are sometimes partially sunk into the ground. They are suitable for winter vegetable crops and early-sown bedding plants, such as begonias and pelargoniums. Mini lean-to greenhouses are suitable for small gardens where space is limited. They can, also, be used to create a separate environment within larger greenhouses. The space inside is large enough to grow two tomato or melon plants in growing bags, or can install shelves to provide a multi-layered growing environment, ideal for many small potted plants and raising summer bedding plants (WCED, 1987).

\section{Construction Materials}

Different materials are used for the different parts. However, wood and aluminum are the two most popular materials used for small greenhouses. Steel is used for larger structures and UPVC for conservatories (Jonathon, 1991).

\section{Ground Radiation}

Reflection of sunrays is mostly used for concentrating them onto reactors of solar power plants. Enhancing the insolation for other purposes has, so far, scarcely been used. Several years ago, application of this principle for increasing the ground irradiance in greenhouses, glass covered extensions in buildings, and for illuminating northward facing walls of 
buildings was proposed (Achard, and Gicqquel, 1986). Application of reflection of sun's rays was motivated by the fact that ground illuminance/irradiance from direct sunlight is of very low intensity in winter months, even when skies are clear, due to the low incident angle of incoming radiation during most of the day. This is even more pronounced at greater latitudes. As can be seen in Figure 12, which depicts a sunbeam split into its vertical and horizontal components, nearly all of the radiation passes through a greenhouse during most of the day.

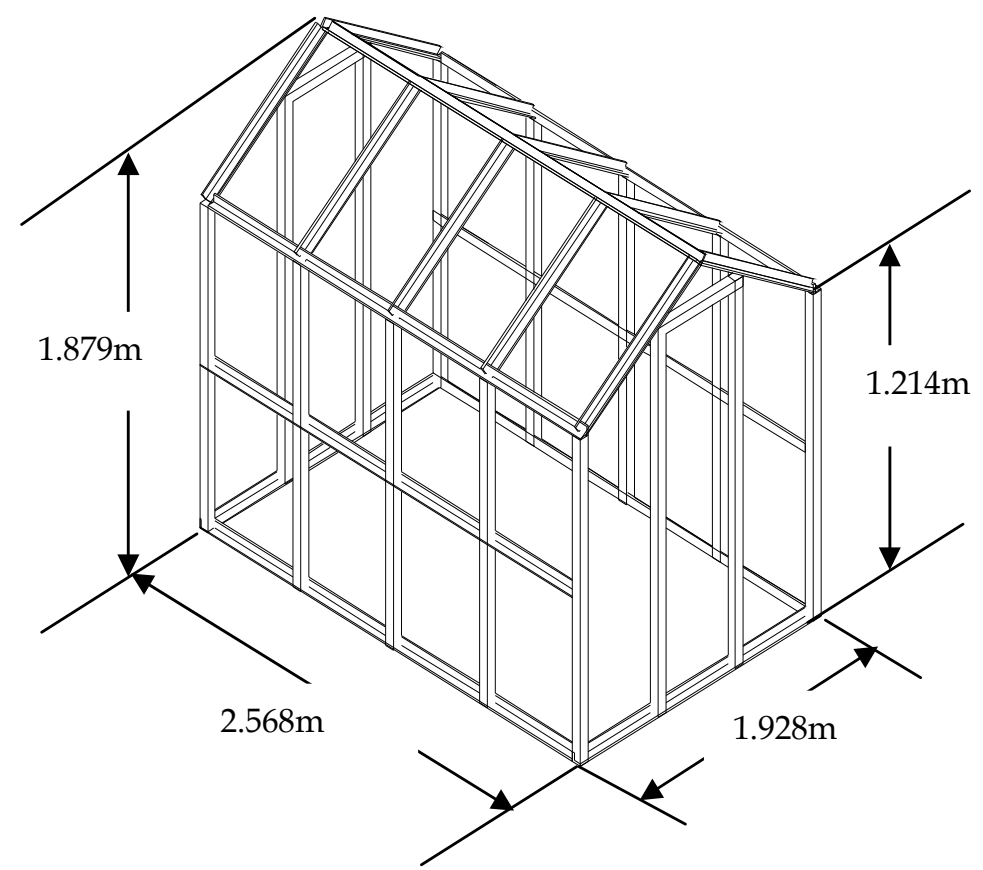

Fig. 11. Greenhouse and base with horticultural glass

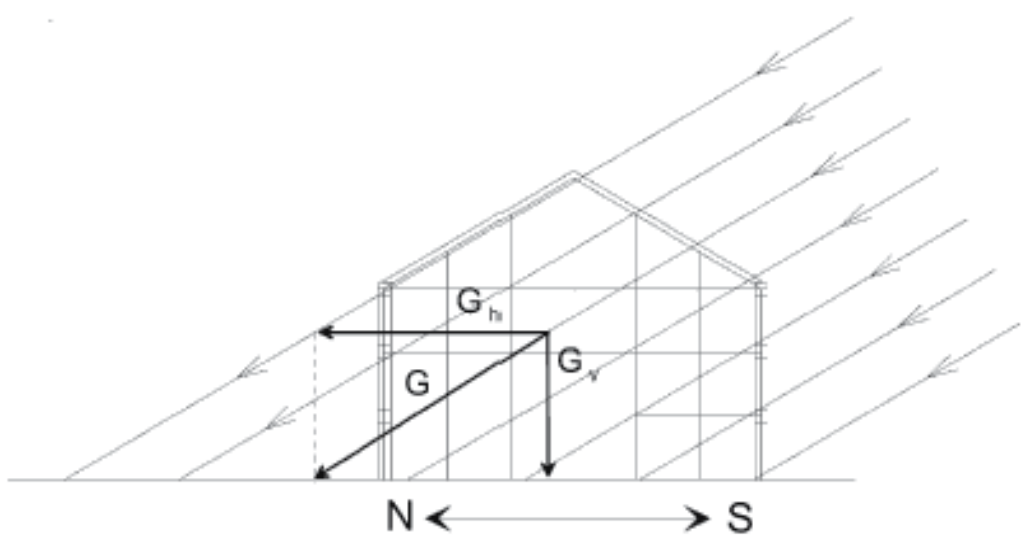

Fig. 12. Relative horizontal and vertical components of solar radiation 


\section{Greenhouse Environment}

It has been known for long time now that urban centres have mean temperatures higher than their less developed surroundings. The urban heat increases the average and peak air temperatures, which, in turn, affect the demand for heating and cooling. Higher temperatures can be beneficial in the heating season, lowering fuel use, but they exacerbate the energy demand for cooling in summer time. In temperate climates neither heating nor cooling may dominate the fuel use in a building, and the balance of the effect of the heat is less. The solar gains, however, would affect the energy consumption. Therefore, lower or higher percentage of glazing, or incorporating of shading devices might affect the balance between annual heating and cooling load. As the provision of cooling is expensive with higher environmental cost, ways of using innovative alternative systems like mop fans will be appreciated (Figures 13-15). Indeed, considerable research activities have been devoted to the development of alternative methods of refrigeration and air-conditioning. The mop fan is a novel air-cleaning device that fulfils the functions of de-dusting of gas streams, removal of gaseous contaminations from gas streams and gas circulation (Bernard, 1994). Hence, the mop fan seems particularly suitable for applications in industrial, agricultural and commercial buildings and greenhouses.

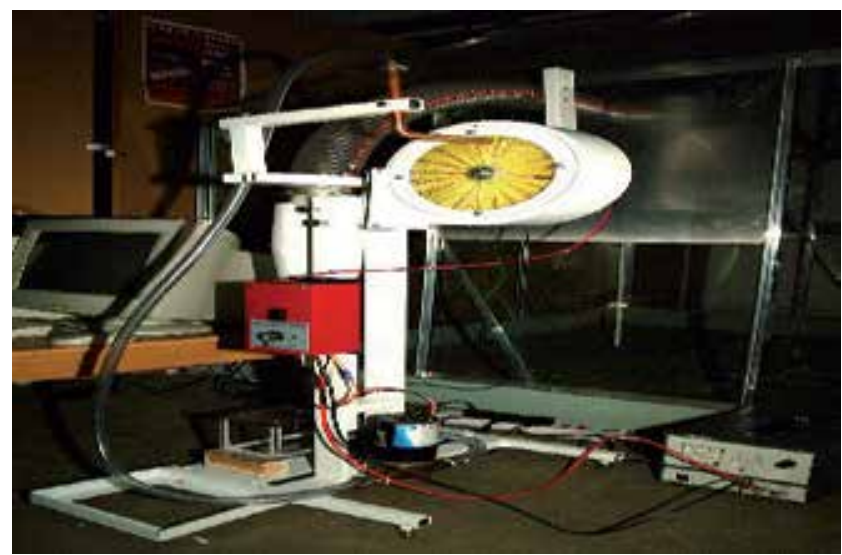

Fig. 13. Mop fan system

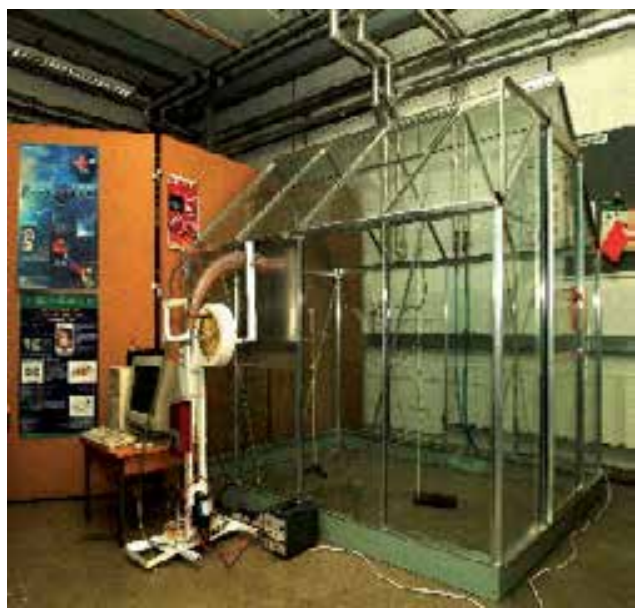

Fig. 14. Mop fan in greenhouse

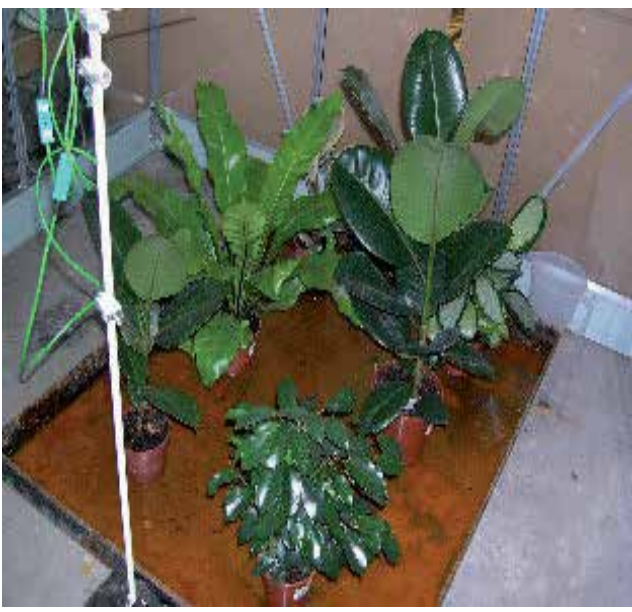

Fig. 15. Plants in greenhouse 
Indoor conditions are usually fixed by comfort conditions, with air temperatures ranging from $15^{\circ} \mathrm{C}$ to $27{ }^{\circ} \mathrm{C}$, and relative humidities ranging from $50 \%$ to $70 \%$ (Omer, 2008). The system performance (COP) is defined as the ration between the cooling effect in the greenhouse and the total amount of air input to the mop fan. Hence,

$$
\mathrm{COP}=\text { cooling delivered/air input to the mop fan }
$$

Therefore, system performance (COP) varies with indoor and outdoor conditions. A lower ambient temperature and a lower ambient relative humidity lead to a higher COP. This means that the system will be, in principle, more efficient in colder and drier climates. The effect of indoor (greenhouse) conditions and outdoor (ambient) conditions (temperature and relative humidity) on system performance is illustrated in Figure 16.

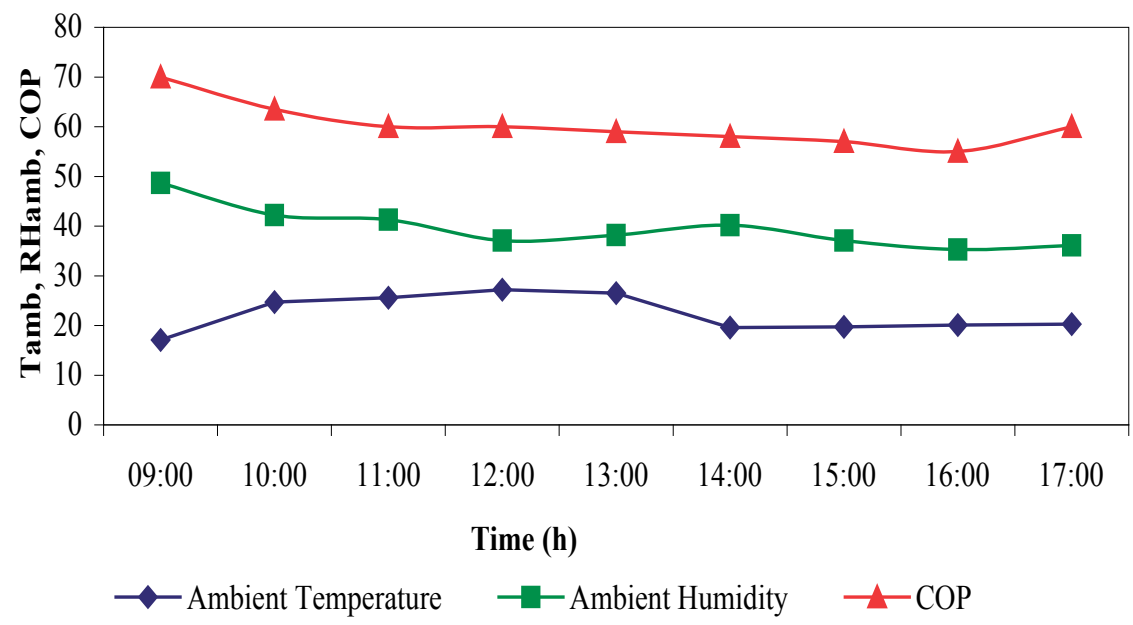

Fig. 16. Ambient temperature, relative humidity and COP

\section{Conclusions}

There is strong scientific evidence that the average temperature of the earth's surface is rising. This is a result of the increased concentration of carbon dioxide and other GHGs in the atmosphere as released by burning fossil fuels. This global warming will eventually lead to substantial changes in the world's climate, which will, in turn, have a major impact on human life and the built environment. Therefore, effort has to be made to reduce fossil energy use and to promote green energies, particularly in the building sector. Energy use reductions can be achieved by minimising the energy demand, by rational energy use, by recovering heat and the use of more green energies. This study was a step towards achieving that goal. The adoption of green or sustainable approaches to the way in which society is run is seen as an important strategy in finding a solution to the energy problem. The key factors to reducing and controlling $\mathrm{CO}_{2}$, which is the major contributor to global warming, are the use of alternative approaches to energy generation and the exploration of how these alternatives are used today and may be used in the future as green energy sources. Even with modest assumptions about the availability of land, comprehensive fuel- 
wood farming programmes offer significant energy, economic and environmental benefits. These benefits would be dispersed in rural areas where they are greatly needed and can serve as linkages for further rural economic development. The nations as a whole would benefit from savings in foreign exchange, improved energy security, and socio-economic improvements. With a nine-fold increase in forest - plantation cover, a nation's resource base would be greatly improved. The international community would benefit from pollution reduction, climate mitigation, and the increased trading opportunities that arise from new income sources. The non-technical issues, which have recently gained attention, include: (1) Environmental and ecological factors e.g., carbon sequestration, reforestation and revegetation. (2) Renewables as a $\mathrm{CO}_{2}$ neutral replacement for fossil fuels. (3) Greater recognition of the importance of renewable energy, particularly modern biomass energy carriers, at the policy and planning levels. (4) Greater recognition of the difficulties of gathering good and reliable renewable energy data, and efforts to improve it. (5) Studies on the detrimental health efforts of biomass energy particularly from traditional energy users. Two of the most essential natural resources for all life on the earth and for man's survival are sunlight and water. Sunlight is the driving force behind many of the renewable energy technologies. The worldwide potential for utilising this resource, both directly by means of the solar technologies and indirectly by means of biofuels, wind and hydro technologies is vast. During the last decade interest has been refocused on renewable energy sources due to the increasing prices and fore-seeable exhaustion of presently used commercial energy sources. Plants, like human beings, need tender loving care in the form of optimum settings of light, sunshine, nourishment, and water. Hence, the control of sunlight, air humidity and temperatures in greenhouses are the key to successful greenhouse gardening. The mop fan is a simple and novel air humidifier; which is capable of removing particulate and gaseous pollutants while providing ventilation. It is a device ideally suited to greenhouse applications, which require robustness, low cost, minimum maintenance and high efficiency. A device meeting these requirements is not yet available to the farming community. Hence, implementing mop fans aides sustainable development through using a clean, environmentally friendly device that decreases load in the greenhouse and reduces energy consumption.

\section{References}

[1] Robinson, G. (2007). Changes in construction waste management. Waste Management World p. 43-49. May-June 2007.

[2] Omer, A.M., and Yemen, D. (2001). Biogas an appropriate technology. Proceedings of the $7^{\text {th }}$ Arab International Solar Energy Conference, P.417, Sharjah, UAE, 19-22 February 2001.

[3] Swift-Hook, D.T., et al. (2007). Characteristics of a rocking wave power devices. Nature 254: 504. 1975.

[4] Sims, R.H. (2007). Not too late: IPCC identifies renewable energy as a key measure to limit climate change. Renewable Energy World 10 (4): 31-39.

[5] Trevor, T. (2007). Fridge recycling: bringing agents in from the cold. Waste Management World 5: 43-47.

[6] International Energy Agency (IEA). (2007). Indicators for Industrial Energy Efficiency and $\mathrm{CO}_{2}$ Emissions: A Technology Perspective. 
[7] Brain, G., and Mark, S. (2007). Garbage in, energy out: landfill gas opportunities for CHP projects. Cogeneration and On-Site Power 8 (5): 37-45.

[8] Rawlings, R.H.D. (1999). Technical Note TN 18/99 - Ground Source Heat Pumps: A Technology Review. Bracknell. The Building Services Research and Information Association.

[9] Oxburgh, E.R. (1975). Geothermal energy. Aspects of Energy Conversion. p. 385-403.

[10] John, W. (1993). The glasshouse garden. The Royal Horticultural Society Collection. UK.

[11] United Nations (UN). (2001). World Urbanisation Prospect: The 1999 Revision. New York. The United Nations Population Division.

[12] WCED. (1987). Our common future. New York. Oxford University Press.

[13] Herath, G. (1985). The green revolution in Asia: productivity, employment and the role of policies. Oxford Agrarian Studies. 14: 52-71.

[14] Jonathon, E. (1991). Greenhouse gardening. The Crowood Press Ltd. UK.

[15] Achard, P., and Gicqquel, R. (1986). European passive solar handbook. Brussels: Commission of the European Communities.

[16] Bernard, S. (1994). Greenhouse gardening the practical guide. UK.

[17] Omer, A.M. (2008). Constructions, applications and the environment of greenhouses, Natural Gas Research Progress- IB, 2008 NOVA Science Publishers, Inc., p.253-288, New York, USA.

\section{Nomenclature}

a annum

ha hectares

1 litre 


\title{
The application of ionic liquids in dissolution and separation of lignocellulose
}

\author{
Jianji Wang', Yong Zheng1 and Suojiang Zhang ${ }^{2}$ \\ ${ }^{1}$ School of Chemical and Environmental Sciences, Key Laboratory of Green Chemical \\ Media and Reactions, Ministry of Education, Henan Normal University, \\ Xinxiang, Henan 453007 \\ 2Institute of Process Engineering, Chinese Academy of Sciences, Beijing 100190 \\ 1,2P. R. China
}

\section{Introduction}

There are many problems in traditional chemical industry, such as environmental pollution, low production efficiency and high energy consumption. Nowadays, energy and environment become two main bottlenecks in the development of chemical industry. As non-renewable fossil resource, petroleum and coal are still widely used in the modern world. The excessive use of fossil resource will accelerate the deterioration of environment. Therefore, it is necessary to find new kinds of energy for the sustainable development and environmental protection.

Biomass is renewable, environmentally friendly and abundant in the natural world. According to the statistics, the total energy produced from photosynthesis is nearly ten times more than that of fossil fuel used in the world every year. However, the utilization rate of biomass energy is less than $1 \%$. Although the preparation of ethanol from glucose and starch has already been employed in industry for a long time, the universal shortage of food restricts the application of this method in the large-scale production of clean energy. Therefore, it is very important to produce green energy and bio-products from lignocellulose which is the most abundant biomass ( $\mathrm{Pu}$ et al., 2008; $\mathrm{Zhu}, 2008$ ). Lignocellulose is hard to be dissolved and separated with common solvents due to its complex structure, strong intra- and inter-molecular hydrogen bonding. Traditional acid and basic systems used in the lignocellulose industry are environmentally polluted, and can not be recycled ( $\mathrm{Li}$ et al., 2007). Therefore, development of new efficient solvents is the first step for the transformation and utilization of lignocellulose.

As novel green solvents, ionic liquids (ILs) have many attractive properties, including negligible vapor pressure, non-flammability, thermal stability and recyclability, and have been used in organic synthesis, electrochemistry, catalysis, extraction and among others (Qian et al., 2005; Dupont et al., 2002; Scurto et al., 2002; Kubo et al., 2002). In 2002, Rogers and co-workers (Swatloski et al., 2002) found that some hydrophilic ILs are effective solvents for the dissolution of cellulose. The high solubility of cellulose in the ILs attracts great attention of the scientists and engineers in the world. Since then, significant progress 
has been made for the dissolution of cellulose and lignin as well as for the separation of lignocellulose components by using ILs (Zhu et al., 2006; Seoud et al., 2007; Winterton, 2006). This chapter aims to provide a summary of our current state of knowledge in this field. Therefore, after a brief introduction to the structural features of the main components (cellulose, hemicellulose and lignin) of lignocellulose and the unusual physico-chemical properties of ionic liquids, the recent progress in the dissolution and separation of lignocellulose components with ILs is reviewed. The dissolution mechanism of cellulose in ILs and the regeneration and reuse of the ILs have also been discussed. At the end of this chapter, the challenges we have to face have been addressed and some suggestions are given for the future work.

\section{The structural features and physico-chemical properties of lignocellulose components and ionic liquids}

In this section, we will have a brief introduction to the structural features of cellulose, hemicellulose and lignin and the unusual physico-chemical properties of ionic liquids. This is designed to lay the foundation for the discussion of the major issues in the next sections.

\subsection{The main components of lignocellulose and their structural features}

Existed as plant cell wall, lignocellulose is mainly composed of cellulose, hemicellulose and lignin. These components have different proportions in various green plants. Generally speaking, the percentages of cellulose, hemicellulose and lignin are approximately $30 \sim 50 \%$, $10 \sim 40 \%$ and 5 30\%, respectively, in lignocellulose (McKendry, 2002). Cellulose is embedded in the network of lignin and hemicellulose which are connected by hydrogen and covalent bonds (Sun et al., 2005).

Cellulose is a typical biopolymer composed of a-D-glucopyranoside units linked by $\beta-1,4$ glycosidic bonds (see Figure 1) (Zhang et al., 2006). The degree of polymerization (DP) of natural cellulose always ranges from 1000 to 1000000 (Champagne \& Li, 2009). The crystal structure of cellulose is very compact owing to its complex and extensive hydrogen bond networks which are hard to be broken. Consequently, cellulose is insoluble in common solvents.

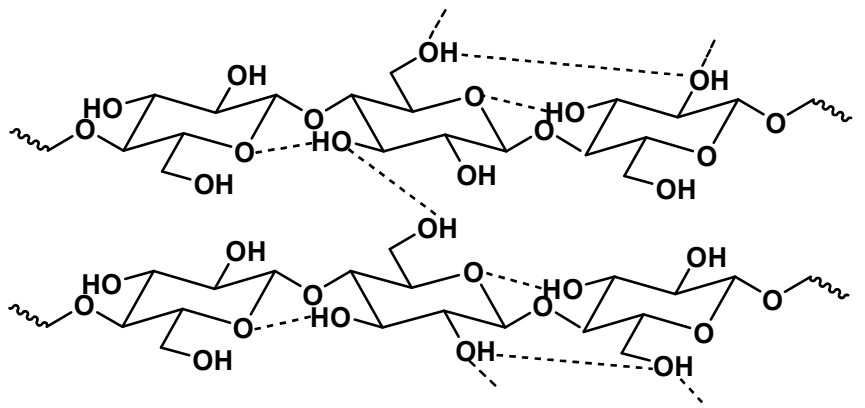

Fig. 1. The structure of cellulose. (Zhang et al., 2006)

Unlike cellulose, hemicellulose is not only a heteropolymer, but also a branched polymer. It is usually polymerized from different monomers, such as hexoses (glucose, mannose and galactose), pentoses (arabinose, xylose) and uronic acids (Vegas, et al., 2004). Because of its 
amorphous structure and lower molecular weight, hemicellulose is more prone to be hydrolyzed by catalysts than cellulose (Liao et al., 2004).

The structure of lignin is much more complex than that of cellulose and hemicellulose. Lignin is a mixture made from the random oxidative coupling of $p$-hydroxycinnamyl monolignols (Río et al., 2008). There are three primary monolignols: $p$-coumaryl, coniferyl- and sinapyl alcohols (see Figure 2) (Hayatsu et al., 1979). As the three monolignols are incorporated into lignin, $p$-hydroxyphenyl, guaiacyl and syringyl units are formed. This makes lignin to have a cross-linked structure, strong chemical bonds and complex compositions. Accordingly, lignin is quite resistant to many chemicals, external forces and degradation.

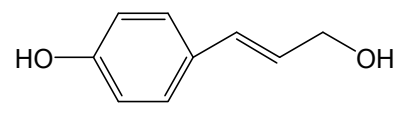

(a)

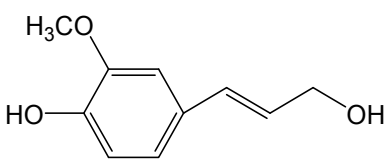

(b)

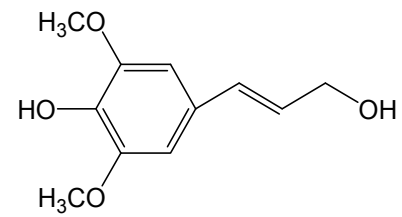

(c)

Fig. 2. The structures of three primary monolignols: (a) $p$-coumaryl alcohol, (b) coniferyl alcohol, (c) sinapyl alcohol. (Hayastu et al., 1979)

\subsection{The structural features and physico-chemical properties of ionic liquids}

In general, ILs are a class of organic salts that exist as liquids at the temperatures below $100^{\circ} \mathrm{C}$. They are composed of organic cations and inorganic/organic anions. According to the structure of cations, these liquid salts can mainly be divided into imidazolium-, pyridinium-, quaternary ammonium- and quaternary phosphonium-based ionic liquids (see Figure 3).

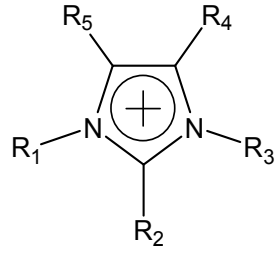

(a)<smiles></smiles>

(b)

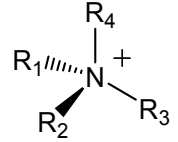

(c)<smiles>[R][P+]([R2])([R])[R]</smiles>

(d)

Fig. 3. The common structures of ILs' cations: (a) imidazolium, (b) pyridinium, (c) quaternary ammonium, (d) quaternary phosphonium.

Compared with traditional solvents, ILs have many excellent physico-chemical properties. These properties can be summarized as follows (Larsen et al., 2000; Zhao et al., 2002):

1) High thermal stability. The decomposition temperatures of many ILs can be more than $300^{\circ} \mathrm{C}$.

2) Broad liquid range from -200 to $300^{\circ} \mathrm{C}$, and excellent dissolution performance for organic, inorganic compounds and polymer materials.

3) Immeasurable vapor pressure and non-flammability under common conditions.

4) High conductivity and wide electrochemical window of $2 \sim 5 \mathrm{~V}$.

5) Designable structures and properties for various practical applications. 
It was shown that imidazolium-based ILs have better performance for the dissolution and separation of lignocellulose components than other ILs under the same conditions. This is probably due to the lower melting points, lower viscosity, higher thermal stability and unique structure of the imidazolium-based ILs. On the other hand, ILs are efficient in dissolution and separation of lignocellulose when they contain $\mathrm{Cl}^{-}$(chloride), $\left[\mathrm{HCO}_{2}\right]_{-}^{-}$ (formate), $\left[\mathrm{CH}_{3} \mathrm{CO}_{2}\right]^{-}$(acetate, Ac-), $\left[\mathrm{NH}_{2} \mathrm{CH}_{2} \mathrm{CO}_{2}\right]^{-}$(aminoethanic acid), $\left[\mathrm{CH}_{3} \mathrm{SO}_{4}\right]^{-}$ (methylsulfate), $\left[\mathrm{RR}^{\prime} \mathrm{PO}_{2}\right]^{-}$(phosphonate), $\left[\mathrm{Me}_{2} \mathrm{C}_{6} \mathrm{H}_{3} \mathrm{SO}_{3}\right]^{-}$(xylenesulphonate) anions and so on.

\section{The dissolution of cellulose and lignin in ionic liquids}

The recent progress in the dissolution of lignocellulose components with ILs is summarized in this section. The main content includes the influence of cationic structure and anionic type of the ILs on the dissolution of cellulose, lignin and hemicellulose, the possible dissolution mechanism, and the recovery and reuse of ILs.

\subsection{The dissolution of cellulose in ionic liquids}

It was first discovered (Graenacher, 1934) in 1930s that cellulose could be dissolved in molten $N$-ethylpyridinium chloride. However, little attention was paid to this finding at that time. With the remarkable progress in the research and development of ILs, more and more researchers have recognized the importance of this field. Until 2002, study first shown that some imidazolium-based ILs could dissolve cellulose efficiently at low temperature $\left(\leq 100^{\circ} \mathrm{C}\right)$ (Swatloski et al., 2002). Since then, more interesting results have been reported during the past few years (Zhang et al., 2005; Fukaya et al., 2006; Fukaya et al., 2008; Vitz et al., 2009; Xu et al., 2010), as shown in Table 1.

\begin{tabular}{|c|c|c|c|}
\hline IL & $\begin{array}{l}\text { Solubility } \\
(\mathrm{w} / \mathrm{w} \%)\end{array}$ & Experimental condition & Ref. \\
\hline$[\mathrm{Bmim}] \mathrm{Cl}$ & 10 & Heating at $100^{\circ} \mathrm{C}$ & Swatloski et al., 2002 \\
\hline$[\mathrm{Bmim}] \mathrm{Cl}$ & 25 & Microwave heating & Swatloski et al., 2002 \\
\hline$[\mathrm{Amim}] \mathrm{Cl}$ & 5 & Heating at $80^{\circ} \mathrm{C}$ within $30 \mathrm{~min}$ & Zhang et al., 2005 \\
\hline$[\mathrm{Amim}] \mathrm{Cl}$ & 14.5 & $\begin{array}{l}\text { Heating at } 80^{\circ} \mathrm{C} \text { after a longer } \\
\text { dissolution time }\end{array}$ & Zhang et al., 2005 \\
\hline$[\mathrm{Amim}]\left[\mathrm{HCO}_{2}\right]$ & 10 & Heating at $60^{\circ} \mathrm{C}$ & Fukaya et al., 2006 \\
\hline$[\mathrm{Emim}]\left[(\mathrm{MeO}) \mathrm{HPO}_{2}\right]$ & 10 & Heating at $45^{\circ} \mathrm{C}$ within $30 \mathrm{~min}$ & Fukaya et al., 2008 \\
\hline$[\mathrm{Emim}]\left[(\mathrm{MeO}) \mathrm{HPO}_{2}\right]$ & $2 \sim 4$ & Room-temperature within $3 \sim 5 \mathrm{~h}$ & Fukaya et al., 2008 \\
\hline$[\mathrm{Emim}]\left[\mathrm{Et}_{2} \mathrm{PO}_{4}\right]$ & 14 & Heating at $100^{\circ} \mathrm{C}$ within $1 \mathrm{~h}$ & Vitz et al., 2009 \\
\hline$[\mathrm{Bmim}] \mathrm{Ac}$ & 15.5 & Heating at $70^{\circ} \mathrm{C}$ & Xu et al., 2010 \\
\hline$[\mathrm{Bmim}]\left[\mathrm{HSCH}_{2} \mathrm{CO}_{2}\right]$ & 12 & Heating at $70^{\circ} \mathrm{C}$ & Xu et al., 2010 \\
\hline [Bmim]Ac/LiAc & 19 & Heating at $70^{\circ} \mathrm{C}$ & Xu et al., 2010 \\
\hline
\end{tabular}

Table 1. The dissolution of cellulose in some ILs. a

a: The cellulose samples used in these studies usually differed in DP, molecular weight or crystal structure. 
It can be seen that in the ILs studied, 1-butyl-3-methylimidazolium chloride ([Bmim]Cl) shown excellent dissolution capability for cellulose. The solubility of cellulose in [Bmim]Cl was as high as $10 \%(\mathrm{w} / \mathrm{w})$ at $100^{\circ} \mathrm{C}$, which increased to $25 \%$ under microwave heating. Cellulose could be easily regenerated from the IL+ cellulose solutions by the addition of $1 \%$ water, while ILs could be recycled and reused after purification.

Some task-specific ILs have also been used to dissolve cellulose. For example, allyl-based ILs 1-allyl-3-methylimidazolium chloride ([Amim]Cl) and 1-allyl-3-methylimidazolium formate ([Amim] $\left[\mathrm{HCO}_{2}\right]$ ) were synthesized successively (Zhang et al., 2005; Fukaya et al., 2006). These ILs have lower melting points, lower viscosity and stronger dissolution capabilities for cellulose than those of the common imidazolium-based ILs with the same anions. $5 \%$ of cellulose $(\mathrm{DP} \approx 650)$ could be dissolved readily in $[\mathrm{Amim}] \mathrm{Cl}$ at $80^{\circ} \mathrm{C}$ within $30 \mathrm{~min}$. After a longer dissolution time, $14.5 \%$ of cellulose solution can be obtained. If $[\mathrm{Amim}]\left[\mathrm{HCO}_{2}\right]$ was used as the solvent, the solubility of cellulose was as high as $10 \%$ at $60^{\circ} \mathrm{C}$.

To reduce the production cost and improve the thermal stability of ILs, a series of alkylimidazolium ILs containing phosphonate-based anions have been synthesized (Fukaya et al., 2008; Vitz et al, 2009). These ILs include 1-ethyl-3-methylimidazolium methyl methylphosphonate $\left([\right.$ Emim $\left.]\left[(\mathrm{MeO}) \mathrm{MePO}_{2}\right]\right)$, 1-ethyl-3-methylimidazolium dimethyl phosphate $\left([\mathrm{Emim}]\left[(\mathrm{MeO})_{2} \mathrm{PO}_{2}\right]\right)$, 1-ethyl-3-methyl-imidazolium methyl phosphate ([Emim][(MeO) $\left.\left.\mathrm{HPO}_{2}\right]\right)$, 1-ethyl-3-methylimidazolium diethyl phosphate ([Emim][Et $\left.\mathrm{PO}_{4}\right]$ ) and 1,3-dimethylimidazolium dimethyl phosphate ([Dmim] $\left.\left[\mathrm{Me}_{2} \mathrm{PO}_{4}\right]\right)$. The preparation of these ILs could be accomplished by only one step with high conversion efficiency. As the main experimental material, alkylphosphate was cheap, less toxic and easy to purchase. The low melting points and viscosity of phosphonate-based ILs facilitated the dissolution of cellulose. It was reported that $10 \%$ of microcrystalline cellulose could be dissolved in [Emim] $\left[(\mathrm{MeO}) \mathrm{HPO}_{2}\right]$ within $30 \mathrm{~min}$ at $45^{\circ} \mathrm{C}$ (Fukaya et al., 2008). Even without pretreatment and heating, the solubility of cellulose could still reach $2 \sim 4 \%$. A later research revealed that [Emim] $\left[\mathrm{Et}_{2} \mathrm{PO}_{4}\right]$ had the ability to dissolve up to $14 \%$ of cellulose at $100^{\circ} \mathrm{C}$ (Vitz et al., 2009). Furthermore, the regenerated cellulose from $[\mathrm{Emim}]\left[\mathrm{Et}_{2} \mathrm{PO}_{4}\right]$ shown a much lower degradation than those regenerated from other ILs.

Our team has been working on the research of ILs for many years and gets much experience in the dissolution of cellulose in ILs (Xu et al., 2010). In our work, a series of ILs based on Brønsted anions, such as Ac-, $\left[\mathrm{NH}_{2} \mathrm{CH}_{2} \mathrm{CO}_{2}\right]^{-}, \quad\left[\mathrm{HSCH}_{2} \mathrm{CO}_{2}\right]^{-}$(thioglycollate) and $\left[\mathrm{OHCH}_{2} \mathrm{CO}_{2}\right]^{-}$(glycollate) were synthesized and used to dissolve cellulose. Among these ILs, [Bmim]Ac and [Bmim] $\left[\mathrm{HSCH}_{2} \mathrm{CO}_{2}\right]$ were found to be the most efficient solvents for the dissolution of microcrystalline cellulose. The solubilities of cellulose were as high as $15.5 \%$ and $13.5 \%$ at $70^{\circ} \mathrm{C}$, respectively. An enhanced dissolution of cellulose has been achieved by the addition of $1 \%$ of lithium salt into the IL solution. These lithium salts include $\mathrm{LiAc}, \mathrm{LiCl}$, $\mathrm{LiBr}, \mathrm{LiClO}_{4}$ and $\mathrm{LiNO}_{3}$. For example, the solubility of microcrystalline cellulose could increase to $19 \%$ in [Bmim]Ac containing $1 \%$ of LiAc.

\subsection{The dissolution mechanism of cellulose in ionic liquids}

The excellent dissolution capability of ILs for cellulose inspires many researchers to explore the possible mechanism. In the early studies, it was widely believed that the ions, especially anions of the ILs could effectively break the extensive intra- and inter-molecular hydrogen bonding network in cellulose. Consquently, cellulose was finally dissolved in the ILs (Swatloski et al., 2002; Zhang et al., 2005; Fukaya, et al., 2006). Based on this hypothesis, the 
interaction between ILs and cellulose was investigated by ${ }^{13} \mathrm{C}$ and ${ }^{35 / 37} \mathrm{Cl} \mathrm{NMR}$ relaxation measurements (Remsing et al., 2006). They found that the carbons C-4" and C-1' of [Bmim] $]^{+}$ cation shown a slight variation in the relaxation times as the concentration of cellobiose in [Bmim] $\mathrm{Cl}$ increased (see Figure 4). Meanwhile, the value changes in ${ }^{13} \mathrm{C} \mathrm{T}_{1}$ and $\mathrm{T}_{2}$ indicated that the $[\mathrm{Bmim}]^{+}$did not have specific interaction with cellobiose. However, the ${ }^{35 / 37 \mathrm{Cl}}$ relaxation rates for the anion $\mathrm{Cl}^{-}$was more dependent on the cellobiose concentration, which implied that $\mathrm{Cl}^{-}$interacted strongly with cellobiose. Their study proved the presence of 1:1 hydrogen bonding between $\mathrm{Cl}^{-}$and carbohydrate hydroxyl proton. Similar conclusions have also been obtained by computer modeling in a later literature (Novoselov et al., 2007).

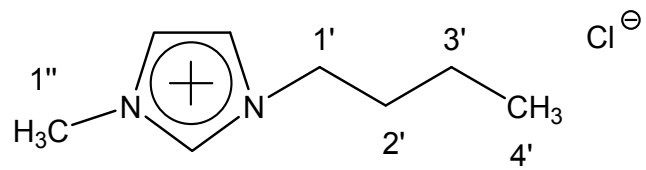

Fig. 4. The structure and numbering of [Bmim]Cl. (Remsing et al., 2006)

In our recent work, the effects of anionic structure and lithium salts addition on the dissolution of microcrystalline cellulose has also been studied through ${ }^{1} \mathrm{H}$ NMR, ${ }^{13} \mathrm{C}$ NMR and solvatochromic UV/vis probe measurements (Xu et al., 2010). It was known that the ${ }^{1} \mathrm{H}$ NMR chemical shift of proton $\mathrm{H}-2$ in the imidazolium ring reflects the hydrogen bond accepting ability of the ILs' anions. When the $\mathrm{H}$ in the Ac- anion of [Bmim] Ac was replaced by an electron-withdrawing group, such as $-\mathrm{OH},-\mathrm{SH},-\mathrm{NH}_{2}$ or $-\mathrm{CH}_{2} \mathrm{OH}$, the solubility of microcrystalline cellulose and ${ }^{1} \mathrm{H}$ NMR chemical shifts of proton $\mathrm{H}-2$ decreased. This indicates that the ILs whose anions have strong hydrogen bond accepting ability are more efficient in dissolving cellulose. Furthermore, the enhanced dissolution of cellulose achieved with the addition of lithium salts suggests that the interaction between $\mathrm{Li}^{+}$and the hydroxyl oxygen of cellulose can break the intermolecular hydrogen bonds of cellulose.

\subsection{The dissolution of lignin in ionic liquids}

Lignin is more difficult to be dissolved than the other components of lignocellulose because of its strong covalent bonds and complex structure. $\mathrm{Pu}$ and his co-workers have determined solubilities of the lignin isolated from a southern pine kraft pulp in some ILs, including 1,3-dimethylimidazolium methylsulfate ([Mmim] $\left.\left[\mathrm{MeSO}_{4}\right]\right)$, 1-hexyl-3-methylimidazolium trifluoromethanesulfonate $\quad\left([\mathrm{Hmim}]\left[\mathrm{CF}_{3} \mathrm{SO}_{3}\right]\right), \quad$ 1-butyl-2,3-dimethylimidazolium tetrafluoroborate $\left(\left[\mathrm{Bm}_{2} \mathrm{im}\right]\left[\mathrm{BF}_{4}\right]\right)$, 1-butyl-3-methylimidazolium hexafluorophosphate ([Bmim] $\left[\mathrm{PF}_{6}\right]$ ) and among others (Pu et al., 2007) (see Table 2).

\begin{tabular}{|l|l|l|}
\hline IL & Temperature $\left({ }^{\circ} \mathrm{C}\right)$ & Solubility $(\mathrm{g} / \mathrm{L})$ \\
\hline$[\mathrm{Mmim}]\left[\mathrm{MeSO}_{4}\right]$ & 50 & 344 \\
\hline$[\mathrm{Hmim}]\left[\mathrm{CF}_{3} \mathrm{SO}_{3}\right]$ & 70 & 275 \\
\hline$[\mathrm{Bmim}]\left[\mathrm{MeSO}_{4}\right]$ & 50 & 312 \\
\hline$[\mathrm{Bmim}] \mathrm{Cl}$ & 75 & 13.9 \\
\hline$[\mathrm{Bmim}] \mathrm{Br}$ & 75 & 17.5 \\
\hline$\left[\mathrm{Bm} \mathrm{im}_{2}\right]\left[\mathrm{BF}_{4}\right]$ & $70-120$ & 14.5 \\
\hline$[\mathrm{Bmim}]\left[\mathrm{PF}_{6}\right]$ & $70-120$ & insoluble \\
\hline
\end{tabular}

Table 2. Solubilities of lignin in some ILs. (Pu et al., 2007) 
The work of $\mathrm{Pu}$ and his co-workers shown that softwood lignin could be dissolved in $[\mathrm{Mmim}]\left[\mathrm{MeSO}_{4}\right]$ and $[\mathrm{Bmim}]\left[\mathrm{MeSO}_{4}\right]$ at room temperature. The solubilities of lignin in these ILs were about $74 \mathrm{~g} / \mathrm{L}$ and $62 \mathrm{~g} / \mathrm{L}$, respectively. When heated up to $50 \sim 70^{\circ} \mathrm{C}$, lignin sample was dissolved more rapidly in $[\mathrm{Mmim}]\left[\mathrm{MeSO}_{4}\right],[\mathrm{Bmim}]\left[\mathrm{MeSO}_{4}\right]$ and $[\mathrm{Hmim}]\left[\mathrm{CF}_{3} \mathrm{SO}_{3}\right]$ with solubilities ranging from $275 \mathrm{~g} / \mathrm{L}$ to $344 \mathrm{~g} / \mathrm{L}$. For [Bmim] $]^{+}$based ILs, the solubilities of lignin followed the order: $\left[\mathrm{MeSO}_{4}\right]^{-}>\mathrm{Cl}^{-}>\mathrm{Br}^{-}>>\mathrm{PF}_{6}$. Therefore, it can be concluded that anions of ILs have important effect on the dissolution of lignin. ILs always have a poor dissolution capability for lignin when they contain larger sized non-coordinating anions, such as $\mathrm{PF}_{6}$.

Owing to the complex structure and strong intra-molecular interactions of lignocellulose, the natural lignin in wood is much more difficult to be dissolved than the pure lignin. However, it is necessary to develop efficient solvents for the dissolution of natural lignin in order to promote the application of lignocellulose. Accordingly, the dissolution of lignin-rich wood in ILs has been studied (Kilpeläinen et al., 2007). It was found that wood chips could be partially dissolved in some ILs, such as [Bmim]Cl. Wood sawdust sample was easier to be dissolved in ILs and its solubilities were both $8 \%$ in $[\mathrm{Bmim}] \mathrm{Cl}$ and [Amim] $\mathrm{Cl}$ at $110^{\circ} \mathrm{C}$. A $5 \%$ of Norway spruce momechanical pulp (TMP) solution could be formed in 1-benzyl-3-methylimidazolium chloride $([\mathrm{Bzmim}] \mathrm{Cl})$ at $130^{\circ} \mathrm{C}$ (see Table 3). The order of dissolution efficiency of lignocellulose in ILs was: ball-milled wood powder > sawdust $\geq$ TMP fibers $>>$ wood chips. It can be inferred that the particle size of wood sample is vital to the wood solubilization. As the structure of wood sample is incompact, ILs are easy to diffuse into the wood's interior and break the intermolecular forces, resulting in a higher solubility of wood.

\begin{tabular}{|l|l|l|l|}
\hline IL & Wood sample $^{\text {a }}$ & Solubility $(\mathrm{w} / \mathrm{w} \%)$ & Dissolution condition \\
\hline$[$ Amim $] \mathrm{Cl}$ & Norway spruce sawdust & 8 & Heating at $110^{\circ} \mathrm{C}, 8 \mathrm{~h}$ \\
\hline$[$ Amim $] \mathrm{Cl}$ & $\begin{array}{l}\text { Ball-milled Southern } \\
\text { pine powder }\end{array}$ & 8 & Heating at $80^{\circ} \mathrm{C}, 8 \mathrm{~h}$ \\
\hline$[\mathrm{Bmim}] \mathrm{Cl}$ & Norway spruce sawdust & 8 & Heating at $110^{\circ} \mathrm{C}, 8 \mathrm{~h}$ \\
\hline$[\mathrm{Bmim}] \mathrm{Cl}$ & Norway spruce TMP & 7 & Heating at $130^{\circ} \mathrm{C}, 8 \mathrm{~h}$ \\
\hline$[\mathrm{Bmim}] \mathrm{Cl}$ & Wood chips & Partially soluble & Heating at $130^{\circ} \mathrm{C}, 8 \mathrm{~h}$ \\
\hline$[$ Bzmim $] \mathrm{Cl}$ & Norway spruce TMP & 5 & Heating at $130^{\circ} \mathrm{C}, 8 \mathrm{~h}$ \\
\hline
\end{tabular}

Table 3. The dissolution of wood samples in ILs. (Kilpeläinen et al., 2007)

a: The wood samples have been subjected to some mechanical pre-treatment before use.

Another study shown that 1-ethyl-3-methylimidazolium acetate ([Emim]Ac) had a higher solvation power for lignin-rich wood than [Bmim] Cl and many other ILs (Sun et al., 2009). Nearly 5\% (w/w) of southern yellow pine (total lignin content: $31.8 \%$ ) or red oak (total lignin content: $23.8 \%$ ) could be dissolved in [Emim]Ac after mild grinding at $110^{\circ} \mathrm{C}$. As the authors analyzed, two main reasons might account for these results. Firstly, the inter- and intra-molecular hydrogen bonds in wood can be efficiently disrupted by the stronger basicity of acetate anion; Secondly, the low melting point and low viscosity of [Emim]Ac facilitate the dissolution of wood. 


\section{The separation of the main components of lignocellulose with ionic liquids}

The efficient separation of the main components of lignocellulose is very important for the utilization of lignocellulose. Although it is difficult to achieve this goal, researchers have explored the possibility for the separation of lignocellulose components with ILs, and some important results have been reported.

\subsection{The separation of cellulose from lignocellulose with ionic liquids}

It was reported that wood could be regenerated from imidazolium-based IL (such as $[\mathrm{Bmim}] \mathrm{Cl},[\mathrm{Amim}] \mathrm{Cl}$ and $[\mathrm{Bzmim}] \mathrm{Cl})+$ wood solutions as an amorphous mixture of its original components after the addition of water (Kilpeläinen et al., 2007). Using cellulase as catalyst, the regenerated cellulose of wood could be converted into glucose, and the hydrolysis percentage of cellulose was about $60 \%$. This provides a new way for the separation of the cellulose of lignocellulose

Cellulose can also be separated from lignocellulose with $[\mathrm{Bmim}] \mathrm{Cl}$ based on the different solubilities of the main components of lignocellulose (Fort et al., 2007). Their work shown that some untreated wood (oak, eucalyptus, poplar and pine) could be partially dissolved in [Bmim] $\mathrm{Cl}$ at $100^{\circ} \mathrm{C}$. After the removal of un-dissolved materials, cellulose could be regenerated from $[\mathrm{Bmim}] \mathrm{Cl}+$ lignocellulose solutions by the addition of one to two volumes of the precipitation solvents, such as 1:1 acetone-water solutions, dichloromethane and acetonitrile. Yields of the reconstituted cellulose ranged from 30 to $60 \%$. Through the characterization of ${ }^{13} \mathrm{C}$ NMR and IR spectrum, the regenerated cellulose was found to be free of lignin and hemicellulose. The properties of cellulose obtained in this way was similar to those of microcrystalline cellulose regenerated from $[\mathrm{Bmim}] \mathrm{Cl}+$ cellulose solutions.

\subsection{The separation of lignin from lignocellulose with ionic liquids}

Some researchers have studied the separation of lignin from lignocellulose-rich wood with ILs (Lee et al., 2009). In their work, [Emim]Ac was first used to pretreat $5 \%(w / w)$ of wood flour at $90^{\circ} \mathrm{C}$ for $24 \mathrm{~h}$. The mixture was washed with water to remove the extract from the residual wood flour solids. After the evaporation of water, [Emim]Ac solution was reused for the pre-treatment of wood flour, and the lignin concentration was increased (see Table 4). Furthermore, chemically unmodified and highly hydrophobic lignin could be easily precipitated from concentrated lignin $+[$ Emim] Ac solutions by the addition of excess water.

\begin{tabular}{|l|l|l|}
\hline Reuse of [Emim]Ac & $\begin{array}{l}\text { Extracted lignin content } \\
(\mathrm{g} / \mathrm{kg})^{\text {a }}\end{array}$ & $\begin{array}{l}\text { Digestibility of pretreated } \\
\text { wood flour }(\%)\end{array}$ \\
\hline 0 & 6.9 & 95.7 \\
\hline 1st & 14.2 & 92.1 \\
\hline 2nd & 21.3 & 92.7 \\
\hline 3rd & 28.4 & 92.7 \\
\hline 4th & 35.6 & 90.2 \\
\hline
\end{tabular}

Table 4. Reuse of [Emim]Ac for the pre-treatment of wood flour. (Lee et al., 2009)

a: Determined by Indulin AT (kraft lignin) standard. 
Lignin can also be separated from lignocellulose with xylenesulphonate- and benzoate-based ILs (Upfal et al., 2005). As indicated by Upfal et al., lignin-containing material (bagasse and wood pulp) could be dissolved in ILs, such as 1-ethyl-3-methylimidazolium xylenesulphonate $([\mathrm{Emim}][\mathrm{XS}])$, tetrabutylammonium xylenesulphonate ([TBA] $[\mathrm{XS}])$ and tetrabutylammonium benzoate ([TBA][Bz]) in the temperature range of $100 \sim 180^{\circ} \mathrm{C}$. After the complete dissolution of lignin-containing material, the solid cellulosic components were filtered and a clear lignin/IL solution was formed. Then, lignin could be separated by precipitation and extraction methods. In the former method, lignin was precipitated from lignin + IL solutions by the addition of water, and adjustment of temperature and/or $\mathrm{pH}$ of the solutions. In the latter method, lignin could be extracted into immiscible organic solvents, such as polyethylene glycol, and then separated by distillation. In this way, $60 \sim 86 \%$ of the lignin component was separated from lignocellulosic materials and the ILs could be regenerated and reused in the separation process (see Table 5).

\begin{tabular}{|l|l|l|l|}
\hline IL & $\mathrm{pH}$ & Lignin removed (\%) & Recovered IL (\%) $^{\mathrm{b}}$ \\
\hline$[$ Emim][XS] & 6 & 70.65 & 102 \\
\hline$[$ Emim][XS] & 4 & 64.46 & 101 \\
\hline$[$ TBA][XS] & 4.5 & 70.61 & 90 \\
\hline$[$ TBA] $[$ XS $]$ & 9 & 65.26 & 84 \\
\hline$[$ TBA] $[$ Bz] & 7 & 68.39 & 48 \\
\hline$[$ TBA] $[\mathrm{Bz}]$ & 4.5 & 74.15 & 56 \\
\hline
\end{tabular}

Table 5. The efficiency in the removal of lignin from bagasse and in the recovery of ILs (Upfal et al., 2005). a

a: The temperature of dissolution was from 100 to $180^{\circ} \mathrm{C}$.

b: Based on lignin recovery as calculated by Kappa number determination.

\subsection{The separation of both cellulose and lignin from lignocellulose with ionic liquids}

Cellulose and lignin can be separated from lignocellulosic materials with ILs according to the results of a patent (Myllymaki \& Aksela, 2005). In their work, lignocellulose-rich wood and straw which had not been subjected to any chemical or mechanical pulping process were used as experimental materials. Lignocellulosic materials were first dissolved in [Bmim] $\mathrm{Cl}$ under microwave heating at the temperatures range from 80 to $170^{\circ} \mathrm{C}$ and/or under pressure. Then, lignin was separated from IL + lignocellulose solutions by extraction, and cellulose could be separated from the remained solutions by the addition of water or ethanol.

Unlike Myllymaki et al. who used natural lignocellulose as experimental materials, Lateef's group used cellulose/lignin mixtures as the model lignocellulosic materials to investigate the separation of cellulose from lignin with ILs (Lateef et al., 2009). Three ionic liquids 1-(2-cyanoethyl)-3-methylimidazolium bromide ([Cmim] Br), 1-propyl-3-methylimidazolium bromide $([\mathrm{Pmim}] \mathrm{Br})$ and $[\mathrm{Bmim}] \mathrm{Cl}$ were synthesized and used as solvents. A mixture of cellulose and lignin was dissolved in each of these ILs at $80 \sim 90^{\circ} \mathrm{C}$. After the saturated solution of cellulose/lignin was created, cellulose was regenerated by the addition of water 
(see Figure 5). The remained solution of lignin in IL was concentrated by the distillation of water under reduced pressure. Then, lignin could be precipitated by the addition of ethanol (see Figure 6). The recovery yields of cellulose and lignin were 98 99\% and $83 \sim 97 \%$, respectively. In general, this work shows us a good example for the separation of natural lignocellulose with ILs.

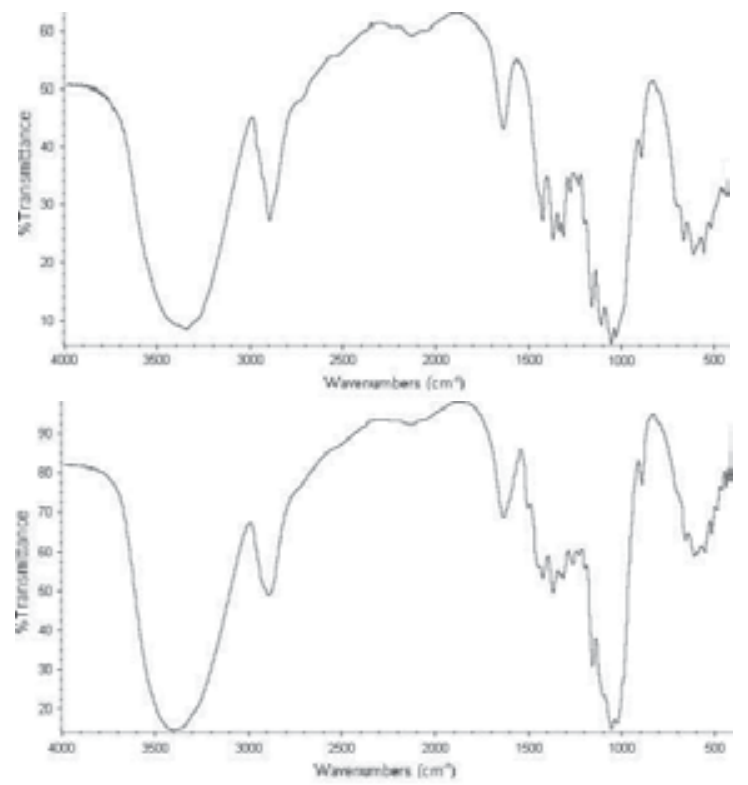

Fig. 5. FTIR spectra: (a) pure cellulose, (b) recovered cellulose from [Bmim]Cl. (Lateef et al., 2009)
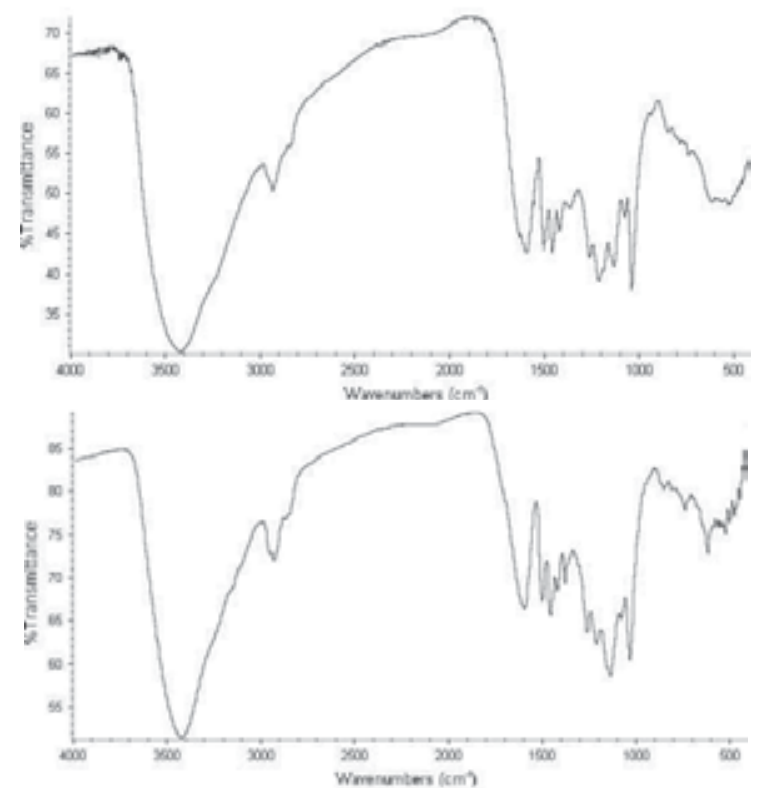

Fig. 6. FTIR spectra: (a) pure lignin, (b) recovered lignin from [Bmim]Cl. (Lateef et al., 2009) 
From the discussion above, it can be concluded that the main components (cellulose, lignin and hemicellulose) of lignocellulose can be separated by various experimental methods. The typical process for the separation of lignocellulose with ILs is summarized in Figure 7.

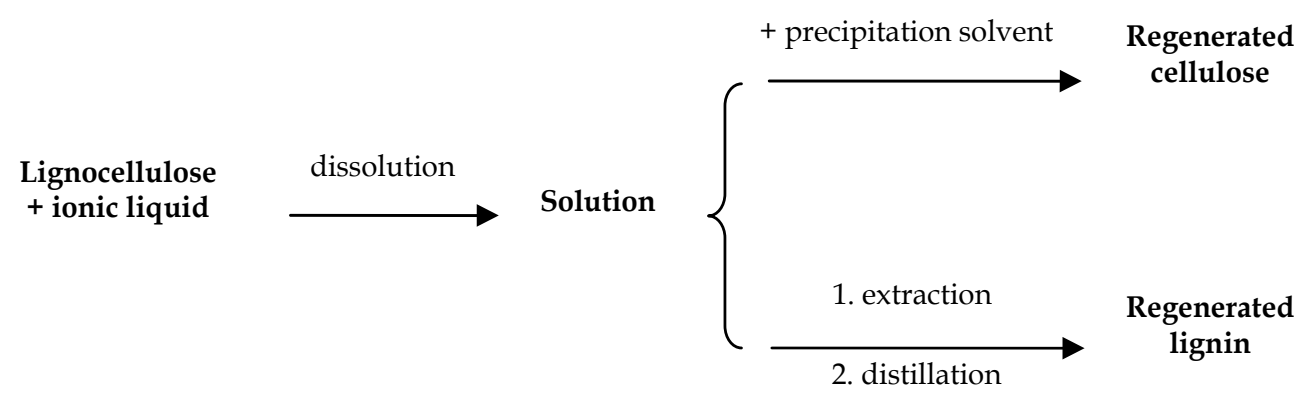

Fig. 7. The typical process for the separation of lignocellulose with ILs.

\section{Future challenges}

Because of the worldwide energy shortage and environmental pollution, we have to make full use of lignocellulose in order to develop clean energy and bio-products in the future. ILs have played a important role in the production of clean energy owing to their excellent physico-chemical properties and outstanding performance in the dissolution and separation of lignocellulose. However, the research on this area is still at its infant stage and some problems have to be solved. In the future work, the following main issues are suggested.

1) To study the interaction mechanism between ILs and cellulose, hemicellulose or lignin further through macroscopic and microcosmic methods, and to know how cations and anions of the ILs disrupt the cross-linked structure, and the intra- and inter-molecular hydrogen bonding of lignocellulose.

2) To develop the knowledge of the relationship between the structure of ILs and their dissolution performance for cellulose, hemicellulose and lignin, and then to design and prepare more new task-specific ILs which are ought to have low viscosity, low melting points and high dissolution and separation capability for lignocellulose.

3) To develop inexpensive methods for the recovery and recycle of ILs, and to promote the applicaiotn of mircowave heating and other intensification technologies in the dissolution and separation of lignocellulose components with ILs.

4) To investigate the effect of precipitation solvents on the crystalline state and thermo-physical properties of regenerated cellulose, hemicellulose and lignin, and then to regulate the structure and properties of the regenerated components for different applications. 


\section{References}

Pu, Y.; Zhang, D.; Singh, P. M. \& Ragauskas, A. J. (2008). The new forestry biofuels sector. Biofuels Bioprod. Bioref., Vol. 2, Issue 1, (January 2008) 58-73, ISSN 1932-104X

Zhu, S. (2008). Use of ionic liquids for the efficient utilization of lignocellulosic materials. J. Chem. Technol. Biotechnol., Vol. 83, Issue 6, (June 2008) 777-779, ISSN 0268-2575

Li, D.; Li, K.; Ma, Y.; Gong, G. \& Qu, F. (2007). Progress in studies of dissolution of cellulose with ionic liquid. Synthetic Fiber in China, Vol. 36, Issue 2, (February 2007) 28-32, ISSN 1001-7054

Qian, W.; Jin, E.; Bao, W. \& Zhang, Y. (2005). Clean and highly selective oxidation of alcohols in an ionic liquid by using an ion-supported hypervalent iodine(Ш) reagent. Angew. Chem. Int. Ed., Vol. 44, Issue 6, (January 2005) 952-955, ISSN 1433-7851

Dupont, J.; Souza, R. F. D. \& Suarez, P. A. Z. (2002). Ionic liquid (molten salt) phase organometallic catalysis. Chem. Rev., Vol. 102, Issue 10, (August 2002) 3667-3692, ISSN 0009-2665

Scurto, A. M.; Aki, S. N. V. K. \& Brennecke, J. F. (2002). CO as a separation switch for ionic liquid/organic mixtures. J. Am. Chem. Soc., Vol. 124, Issue 35, (August 2002) 10276-10277, ISSN 0002-7863

Kubo,W.; Kitamura,T.; Hanabusa, K.; Wada, Y. \& Yanagida, S. (2002). Quasi-solid-state dye-sensitized solar cells using room temperature molten salts and a low molecular weight gelator. Chem. Commun., Issue 4, (January 2002) 374-375, ISSN 1359-7345

Swatloski, R. P.; Spear, S. K.; Holbrey, J. D. \& Rogers, R. D. (2002). Dissolution of cellose with ionic liquids. J. Am. Chem. Soc.,. Vol. 124, Issue 18, (April 2002) 4974-4975, ISSN $0002-7863$

Zhu, S.; Wu, Y.; Chen, Q.; Yu, Z.; Wang, C.; Jin, S.; Ding, Y. \& Wu, G. (2006) Dissolution of cellulose with ionic liquids and its application: a mini-review. Green Chem., Vol. 8, Issue 4, (March 2006) 325-327, ISSN 1463-9262

Seoud, O. A. E.; Koschella, A.; Fidale, L. C.; Dorn, S. \& Heinze, T. (2007). Applications of ionic liquids in carbohydrate chemistry: A window of opportunities. Biomacromolecules, Vol. 8, Issue 9, (August 2007) 2629-2647, ISSN 1525-7797

Winterton, N. (2006). Solubilization of polymers by ionic liquids. J. Mater. Chem., Vol. 16, Issue 44, (October 2006) 4281-4293, ISSN 0959-9428

McKendry, P. (2002) Energy production from biomass (part 1): overview of biomass. Biores. Technol., Vol. 83, Issue 1, (May 2002) 37-46, ISSN 0960-8524

Sun, X.; Sun, R.; Fowler, P. \& Baird, M. S. (2005) Extraction and characterization of original lignin and hemicelluloses from wheat straw. J. Agric. Food Chem., Vol. 53, Issue 4, (February 2005) 860-870, ISSN 0021-8561

Zhang, S.; Lv, X. et al. (2006). Ionic liquids-from basic research to application in industry. Science Press, ISBN 7-03-016882-8, Beijing

Champagne, P. \& Li, C. (2009). Enzymatic hydrolysis of cellulosic municipal wastewater treatment process residuals as feedstocks for the recovery of simple sugars. Biores. Technol., Vol. 100, Issue 23, (December 2009) 5700-5706, ISSN 0960-8524

Vegas, R.; Alonso, J. L. Domínguez, H. \& Parajó, J. C. (2004). Processing of rice husk autohydrolysis liquors for obtaining food ingredients. J. Agric. Food Chem., Vol. 52, Issue 24, (November 2004) 7311-7317, ISSN 0021-8561 
Liao, W.; Liu, Y.; Liu, C. \& Chen, S. (2004). Optimizing dilute acid hydrolysis of hemicellulose in a nitrogen-rich cellulosic material-dairy manure. Biores. Technol., Vol. 94, Issue 1, (August 2004) 33-41, ISSN 0960-8524

Río, J. C. D.; Rencoret, J.; Marques, G.; Gutiérrez, A.; Ibarra, D.; Santos, J. I.; Barbero, J. J.; Zhang, L. \& Martínez, Á. T. (2008). Highly acylated (acetylated and/or $p$-coumaroylated) native lignins from herbaceous plants. J. Agric. Food Chem., Vol. 56, Issue 20, (September 2008) 9525-9534, ISSN 0021-8561

Hayatsu, R.; Winans, R. E.; Mcbeth, R. L.; Scott, R. G.; Moore, L. P. \& Studier, M. H. (1979). Lignin-like polymers in coals. Nature, Vol. 278, (March 1979) 41-43, ISSN 0028-0836

Larsen, A. S.; Holbrey, J. D.; Tham,F. S. \& Reed, C. A. (2000). Designing ionic liquids: imidazolium melts with inert carborane anions. J. Am. Chem. Soc., Vol. 122, Issue 30, (July 2000) 7264-7272, ISSN 0002-7863

Zhao, D.; Wu, M.; Kou, Y. \& Min, E. (2002). Ionic liquids: applications in catalysis. Catal. Today, Vol. 74, Issue 1, (May 2002) 157-189, ISSN 0920-5861

Grenacher, C. (1934). Cellulose solution. US Patent Office, Pat. No. 1943176

Zhang, H.; Wu, J.; Zhang, J. \& He, J. (2005). 1-Allyl-3-methylimidazolium chloride room temperature ionic liquid: a new and powerful nonderivatizing solvent for cellulose. Macromolecules, Vol. 38, Issue 20, (September 2005) 8272-8277, ISSN 0024-9279

Fukaya, Y.; Sugimoto, A. \& Ohno, H. (2006). Superior solubility of polysaccharides in low viscosity, polar, and halogen-free 1,3-dialkylimidazolium formates. Biomacromolecules, Vol. 7, Issue 12, (November 2006) 3295-3297, ISSN 1525-7797

Fukaya, Y.; Hayashi, K.; Wada, M. \& Ohno, H. (2008). Cellulose dissolution with polar ionic liquids under mild conditions: required factors for anions. Green Chem., Vol. 10, Issue 1, (November 2008) 44-46, ISSN 1463-9262

Vitz, J.; Erdmenger, T.; Haensch, C. \& Schubert, U. S. (2009). Extended dissolution studies of cellulose in imidazolium based ionic liquids. Green Chem., Vol. 11, Issue 3, (January 2009) 417-424, ISSN 1463-9262

Xu, A.; Wang, J. \& Wang, H. (2010). Effects of anionic structure and lithium salts addition on the dissolution of cellulose in 1-butyl-3-methylimidazolium-based ionic liquid solvent systems. Green Chem., Vol. 12, Issue 2, (November 2009) 268-275, ISSN 1463-9262

Remsing, R. C.; Swatloski, R. P.; Rogers, R. D. \& Moyna, G. (2006). Mechanism of cellulose dissolution in the ionic liquid 1-n-butyl-3-methylimidazolium chloride: a ${ }^{13} \mathrm{C}$ and 35/37 Cl NMR relaxation study on model systems. Chem. Commun., Issue 12, (February 2006) 1271-1273, ISSN 1359-7345

Novoselov, N. P.; Sashina, E. S.; Petrenko, V. E. \& Zaborsky, M. (2007). Study of dissolution of cellulose in ionic liquid by computer modeling. Fibre Chem., Vol. 39, Issue 2, (March 2007) 153-158, ISSN 0015-0541

Pu, Y.; Jiang, N. \& Ragauskas, A. J. (2007). Ionic liquid as a green solvent for lignin. J. Wood Chem. Technol., Vol. 27, Issue 1, (January 2007) 23-33, ISSN 0277-3813

Kilpeläinen, I.; Xie, H.; King, A.; Granstrom, M.; Heikkinen, S. \& Argyropoulos, D. S. (2007). Dissolution of wood in ionic liquids. J. Agric. Food Chem., Vol. 55, Issue 22, (October 2007) 9142-9148, ISSN 0021-8561 
Sun, N.; Rahman, M.; Qin, Y.; Maxim, M. L.; Rodríguez, H. \& Rogers, R. D. (2009). Complete dissolution and partial delignification of wood in the ionic liquid 1-ethyl-3-methylimidazolium acetate. Green Chem., Vol. 11, Issue 5, (March 2009) 646-655, ISSN 1463-9262

Fort, D. A.; Remsing, R. C.; Swatloski, R. P.; Moyna, P.; Moyna, G. \& Rogers, R. D. (2007). Can ionic liquids dissolve wood? Processing and analysis of lignocellulosic materials with 1-n-butyl-3-methylimidazolium chloride. Green Chem., Vol. 9, Issue 1, (January 2007) 63-69, ISSN 1463-9262

Lee, S. H.; Doherty, T. V.; Linhardt, R. J. \& Dordick. J. S. (2009). Ionic liquid-mediated selective extraction of lignin from wood leading to enhanced enzymatic cellulose hydrolysis. Biotechnol. Bioeng., Vol. 102, Issue 5, (April 2009) 1368-1376, ISSN 0006-3592

Upfal, J.; Macfarlane, D. R. \& Forsyth, S. A. (2005). Solvents for use in the treatment of lignin-containing materials. WO Pat, 2005/017252, (February 2005)

Myllymaki, V. \& Aksela, R. (2005). Dissolution method for lignocellulosic materials. WO Pat, 2005/017001, (February 2005)

Lateef, H.; Grimes, S.; Kewcharoenwong, P. \& Feinberg, B. (2009). Separation and recovery of cellulose and lignin using ionic liquids: a process for recovery from paper-based waste. J. Chem. Technol. Biotechnol., Vol. 84, Issue 12, (August 2009) 1818-1827, ISSN 0268-2575 


\title{
Decentralized production of hydrogen for residential PEM fuel cells from piped natural gas by low temperature steam-methane reforming using sorption enhanced reaction concept
}

\author{
Michael G. Beaver and Shivaji Sircar ${ }^{*}$ \\ Chemical Engineering Department \\ Lehigh University, Bethlehem, Pa 18015, U.S.A.
}

\begin{abstract}
Background
Decentralized generation of small-scale stationary power $(<250 \mathrm{KW})$ for residential or commercial use has been a subject of much interest during the last decade and many corporations around the world have engaged in research and development of fuel cell technology for this application [1-10]. The driver for this technology is rapidly expanding worldwide demand for more heating, cooling and electrical supply by increasing populations and growing economics $[1,2,4,8]$. Some of the potential benefits include (a) quiet and reliable operation, (b) power on demand, (c) efficiency at low load, (d) higher efficiency vis a vis combustion route of power generation, (e) lower $\mathrm{CO}_{2}$ production than combustion, (f) absence of transmission line loss, and (f) absence of $\mathrm{SO}_{\mathrm{x}}$ and $\mathrm{NO}_{\mathrm{x}}$ production at the point of operation.
\end{abstract}

\section{Proton Exchange Membrane (PEM) Fuel Cell}

Proton exchange membrane or polymer electrolyte membrane (PEM) fuel cell technology which transforms the chemical energy liberated during the electrochemical reaction between hydrogen and oxygen to electric energy as opposed to direct combustion of hydrogen and oxygen to produce thermal energy has attracted most attention [11 - 13].

Some of the attractive features of the PEM fuel cells include (a) delivery of high power density, (b) light weight and compactness, (c) relatively low temperature operation $(\sim 60$ $80^{\circ} \mathrm{C}$ ), (d) use of non-corrosive electrolyte (e) quick start-up, (f) rapid response to demand changes in power, (g) elimination of storage battery, and (h) durability $[2,12,13]$.

*Corresponding author, email: sircar@aol.com 


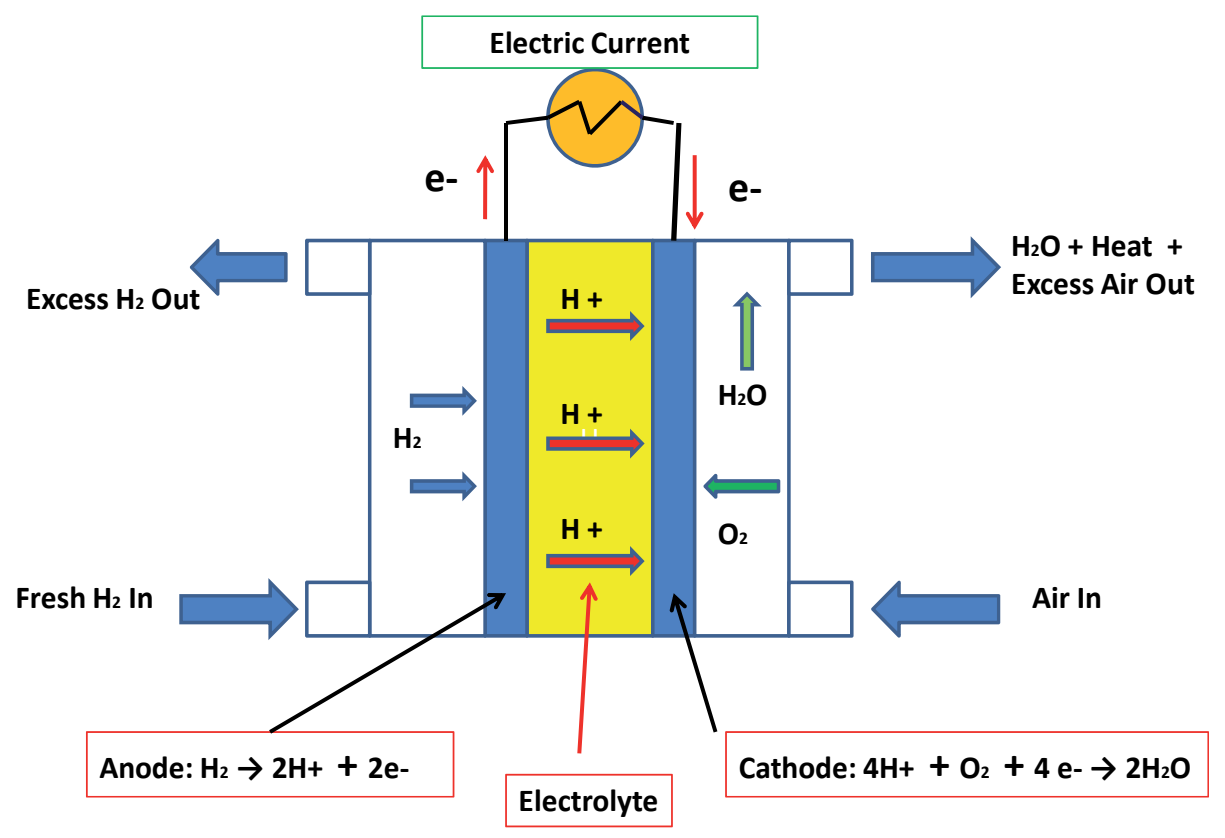

Fig. 1. Cartoon of a hydrogen PEM fuel cell.

Figure 1 is a cartoon depicting the principle of operation of a hydrogen PEM fuel cell [11]. It uses a solid polymer as an electrolyte and porous carbon electrodes containing primarily a platinum catalyst. The most commonly used membrane is humidified Nafion developed by DuPont Corp. The fuel cell needs pure hydrogen, oxygen (from air) and water (to moisten the membrane) for operation. $\mathrm{H}_{2}$ is catalytically dissociated into a proton and an electron at the anode followed by selective transport of only the proton through the membrane to the cathode, where it reacts with dissociated $\mathrm{O}_{2}$ to produce $\mathrm{H}_{2} \mathrm{O}$ and heat. The relevant chemical reactions at the electrodes are shown in the figure. The net reaction $\left(2 \mathrm{H}_{2}+\mathrm{O}_{2} \leftrightarrow 2 \mathrm{H}_{2} \mathrm{O}\right)$ is highly exothermic which generates a large amount of heat in the fuel cell. The free electron released at the anode moves to the cathode through an external circuit, thereby, generating electric current.

The purities of $\mathrm{H}_{2}$ and $\mathrm{O}_{2}$ used in the PEM hydrogen fuel cell are critical issues. The catalytic activity of the platinum electrodes in a PEM fuel cell is poisoned by the presence of trace amounts of $\mathrm{CO}, \mathrm{NH}_{3}, \mathrm{H}_{2} \mathrm{~S}$ and $\mathrm{HCN}$ in the $\mathrm{H}_{2}[4,11,14]$, as well as by the presence of trace amounts of $\mathrm{SO}_{2}$ and $\mathrm{H}_{2} \mathrm{~S}$ in the $\mathrm{O}_{2}$ (air) [15]. Presence of $\mathrm{CH}_{4}$ in the $\mathrm{H}_{2}$ is regarded to be inert towards the performance of the electrodes. $\mathrm{CO}_{2}$ itself is also regarded to be inert, but the formation of trace $\mathrm{CO}$ by reverse water gas shift reaction (RWGS) at the anode $\left[\mathrm{CO}_{2}+\mathrm{H}_{2} \leftrightarrow\right.$ $\mathrm{CO}+\mathrm{H}_{2} \mathrm{O}$ ] due to the presence of $\mathrm{CO}_{2}$ in $\mathrm{H}_{2}$ can have the same detrimental effect as in the presence of trace $\mathrm{CO}$ in $\mathrm{H}_{2}$ [14].

Figure 2 shows thermodynamic estimation of $\mathrm{CO}$ formation by reaction between $\mathrm{CO}_{2}$ and $\mathrm{H}_{2}$ at different temperatures of operation of a PEM fuel cell [14]. It may be seen that a considerable amount of CO, albeit in parts per million level, is formed at the anode which is sufficient to poison the catalyst by being selectively chemisorbed on the platinum electrode over $\mathrm{H}_{2}$. 


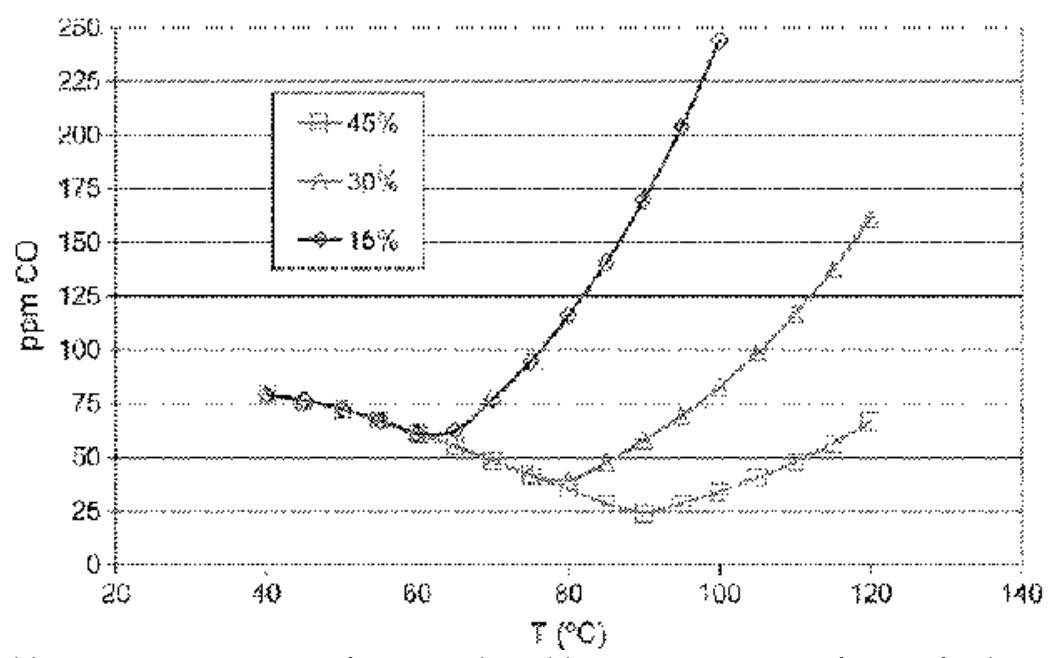

Fig. 2. Equilibrium concentration of $C O$ produced by RWGS reaction from a feed gas containing 3:1 $\mathrm{H}_{2}: \mathrm{CO}_{2}$ at 1.5 bar and different temperatures in presence of different concentrations of water. Reprinted from J. Power Sources, 110, 117-124 (2002) with permission from Elsevier.

Figures 3 and 4, respectively, show two sets of experimental data demonstrating the detrimental performance of a PEM fuel cell in presence of bulk $\mathrm{CO}_{2}$ in $\mathrm{H}_{2}$ [14] and trace $\mathrm{SO}_{2}$ in air [15].

Figure 3 shows that the cell voltage for a given current density decreases as the $\mathrm{CO}_{2}$ concentration in the feed $\mathrm{H}_{2}$ increases. Figure 4 shows that the normalized output voltage of a fuel cell decreases with operation time when the air introduced at the cathode is contaminated with even a trace amount $(<1.5 \mathrm{ppm})$ of $\mathrm{SO}_{2}$. The rate of degradation of the cell performance increases rapidly as the concentration of contaminated $\mathrm{SO}_{2}$ is increased.

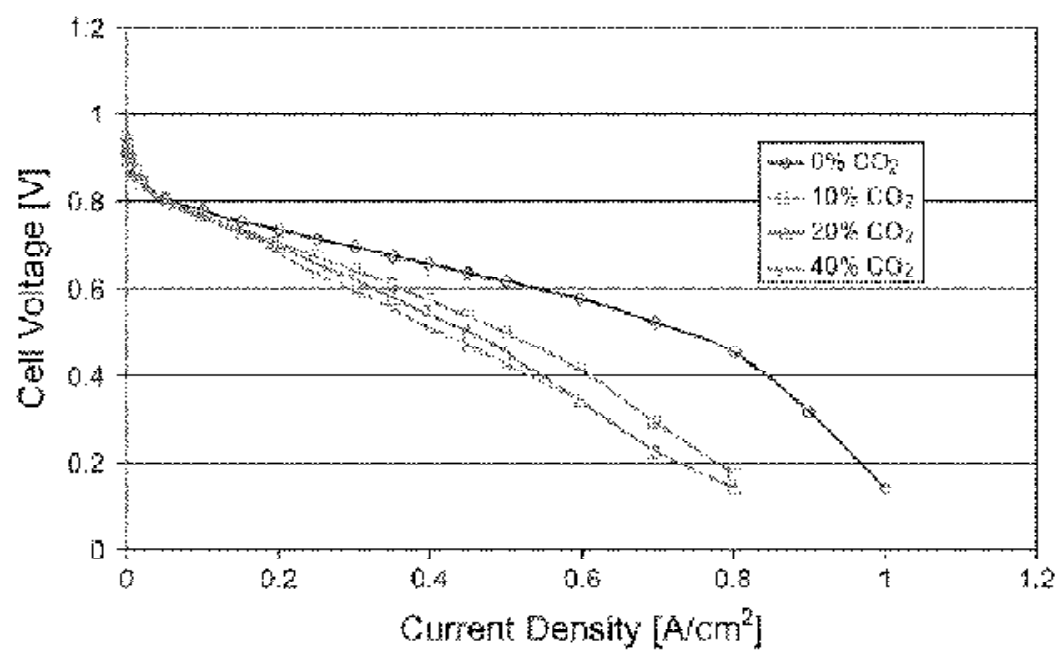

Fig. 3. Polarization curves of a Nafion fuel cell at various $\mathrm{CO}_{2}$ concentrations in the feed $\mathrm{H}_{2}$ at $65^{\circ} \mathrm{C} . \mathrm{P}=1.5 \mathrm{~atm}$. Reprinted from J. Power Sources, 110, 117-124 (2002) with permission from Elsevier. 


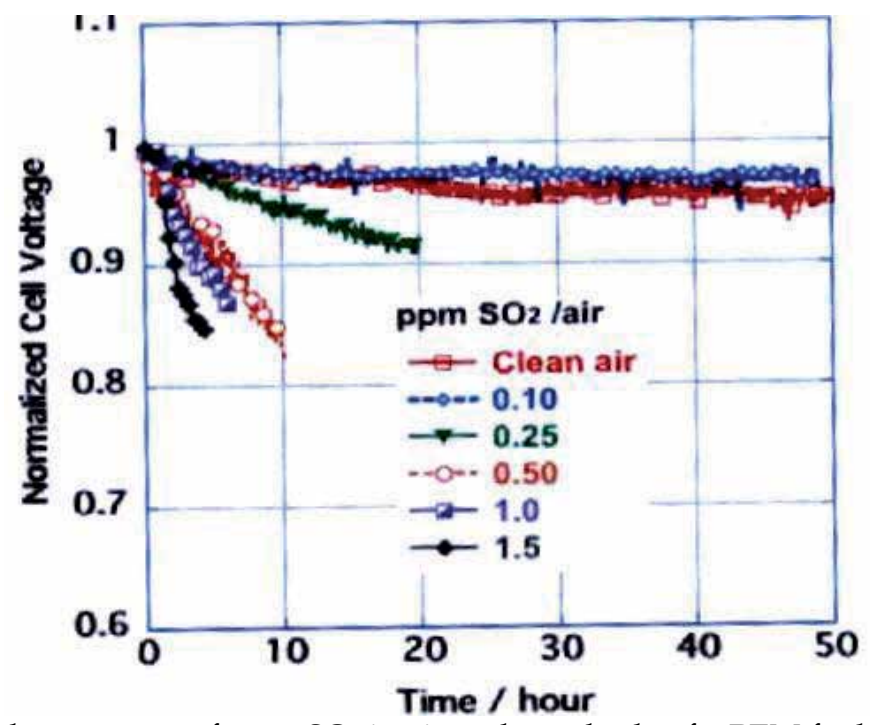

Fig. 4. Effect of the presence of trace $\mathrm{SO}_{2}$ in air at the cathode of a PEM fuel cell.

Consequently, essentially $\mathrm{CO}_{x}$, sulfur, and $\mathrm{NH}_{3}$ free $\mathrm{H}_{2}$ and air streams are needed as feed gases for efficient and durable operation of a PEM fuel cell. A 2005 draft specification of the fuel cell grade hydrogen suggested by the U. S. Department of Energy is provided in Table 1 [15].

\begin{tabular}{cc}
\hline Components & Levels \\
\hline Hydrogen & $>99,9 \%$ \\
$\mathrm{CO}$ & $\sim 0.1 \mathrm{ppm}$ \\
$\mathrm{CO}_{2}$ & $\sim 5.0 \mathrm{ppm}$ \\
$\mathrm{NH}_{3}$ & $\sim 1 \mathrm{ppm}$ \\
\hline Non $\mathrm{CH}_{4}$ hydrocarbons & $\sim 100 \mathrm{ppm}$ \\
\hline
\end{tabular}

Table 1. Suggested specification of $\mathrm{H}_{2}$ purity for PEM fuel cell [15].

This requirement of very high purity $\mathrm{H}_{2}$ may be a potential limitation of the use of a PEM fuel cell for residential use. It should, however, be noted that a very active R \& D effort is being carried out to produce more $\mathrm{CO}_{\mathrm{x}}$ tolerant anode catalysts by employing platinumruthenium catalysts made by different preparation methods as well as by using other catalyst formulations [16 - 21 ]. The other potential limitations of commercializing residential fuel cells may be (a) high manufacturing costs, (b) complex heat and water management issues, (c) long warm up period, (d) inferior performance when cold, and (e) membrane life and cost of replacement [12].

\section{Natural Gas as source of Hydrogen}

The high purity $\mathrm{H}_{2}$ required by a PEM fuel cell must be easily available at the point of location of residential use. One potential solution is to directly produce fuel-cell grade $\mathrm{H}_{2}$ at the site of the fuel cell by steam reforming of methane [22]. A network of pipe lines to 
supply natural gas for domestic (heating or cooking), and commercial (heating) applications already exists in the infrastructure of many advanced countries. The gas is typically available at a pressure of $2-60$ psig, and is centrally processed to remove impurities like $\mathrm{H}_{2} \mathrm{O}, \mathrm{CO}_{2}, \mathrm{~S}$, He, and heavy hydrocarbons.

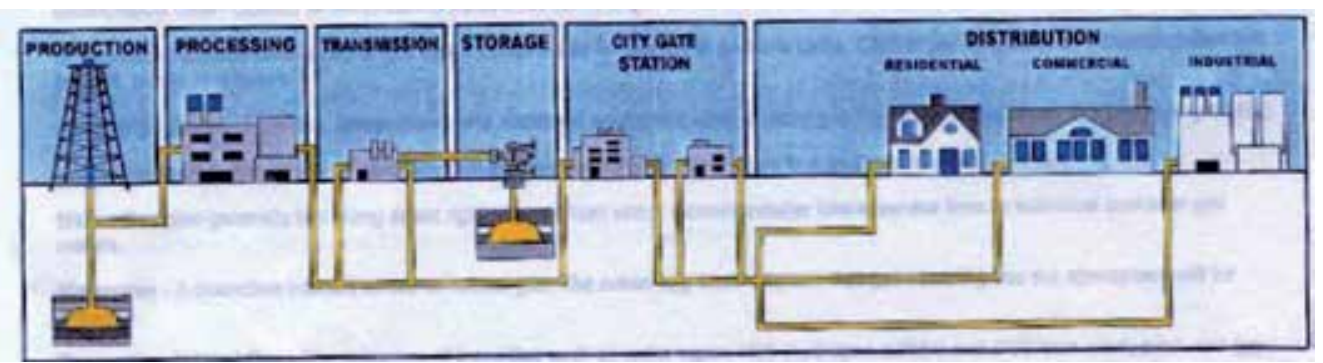

Fig. 5. Lay-out of infrastructure for natural gas supply.

Figure 5 shows a cartoon of a typical infrastructure lay-out for natural gas production, processing (impurity removal), transmission, storage, and distribution [23]. The gas leaves the transmission system and enters the distribution system at the city gate stations where it may be odorized by adding trace amounts of mercaptans as a safety measure for domestic use.

\section{Production of Fuel Cell Grade $\mathrm{H}_{2}$ from Natural Gas}

Catalytic reformation of $\mathrm{CH}_{4}$ by reaction with steam is the most efficient and economically viable route of production of $\mathrm{H}_{2}$ and many commercial processes employing this principle have been developed [24]. The primary reactions in the reforming reactor are:

- Endothermic steam-methane reforming (SMR) reaction :

$\mathrm{CH}_{4}+\mathrm{H}_{2} \mathrm{O} \leftrightarrow \mathrm{CO}+3 \mathrm{H}_{2} ; \quad \Delta \mathrm{H}_{\mathrm{R}}=+206 \mathrm{~kJ} /$ mole

- Exothermic water gas shift (WGS) reaction :

$\mathrm{CO}+\mathrm{H}_{2} \mathrm{O} \leftrightarrow \mathrm{CO}_{2}+\mathrm{H}_{2} ; \quad \Delta \mathrm{H}_{\mathrm{R}}=-41 \mathrm{~kJ} /$ mole

- Endothermic net reaction :

$$
\mathrm{CH}_{4}+2 \mathrm{H}_{2} \mathrm{O} \leftrightarrow \mathrm{CO}_{2}+4 \mathrm{H}_{2} ; \Delta \mathrm{H}_{\mathrm{R}}=+165 \mathrm{~kJ} / \mathrm{mole}
$$

These reactions are controlled by the chemical thermodynamic equilibria, which dictate the preferred reaction conditions (pressure, temperature and feed $\mathrm{H}_{2} \mathrm{O}: \mathrm{CH}_{4}$ ratio), the $\mathrm{H}_{2}$ conversion, and the composition of the SMR reaction product gas containing $\mathrm{H}_{2}+\mathrm{CO}_{2}$ (bulk) $+\mathrm{CO}$ (dilute) $+\mathrm{CH}_{4}$ (dilute) on a dry basis.

Figure 6 shows the equilibrium constants for the reversible SMR (KSMR) and WGS (K $\left.\mathrm{K}_{W S}\right)$ reactions [25], and the estimated thermodynamic conversion of $\mathrm{CH}_{4}$ to $\mathrm{H}_{2}$ by SMR as a function of reaction temperature (reactor pressure $=1.5 \mathrm{~atm}$, feed $\mathrm{H}_{2} \mathrm{O} / \mathrm{CH}_{4}$ ratio $=5: 1$ ). It may be seen that the maximum conversion $(\sim 90 \%)$ of $\mathrm{CH}_{4}$ to $\mathrm{H}_{2}$ can be achieved at a reaction temperature of $\sim 700-800^{\circ} \mathrm{C}$. Such high temperature requires expensive metallurgy for reactor construction, and a rather complex system of heat management. Table 2 shows the equilibrium compositions of the SMR reactor gas at different operating temperatures for a reactor feed gas containing 5:1 $\mathrm{H}_{2} \mathrm{O}: \mathrm{CH}_{4}$ at $1.5 \mathrm{~atm}$. It shows that the reactor effluent gas must be stringently purified in order to produce a stream of pure $\mathrm{H}_{2}$. 


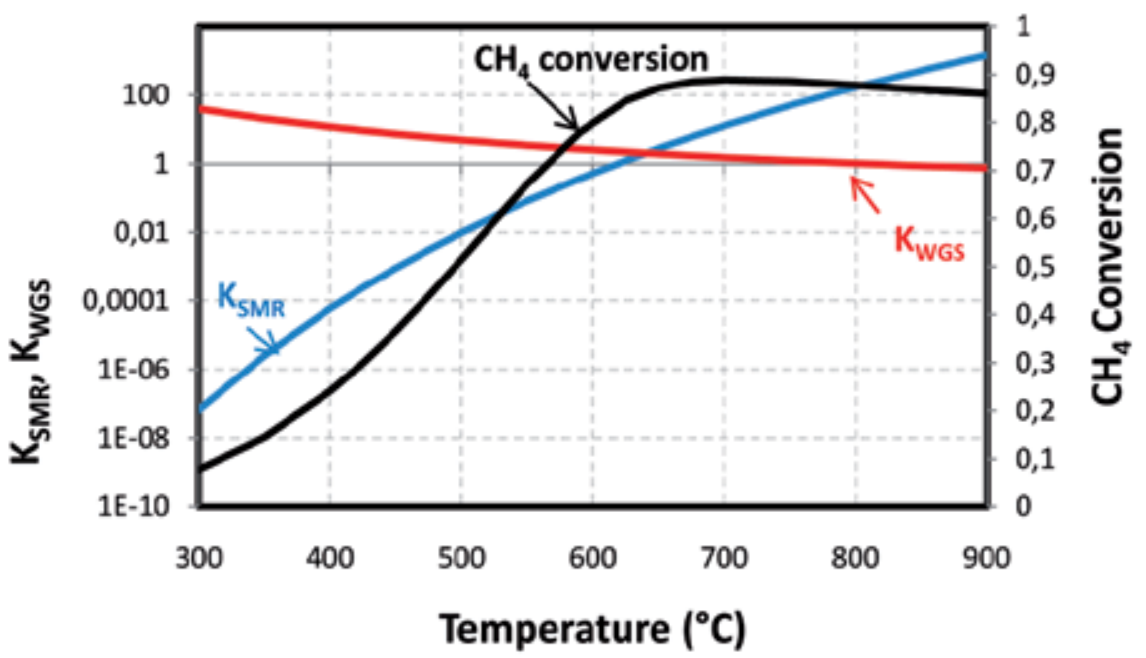

Fig. 6. Reaction equilibrium constants and thermodynamic $\mathrm{CH}_{4}$ to $\mathrm{H}_{2}$ conversion for SMR reaction.

\begin{tabular}{ccccc}
\hline $\begin{array}{c}\text { Reaction } \\
\text { Temperature (C) }\end{array}$ & \multicolumn{3}{c}{ Reactor effluent gas composition (dry basis) } \\
(mole \%)
\end{tabular}

Table 2. Equilibrium compositions of SMR reactor effluent gases.

\section{Conventional Process Scheme for $\mathrm{H}_{2}$ Production by SMR [24]}

The most common commercial method for production of high purity $\mathrm{H}_{2}(99.999+\%)$ from natural gas for fuel cell use consists of high temperature $\left(\sim 800-900^{\circ} \mathrm{C}\right)$ catalytic steammethane reforming (SMR), followed by catalytic water gas shifting (WGS) of the reaction products at $\sim 300-400^{\circ} \mathrm{C}$, and finally purification of the WGS reactor effluent gas to produce pure $\mathrm{H}_{2}$ at feed gas pressure by employing a multi-step, multi column, pressure swing adsorption (PSA) process [24]. The feed natural gas to the process is pre-treated to remove trace $S$ and $\mathrm{N}$ impurities, if needed. The PSA process is operated at a near ambient temperature $\left(20-40^{\circ} \mathrm{C}\right)$ by employing physi-sorbents like zeolites, aluminas, and activated carbons for removal of the impurities $\left(\mathrm{H}_{2} \mathrm{O}, \mathrm{CO}_{2}, \mathrm{CO}, \mathrm{CH}_{4}, \mathrm{~N}_{2}\right)$ from the $\mathrm{H}_{2}$ product gas. The feed gas to the PSA system typically contains $15-25 \% \mathrm{CO}_{2}+1-4 \% \mathrm{CO}+1-5 \% \mathrm{CH}_{4}+0.2 \%$ $\mathrm{N}_{2}$ in $\mathrm{H}_{2}$ (dry basis). A waste gas containing all of the carbon impurities and un- recovered hydrogen is also produced by the PSA system which is used as fuel in the SMR furnace. 
Figure 7 shows a simplified box diagram of the process for production of ultra pure $\mathrm{H}_{2}$ from natural gas by the conventional SMR-WGS-PSA route.

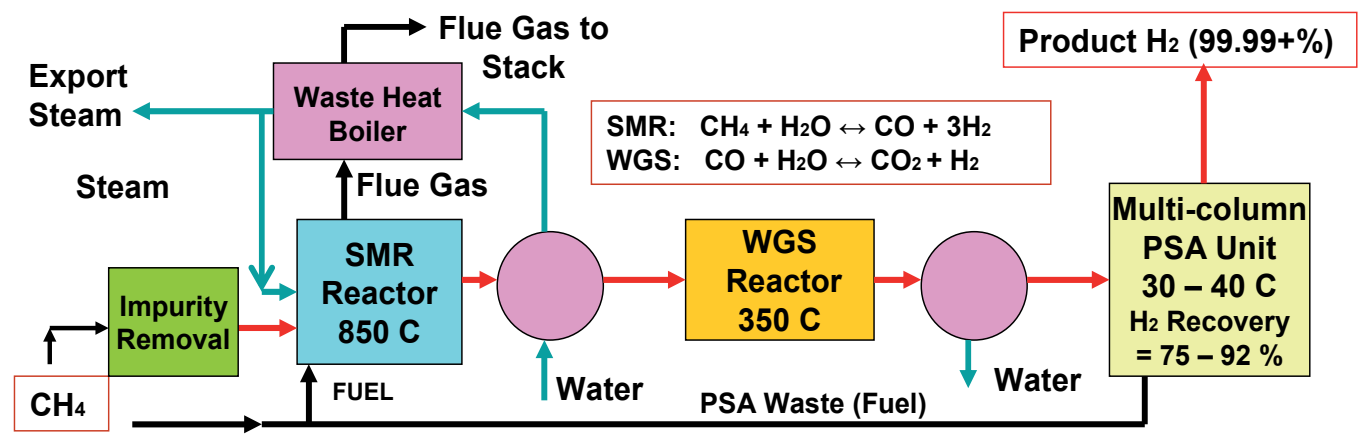

Fig. 7. Conventional steam-methane reforming route of $\mathrm{H}_{2}$ production from natural gas.

Although the scheme shown by Figure 7 has become the state of the art technology for production of $\sim 1$ to 150 MMSCFD of $\mathrm{H}_{2}$ from $\mathrm{CH}_{4}$, there are several unattractive but unavoidable features for scaling down the process for residential fuel cell use $\left(\mathrm{H}_{2}\right.$ demand for a $250 \mathrm{~kW}$ PEM fuel cell is only $\sim 0.15$ MMSCFD). These include (a) operation of the SMR reactor at high temperature, (b) use of a part of the purified $\mathrm{H}_{2}$ product $(8-25 \%)$ to regenerate the PSA adsorbents by purge, thereby reducing the over-all recovery of $\mathrm{H}_{2}$ produced by the SMR and WGS reactions, (c) generation of export steam in order to recover the excess heat required for the operation of the relatively low efficiency SMR reactor, and (d) fairly complex nature of the process using several unit operations which requires large footprint and capital cost.

\section{Alternative Process Scheme for $\mathrm{H}_{2}$ production by SMR $[1,26]$}

An alternative process scheme has been developed for production of fuel cell grade $\mathrm{H}_{2}$ from $\mathrm{CH}_{4}$ by SMR $[1,26]$. It replaces the PSA purification step of the conventional scheme of Figure 7 by a catalytic PROX /SELOX (Preferential/ Selective Oxidation) reactor which selectively oxidizes the residual $\mathrm{CO}(\sim 1-4 \%)$ from the WGS reactor effluent gas to $\mathrm{CO}_{2}$ $\left(\mathrm{CO}+0.5 \mathrm{O}_{2} \rightarrow \mathrm{CO}_{2}\right)$ in presence of excess $\mathrm{H}_{2}$ at a moderate temperature of $80-200^{\circ} \mathrm{C}$. A small quantity of air is added to the PROX reactor feed to supply the oxygen needed for this purpose. The CO level can be reduced to $\sim 10 \mathrm{ppm}$ by the PROX concept. Figure 8 is a schematic box diagram for this approach.

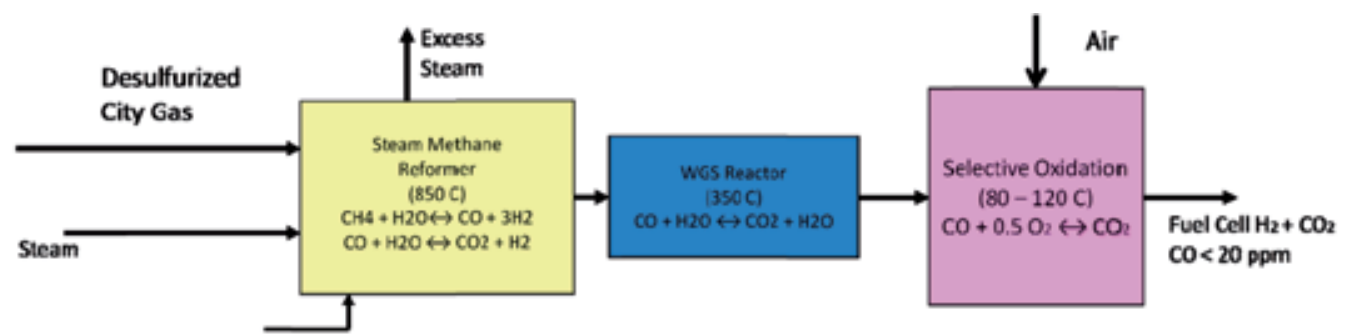

\section{$\mathrm{CH}_{4}$ Fuel}

Fig. 8. Alternative steam-methane reforming route of $\mathrm{H}_{2}$ production from natural gas. 
Selectivity of $\mathrm{CO}$ oxidation to produce $\mathrm{CO}_{2}$ vis a vis $\mathrm{H}_{2}$ oxidation to produce $\mathrm{H}_{2} \mathrm{O}$, and the absolute conversion of $\mathrm{CO}$ to $\mathrm{CO}_{2}$ are two critical performance markers for the PROX catalyst. A large volume of research on mono- and bi- metallic PROX catalyst formulation, nature of support matrix, and method of preparation has been published, and the subject is an active area of research around the world [27 - 38]. The common catalysts include noble metals ( $\mathrm{Pt}, \mathrm{Ru}, \mathrm{Rh}, \mathrm{Pd})$ supported on a porous matrix such as alumina $[32,38]$. Some of them offer good catalytic activity ( $100 \%$ CO conversion with $30-50 \%$ selectivity) in the temperature range of $130-200^{\circ} \mathrm{C}$.

The performance of a PROX catalyst may substantially deteriorate in the presence of $\mathrm{H}_{2} \mathrm{O}$ and $\mathrm{CO}_{2}$. Figure 9 shows an example where both the $\mathrm{CO}$ conversion (solid lines) and selectivity (dashed lines) of a PROX catalyst [1\% (1:1) $\mathrm{Pt} \mathrm{Au} / \mathrm{CeO}_{2}$ produced by single stepsol-gel method] decrease substantially in presence of $\mathrm{CO}_{2}$ in the reactant gas $\left(1 \% \mathrm{CO}, 1 \% \mathrm{O}_{2}\right.$, $0-25 \% \mathrm{CO}_{2}, 40 \% \mathrm{H}_{2}$ and balance $\mathrm{He}$ ) at all temperatures [37].

Figure 10 shows another example of the performance of a PROX catalyst (Pt/FAU) at a temperature of $165^{\circ} \mathrm{C}$ where the $\mathrm{CO}$ conversion and selectivity were not affected by the presence of $\mathrm{CO}_{2}$ and $\mathrm{H}_{2} \mathrm{O}$ in a long term stability test [38]. The reactant for this test contained $1.21 \% \mathrm{CO}, 2.9 \% \mathrm{H}_{2} \mathrm{O}, 25.25 \% \mathrm{CO}_{2}$ and $70.63 \% \mathrm{H}_{2}$.

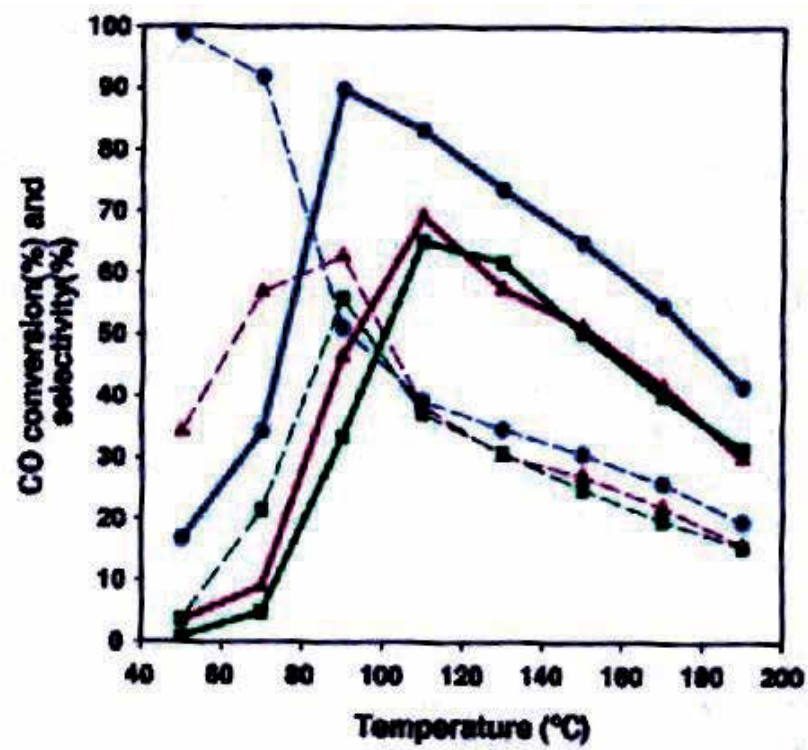

Fig. 9. Effect of $\mathrm{CO}_{2}$ in feed gas on performance of a PROX catalyst.

- $0 \% \mathrm{CO}_{2}, \Delta 5 \% \mathrm{CO}_{2} \square 25 \% \mathrm{CO}_{2}$

Reprinted from J. Power Sources, 163, 547-554 (2006) with permission from Elsevier.

Clearly, a practical PROX catalyst for producing an essentially $\mathrm{CO}$ free $\mathrm{H}_{2}$ for fuel cell application must exhibit $\sim 100 \% \mathrm{CO}$ conversion in presence of $\mathrm{CO}_{2}$ and $\mathrm{H}_{2} \mathrm{O}$. Less than 100 $\% \mathrm{CO}$ oxidation selectivity may be acceptable albeit with the loss of some $\mathrm{H}_{2}$ produced by SMR. The presence of $\mathrm{CO}_{2}$ in the effluent gas from a PROX reactor, however, can be the cause of anode deactivation of a PEM fuel cell due to reformation of CO by RWGS reaction as discussed earlier. 


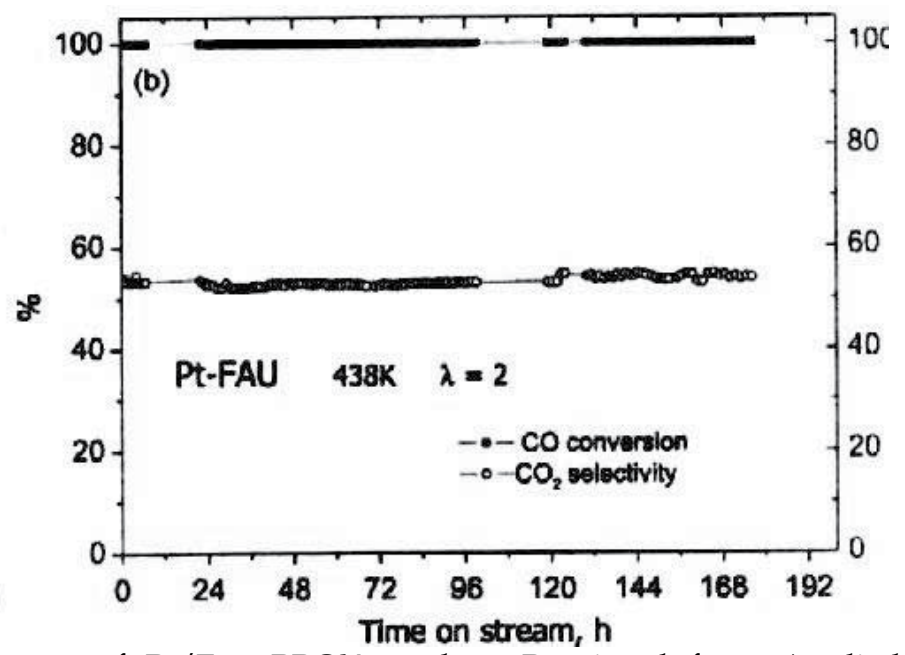

Fig. 10. Performance of Pt/Fau PROX catalyst. Reprinted from Applied Catalysis A; General, 366, 242-251 (2009) with permission from Elsevier.

\section{Sorption Enhanced Reaction (SER) Concepts for $\mathrm{H}_{2}$ Production by Low Temperature SMR}

Recently, several novel adsorptive process concepts called 'sorption enhanced reaction (SER)' have been designed to substantially enhance the performance of SMR and WGS reactors for production of fuel cell grade $\mathrm{H}_{2}$ from $\mathrm{CH}_{4}$ by circumventing the thermodynamic limitations of these reactions. The key benefits include:

- Drastically increase the $\mathrm{H}_{2}$ product purity and conversion in a single unit operation

- Significantly lower the SMR reaction temperature without sacrificing process performance

- Enhance the kinetics of the forward SMR reaction

- Increase the over-all $\mathrm{H}_{2}$ recovery from the plant

- $\quad$ Reduce the plant foot print and cost by integration of the reactors

(SMR and WGS) and the PSA unit as a single unit operation, and by lowering the temperature of SMR reaction (easier heat management and loss).

These advantages are achieved by applying the Le Chatelier's principle, whereby one of the reaction products, $\mathrm{CO}_{2}$, is selectively removed from the reaction zone at the reaction temperature. An admixture of a reversible $\mathrm{CO}_{2}$ chemisorbent, which can selectively sorb $\mathrm{CO}_{2}$ in presence of steam at the reaction temperature, and an SMR catalyst is used in the sorber-reactor for this purpose. The chemisorbent is periodically regenerated for re-use by desorbing the $\mathrm{CO}_{2}$ using the principles of pressure swing adsorption (PSA) or thermal swing adsorption (TSA) processes.

A recent monograph entitled 'Sorption Enhanced Reaction Concepts for Hydrogen Production: Materials and Processes' [39] and a review article entitled 'Reversible Chemisorbents for $\mathrm{CO}_{2}$ and their Potential Applications' [40] describe the current state of the art on the SER processes for $\mathrm{H}_{2}$ production by SMR and the $\mathrm{CO}_{2}$ chemisorbents used in them. Chemisorbents utilizing either bulk (e.g. $\mathrm{CaO}$ ) or surface (e.g. $\mathrm{K}_{2} \mathrm{CO}_{3}$ promoted 
hydrotalcite) reactions with $\mathrm{CO}_{2}$ have been used in these processes [39, 40]. Fixed bed sorber-reactors using both types of chemisorbents have been considered by most authors [39], while a fluidized bed sorber- reactor using the first type of chemisorbent has been evaluated by Harrison [39, 41].
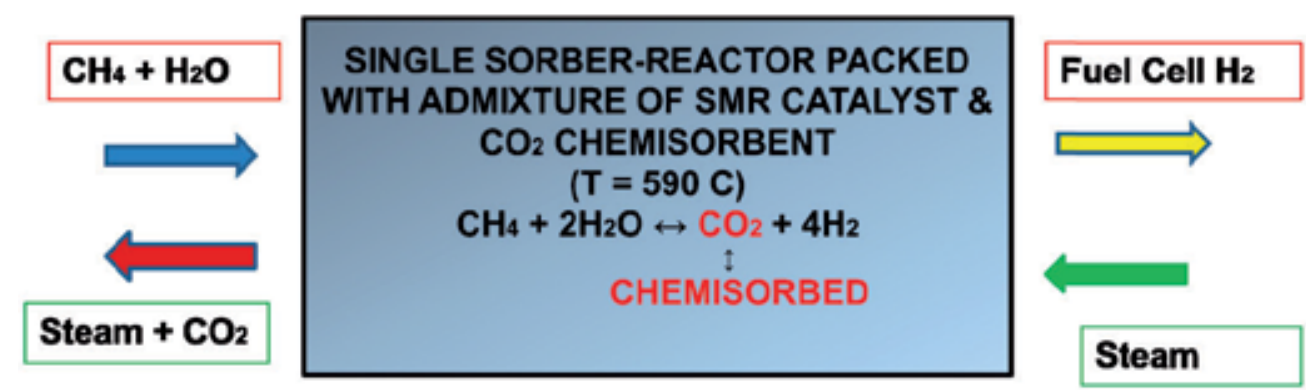

Fig. 11. Conceptual sketch of SER SMR process concepts.

A fixed- bed cyclic SER process employing a $\mathrm{CO}_{2}$ chemisorbent utilizing surface reaction may be preferred for the residential fuel cell application because of (a) direct production of high purity $\mathrm{H}_{2}$ by SMR with high conversion of $\mathrm{CH}_{4}$ to $\mathrm{H}_{2}$, (b) relatively lower temperature of operation, (c) ease of $\mathrm{CO}_{2}$ regeneration using conventional principles of pressure or thermal swing adsorption processes, (d) use of steam purge for $\mathrm{CO}_{2}$ desorption, (e) process compactness, (f) faster chemisorption kinetics, and (g) absence of sorbent transportation. Figure 11 is a conceptual drawing of a generic fixed-bed SER process concept for directly producing fuel cell grade $\mathrm{H}_{2}$ by low temperature SMR.

\section{Surface reaction based $\mathrm{CO}_{2}$ chemisorbent used in SER processes for $\mathrm{H}_{2}$ production by SMR}

$\mathrm{K}_{2} \mathrm{CO}_{3}$ promoted hydrotalcite has been found to be an acceptable $\mathrm{CO}_{2}$ chemisorbent for fixed-bed adsorptive SER processes (PSA or TSA) operated at a temperature of $400-550^{\circ} \mathrm{C}$ for production of fuel cell grade $\mathrm{H}_{2}$ by SMR [40,42] because it provides (i) a decent cyclic $\mathrm{CO}_{2}$ working capacity under a pressure or thermal swing mode of SER process operation, (ii) fast $\mathrm{CO}_{2}$ chemisorption kinetics, (iii) moderate isosteric heat of $\mathrm{CO}_{2}$ sorption, (iv) nearly infinite selectivity of sorption for $\mathrm{CO}_{2}$ in presence of steam, $\mathrm{CO}, \mathrm{CH}_{4}$ and $\mathrm{H}_{2}$, (v) relatively easy desorption of $\mathrm{CO}_{2}$ by purge using steam, and (vi) thermal stability. Some of the key relevant characteristics of $\mathrm{CO}_{2}$ chemisorption on the material are described below:

Chemisorption Equilibria [40, 42]:

Figure 12 shows the equilibrium $\mathrm{CO}_{2}$ chemisorption isotherms on a sample of the promoted hydrotalcite at different temperatures. An analytical isotherm model incorporating simultaneous Langmuirian surface chemisorption and an additional surface reaction between the chemisorbed and gaseous $\mathrm{CO}_{2}$ molecules describes the isotherms adequately (lines in Figure 12). The heats of these reactions are moderate, being respectively, 5.0 and $10.1 \mathrm{Kcal} / \mathrm{mole}$. 
Mass transfer rate for $\mathrm{CO}_{2}$ chemisorption [40, 42, 53]:

The conventional linear driving force (LDF) model was found to adequately describe the over-all mass transfer of $\mathrm{CO}_{2}$ on promoted hydrotalcite [40].The same LDF mass transfer coefficient $(\mathrm{k})$ described both sorption and desorption of $\mathrm{CO}_{2}$. Figure 13 shows the temperature coefficient of $\mathrm{k}[40,53]$. The activation energy for $\mathrm{k}$ was $4.5 \mathrm{Kcal} / \mathrm{mole}$.

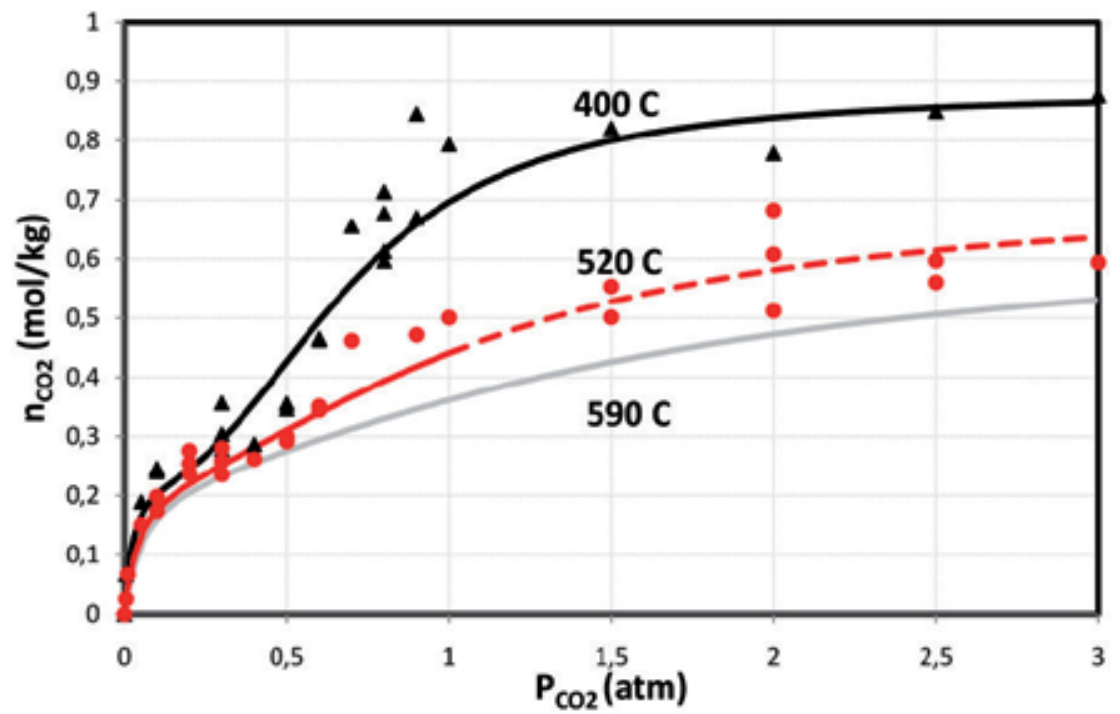

Fig. 12. Chemisorption isotherms of $\mathrm{CO}_{2}$ on $\mathrm{K}_{2} \mathrm{CO}_{3}$ promoted hydrotalcite.

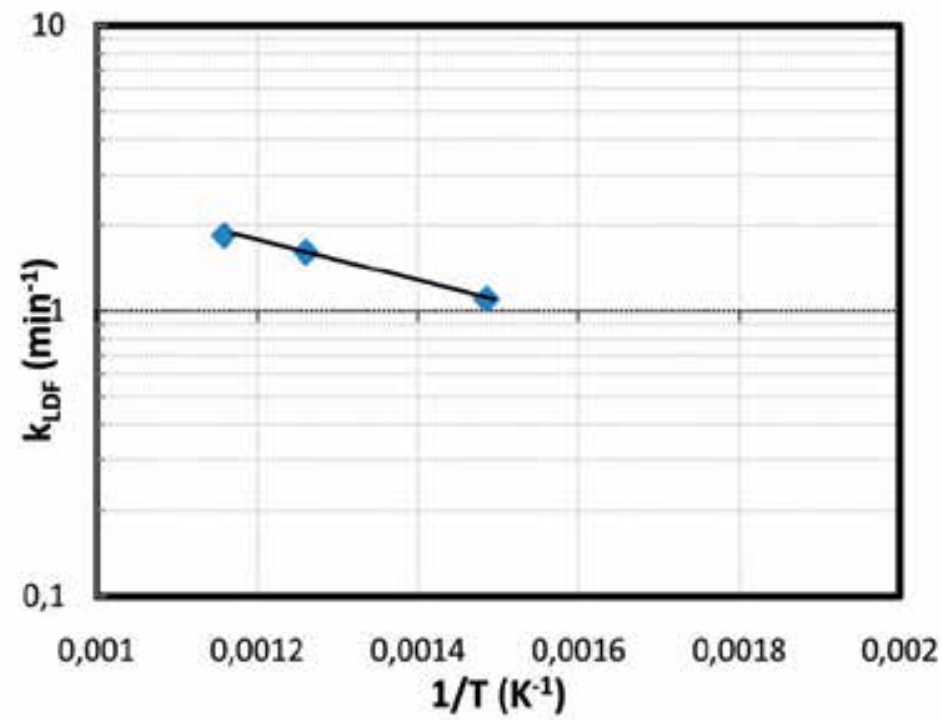

Fig. 13. Temperature dependence of $\mathrm{CO}_{2}$ mass transfer coefficient on $\mathrm{K}_{2} \mathrm{CO}_{3}$ promoted hydrotalcite. 
Experimental demonstration of SER-SMR concept [53]:

Figure 14 experimentally demonstrates the SER concept using a packed column $(63.4 \mathrm{~cm}$ long) of a 2:1 admixture of $\mathrm{K}_{2} \mathrm{CO}_{3}$ promoted hydrotalcite and a commercial $\mathrm{Ni} / \mathrm{Al}_{2} \mathrm{O}_{3} \mathrm{SMR}$ catalyst (Sud Chemie Corp.). A pre-heated feed gas mixture containing $\sim 37$ mole $\% \mathrm{H}_{2} \mathrm{O}+$ 7.4 mole \% $\mathrm{CH}_{4}+\mathrm{Ar}$ was passed through the column at near ambient pressure. The column was initially heated to $550^{\circ} \mathrm{C}$ and filled with Ar.

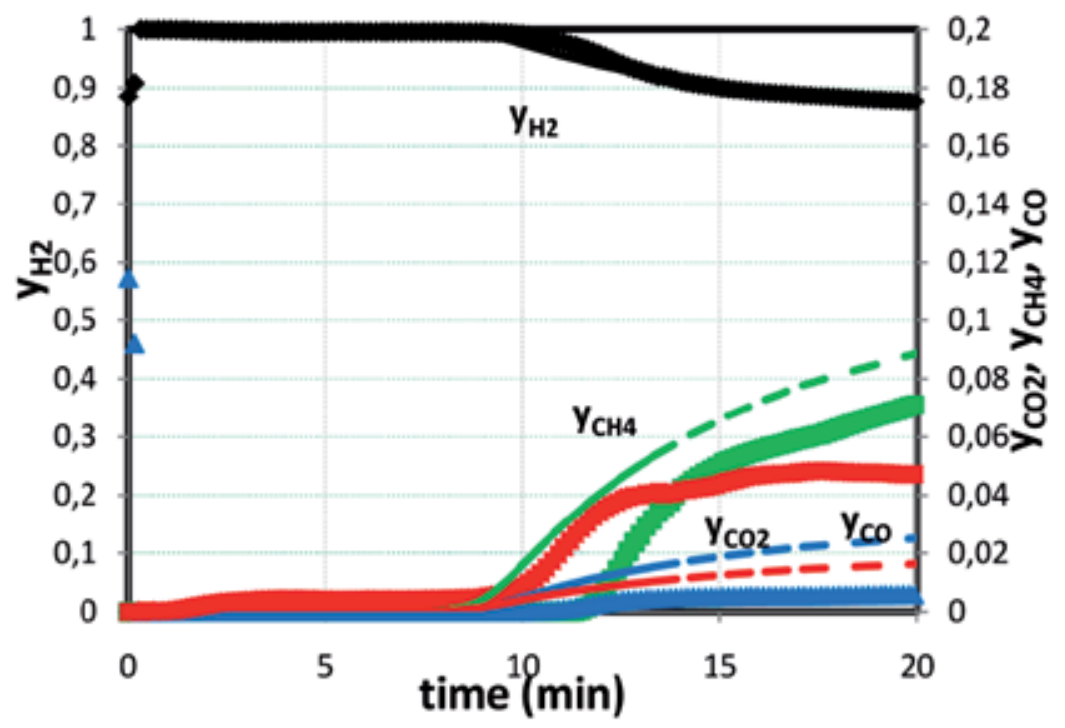

Fig. 14. Experimental demonstration of SER- SMR concept at $550^{\circ} \mathrm{C}$ using promoted hydrotalcite.

It may be seen from Figure 14 that the effluent gas from the sorber- reactor (solid lines) contained a stream of high purity $\mathrm{H}_{2}\left(\mathrm{CO}_{\mathrm{x}}<20 \mathrm{ppm}\right)$ which was suitable for use in a $\mathrm{H}_{2}$ fuel cell for a period of time. Thereafter, $\mathrm{CO}, \mathrm{CH}_{4}$, and $\mathrm{CO}_{2}$ simultaneously broke through the sorber-reactor and their mole fractions rapidly rose to different plateau levels which corresponded to the thermodynamic reaction product concentrations of the SMR reaction (without the chemisorbent) at the reaction temperature. The average $\mathrm{CH}_{4}$ mole fraction of the high purity $\mathrm{H}_{2}$ product stream was 0.35 mole \%. The conversion of feed $\mathrm{CH}_{4}$ to pure $\mathrm{H}_{2}$ product was $98.6 \%$. The dashed lines in the Figure are simulated performance using a model [53].

\section{Pressure swing sorption enhanced reaction (PSSER) process}

A pressure swing sorption enhanced reaction (PSSER) process for low temperature $\left(\sim 500{ }^{\circ} \mathrm{C}\right)$ SMR was designed by Sircar and coworkers $[43,44]$. The process employed a pair of fixed bed sorber-reactors and it could directly produce a fuel-cell grade $\mathrm{H}_{2}$ using $\mathrm{K}_{2} \mathrm{CO}_{3}$ promoted hydrotalcite as the $\mathrm{CO}_{2}$ chemisorbent in the process. The sorbent was periodically regenerated by purging it with steam at the reaction temperature under a sub-atmospheric pressure condition. The cyclic process consisted of four steps: (a) sorption -reaction at a super-ambient pressure to produce the fuel-cell grade $\mathrm{H}_{2}$ product at feed gas pressure, (b) 
counter-current depressurization to near ambient pressure, (c) counter-current steam purge at sub-atmospheric pressure, and (d) counter-current pressurization with steam to feed pressure. These PSSER process steps were operated under a nearly isothermal condition.

A shell and tube reactor design was suggested for the above-described PSSER process. Two different types of indirect heat transfer methods were also proposed for supplying the endothermic heat of SMR reaction and heat for $\mathrm{CO}_{2}$ desorption. They consisted of (a) flowing a vaporized heat transfer liquid through the shell side of the reactor so that the condensing vapor would supply the heat of reaction in the reactor and maintain a constant reactor temperature during all steps of the process, and (b) indirect gas heating (IGH) by flowing a hot flue gas through the shell side of the reactor with finned tubes to supply the heat of reaction [43].

Figure 15 is a schematic flow diagram of a two column PSSER system for production of $\mathrm{H}_{2}$. An example of the cyclic steady state performance of the PSSER process from a pilot scale test apparatus is given in Table 3 which shows that fuel-cell grade $\mathrm{H}_{2}$ with high $\mathrm{CH}_{4}$ to $\mathrm{H}_{2}$ conversion can be achieved by the process. Sircar and co-workers also proposed that the performance of the PSSER process could be improved by (a) use of a catalyst only section in the feed end of the sorber-reactor, (b) using a dilute amount of $\mathrm{H}_{2}$ with the purge steam, and (c) imposing a moderately increasing temperature gradient from the feed to the product end of the sorber-reactor [45].

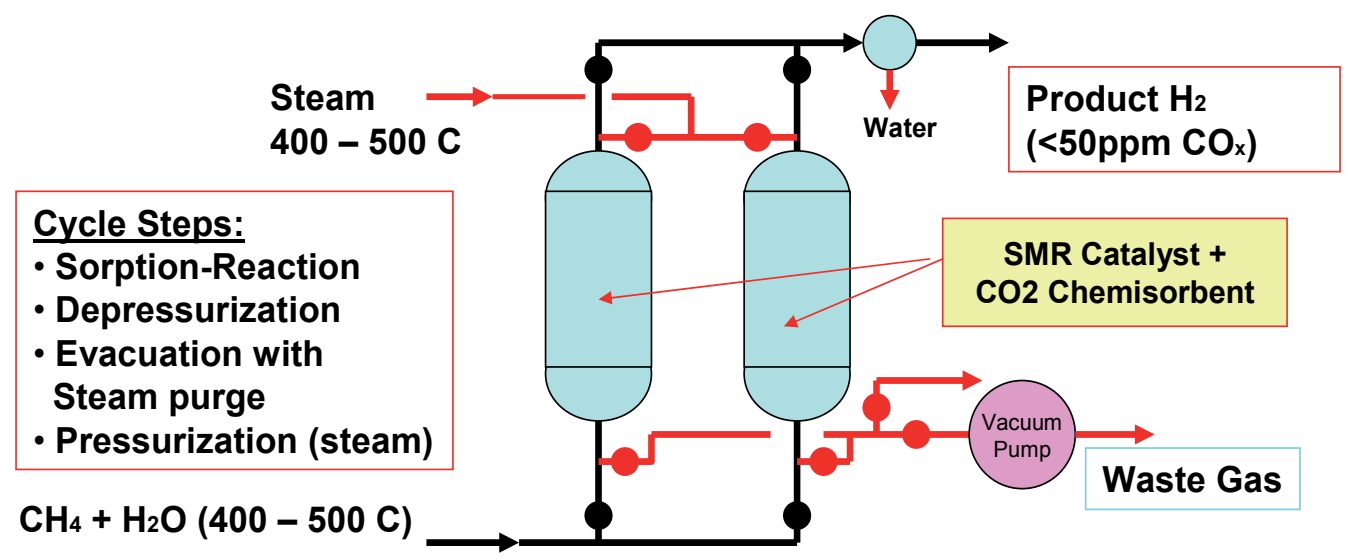

Fig. 15. Schematic flow sheet of a PSSER system.

\begin{tabular}{|l|l|l|l|l|}
\hline \multicolumn{1}{|c|}{ Process } & $\begin{array}{l}\mathrm{H}_{2} \text { Product Purity } \\
\text { (dry basis) }\end{array}$ & $\begin{array}{c}\mathrm{H}_{2} \\
\text { Productivity } \\
\text { (mol/kg) }\end{array}$ & $\begin{array}{c}\mathrm{CH}_{4} \text { to } \mathrm{H}_{2} \\
\text { Conversion } \\
\text { (net) }\end{array}$ & $\begin{array}{l}\text { Steam Purge Duty } \\
\text { (mol. steam per } \\
\text { mol. of } \mathrm{H}_{2} \text { Product) }\end{array}$ \\
\hline $\begin{array}{l}\text { PSSER [Experimental] } \\
6: 1 \mathrm{H}_{2} \mathrm{O}: \mathrm{CH}_{4} \text { Feed } \\
\mathrm{P}=1.78 \text { bar; } \mathrm{T}=490^{\circ} \mathrm{C} \\
\text { Catalyst }=33 \%\end{array}$ & $\begin{array}{l}\mathrm{H}_{2}=94.4 \% \\
\mathrm{CH}_{4}=5.6 \%\end{array}$ & $\begin{array}{l}\mathrm{CO}=<30 \mathrm{ppm} \\
\mathrm{CO}_{2}=40 \mathrm{ppm}\end{array}$ & $73 \%$ & 7.5 \\
\hline $\begin{array}{l}\text { TSSER [Simulated] } \\
4: 1 \mathrm{H}_{2} \mathrm{O}: \mathrm{CH}_{4} \text { Feed } \\
\mathrm{P}=1.5 \text { bar; } \mathrm{T}=490^{\circ} \mathrm{C} \\
\text { Catalyst }=10 \%\end{array}$ & $\begin{array}{l}\mathrm{H}_{2}=99.99 \% \\
\mathrm{CH}_{4}=60 \mathrm{ppm}\end{array}$ & 0.39 & $96.4 \%$ & 5.8 \\
\hline $\mathrm{CO}=10 \mathrm{ppm}$ & & & \\
\hline
\end{tabular}

Table 3. Performance of PSSER and TSSER processes 
Rodrigues and co-workers [46-50] developed a detailed mathematical model of the abovedescribed PSSER process to simulate its performance for producing fuel-cell grade hydrogen. The model simulations were also used to investigate several new operational schemes for improving the performance of the PSSER process (higher conversion and purer $\mathrm{H}_{2}$ ). They included (a) introduction of a purge step with a mixture of $\mathrm{N}_{2}$ and $\mathrm{H}_{2}$ prior to steam purge, and (b) packing different sections (three) of the sorber-reactor using different catalyst-sorbent ratios, the sections at the feed and the product ends being lean in sorbent, and operating the sections at different temperatures, the product -end section having a lower temperature.

\section{Thermal swing sorption enhanced reaction (TSSER) process}

A rapid thermal swing sorption enhanced reaction (TSSER) process for low temperature ( $\left.520-590^{\circ} \mathrm{C}\right) \mathrm{SMR}$ was recently designed by Sircar and co-workers [51 - 53]. The process employed a pair of fixed bed sorber-reactors and it could directly produce fuel-cell grade $\mathrm{H}_{2}$ using $\mathrm{K}_{2} \mathrm{CO}_{3}$ promoted hydrotalcite as the $\mathrm{CO}_{2}$ chemisorbent in the process. The process uses two cyclic steps:

(a) sorption-reaction step where a mixture of $\mathrm{H}_{2} \mathrm{O}$ and $\mathrm{CH}_{4}$ is fed at a pressure of $\sim 1.5-2.0$ bar and a temperature of $\sim 490^{\circ} \mathrm{C}$ into a fixed-bed reactor, which is packed with an admixture of the SMR catalyst and the chemisorbent, and which is pre-heated to $\sim 520$ $590^{\circ} \mathrm{C}$. The effluent from the reactor is fuel-cell grade $\mathrm{H}_{2}$ at feed pressure.

(b) thermal regeneration step where the reactor is simultaneously depressurized to nearambient pressure and counter-currently purged with superheated steam at ambient pressure and at $\sim 520-590^{\circ} \mathrm{C}$, followed by counter-current pressurization of the reactor with steam at $\sim 520-590^{\circ} \mathrm{C}$ to the feed pressure. The reactor effluent for this step is a $\mathrm{CO}_{2}$ rich waste gas.

The key advantages of the proposed TSSER concept over the above-described PSSER process are (a) elimination of the usually expensive, sub-atmospheric steam purge step for desorption of $\mathrm{CO}_{2}$ and, consequently absence of a rotating machine (vacuum pump) in the process, (b) direct supply of the heat of endothermic SMR reaction from the sensible heat stored in the reactor at the start of step (a), (c) higher utilization of the specific $\mathrm{CO}_{2}$ capacity of the chemisorbent in the cycle due to more stringent regeneration, $(\mathrm{d})$ higher conversion of $\mathrm{CH}_{4}$ to $\mathrm{H}_{2}$, (e) higher purity of $\mathrm{H}_{2}$ product, and (f) lower steam purge requirement per unit amount of $\mathrm{H}_{2}$ product.

Figure 16 is a schematic drawing of a two-column embodiment of the concept using a shell and tube design of the sorber-reactors. The tubes will be packed with an admixture of the SMR catalyst and the $\mathrm{CO}_{2}$ chemisorbent. The outside walls of the tubes will be maintained at a constant temperature by cross-flowing super-heated steam in the shell side. Figure 16 clearly exhibits the compactness of the proposed idea compared with the rather involved flow sheet for the conventional SMR-WGS-PSA route of Figure 7. 


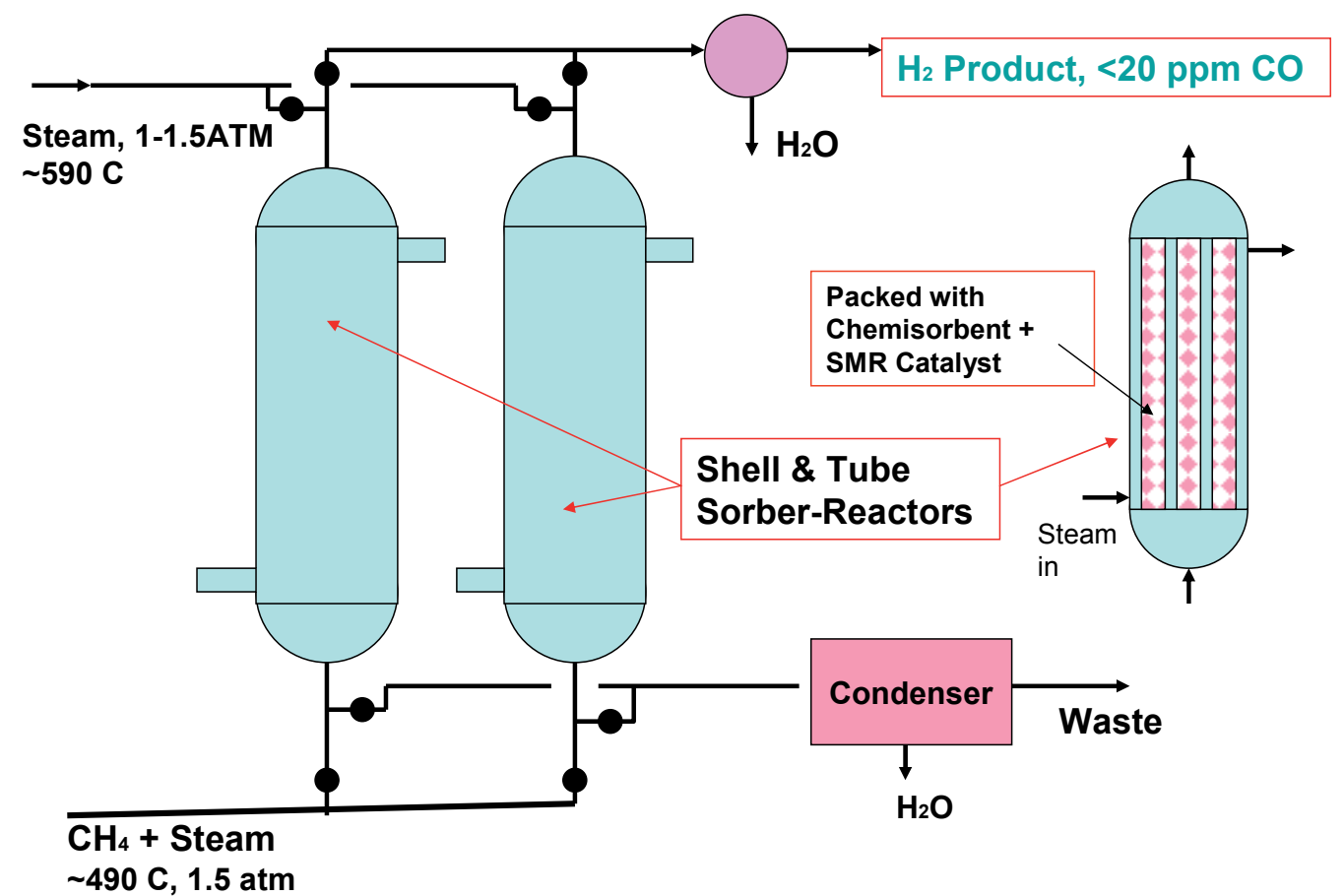

Fig. 16. Schematic drawing of the TSSER concept.

The performance of a TSSER process design [sorber-reactor tubes $\left(\mathrm{I} . \mathrm{D}=2.54 \mathrm{~cm}\right.$, length, $\mathrm{L}_{\mathrm{c}}=$ $250 \mathrm{~cm})$ packed with an admixture of a commercial SMR catalyst $(10 \%)$ and promoted hydrotalcite $(90 \%)$ ] was estimated using a mathematical model which simulated the operation of the individual steps (10 minutes each) of the process. A detailed description of the model can be found elsewhere [51]. The thermodynamic and kinetic properties of the SMR reaction were obtained from the published literature [25, 54], and those for chemisorption of $\mathrm{CO}_{2}$ are given by Figures 12 and 13. The feed gas $\left(\mathrm{H}_{2} \mathrm{O}: \mathrm{CH}_{4}=5: 1, \mathrm{P}=1.5\right.$ atm. $\mathrm{T}=450 \mathrm{C}$ ) was introduced to the sorber- reactor which was preheated to 520,550 , or $590 \mathrm{C}$.

Figure 17 shows an example of the simulation results. The profiles of $\mathrm{CO}_{2}$ loadings are plotted as a function of dimensionless distance $\left(\mathrm{L} / \mathrm{L}_{\mathrm{c}}\right)$ in the sorber- reactor at the ends of steps (a) and (b) of the TSSER process at three different reaction temperatures [53]. The superior performance of the process at higher reaction temperatures is self evident. 


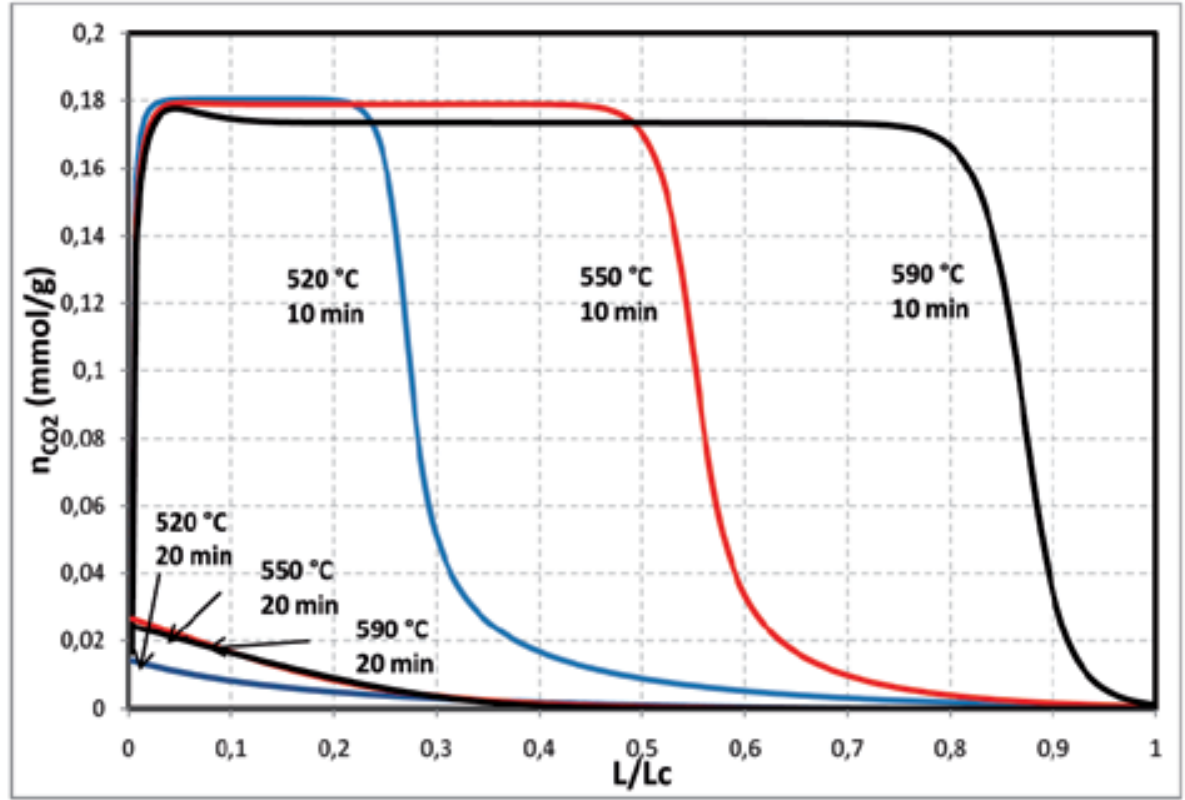

Fig. 17. Simulated profiles of $\mathrm{CO}_{2}$ loadings in sorber-reactor: End of step (a) - solid lines (10 min); end of step (b) - dashed lines (20 min).

Table 4 summarizes the simulation results. It may be seen that the TSSER concept produces fuel cell grade $\mathrm{H}_{2}$ by low temperature SMR with very high $\mathrm{CH}_{4}$ to $\mathrm{H}_{2}$ conversion at all temperatures. The specific $\mathrm{H}_{2}$ productivity (mol. $\mathrm{kg}^{-1}$ of total solid in sorber reactor) however increases and the steam purge duty by the process decreases as the reaction $\mathrm{T}$ is increased from 520 to $590^{\circ} \mathrm{C}$.

It may also be seen from Table 4 that the conversion of $\mathrm{CH}_{4}$ to $\mathrm{H}_{2}$ and the purity of $\mathrm{H}_{2}$ product achieved by the TSSER concept far exceed those governed by the thermodynamics of catalyst-only SMR reaction (Figure 6 and Table 2) at any given temperature. Consequently, the concept permits operation of the SMR reaction at a much reduced temperature without sacrificing product $\mathrm{H}_{2}$ conversion and purity.

\begin{tabular}{|c|c|c|c|c|c|c|}
\hline Reactor Feed & $\begin{array}{c}\text { Reactor } \mathrm{T} \\
\left({ }^{\circ} \mathrm{C}\right)\end{array}$ & $\begin{array}{c}\mathrm{H}_{2} \text { Product } \\
\text { Purity } \\
(\mathrm{ppm})\end{array}$ & $\begin{array}{c}\mathrm{H}_{2} \text { Productivity } \\
\text { (moles/kg of } \\
\text { total solid) }\end{array}$ & $\begin{array}{c}\text { Feed } \mathrm{CH}_{4} \text { to } \\
\text { Product } \mathrm{H}_{2} \\
\text { Conversion } \\
(\%)\end{array}$ & $\begin{array}{c}\text { Steam purge duty for } \\
\text { regeneration in step }(\mathrm{b}) \\
\text { (moles/mole of } \mathrm{H}_{2} \\
\text { product }\end{array}$ \\
\hline $1: 5 \mathrm{CH}_{4}: \mathrm{H}_{2} \mathrm{O}$ & Pressure (Bar) & 590 & $\begin{array}{c}\mathrm{CO}=10 \\
\mathrm{CO}_{2}=13 \\
\mathrm{CH}_{4}=60\end{array}$ & 0.440 & $99.8 \%$ & 7.2 \\
\hline 1.5 & 1.5 & 550 & $\begin{array}{c}\mathrm{CO}=10 \\
\mathrm{CO}_{2}=23 \\
\mathrm{CH}_{4}=129\end{array}$ & 0.296 & $99.5 \%$ & 8.2 \\
\hline $1: 5$ & 1.5 & 520 & $\begin{array}{c}\mathrm{CO}_{2} 10 \\
\mathrm{CO}_{2}=31 \\
\mathrm{CH}_{4}=480\end{array}$ & 0.157 & $99.1 \%$ & 13.3 \\
\hline
\end{tabular}

Table 4. Simulated performances of the TSSER concept 
The model was also used to evaluate the performance of the TSSER process under conditions identical to that used for the PSSER process reported in Table 3. The comparative results given in Table 3 demonstrate the superiority of the TSSER concept (higher $\mathrm{H}_{2}$ purity, higher specific $\mathrm{H}_{2}$ productivity by the catalyst-chemisorbent admixture, and higher $\mathrm{CH}_{4}$ to $\mathrm{H}_{2}$ conversion).

It should be mentioned here that the model was also used to simulate the performance of another rapid TSSER process designed for simultaneous production of fuel cell grade $\mathrm{H}_{2}$ and a compressed $\mathrm{CO}_{2}$ by-product stream to facilitate its sequestration from a synthesis gas produced by gasification of coal [55].

\section{Thermal efficiency of the TSSER concept}

A thermal efficiency for this process was defined as

$$
\eta_{T h}=\frac{L H V_{H 2 \text { Pr oduct }}}{L H V_{N G \text { feed }}+L H V_{N G \text { fuel }}}
$$

where $L H V_{N G \text { feed }}=$ heating value of the natural gas fed into the TSSER unit, $L H V_{N G \text { fuel }}=$ heating value of supplemental fuel for (a) supplying additional heat of SMR reaction, (b) adding additional heat to feed and desorption gas streams, and (c) supplying heat of desorption to the bed for regeneration of the sorbent. Assuming LHV values of 120.1 $\mathrm{MJ} / \mathrm{kg}$ and $47.1 \mathrm{MJ} / \mathrm{kg}$ for $\mathrm{H}_{2}$ and natural gas, respectively, the thermal efficiency of the TSSER process was calculated to be $79.6 \%$. This shows that the process is highly efficient for production of $\mathrm{H}_{2}$ from $\mathrm{CH}_{4}$.

The TSSER process will potentially provide an efficient but relatively simple and compact alternative for direct production of fuel-cell grade hydrogen by low temperature SMR without producing export steam.

Figure 18 is a heat integrated flow diagram of a TSSER concept designed for production of hydrogen for a $250 \mathrm{KW}$ residential PEM fuel cell which requires $\sim 3$ kilo liters of $\mathrm{H}_{2}$ per minute. The system contains two shell and tube sorber-reactors, heat exchangers, make-up heaters and blowers. Each sorber-reactor contains 2665 tubes [2.54 cm ID x $250 \mathrm{~cm}$ long, intra tube void fraction $=0.25$, each packed with $\sim 1.1 \mathrm{~kg}$ of an admixture of the SMR catalyst $(10 \%)$ and $\mathrm{CO}_{2}$ chemisorbent]. The feed (5:1 steam: methane) to the reactor was at $450^{\circ} \mathrm{C}$ and at a pressure of 1.5 bar. The reaction temperature was $590^{\circ} \mathrm{C}$. The cycle time for each step was 10 minutes. The design was based on the simulated performance data of Table 4 .

A first pass estimation of the capital and operating costs $\left(\$ / \mathrm{kg}\right.$ of $\left.\mathrm{H}_{2}\right)$ of the TSSER process for $\mathrm{H}_{2}$ production for a $250 \mathrm{KW}$ residential fuel cell is given in Table 5 which indicates that the cost is very competitive (cost of distributed production from natural gas $\sim \$ 2.5-3.5 / \mathrm{kg}$ of $\left.\mathrm{H}_{2}\right)[56]$. 


\section{Design \& Cost of a TSSER Process for a Residential Fuel Cell}

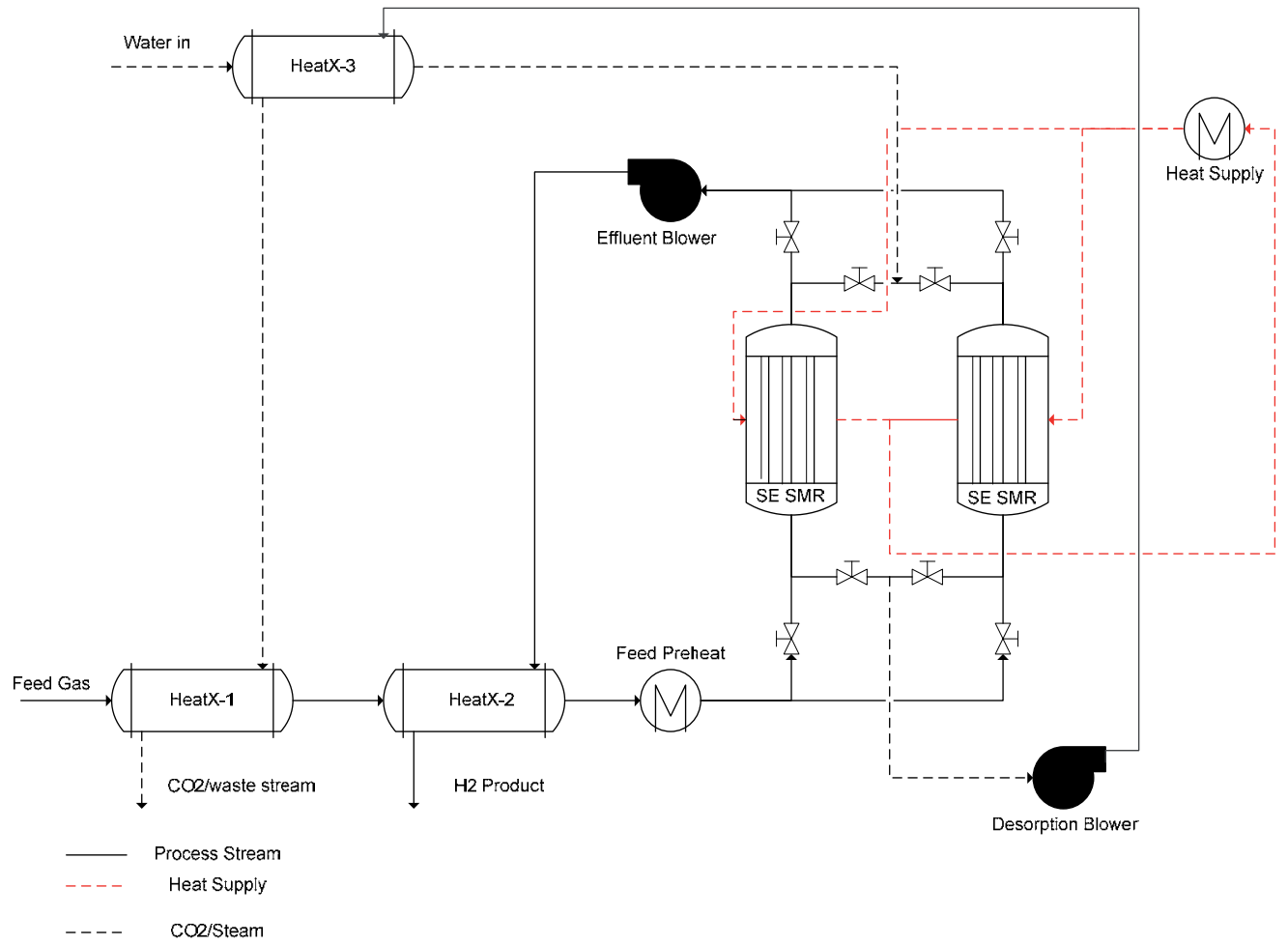

Fig. 18. Tentative flow sheet for a TSSER system supplying $\mathrm{H}_{2}$ to a $250 \mathrm{KW}$ residential PEM fuel cell.

\begin{tabular}{|c|c|}
\hline Capital Costs, $\$ / \mathrm{kg} \mathrm{H}_{2}$ & $250 \mathrm{~kW}$ \\
\hline SER-SMR vessels & 0.13 \\
\hline Over all Vessel dimensions & $\begin{array}{l}5.0^{\prime} \text { Dia. } \\
8.2^{\prime} \mathrm{High}\end{array}$ \\
\hline Blowers & 0.11 \\
\hline Heat Exchangers & 0.02 \\
\hline Sorbent/catalyst & 0.01 \\
\hline Total & 0.27 \\
\hline \multicolumn{2}{|l|}{ Operating costs, $\left(\$ / \mathrm{kg} \mathrm{H}_{2}\right)$} \\
\hline Electricity for blowers & 0.65 \\
\hline Steam consumption & 0.02 \\
\hline Supplemental heat & 0.14 \\
\hline Total & 0.71 \\
\hline
\end{tabular}

Table 5. First pass cost estimation of TSSER process. 


\section{Summary}

Decentralized residential power generation employing a $\mathrm{H}_{2}$ PEM fuel cell requires that essentially $\mathrm{CO}_{x}$ free $\mathrm{H}_{2}$ be produced on site by catalytic steam reforming of piped natural gas and then purifying the product $\mathrm{H}_{2}$ (removal of bulk $\mathrm{CO}_{2}$ and dilute $\mathrm{CO}$ impurities). Currently, it may be achieved by subjecting the reformed gas to water gas shift reaction followed by (a) removal of all impurities by a PSA process or (b) selective oxidation in a catalytic PROX reactor to reduce only the CO impurity below $\sim 10 \mathrm{ppm}$ for use in the fuel cell. The latter approach assumes that the detrimental effect of $\mathrm{CO}_{2}$ on the performance of the fuel cell is minimum. This assumption may not be valid.

A recently developed thermal swing sorption enhanced reaction (TSSER) process scheme can be used to combine reformation, shifting, and purification in a compact, single unit operation for this application. The process permits circumvention of the thermodynamic limits of the SMR reaction and permits direct production of fuel cell grade $\mathrm{H}_{2}$ with high recovery and purity, yet operating the SMR reaction at a lower temperature. Simulated performance of the process, preliminary process design for supplying $\mathrm{H}_{2}$ to a $250 \mathrm{KW}$ fuel cell, and first pass costs are described.

\section{References}

1. Okoda, O., Yokoyama, K, Development of polymer electrolyte fuel cell cogeneration systems for residential applications, Fuel Cells, 1, 72 (2001)

2. Jackson, C., Dudfield, C., Moore, J, PEM Fuel cell technology feature- for small scale stationary power, Intelligent Energy Ltd., Loughborough, UK.

3. Walsh, B., Wichert, R, Fuel cell technology, wbdg.org/resources,fuelcell.php

4. Lasher, S., Zogg, R., Carlson, E., Couch, P., Hooks, M., Roth, K., Brodrick, J, PEM fuel cells for distributed generation, ASHRAE J., pp45-46, (2006).

5. Sinyak, Yu. V., Prospects for hydrogen use in decentralized power and heat supply, Studies on Russian Economic Development, Springer Science, 18, 264-275 (2007).

6. Jean, G. V, Hydrogen fuel cells to power homes, vehicles in Japan, nationaldefensemagazine.org/archive/2008

7. Residential fuel cell heat \& power system, Acumentrics.com/products-fuel-cell-homeenergy.htm

8. Home power hydrogen fuel cells, absak.com/library/small-hydrogen-fuel-cell-generators (2008).

9. Fuel cells come home. Homeenergy.org/archive/hem.dis.anl.gov (1998).

10. Residential PEM fuel cell system,e1ps.tripod.com/fuelcellfuture/id4.html 11.

11. Proton exchange membrane fuel cell, en.wikipedia.org/wiki/Proton_exchange_membrane_fuel_cell

12. The fuel cell, batteryuniversity.com/ parttwo-52.htm

13. Types of fuel cells, Department of energy,

1.eere.energy.gov/hydrogenandfuelcells/fuelcells/fc_types.html

14. Bruijn, F. A., Papageorgopoulos, D. C., Sitters, E. F., Janssen, G. J. M,

The influence of carbon dioxide on PEM fuel cell anodes, J. Power Sources, 110, 117-124 (2002). 
15. Uribe, F., Brosha, E., Garzon, F., MIkkola, M., Pivovar, B., Rockward, T., Valerio, J., Wilson, M, Effect of fuel and air impurities on PEM fuel cell performance, DOE Hydrogen Program Project Report (2005).

16. Auer, E., Freund, A., Lehmann, T, CO-tolerant anode catalyst for PEM fuel cells and a process for its preparation, U.S. Patent 6,007,934 (1999)

17. Lee, S. J., Mukerjee, S., Ticianelli, E. A., McBreen, J, Electrocatalysis of CO tolerance in hydrogen oxidation reaction inPEM fuel cells, Electrochima Acta., 44, 3283-3293 (1999)

18. Yu, H., Hou, Z., Yi, B., Lin, Z, Composite anode for CO tolerance PEM fuel cells, J. Power Sources, 105, 52-57 (2002).

19. Divisek, J., Oetjen, H. F., Peinecke, V., Schmidt, V. M., Stimming, U, Components for PEM fuel cell systems using hydrogen and CO containing fuels, Electrochimica Acta., 43, 3811-3815 (1998).

20. Bayrakceken, A., Turker, L., Eroglu, I, Improvement of carbon dioxide tolerance of PEMFC electrocatalyst by using microwave irradiation technique, Int. J. Hydrogen Energy, 33, 7527-7537 (2008).

21. Tanaka, K. I., Shou, M., He, H., Zhang, C., Lu, D, A CO-tolerant hydrogen fuel cell system designed by combining with an extremely active Pt/CNT catalyst, Catalyst Letters, 127, 148-151 (2009).

22. Farrauto, R., Hwang, S., Shore, L., Ruettinger, W., Lampert, J., Giroux, T., Liu, Y., Ilolinich, $\mathrm{O}$, New material needs for hydrocarbon fuel processing: Generating hydrogen for the PEM fuel cell, Annual Review of Materials Research, 33, 1 - 27 (2003).

23. Why natural gas? Learn about natural gas, foodtechinfo.com/Why_ Gas/Learn_About_Natural_Gas.htm

24. Leiby, S. M, Options for refinery hydrogen, PEP Report No. 212, Process Economics Program, SRI International, Menlo Park, CA. (Feb. 1994).

25. Twigg, M. V., ed, Catalyst Handbook, Wolfe, London (1989).

26. Ghenclu, A. F, Review of fuel processing catalysts for hydrogen production in PEM fuel cell systems, Current Opinion in Solid State and Material Science, 6,389-399 (2002).

27. Avgouropoulos, G., Ioannides, T., Papadopoulos, Ch., Batista, J., Hocevar, S., Matralis, H. K, A comparative study of $\mathrm{PtY}-\mathrm{Al}_{2} \mathrm{O}_{3}, \mathrm{Au} / \mathrm{a}-\mathrm{Fe}_{2} \mathrm{O}_{3}$ and $\mathrm{CuO}-\mathrm{CeO}_{2}$ catalysts for the selective oxidation of carbon monoxide in excess hydrogen, Catalysis Today, 75 , 157-167 (2002).

28. Snytnikov, P. V., Sobyanin, V. A., Belyaev, P., Tsyruinikov, G., Shitova, N. B., Shiyapin, D. A, Selective oxidation of carbon monoxide in excess hydrogen over $\mathrm{Pt}-, \mathrm{Ru}-$ and Pd supported catalysts, Applied Catalysis A: General, 239, 149-156 (2003).

29. Roh, H. S., Potdar, H. S., Jun, K. W., Han, S. Y., Kim, J. W, Low temperature selective CO oxidation in excess of $\mathrm{H}_{2}$ over $\mathrm{Pt} / \mathrm{Ce}-\mathrm{ZrO}_{2}$ catalysts, Catalysis Letters, 93, Nos 3 - 4 (2004).

30. Rosso, I, Antonini, M, Galletti, C, Saracco, G., Specchia, V, Selective CO-oxidation over $\mathrm{Ru}$-based catalysts in $\mathrm{H}_{2}$ rich gas for Fuel cell applications, Topics in Catalysis, 3031, No 1, (2004).

31. Kwak, C., Park, T. J., Suh, D. J, Preferential oxidation of carbon Monoxide in hydrogen rich gas over platinum-cobalt-alumina aerogel catalysts, Chem. Eng. Sci., 60, 12111217 (2005). 
32. Cominos, V., Hessel, V., Hofmann, C, Kolb, G, Ziogas, A, Delsman, E. R, Schouten, J. C, Selective oxidation of carbon monoxide in a Hydrogen-rich fuel cell feed using a catalyst coated, microstructured reactor, Catalysis Today, 110, 140-153 (2005).

33. Suh, D. j., Kwak, C., Kim, J. H., Kwon, S. M., Park, T. J, Removal of carbon monoxide from hydrogen rich fuels by selective low-temperature oxidation over base metal added platinum catalysts, J. Power Sources, 142, 70-74 (2004).

34.Caputo, T., Lisi, L., Pirone, R., Russo, G, Kinetics of preferential oxidation of CO over $\mathrm{CuO} / \mathrm{CeO}_{2}$ catalysts in $\mathrm{H}_{2}$ - rich gases, Ind. Eng. Chem. Res., 46, 6793-6800 (2007).

35. Chen, Z. Y., Liaw, B. J., Chang, W. C., Huang, C. T, Selective oxidation of CO in excess hydrogen over $\mathrm{CuO} / \mathrm{Ce}_{x} \mathrm{Zr}_{1-\mathrm{x}} \mathrm{O}_{2}-\mathrm{Al}_{2} \mathrm{O}_{3}$ catalysts, Int. J. Hydrogen Energy, 32, 45504558 (2007).

36. Siri, G. J., Bertolini, G. R., Ferretti, O. A, Preferential oxidation of $\mathrm{CO}$ in presence of $\mathrm{H}_{2-}$ behavior of $\mathrm{PtSn} / \mathrm{\gamma}-\mathrm{Al}_{2} \mathrm{O}_{3}$ catalysts modified by $\mathrm{K}$ or Ba, Lat. Am. Appl.Res., 37No 4 (2007).

37. Monyanon, S., Pongstabodee, S., Luengnaruemitchai, A, Catalytic activity of Pt$\mathrm{Au} / \mathrm{CeO}_{2}$ catalyst for the preferential oxidation of $\mathrm{CO}$ in $\mathrm{H}_{2}$-rich stream, Journal of Power Sources, 163, 547 - 554 (2006)

38. Sebastian, V., Irusta, S., Mallads, R., Santamaria, J, Selective Oxidation of CO in presence of $\mathrm{H}_{2}, \mathrm{CO}_{2}$ and $\mathrm{H}_{2} \mathrm{O}$ on different zeolite-supported Pt catalysts, Applied Catalysis A; General, 366, 242-251 (2009).

39. Sircar, S., Lee, K.B, (Eds), 'Sorption Enhanced Reaction Concepts for Hydrogen Production: Materials \& Processes', Research Signpost, Trivandrum, Kerala, India (2010).

40. Lee, K. B., Beaver, M. G., Caram, H. S., Sircar, S, Reversible chemisorbents for carbon dioxide and their potential applications, I \& EC Res., 47, 8048-8062 (2008).

41. Harrison, D. P, Sorption Enhanced Hydrogen Production: A review, I \& EC Res., 47, 6486-6501 (2008).

42. Lee, K. B., Verdooren, A., Caram, H.S., Sircar, S, Chemisorption of carbon dioxide on potassium carbonate promoted hydrotalcite, J. Coll. Interface Sci., 308, 30 - 39 (2007).

43. Hufton, J. R., Mayorga, S., Sircar, S, Sorption enhanced reaction process for hydrogen production, AIChE J., 45, 248-256 (1999).

44. Waldron, W. E., Hufton, J. R., Sircar, S, Production of hydrogen by cyclic sorption enhanced reaction process, AIChE J., 47, 1477 - 1479 (2001).

45. Sircar, S., Hufton, J. R., Nataraj, S, Process and apparatus for the production of hydrogen by steam reforming of hydrocarbon, U. S. Patent, 6,103,143 (2000).

46. Xiu, G.H., Soares, J. L., Li, P., Rodrigues, A. E, Simulation of five step one-bed sorption enhanced reaction process, AIChE, J., 48, 2817-2832 (2002).

47. Xiu, G.H., Li, P., Rodrigues, A. E, Sorption enhanced reaction process with reactive regeneration, Chem. Eng. Sci., 57, 3893-3908 (2002).

48. Xiu, G.H., Li, P., Rodrigues, A. E, Adsorption-enhanced steam methane reforming with intra-particle diffusion limitations, Chem. Eng. J., 95, 83-93 (2003).

49. Xiu, G.H., Li, P., Rodrigues, A. E, New generalized strategy for improving sorption enhanced reaction process, Chem. Eng. Sci., 58, 3425-3437 (2003)

50. Xiu, G.H., Li, P., Rodrigues, A. E, Subsection-controlling strategy for improving sorption enhanced reaction process, Chem. Eng. Res. Des., 82, 192-202 (2004). 
51. Lee, K. B., Beaver, M. G., Caram, H. S., Sircar, S, Novel thermal swing sorption enhanced reaction process for hydrogen production by low temperature steam-methane reforming, I \& EC Res., 46,5003-5014 (2007).

52. Lee, K. B., Beaver, M. G., Caram, H. S., Sircar, S, Production of fuel-cell grade hydrogen by thermal swing sorption enhanced reaction concept, Int. J. Hydrogen Energy, 33, 781-790 (2008).

53. Beaver, M. B., Caram, H. S., Sircar, S, Sorption enhanced reaction process for direct production of fuel-cell grade hydrogen by low temperature catalytic steammethane reforming. J. Power Sources, 195, 1998-2002 (2010)

54. Xu, J. G., Froment, G. F, Methane steam reforming, methanation, and water gas shift: I. Intrinsic kinetics, AiChE J., 35, 88-96 (1989).

55. Lee, K. B., Beaver, M. G., Caram, H. S, Sircar, S, Reversible chemisorptions of $\mathrm{CO}_{2}$ : simultaneous production of fuel-cell grade $\mathrm{H}_{2}$ and compressed $\mathrm{CO}_{2}$ from synthesis gas. Adsorption, 13, 385-397 (2007).

56. Agrawal, R., Offutt, M., Ramage, M. P, Hydrogen economy- an opportunity for chemical engineers? AIChE J., 51, 1582- 1589 (2005). 


\title{
Exergy analysis of low and high temperature water gas shift reactor with parabolic concentrating collector
}

\author{
Murat OZTURK \\ Department of Physics, Science-Literature Faculty, Suleyman Demirel University, \\ Cunur Campus, Isparta \\ Turkey
}

\begin{abstract}
Energy is one of the building blocks of modern society. The growth of the modern society has been fueled by cheap, abundant energy resources. Since the Industrial Revolution, the world concentrated on fossil fuels to provide energy needed for running factories, transportation, electricity generation, homes and buildings. In parallel to the increase in the consumption of energy, living standards increased. High living standards of today are owed to the fossil fuels. But, the utilization of fossil fuels in different applications has caused global warming, climate change, melting of ice caps, increase in sea levels, ozone layer depletion, acid rains, and pollution. Nowadays, total worldwide environmental damage adds up to US\$5 trillion a year. On the other hand, fossil fuels are not infinite. World will be out of fossil fuels in the future. Alternatives to the use of non-renewable and polluting fossil fuels have to be investigated. One such alternative is solar energy. Solar energy is the only sources from which we can use more energy than at present, without adding new thermal energy into atmosphere. It may be used in many applications, such as active and passive space heating and cooling, industrial process heating, desalination, water heating, electric generating and solar reactor as a new perspective. Parabolic trough collectors generate thermal energy using solar energy. They are the most deployed type of solar concentrators. Especially, they are very suitable for application of middle temperature solar power systems. Storing of the solar energy is not a good way using the solar energy due to entropy generation process associated with the heat transfer. Instead of that, solar energy can be used to produce hydrogen using solar reactor. Several technologies to produce hydrogen from fossil fuels have already been developed. Although hydrogen itself is clean and has zero emission, its production from fossil fuels with existing technologies is not. It also relies on fossil fuels that no one exactly knows when they will run out. Hydrogen production with renewable energies (e.g., solar, wind, etc.), therefore, can be a viable long-term, may be, an eternal solution. Among renewable energies, solar energy is cost competitive with other conventional energy generation systems in some locations, and is the fastest growing sector. The conventional energy analysis (based on the first law analysis of thermodynamics) does not give the qualitative assessment of the various losses occurring in the components. So
\end{abstract}


exergy analysis (based on the second law analysis thermodynamic) is used to get a clear picture of the various losses quantitatively as well as qualitatively. Exergy is the maximum amount of work that can be obtained if a material or some form of energy is converted to its inert reference state. Also, exergy is the minimum amount of work to be supplied if a material or form of energy has to be produced from the inert reference system. The reference system includes, in addition to physical parameters such as temperature and pressure, references for chemical elements. Exergy analysis of cylindrical parabolic solar reactor is particularly useful in their design. Exergy analysis provides the basis for choosing the operating parameters of the solar reactors. The requirements for greater conversion efficiency and the introduction of new devices have led to the need for improved methods of prediction of design parameters. Performance analysis of cylindrical parabolic reactors through exergy analysis has led the designer to improve the design parameters.

Water Gas Shift (WGS) reaction is a main step in hydrogen and ammonia production. Also, it has been used for detoxification of town gas. On the basis of thermodynamic and kinetic considerations, the WGS reaction is usually performed by two stages, first at a hightemperature stage, in the range of 593-723 K, and the other low-temperature stage, in the range of 473-523 K. The high-temperature water gas shift (HT-WGS) reaction uses $\mathrm{Fe}_{2} \mathrm{O}_{3} / \mathrm{Cr}_{2} \mathrm{O}_{3}$ as catalyst, while the low-temperature water gas shift (LT-WGS) reaction is normally performed on $\mathrm{CuO} / \mathrm{ZnO} / \mathrm{Al}_{2} \mathrm{O}_{3}$ catalyst. By using parabolic concentrating collectors which are simple technology, $\mathrm{H}_{2}$ and $\mathrm{CO}_{2}$ can be produced by applying water-gas shift reaction with $\mathrm{H}_{2} \mathrm{O}$ and $\mathrm{CO}$ which emitted to atmosphere by any reaction under $475 \mathrm{~K}$. Produced hydrogen can be used in energy generation systems or chemical industries while carbon dioxide can be used in green houses or carbon industry. The WGS reaction has the advantage of producing long term storable energy carriers from solar energy. This conversion also enables solar energy transportation from the sunbelt to remote population centers.

This chapter presents a second law analysis based on an exergy concept for the simple solar cylindrical parabolic reactor for better evaluation. Also this paper presents the methodology of detailed exergy analysis of the solar cylindrical parabolic reactor and distribution of the exergy losses for HT-WGS, between 593 and $723 \mathrm{~K}$ and LT-WGS, between 473-523 K. Exergy analysis of the solar energy conversion processes help to define the optimum system that covers the imposed thermal and economical constraints. It is found that the main exergy loss takes place at the collector-receiver assembly. The analysis and results in this study can be used for evaluating the component irreversibilities of solar cylindrical parabolic reactor. Exergy analysis of solar reactor systems provides more meaningful and useful information than energy analysis for researchers and wind energy companies before making decisions .

Keywords: Solar reactor, water-gas shift reaction, exergy analysis, cylindrical parabolic collector, solar energy.

\section{Introduction}

Energy is defined as the capability of doing work in thermodynamic. Energy constitutes one of the main inputs for sustainable economic and social development. Energy consumption is increasing simultaneously with increasing industrialization, population, urbanization, and technological improvement (Spalding et al., 2005). In order to achieve a sustainable development, which supports economic and social development, energy supply and 
demand at minimum amount and cost with the minimum destructive effect on the environment should be set as the main objective. Building an economy based upon a clean, renewable fuel is critical to securing a livable planet for future human generations.

There are a lot of energy sources in the world, such as coal, petroleum, natural gas, solar energy, wind, biomass, hydropower, etc. These sources of course, can be classified in several ways. According to the United Nations classification, primary energy sources are classified as renewable and non-renewable. Renewable energy is defined as an energy from the supply of which is partly or wholly regenerated in the course of the annual solar cycle and/or the supply which is considered unlimited for all intents and purposes. For example, solar, wind, biomass, hydropower, tidal power, wave power, etc. However, non-renewable energy is defined as energy form, the supply of which can not be regenerated such as coal, petroleum, natural gas, etc. It should be pointed out that, non-renewable energy sources are limited, besides they are pollutant for environment. Therefore, renewable energy sources are good alternatives to the non-renewable energy sources (Dincer \& Mark, 1999). Compared to the non-renewable energy sources, others are much clean, bides, inexpensive. Some of the renewable energy sources require considerably much amount of money for installation but they are clean sources (e.g. hydropower, geothermal energy etc.). It is obvious that, solar energy being inexpensive and clean energy sources compared to the non-renewable energy sources seems to hold much promise for the future. One of the reasons for the use of solar energy is to reduce the environmental pollution and cost for its control.

Today, renewable energies supply $14 \%$ of the world primary energy demand. The primary source of all renewable energies except geothermal energy is solar radiation. The amount of solar energy striking the earth's surface is $5.4 \times 10^{24} \mathrm{~J}$ per year (Sorensen, 2004). The world primary energy demand is approximated to be 11000 Mtoe (million ton of equivalent oil) in 2006 (IEA, 2004). Thus the solar energy intercepted by the earth is approximately 11500 times greater than the world's total primary energy demand in the year 2006. Solar energy should be transformed into usable energy forms in order to be utilized. Solar energy is mainly exploited in two ways. It can be converted to either heat or electricity. Converting solar energy to heat is possible by using solar thermal energy technologies. Converting solar energy directly to electricity is achievable by using photovoltaic cells (PV). Also there are indirect ways of converting solar energy into electricity by using solar thermal energy technologies. Energy (heat or electricity) obtained from solar energy technologies can be used for many purposes including the following: drying, heating, cooking, cooling, desalination (Kalogirou, 1997), generating electricity (Mills, 2004), (Trieb, Lagni $\beta \&$ Klai $\beta$, 1997) and chemical reactor.

Key advantages of solar thermal systems are as follows (European Solar Thermal Industry Federation [ESTIF];

- reduces the dependency on imported fuels

- improves the diversity of energy supply

- saves scarce natural resources

- saves $\mathrm{CO}_{2}$ emissions at very low costs

- curbs urban air pollution

- is proven and reliable

- is immediately available

- owners of systems save substantially on their heating/cooling bills

- creates local jobs and stimulates the local economy

- inexhaustible 
Solar radiation is converted into thermal energy in the focus of solar thermal concentrating systems. These systems are classified by their focus geometry as either point-focus concentrators (central receiver systems and parabolic dishes) or line-focus concentrators (parabolic-trough collectors (PTCs) and linear Fresnel collectors). PTCs focus direct solar radiation onto a focal line on the collector axis. A receiver tube with a fluid flowing inside that absorbs concentrated solar energy from the tube walls and raises its enthalpy is installed in this focal line. The collector is provided with one-axis solar tracking to ensure that the solar beam falls parallel to its axis. PTCs can only use direct solar radiation, called beam radiation or Direct Normal Irradiance (DNI), i.e., the fraction of solar radiation which is not deviated by clouds, fumes or dust in the atmosphere and that reaches the Earth's surface as a parallel beam.

PTC applications can be divided into two main groups. The first and most important is Concentrated Solar Power (CSP) plants. There are currently several commercial collectors for such applications that have been successfully tested under real operating conditions. Typical aperture widths are about $6 \mathrm{~m}$, total lengths are from 100 to $150 \mathrm{~m}$ and geometrical concentrating ratios are between 20 and 30 . Temperatures are from 300 to $400{ }^{\circ} \mathrm{C}$. CSP plants with PTCs are connected to steam power cycles both directly and indirectly. Although the most famous example of CSP plants is the SEGS plants in the United States, a number of projects are currently under development or construction worldwide.

The other group of applications requires temperatures between 100 and $250{ }^{\circ} \mathrm{C}$. These applications are mainly industrial process heat (IPH), low-temperature heat demand with high consumption rates (domestic hot water, DHW, space heating and swimming pool heating) and heat-driven refrigeration and cooling. Typical aperture widths are between 1 and $3 \mathrm{~m}$, total lengths vary between 2 and $10 \mathrm{~m}$ and geometrical concentrating ratios are between 15 and 20.

\section{Availability of Solar Energy}

The sun's energy is created in the interior regions as a result of a continuous fusion reaction, a process in which four hydrogen protons are combined to form one helium atom by releasing energy. Almost $90 \%$ of this energy is generated in the region 0.23 times the radius of the sun and then transferred by radiation up to a distance of about $0.7 \mathrm{R}$ (where $\mathrm{R}$ is the radius of the sun) from the center. Outside this region there is the convective zone where the temperature is in the range of $6000 \mathrm{~K}$. The energy created in the interiors is dissipated by radiation from the outer surface at an effective temperature of about $5762 \mathrm{~K}$ into space. Thus, the sun with its radius $6.9 \times 10^{8} \mathrm{~m}$ and mass $1.991 \times 10^{30} \mathrm{~kg}$ is almost an inexhaustable sources of energy for the earth. The radiation emitted by the sun propagates through space with a velocity of $3 \times 10^{8} \mathrm{~m} / \mathrm{s}$ and takes about 8 minutes to travel the average distance of $1.5 \times 10^{11} \mathrm{~m}$ between the earth and the sun to reach the earth's atmosphere.

\subsection{Extraterrestrial Solar Radiation}

The intensity of solar radiation incident per unit area exposed normally to the sun's rays at the average sun-earth distance (i.e., $1.5 \times 10^{11} \mathrm{~m}$ ), measured outside the earth's atmosphere, is called the solar constant, $\mathrm{I}_{\mathrm{sc}}$. The currently accepted value of this constant, given in different units, is $1353 \mathrm{~W} / \mathrm{m}^{2}, 429.2 \mathrm{Btu} /\left(\mathrm{ft}^{2} . \mathrm{h}\right), 4871 \mathrm{KJ} /\left(\mathrm{m}^{2} \mathrm{~h}\right)$ and $1.937 \mathrm{cal} /\left(\mathrm{cm}^{2} . \mathrm{min}\right)$. 
The effective temperature of the sun's surface $\left(T_{s}\right)$ can be determined from utilizing the value of the solar constant in the fourth power black-body radiation law (Tiwari, 2003).

$$
q=\left(\frac{r}{R}\right)^{2} \sigma T_{s}^{4}
$$

where $q$ is the radiative flux normal to the sun's beam outside the earth's atmosphere based on the mean earth-sun distance, $1353 \mathrm{~W} / \mathrm{m}^{2} ; \mathrm{r}$ is the radius of the solar disc, $6.9598 \times 10^{8} \mathrm{~m}$; $\mathrm{R}$ is the mean earth-sun distance, $1.496 \times 10^{11} \mathrm{~m} ; \sigma$ is Stefan-Boltzmann constant, $5.6697 \times 10^{-8}$ $\mathrm{W} / \mathrm{m}^{2} \mathrm{~K}^{4}$. Then, the effective temperature of the sun's surface is determined as, $\mathrm{T}_{\mathrm{s}}=5762 \mathrm{~K}$. As the earth moves about the sun in a slightly elliptical orbit, the distance between the earth and the sun varies from the $98.3 \%$ of the mean distance when the earth is closest to the sun to the $101.7 \%$ of the mean distance when the earth-sun distance is maximum. It is apparent from Equation (1) that for the fixed value of $\mathrm{T}_{\mathrm{s}}$, the extraterrestrial radiation varies inversely as the square of the earth-sun distance. The intensity of extraterrestrial radiation varies approximately by $\pm 3.4 \%$ about the solar constant (Saying, 1979). That is, from a maximum value of $1399 \mathrm{~W} / \mathrm{m}^{2}$ on December 21 to a minimum of $1310 \mathrm{~W} / \mathrm{m}^{2}$ on June 21 . To illustrate the absorption of solar radiation by ozone, oxygen, water vapor and carbon dioxide, the solar spectrum measured on the ground level for an air mass $m=1$, a clear atmosphere, a reducible water of $20 \mathrm{~mm}$ and the equivalent path of ozone $3.4 \mathrm{~mm}$ at normal pressure and temperature are given in Figure 1.

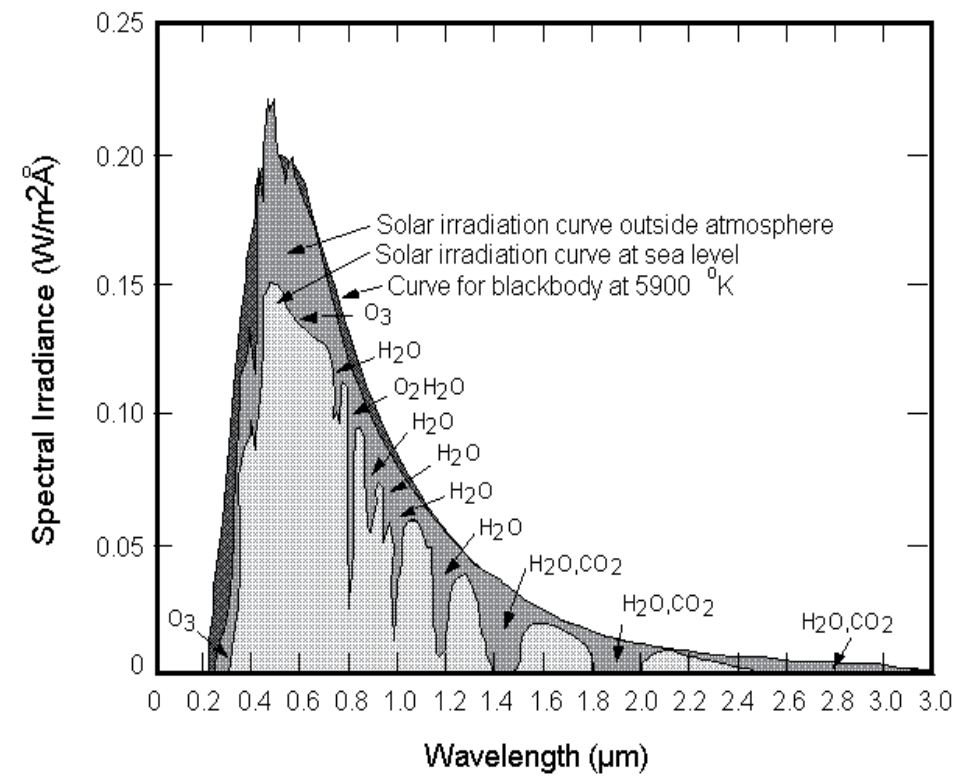

Fig. 1. Spectral distribution of extraterrestrial solar radiation based on the solar constant (ISC $\left.=1353 \mathrm{~W} / \mathrm{m}^{2}\right)$, (Goswami et al., 1999) 


\subsection{Atmospheric Attenuation Effect}

In passing through the earth's atmosphere the solar radiation is absorbed and scattered by the atmospheric material, approximately $99 \%$ of which is contained within a distance of about $30 \mathrm{~km}$ from the earth's surface. As a result of atmospheric scattering, some of the solar radiation is reflected back into the outer space, while some of the scattered radiation reaches the earth's surface from all directions over the sky as diffuse radiation. The part of the solar radiation that is neither scattered nor absorbed by the atmosphere reaches the earth's surface as beam, which is called the direct radiation. The direct component of the intensity solar radiation is represented by the symbol, $I_{D}$ and the diffuse term by $I_{d}$.

The solar radiation from the sun arrives to the earth with a $1 / 2^{0}$ cone. When passing through a turbid atmosphere with large aerosol there is a broadening of the angular cone through which the sun's rays arrive, caused by forward scattering. This is referred to as circumsolar radiation, ICS. Under turbid sky conditions a significant amount of energy is translated into a cone of near $5^{0}$ about the sun's center. This radiation, which has the same general angular time variations as the primary direct component from the sun, is focusable with some types of collectors. On the other hand, this energy is not all available to highly concentrating collectors, such as parabolic trough collectors.

The extent of absorption and scattering of radiation by the atmosphere depends on the length of the atmospheric path traversed by the sun's beam and the composition of the atmosphere. The atmospheric path traversed by the beam is shortest if the sun is directly overhead (i.e., the sun is at zenith). In general, the beam follows an inclined path in reaching the earth's surface. To take into account the effect of inclination on the length of the path traversed by the sun's ray through the atmosphere, a dimensionless quantity, $\mathrm{m}$, called the air mass is defined as

$$
m=\frac{m_{a}}{m_{a, e x}}
$$

where $m_{a}$ is mass of the atmosphere in the actual path of the beam, $m_{a, e x}$ is mass of atmosphere which would exist if the sun were directly overhead. Clearly if $\mathrm{m}$ is equal to 1 , corresponds to the case when the sun is directly overhead and if $m$ is equal to 0 , the case of no atmosphere (Goswami et al., 1999). For most practical purposes the air mass is approximated by a flat earth model and related to the solar altitude angle, $\beta$ and the solar zenith angle $\psi$ by the following simple relation.

$$
m \cong \frac{1}{\sin \beta}=\frac{1}{\cos \psi}
$$

A more accurate representation of $\mathrm{m}$ is obtainable by making use of the spherical earth model; the resulting expression is given as

$$
m \cong \frac{L}{H}=\left[1+2 \eta+(\eta \cos \psi)^{2}\right]^{1 / 2}-\eta \cos \psi
$$


where $\mathrm{L}$ is path of the beam through the atmosphere, $\mathrm{H}$ is thickness of atmosphere $\left(1.524 \times 10^{5} \mathrm{~m}\right), \eta$ is $R / H$ and is 41.8 if radius of the earth $(\mathrm{R})$ is equal to $0.6372 \times 10^{7} \mathrm{~m}$. The absorption and scattering of solar radiation by the atmospheric materials take place in a selective manner. The ozone, water vapor, carbon dioxide, nitrogen, oxygen, aerosols or dust particles, water droplets in the clouds and other constituents of the atmosphere all participate in the attenuation of solar radiation by absorption and/or scattering (Kreider andKreith, 1975).

The ozone in the atmosphere is concentrated in a layer between 10 to $30 \mathrm{~km}$ above the earth's surface, with the maximum concentration occurring between about 25 to $30 \mathrm{~km}$. Ozone is a very strong absorber of solar radiation in the ultraviolet range between 0.2 to 0.29 $\mu \mathrm{m}$, relatively absorber in the range between 0.29 to $0.34 \mu \mathrm{m}$ and has a weak absorption in the range 0.44 to $0.7 \mu \mathrm{m}$. There is a variation in the concentration and total content of ozone both geographically and seasonally. The total ozone content may vary from $3.8 \mathrm{~mm}$ of ozone (i.e., at normal temperature and pressure) at upper latitudes to about $2.4 \mathrm{~mm}$ over the equator. Also, the total amount in the upper latitudes may vary from 3.0 to $5.0 \mathrm{~mm}$ (Bayazitoglu, 1986).

The reducible water content of the atmosphere varies from a low value of $2 \mathrm{~mm}$ (i.e., the height of water in $\mathrm{mm}$ if the water vapor in the air column above the ground per unit area were condensed into liquid) to about $50 \mathrm{~mm}$ for hot, very humid summer days without cloud formation. The water vapor in the atmosphere absorbs solar radiation strongly in wavelengths beyond about $2.3 \mu \mathrm{m}$. In the range of wavelengths between 0.7 to $2.3 \mu \mathrm{m}$, there are several absorption bands.

The oxygen absorption of solar radiation occurs in a very narrow line centered at $0.762 \mu \mathrm{m}$. Carbon dioxide is also, a strong absorber of solar radiation in wavelengths beyond about 2.2 $\mu \mathrm{m}$ and has band absorption at selective wavelengths in the range from 0.7 to $2.2 \mu \mathrm{m}$.

The scattering of solar radiation by air molecules, water droplets contained in the clouds, and aerosols or dust particles also attenuates the direct solar radiation passing through the atmosphere. The air molecules (i.e., nitrogen, oxygen and other constituents) scatter radiation in very short wavelengths comparable to the size of molecules; such scattering is called the Rayleigh scattering. Water droplets, aerosols and other atmospheric turbidity scatter radiation in wavelengths comparable to the diameters of such particles. Therefore, an increase in the turbidity or dust loading of the atmosphere and/or the coverage of the sky by clouds increases the scattering of solar radiation. As a result of scattering, part of the direct radiation is converted into diffuse radiation. The higher the turbidity and cloud coverage, the larger is the scattering of radiation in the long wavelengths, which in turn causes the whiteness of the sky.

The atmospheric dust loading which has even smaller percentage contribution by weight than water drops, can particularly change the direct solar radiation. The atmospheric dust loading varies over a range of several decades as a result largely of volcanic action. The solar radiation, first, passes through an upper dust layer from 15 to $25 \mathrm{~km}$, and later enters into a lower layer of dust and water vapor in the 0 to $3 \mathrm{~km}$ region. 


\section{Estimation of Solar Radiation Data}

\subsubsection{Hourly Total Radiation on a Horizontal Surface}

\subsubsection{Extraterrestrial Radiation}

The radiation that would be received in the absence of the atmosphere is called extraterrestrial radiation. It can be calculated between hour angles $1 w$ and $2 w$ as follows in $\mathrm{J} / \mathrm{m}^{2}$ (Duffie and Beckman, 1991):

$$
\begin{aligned}
I_{o}= & \frac{12 \cdot 3600}{\pi} \cdot G_{s c} \cdot\left(1+0.033 \cdot \cos \frac{360 \cdot n}{365}\right) x \\
& {\left[\cos L \cdot \cos D\left(\sin w_{2}-\sin w_{1}\right)+\frac{\pi \cdot\left(w_{2}-w_{1}\right)}{180} \cdot \sin L \cdot \sin D\right] }
\end{aligned}
$$

where $G_{s c}$ is solar constant in the value of $1367 \mathrm{~W} / \mathrm{m}^{2}, n$ is the number of day in a year $(1 \leq n \leq 365)$, $\mathrm{L}$ is latitude of the location, $\mathrm{D}$ is the declination angle, $\mathrm{w}$ is the hour angle and is the angle between the longitude of the considered location and the line connecting the center of the earth. The hour angle is zero at local solar noon and changes by $15^{\circ}$ per hour $(360 / 24)$ for earlier or later than noon. It has positive sign for afternoon hours, negative sign for morning hours.

The calculation of the length of a day is necessary to determine the solar gain for hourly basis. It enables to know the sunrise and sunset hours for a particular day. Hour angle at sunset can be determined by:

$$
w_{s}=\arccos (-\tan L \cdot \tan D)
$$

and the length of the day (the number of daylight hours) is expressed as follows:

$$
N=\frac{2}{15} \cdot w_{s}
$$

\subsubsection{Estimation of Hourly Radiation from Daily Data}

The calculation of the performance for a system in short-time bases makes necessary the use of daily solar radiation data. Thus, daily radiation or monthly average daily radiation by meteorological data can be used to calculate the hourly radiation. Statistical studies have lead to $r_{t}$ ratio, the ratio of hourly total to daily total radiation (Tiwari, 2003).

$$
r_{t}=\frac{I}{H}=\frac{\pi}{24}(a+b \cdot \cos w) \cdot \frac{\cos w-\cos w_{s}}{\sin w_{s}-\frac{\pi \cdot w_{s}}{180} \cdot \cos w_{s}}
$$


where $w$ is the hour angle in degrees for the time in question. The coefficients $a$ and $b$ are given by:

$$
\begin{gathered}
a=0.409+0.5016 \cdot \sin \left(w_{s}-60\right) \\
b=0.6609+0.4767 \cdot \sin \left(w_{s}-60\right)
\end{gathered}
$$

\subsubsection{Beam and Diffuse Component of Hourly Radiation}

The fraction hourly diffuse radiation on a horizontal surface can be expressed by the Erbs correlation (Duffie and Beckman, 1991):

$$
\frac{I_{d}}{I}=\left\{\begin{array}{lll}
1.0-0.09 k_{T} & \text { for } & k_{T} \leq 0.22 \\
\left(\begin{array}{ll}
0.9511-0.1604 . k_{T}+4.388 . k_{T}^{2} \\
-16.638 . k_{T}^{3}+12.336 . k_{T}^{4}
\end{array}\right) & \text { for } & 0.22 \prec k_{T} \leq 0.80 \\
0.165 & \text { for } & k_{T} \succ 0.80
\end{array}\right.
$$

where $k T$ is the hourly clearness index and is expressed as a function of the extraterrestrial radiation as follows:

$$
k_{T}=\frac{I}{I_{o}}
$$

Consequently, hourly beam radiation on a horizontal plane can be written by using the hourly diffuse and the total radiation data as follows:

$$
I_{b}=I-I_{d}
$$

\subsubsection{Hourly Total Radiation on a Tilted Surface}

One of the most important factors to gain the maximum available solar radiation for a certain season or month is the tilt angle. There are several suggestions on the collector tilt angle as dependent on the latitude of the place where the collector is located. It will be make a seasonal suggestion; for summer period $\mathrm{T}=\mathrm{L}-15$, for winter period $\mathrm{T}=\mathrm{L}+15$ and for whole year period $\mathrm{T}=\mathrm{L}$.

It is necessary to define the ratio of total radiation on the tilted surface to that on the horizontal surface $R$ :

$$
R=\frac{I_{T}}{I}
$$

where $\mathrm{I}_{\mathrm{T}}$ is total radiation on a tilted surface and $\mathrm{I}$ is total radiation on a horizontal surface. Similar for beam radiation

$$
R_{b}=\frac{I_{b, t s}}{I_{b, h s}}
$$


where $I_{b, t s}$ is beam radiation on a tilted surface and $I_{b, h s}$ is beam radiation on a horizontal surface. The ratio of beam radiation on a tilted surface to that on a horizontal surface can also be determined by the other equation for the northern hemisphere (Duffie and Beckman, 1991):

$$
R_{b}=\frac{\cos (L-T) \cdot \cos D \cdot \cos w+\sin (L-T) \cdot \sin D}{\cos L \cdot \cos D \cdot \cos w+\sin L \cdot \sin D}
$$

A tilted surface also receives solar radiation reflected from the ground and other surroundings. By using a simple isotropic diffuse model, that is the assumption of that the combination of diffuse and ground reflected radiation is isotropic, total solar radiation on a tilted surface can be calculated as (Saying, 1979):

$$
I_{T}=I_{b} \cdot R_{b}+I_{d} \cdot\left(\frac{1+\cos T}{2}\right)+I \cdot \rho_{g} \cdot\left(\frac{1-\cos T}{2}\right)
$$

where $(1+\cos T) / 2$ term is the view factor to the sky, $(1-\cos T) / 2$ term is the view factor to ground for tilted surface and $\rho_{g}$ is the diffuse reflectance for the surroundings.

\section{Parabolic Trough Solar Collector}

Parabolic trough technology has proven to be the most mature and lowest cost solar thermal technology available today (Price et al., 2002) and are efficiently employed for high temperature (300-400 $\circ$ C) without any serious degradation in the efficiency. One of the major advantages of parabolic trough collector is the low-pressure drop associated with the working fluid when it passes through a straight absorber/receiver tube. The receiver is an important component for solar energy collection and subsequent transformation. Conventional line-focusing receiver designs incorporate transparent enclosure and selective surfaces to reduce convection and radiation losses. The thermal losses from the receiver of a concentrating solar collector significant influence the performance of the collector system under high temperature operation. Investigation of heat loss from the receiver and heat transfer from the receiver to the working fluid are very important in determining the performance of solar parabolic trough collector. The parabolic solar concentrator has three main parts, namely;

- Absorber

- Glass Envelope

- Reflector

\subsection{Absorber}

The selective surface is necessary if the losses are to be saved. There is a considerable difference between the absorptivities of absorber surface with and without a special coating. The absorber tube is coated with a spectrally selective material to maximize solar absorption and minimize thermal emission from its surface. The absorptance and emittance of some type of coating are listed in Table 1. 


\begin{tabular}{|l|c|c|c|}
\hline Type of coating & $\begin{array}{c}\text { Absorptivity } \\
(\alpha)\end{array}$ & $\begin{array}{c}\text { Emissivity } \\
(\varepsilon)\end{array}$ & $\begin{array}{c}\text { Ratio } \\
(\alpha / \varepsilon)\end{array}$ \\
\hline Black nickel on galvanized steel & 0.89 & 0.12 & 7.42 \\
\hline Black chromium on duty nickel & 0.92 & 0.085 & 11 \\
\hline $\begin{array}{l}\text { Black nickel (Zn or Ni oxides and sulfur on } \\
\text { bright nickel) }\end{array}$ & 0.93 & 0.11 & 8.46 \\
\hline Black nickel & 0.88 & 0.066 & 13.3 \\
\hline Nextel black paint & 0.97 & 0.97 & 1 \\
\hline PbS (on Al) & 0.89 & 0.20 & 4.45 \\
\hline CuO (on Al) & 0.85 & 0.11 & 7.23 \\
\hline Ebanol C on copper & 0.91 & 0.15 & 5.69 \\
\hline Stainless steel, 16\% Cr, heated 3 hr at 600 ${ }^{\circ} \mathrm{C}$ & 0.75 & 0.10 & 7.5 \\
\hline Aluminium treated with $\mathrm{KMnO}_{4}$ & 0.80 & 0.35 & 2.29 \\
\hline Platinum black & 0.95 & 0.91 & 1.04 \\
\hline
\end{tabular}

Table 1. Absorptivity emissivity ratio for some coatings (Saying, 1979)

\subsection{Glass Cover}

A glass envelope was put around the tubular absorber to decrease the losses to the surroundings. This glass forms a gap between the absorber and itself. As a result, the gaps acts as insulation and reduce the convective losses. Surely, it will decrease the convective losses further if air in this gap is evacuated by a vacuum pump. Type of the glass is an important factor affecting the percent of radiation transmitted to the absorber. The reason of using pyrex can be explained as the behavior of the glass below 2.5 microns. Pyrex glass can transmit almost $91 \%$ of the incident (short wave) radiation while not allowing long wave radiation emitted by the absorber. Some of the common glazing materials are given in Table 2 .

\begin{tabular}{|l|c|c|c|}
\hline Glass & $\begin{array}{c}\text { Transmissivity } \\
(\tau)\end{array}$ & $\begin{array}{c}\text { Absorptivity } \\
(\alpha)\end{array}$ & $\begin{array}{c}\text { Reflectivity } \\
(\rho)\end{array}$ \\
\hline High transparent pyrex & 0.90 & 0.02 & 0.08 \\
\hline Common window glass & 0.87 & 0.04 & 0.09 \\
\hline Regular plate $(1 / 4$ inc) & 0.77 & 0.16 & 0.07 \\
\hline Heat absorbing plate $(1 / 4$ inc) & 0.41 & 0.53 & 0.06 \\
\hline Double window glass & 0.76 & $0.04+0.04$ & - \\
\hline Double regular plate & 0.60 & $0.07+0.10$ & - \\
\hline
\end{tabular}

Table 2. Transmissivity, absorptivity and reflectivity of glazing materials (Saying, 1979)

\subsection{Reflector}

The reflector is one of the most important components of the parabolic solar concentrator. Reflectors can be situated at an optimum angle to gain the greatest possible level of sunlight that can be achieved onto the panel. This idea of using this type of reflector is a lot simpler and less complicated than the existing concentrators, for example the parabolic concentrator. In Table 3, some of the reflectors are given with their reflectivity values. 


\begin{tabular}{|l|l|}
\hline Materials & Reflectance \\
\hline Silver (unstable as front surface mirror) & $0.94 \pm 0.02$ \\
\hline Gold & $0.76 \pm 0.03$ \\
\hline Aluminized acrylic, second surface & 0.86 \\
\hline Various aluminum surfaces-range & $0.82-0.92$ \\
\hline Copper & 0.75 \\
\hline Back-silvered water-white plate glass & 0.88 \\
\hline Aluminized type-C Mylar (from Mylar side) & 0.76 \\
\hline
\end{tabular}

Table 3. Solar reflectance values for reflector materials (Goswami et al., 1999)

\section{Water-Gas Shift (WGS) Reaction}

The water-gas shift (WGS) reaction is a main step in hydrogen and ammonia production. It has been used for detoxification of town gas (Kodama, 2003). On the basis of thermodynamic and kinetic considerations, the WGS reaction is usually performed two stages. First at a high-temperature stage is the range of $320-450{ }^{\circ} \mathrm{C}$, and the other low temperature stage is the range of $200-250^{\circ} \mathrm{C}$ (Eskin, 1999). The high temperature shift (HTS) reaction uses $\mathrm{Fe}_{2} \mathrm{O}_{3} / \mathrm{Cr}_{2} \mathrm{O}_{3}$ as catalyst, while the low-temperature shift (LTS) reaction is normally performed on $\mathrm{CuO} / \mathrm{ZnO} / \mathrm{Al}_{2} \mathrm{O}_{3}$ catalyst (Kodama, 2003).

Recently, the renewed interest in the removal of CO by the WGS reaction has grown significantly because of the increasing attention to pure hydrogen production for its use in fuel cell (Newsome, 1980). The WGS reaction,

$$
\mathrm{CO}+\mathrm{H}_{2} \mathrm{O} \rightarrow \mathrm{CO}_{2}+\mathrm{H}_{2} ; \Delta \mathrm{H}_{298}=-41 \mathrm{~kJ} / \mathrm{mol}
$$

is limited by its thermodynamic equilibrium.

\section{The model of solar reactor}

The simple solar reactor arrangement is schematically shown in Figure 2 some typical properties used in the following illustration are shown in it. This solar reactor system with the use of solar energy consists of two subsystems: the parabolic through solar collector subsystem and WGS chemical reactor, reformer. The cold air enters at a temperature of $200{ }^{\circ} \mathrm{C}$ and exists at a temperature of $600{ }^{\circ} \mathrm{C}$. The hot air enters the reformer where it heats up $\mathrm{CO}$ and $\mathrm{H}_{2} \mathrm{O}$ at a temperature of $350{ }^{\circ} \mathrm{C}$. So that, WGS reaction occurs at this temperature in the reformer. 


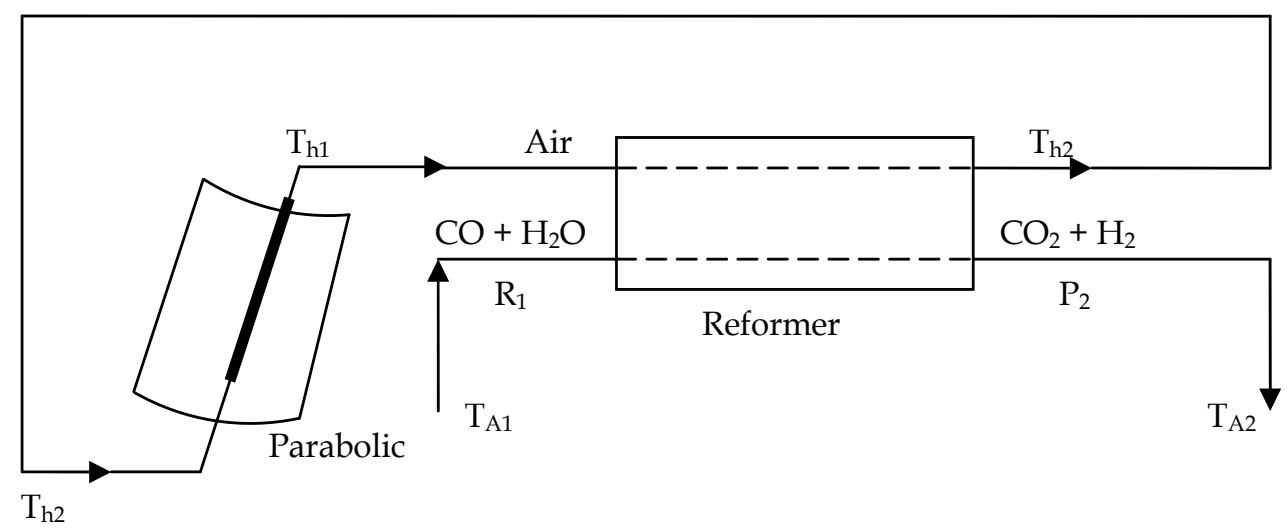

Fig. 2. WGS Chemical reactor

\section{The Theory of Exergy}

Exergy as a concept emerged as corollary to the second law of thermodynamics and can be expressed simply as the amount of available energy a system possesses with respect to a specified reference level. This reference level is often taken to be that of the environment. When taken as such, the exergy of a system represents the maximum amount of work that can be extracted from the system if it were allowed to completely return to equilibrium with the environment in a reversible manner. Conversely, looking at it from the opposite vantage, exergy is a measured of the minimum amount of energy required to create a given system from materials in equilibrium with the environment.

While its rigorous definition is based upon the reversible work available in a system, the term exergy is also frequently used to describe transfer of work to or from a system. Hence, when one talks about the power consumption of a piece of equipments, this can be expressed in terms of the rate of exergy consumption. Indeed, the colloquial use of the energy in industry can in most cases is replaced by more appropriate term exergy. The distinction between exergy as a property signifying the available reversible work of a system and exergy as a work transfer that evokes change in a system (either reversible or irreversibly) can be the source of some confusion.

\subsection{Exergy analysis of solar reactor}

Exergy analysis is an effective and illuminating form of second law analysis (Hua et al., 2005). Exergy is defined as the maximum amount of work that can be produced by a stream of material or a system as it comes into equilibrium with its environment. Exergy may be loosely interpreted as a universal measure of the work potential or quality of different forms of energy in relation to a given environment.

The exergy transfer can be associated with mass flow, with work interaction and with heat interaction (Lian, 2006). Dynamic and kinetic exergy are two more forms of exergy that exist in renewable energy sources technology (Singh, 2000). 
The exergy associated with heat interaction is given by the equation (Magal, 1994):

$$
E=\int_{o}^{f}\left(1-\frac{T_{o}}{T_{s}}\right) d \dot{Q}
$$

where $T_{0}$ is the ambient temperature, $T$ is the temperature at which the heat transfer takes place, o denotes the dead state, $\mathrm{f}$ denotes the final state and $\dot{Q}$ is the infinitesimal heat transfer rate at the boundary of the control mass (Haught, 1984).

Total irreversibility of WGS solar reactor which is given Figure 2 is

$$
I_{\text {total }}=I_{\text {solar }}+I_{\text {collector }}+I_{A}+I_{C H}
$$

where $I_{\text {solar, }} I_{\text {collector, }} \mathrm{I}_{\mathrm{A}}, \mathrm{I}_{\mathrm{CH}}$ is solar, parabolic collector, air and chemical reaction in the reformer irreversibility, respectively.

\subsection{Exergy Analysis of Solar Radiation}

Exergy balance of solar radiation is

$$
E_{\text {solar }}=E_{G}-E x_{\text {solar }}
$$

where $E_{\text {solar }}$ is irreversibility of solar radiation, $E_{G}$ is the global irradiance, $E_{G}=f \sigma T_{s}^{4}$ where $\mathrm{f}$ is the dilution factor and $T_{s}$ is the solar temperature which is $5777 \mathrm{~K}, E x_{\text {solar }}$ is the exergy released by the solar irradiance (You and $\mathrm{Hu}, 2002$ )

$$
E x_{\text {solar }}=I_{e}\left(1-\frac{4 T_{0}}{3 T_{s}}(1-0.28 \ln f)\right)
$$

where $I_{e}$ is the direct irradiance, $T_{0}$ is the ambient temperature.

\subsection{Exergy Analysis of Cylindrical Parabolic Collector}

Exergy balance of solar cylindrical parabolic collector is

$$
E_{\text {collector }}=E x_{\text {solar }}-E x_{Q}
$$

where $E_{\text {collector }}$ is irreversibility of cylindrical parabolic collector, $E x_{Q}$ is the exergy transfer accompanying

$$
E x_{Q}=Q_{s}^{u}\left\{1-\frac{T_{0}}{T_{h 1}-T_{h 2}} \ln \left[\frac{T_{h 1}}{T_{h 2}}\right]\right\}
$$


where, $T_{h 1}, T_{h 2}$ are the temperature of the solar heat carrier entering and exiting the heat exchanger(s), respectively and $Q_{s}^{u}$ is the useful transferred solar heat,

$$
Q_{s}^{u}=I_{e}(\alpha \tau) F_{k}+(\alpha \varepsilon) F_{k} \frac{\sigma T_{c}^{4}}{C}-(\varepsilon \bar{\rho}) F_{k} \frac{\sigma T^{4}}{C}-U_{L} F_{k} \frac{T-T_{o}}{C}
$$

where $\alpha \tau=\alpha_{a} \tau_{c} /\left[1-\rho_{c}\left(1-\alpha_{a}\right)\right]$ and $\alpha_{\mathrm{a}}$ is the absorptivity of the absorber, $\tau_{\mathrm{c}}$ is the transmissivity of the cover, and $\rho_{\mathrm{c}}$ is the fraction backscattered by the cover, $\alpha \varepsilon=\alpha_{a} \varepsilon_{c} /\left[1-\rho_{c}\left(1-\alpha_{a}\right)\right]$ and $\varepsilon_{c}$ is the emissivity of the cover, $\varepsilon \bar{\rho}=\varepsilon_{a}\left(1-\rho_{c}\right) /\left[1-\rho_{c}\left(1-\alpha_{a}\right)\right]$ and $\varepsilon_{\mathrm{a}}$ is the emissivity of the absorber, $\sigma$ is the StefanBoltzmann constant, $\bar{\rho}$ is the average reflectivity, $\mathrm{U}_{\mathrm{L}}$ is the heat loss coefficient, $\mathrm{F}_{\mathrm{k}}$ is termed as collector efficiency factor which is close to 1 for a well designed receiver or collector, $\mathrm{T}$ is the fluid temperature, $T_{c}$ is the cover temperature, $T_{o}$ is the ambient temperature, $C$ is the concentration ratio (You and $\mathrm{Hu}, 2002$ ).

\subsection{Exergy analysis of reformer}

Total exergy anaylsis of reformer consists of exergy analysis of air at heat reformer and chemical and physical exergy analysis of reactants and products.

\subsubsection{Exergy analysis of air at heat reformer}

Exergy balance of air in heat reformer is

$$
E_{\text {air }}=E_{E n A}-E_{E x A}
$$

where $E_{\text {air }}$ is irreversibility of air at heat reformer, $E_{E n A}$ and $E_{E x A}$ are exergy of entering and exiting air, respectively and they are calculated from (Kotas, 1985),

$$
\begin{aligned}
& E_{E n A}=n_{A} \widetilde{\varepsilon}_{p h, E n A} \\
& E_{E x A}=n_{A} \widetilde{\varepsilon}_{p h, E x A}
\end{aligned}
$$

where $n_{A}$ is the mol number and $\widetilde{\varepsilon}_{p h, E n A}$ and $\widetilde{\varepsilon}_{p h, E x A}$ are the physical exergy of the entering and exiting air, respectively. In the general form of physical exergy of gases is (Kotas, 1985)

$$
\tilde{\varepsilon}_{p h}=\tilde{C}_{p}^{h}\left(T-T_{0}\right)-T_{0} \tilde{C}_{p}^{s} \ln \left(T / T_{0}\right)+R T_{0} \ln \left(P / P_{0}\right)
$$


where $R$ is the universal gas constant. Physical exergy of entering air, at $\mathrm{P}=\mathrm{P}_{0}$ is

$$
\widetilde{\varepsilon}_{p h, E n A}=\widetilde{C}_{p, E n}^{h}\left(T_{h 1}-T_{0}\right)-T_{0} \widetilde{C}_{p, E n}^{s} \ln \left(T_{h 1} / T_{0}\right)
$$

where $\widetilde{C}_{p, E n}^{h}$ is mean isobaric heat capacity for enthalpy of entering and $\widetilde{C}_{p, E n}^{s}$ is mean isobaric heat capacity for entropy of entering air. Physical exergy of exiting air, at $\mathrm{P}=\mathrm{P}_{0}$ is

$$
\widetilde{\varepsilon}_{p h, E x A}=\widetilde{C}_{p, E x}^{h}\left(T_{h 2}-T_{0}\right)-T_{0} \widetilde{C}_{p, E x}^{s} \ln \left(T_{h 2} / T_{0}\right)
$$

where $\widetilde{C}_{p, E x}^{h}$ is mean isobaric heat capacity for enthalpy of exiting air and $\widetilde{C}_{p, E x}^{s}$ is mean isobaric heat capacity for entropy of exiting air. Mol number of entering air given in Equation (27) and (28) is

$$
n_{A}\left(h_{A_{1}, E n}-h_{A, E x_{2}}\right)=\left(H_{p h, P_{2}}-H_{p h, R_{1}}\right)+\left(H_{d, P_{2}}^{0}-H_{d, R_{1}}^{0}\right)
$$

For air, the following assumption can be written

$$
\left(h_{A, E n}-h_{A, E x}\right)=\left(T_{h 1}-T_{0}\right) \widetilde{C}_{p, E n}^{h}-\left(T_{h 2}-T_{0}\right) \widetilde{C}_{p, E x}^{h}
$$

Assuming the reactants and products to behave as ideal gases;

$$
H_{\text {mixture }}=\sum_{i}\left(n_{i} \tilde{h}_{i}\right)
$$

where $n_{i}$ is mol number of $\mathrm{i}^{\text {th }}$ reactant. Hence from Equation (34)

$$
H_{d, P_{2}}^{o}-H_{d, R_{1}}^{o}=\left(\tilde{h}_{C O_{2}}^{o}-\widetilde{h}_{H_{2}}^{o}\right)-\left(\tilde{h}_{C O}^{o}-\tilde{h}_{H_{2} O}^{o}\right)
$$

The change in the physical enthalpy can be expressed as,

$$
H_{p h, P_{2}}-H_{p h, R_{1}}=\left(T_{A 2}-T_{0}\right)\left(\widetilde{C}_{p, C O_{2}}^{h}+\widetilde{C}_{p, H_{2}}^{h}\right)-\left(T_{A 1}-T_{0}\right)\left(\widetilde{C}_{p, C O}^{h}+\widetilde{C}_{p, H_{2} O}^{h}\right)
$$

where $T_{A 1}$ and $T_{A 2}$ are chemical compositions temperature at the entering and exiting of the solar cylindrical parabolic collector, respectively. 


\subsubsection{Chemical and physical exergy analysis of reactants and products}

Chemical and physical exergy balance of reactants and products is

$$
E x_{\mathrm{Re}}=E x_{P u}+E_{c h, p h}
$$

where $E x_{\mathrm{Re}}$ is chemical exergy of reactants and $E x_{P u}$ is chemical exergy of product and $E_{c h, p h}$ is the irreversibility of chemical reaction (Kotas, 1985).

$$
\begin{aligned}
& E x_{\mathrm{Re}}=n_{\mathrm{Re}}\left(\widetilde{\varepsilon}_{c h, \mathrm{Re}}+\widetilde{\varepsilon}_{p h, \mathrm{Re}}\right) \\
& E x_{P u}=n_{P u}\left(\widetilde{\varepsilon}_{c h, P u}+\widetilde{\varepsilon}_{p h, P u}\right)
\end{aligned}
$$

The molar standard chemical exergy from the reactants and products is calculated from [15]

$$
\widetilde{\varepsilon}_{c h}=\sum_{i} x_{i} \widetilde{\varepsilon}_{i}^{0}+\widetilde{R} T_{0} \sum_{i} x_{i} \ln x_{i}
$$

where $x_{i}$ is the mole fraction. It follows from the Gibbs-Dalton rules that the physical exergy of a mixture of $\mathrm{N}$ components can be evaluated from:

$$
\widetilde{\varepsilon}_{p h}=\sum_{i=1}^{N} x_{i} \widetilde{\varepsilon}_{i}^{\Delta T}+R T_{0} \ln \left(P / P_{0}\right)
$$

where $\mathrm{P}$ is the total pressure of the mixture. Using tabulated of the mean molar isobaric exergy capacity $\widetilde{C}_{p}^{\varepsilon}$, Equation (41) can be written in the following form,

$$
\widetilde{\varepsilon}_{p h}=\left(T-T_{0}\right) \sum_{i=1}^{N} x_{i} \widetilde{C}_{p, i}^{\varepsilon}+\widetilde{R} T_{0} \ln \left(P / P_{0}\right)
$$

\section{Exergetic Efficiency}

Systems or devices designed to do work by utilization of a chemical reaction process, such as solar power plants, have irriversibilities and losses associated with their operation. Accordingly, actual devices produce work equal to only a fraction of the maximum theoretical value that might be obtained in idealized circumstances.

The real thermodynamic inefficiencies in a thermal system are related to exergy destruction and exergy loss. An exergy analysis identifies the system components with the highest exergy destruction and the processes that cause them. However, only a part of the exergy destruction in a component can be avoided. A minimum exergy destruction rate for each 
system component is imposed by physical, technological, and economic constraints. The difference between the total and the unavoidable exergy destruction rate represents the avoidable exergy destruction rate, which provides a realistic measure of the potential for improving the thermodynamic efficiency of a component. Exergy loss of the system components is

$$
E x_{\text {loss }}=\frac{E x_{\text {in }}-E x_{\text {out }}}{E x_{\text {in }}} \times 100 \%
$$

where $E x_{i n}$ is the entering exergy in the system and $E x_{\text {out }}$ is the exiting exergy from the system. The performance of systems intended to do work can be obtained as the ratio of the actual work developed to the maximum theoretical work. This ratio is a type of exergetic (second law) efficiency.Exergy efficiency of the each component based on the second law of the thermodynamics is

$$
\eta_{I I}=\frac{E x_{o u t}}{E x_{\text {in }}} \times 100 \%
$$

Energy efficiency does not meet searchers' need and does not give a complete understanding of any process. Thus, use of exergy efficiency analysis is more appropriate, because it mentions not only losses but also internal irreversibilities which can be improved for overall performance of a process (Moran, 1989). In many cases, the internal irreversibilities are more significant and more difficult to deal with than external losses (Dincer, 2007).

Also, exergy efficiency of solar water-gas shift reactor is

$$
\eta_{\text {reactor }}=\frac{\left(n_{A} x \widetilde{\varepsilon}_{H_{2}}^{0}\right) / 3600}{E x_{\text {total received }}} \times 100
$$

where $E x_{\text {total received }}$ is exergy received from the solar energy.

\section{Case Studies}

To illustrate the principle of this approach, the following two case studies, low temperature water-gas shift reaction (LT-WSR) and high temperature water-gas shift reaction (HT-WSR), are investigated. For general assumption, the ambient temperature for exergy evaluation is assumed to be $293.15 \mathrm{~K}$ and neglecting the losses of heat in the reformer. Water is chosen as the working fluid in the solar cylindrical parabolic collector. Assuming that, $\mathrm{T}_{\mathrm{s}}=5777 \mathrm{~K}$, standard spectrum with $\mathrm{f}=1.3 \times 10^{-5}, \mathrm{I}_{\mathrm{e}}=900 \mathrm{Wm}^{-2},(\alpha \tau) \mathrm{F}_{\mathrm{k}}=0.8,(\varepsilon \bar{\rho}) \mathrm{F}_{\mathrm{k}}=0.8,(\alpha \varepsilon) \mathrm{F}_{\mathrm{k}}=0.8, \mathrm{U}_{\mathrm{L}}=20$ $\mathrm{W} / \mathrm{m}^{2} \mathrm{~K}, \sigma=5,67 \times 10^{-8} \mathrm{~W} / \mathrm{m}^{2} \mathrm{~K}^{4}$. 


\subsection{Parabolic Trough Collector with LT-WSR}

Water is chosen as the working fluid in the solar cylindrical parabolic collector. Mean isobaric heat capacity for enthalpy and entropy for entering and existing air at given temperature are given in Table 4. Assuming that, $\mathrm{E}_{\mathrm{G}}=800 \mathrm{~W} / \mathrm{m}^{2}, \mathrm{I}_{\mathrm{e}}=600 \mathrm{~W} / \mathrm{m}^{2}, \mathrm{C}=16.76, \mathrm{~T}_{\mathrm{c}}=708 \mathrm{~K}, \mathrm{~T}_{\mathrm{h} 1}=673 \mathrm{~K}$, $\mathrm{T}_{\mathrm{h} 2}=473 \mathrm{~K}$. The thermodynamic parameters of selected case study are listed in Table 5. Substituting the calculated values of enthalpy changes in Eg. (34), $n_{A}$ is $3.69 \mathrm{kmol}$. For the reactants and products, $\widetilde{\varepsilon}_{p h, E n A}$ is 3880.2 and $\widetilde{\varepsilon}_{p h, E x A}$ is $1092.1 \mathrm{~kJ} / \mathrm{kmol}$, respectively.

\begin{tabular}{|c|c|}
\hline$\widetilde{C}_{p, E n}^{h}($ at $673.15 \mathrm{~K})$ & $29.36 \mathrm{~kJ} / \mathrm{kmolK}$ \\
\hline$\widetilde{C}_{p, E n}^{s}($ at $673.15 \mathrm{~K})$ & $29.86 \mathrm{~kJ} / \mathrm{kmolK}$ \\
\hline$\widetilde{C}_{p, E x}^{h}($ at $473.15 \mathrm{~K})$ & $29.02 \mathrm{~kJ} / \mathrm{kmolK}$, \\
\hline$\widetilde{C}_{p, E x}^{s}$ (at $\left.473.15 \mathrm{~K}\right)$ & $29.44 \mathrm{~kJ} / \mathrm{kmolK}$, \\
\hline
\end{tabular}

Table 4. Mean isobaric heat capacity for enthalpy and entropy for air at given temperature

\begin{tabular}{|c|c|c|c|c|}
\hline Properties & $\mathbf{C O}$ & $\mathbf{H}_{2} \mathbf{O}$ & $\mathbf{C O}_{2}$ & $\mathbf{H}_{2}$ \\
\hline$\widetilde{h}$ & 283150 & 0 & 0 & 242000 \\
\hline$\widetilde{C}_{p}^{h}$ & $29.32($ at $373 \mathrm{~K})$ & $33.15($ at $373 \mathrm{~K})$ & $44.08($ at $623 \mathrm{~K})$ & 29.28 (at $623 \mathrm{~K})$ \\
\hline$\widetilde{\varepsilon}^{o}$ & 275430 & 11710 & 20140 & 238490 \\
\hline$\widetilde{C}_{p}^{\varepsilon}$ & $3.17($ at $373 \mathrm{~K})$ & $3.55($ at $373 \mathrm{~K})$ & 14.78 (at $623 \mathrm{~K})$ & 9.52 (at $623 \mathrm{~K})$ \\
\hline
\end{tabular}

Table 5. Thermodynamic properties of reactants and products (Magal, 1994; Moran, 1989)

Table 6 presents the results of the exergy analysis for solar cylindrical parabolic reactor plant with low temperature water-gas shift reaction under consideration. The first column gives the input exergy of each component and second column gives the output exergy. The difference between the first and second column is irreversibility which is given in third column. The fourth column gives the exergy loss and the fifth column give the efficiency of each components of the solar chemical reactor based on the second law of thermodynamics.

\begin{tabular}{|c|c|c|c|c|c|}
\hline Subsystem & $\begin{array}{c}\text { Exergy received } \\
(\mathbf{k W})\end{array}$ & $\begin{array}{l}\text { Exergy delivered } \\
(\mathbf{k W})\end{array}$ & $\begin{array}{l}\text { Irreversibility } \\
(\mathrm{kJ})\end{array}$ & $\begin{array}{c}E_{\text {loss }} \\
(\%)\end{array}$ & $\begin{array}{r}\eta_{\text {II }} \\
(\%)\end{array}$ \\
\hline Solar & $\mathrm{E}_{\mathrm{G}}=800$ & $E x_{\text {solar }}=559$ & $\mathrm{E}_{\mathrm{solar}}=241$ & 30.12 & 69.88 \\
\hline Collector & $E x_{\text {solar }}=559$ & $E x_{Q}=73.48$ & $\mathrm{E}_{\text {collector }}=485.52$ & 86.85 & 13.15 \\
\hline Air & $E_{E n A}=3.97$ & $E_{E x A}=1.12$ & $\mathrm{E}_{\mathrm{air}}=2.85$ & 71.78 & 28.22 \\
\hline Chemical & $E x_{R 1}=82.18$ & $E x_{P 2}=77.97$ & $\mathrm{E}_{\mathrm{ch}}=4.21$ & 5.12 & 94.88 \\
\hline Reformer & $\left(E_{E n, A}+E x_{R 1}\right)=86.15$ & $\left(E_{E x, A}+E x_{P 2}\right)=79.09$ & $E_{\text {reformer }}=7.06$ & 8.19 & 91.81 \\
\hline Reactor & $E x_{\text {total received }}=559$ & $E x_{\text {total delivered }}=132.49$ & $\mathrm{E}_{\text {total }}=426.51$ & 76.29 & 23.71 \\
\hline
\end{tabular}

Table 6. Exergetic analysis of each components of the solar cylindrical parabolic reactor 
It can be seen from the Table 6, the percentage exergy loss in the collector subsystem has the greatest value, $86.85 \%$. In other words, exergetic efficiency $\left(\eta_{\mathrm{II}}\right)$ in the collector subsystem has the minimal value. Moreover, it is known that exergy loss does not imply that it is lost forever; a good amount of it can be recovered for future use. Hence, in the solar cylindrical reactor, it is the solar collector assembly, where the effort has to be concentrated to reduce the exergy loss. Total exergetic efficiency of the solar chemical reactor is $23.71 \%$. Exergy received of the solar cylindrical parabolic collector is equal to exergy received of collector but exergy delivered of this process is equal to exergy delivered of collector plus chemical and physical exergy difference of entering and existing products. The main reason of low efficiency of device driven by solar radiation lies in the impossibility of full absorption of the insulation (Petela, 2005). To obtain high quality energy, at high temperature, the absorbing surface has to be at high temperature, which produces a large loss of energy by emission from the surface. This factor influences exergy efficiencies.

\subsection{Parabolic Trough Collector with HT-WSR}

Water is chosen as the working fluid in the solar cylindrical parabolic collector. Mean isobaric heat capacity for enthalpy and entropy for entering and existing air at given temperature are given in Table 7. Assuming that, $\mathrm{E}_{\mathrm{G}}=900 \mathrm{~W} / \mathrm{m}^{2}, \mathrm{I}_{\mathrm{e}}=700 \mathrm{~W} / \mathrm{m}^{2}, \mathrm{C}=21.84$, $\mathrm{T}_{\mathrm{c}}=808 \mathrm{~K}, \mathrm{~T}_{\mathrm{h} 1}=773 \mathrm{~K}, \mathrm{~T}_{\mathrm{h} 2}=573 \mathrm{~K}$. The thermodynamic parameters of selected case study are listed in Table 8. Substituting the calculated values of enthalpy changes in Eg. (34), $n_{A}$ is $2 \mathrm{kmol}$. For the reactants and products, $\widetilde{\varepsilon}_{p h, E n A}$ is 5654.2 and $\widetilde{\varepsilon}_{p h, E x A}$ is $2345.6 \mathrm{~kJ} / \mathrm{kmol}$, respectively.

\begin{tabular}{|c|c|}
\hline$\widetilde{C}_{p, E n}^{h}($ at $773.15 \mathrm{~K})$ & $29.53 \mathrm{~kJ} / \mathrm{kmolK}$ \\
\hline$\widetilde{C}_{p, E n}^{s}($ at $773.15 \mathrm{~K})$ & $29.97 \mathrm{~kJ} / \mathrm{kmolK}$ \\
\hline$\widetilde{C}_{p, E x}^{h}($ at $573.15 \mathrm{~K})$ & $29.19 \mathrm{~kJ} / \mathrm{kmolK}$, \\
\hline$\widetilde{C}_{p, E x}^{s}($ at $573.15 \mathrm{~K})$ & $29.65 \mathrm{~kJ} / \mathrm{kmolK}$, \\
\hline
\end{tabular}

Table 7. Mean isobaric heat capacity for enthalpy and entropy for air at given temperature

\begin{tabular}{|c|c|c|c|c|}
\hline Properties & $\mathbf{C O}$ & $\mathbf{H}_{2} \mathbf{O}$ & $\mathbf{C O}_{2}$ & $\mathbf{H}_{2}$ \\
\hline$\widetilde{h}$ & 283150 & 0 & 0 & 242000 \\
\hline$\widetilde{C}_{p}^{h}$ & $29.57($ at $473 \mathrm{~K})$ & $33.93($ at $473 \mathrm{~K})$ & $45.44($ at $723 \mathrm{~K})$ & $35.33($ at $723 \mathrm{~K})$ \\
\hline$\widetilde{\varepsilon}^{o}$ & 275430 & 11710 & 20140 & 238490 \\
\hline$\widetilde{C}_{p}^{\varepsilon}$ & $6.33($ at $473 \mathrm{~K})$ & $7.22($ at $473 \mathrm{~K})$ & $17.81($ at $723 \mathrm{~K})$ & $11.21($ at $723 \mathrm{~K})$ \\
\hline
\end{tabular}

Table 8. Thermodynamic properties of reactants and products (Magal, 1994; Moran, 1989)

Table 9 presents the results of the exergy analysis for solar cylindrical parabolic reactor plant with low temperature water-gas shift reaction under consideration. The first column gives the input exergy of each component and second column gives the output exergy. The 
difference between the first and second column is irreversibility which is given in third column. The fourth column gives the exergy loss and the fifth column give the efficiency of each components of the solar chemical reactor based on the second law of thermodynamics.

\begin{tabular}{|c|c|c|c|c|c|}
\hline Subsystem & $\begin{array}{c}\text { Exergy received } \\
(\mathbf{k W})\end{array}$ & $\begin{array}{c}\text { Exergy delivered } \\
(\mathbf{k W})\end{array}$ & $\begin{array}{c}\text { Irreversibility } \\
(\mathbf{k W})\end{array}$ & $\begin{array}{c}\text { Ex }_{\text {loss }} \\
(\%)\end{array}$ & $\begin{array}{l}\eta_{\mathrm{II}} \\
(\%)\end{array}$ \\
\hline Solar & $\mathrm{E}_{\mathrm{G}}=900$ & $E x_{\text {solar }}=652$ & $\mathrm{E}_{\text {solar }}=248$ & 27.55 & 72.45 \\
\hline Collector & $E x_{\text {solar }}=652$ & $E x_{Q}=148.2$ & $\mathrm{E}_{\text {collector }}=503.8$ & 77.26 & 22.74 \\
\hline Air & $E_{E n A}=3.14$ & $E_{E x A}=1.83$ & $E_{\text {air }}=1.31$ & 41.72 & 58.28 \\
\hline Chemical & $E x_{R 1}=83.1$ & $E x_{P 2}=82.63$ & $\mathrm{E}_{\mathrm{ch}}=0.56$ & 0.56 & 99.44 \\
\hline Reformer & $\left(E_{E n, A}+E x_{R 1}\right)=86.24$ & $\left(E_{E x, A}+E x_{P 2}\right)=84.46$ & $E_{\text {reformer }}=1.87$ & 2.16 & 97.84 \\
\hline Reactor & $E x_{\text {total received }}=652$ & $E x_{\text {total delivered }}=185.56$ & $E_{\text {total }}=466.44$ & 71.54 & 28.46 \\
\hline
\end{tabular}

Table 9. Exergetic analysis of each components of the solar cylindrical parabolic reactor

It can be seen from the Table 9, the percentage exergy loss in the collector subsystem has the greatest value, $77.26 \%$. Total exergetic efficiency of the solar chemical reactor is $28.46 \%$.

\section{Conclusion}

Exergy analysis is now a well accepted tool for process optimization. Exergy analysis do a better job of quantifying the efficiency of energy conversation processes than those traditionally accepted based on the energy efficiency. Exergy analysis reflects more accurately the true performance of a technological system. Also, minimizing the exergy destroyed throughout the industrial chain can decrease the total impact of a process upon the environment. The motivation for the present study lies in the increased in utilization of medium temperature heat sources such as solar energy and in the increased interest and success in applying exergy analysis as a measure of system performance. It is argued that irreversibility analysis represents suitable basis for the evaluation of the usefulness of medium temperature heat.

The exergy analysis of solar energy conversation systems is particularly useful in their design and provides the basis for choosing the operating range. Also, exergy analysis is now a well-accepted tool for process optimization. The motivation for the present study lies in the increased utilization of medium temperature heat sources such as solar energy and in the increased interest and success in applying exergy efficiency as a measure of system performance. It is argued that exergy analysis represents suitable basis for the evaluation of the usefulness of medium temperature solar reactor.

The requirements for greater exergy efficiencies and introduction of new solar devices have led to the need for improved methods of predicting design parameters. In this study, exergy analysis applied to the solar cylindrical parabolic reactor. Irreversibility rates of solar radiation, cylindrical parabolic collector and reformer, obtained in the analysis of solar chemical reactor system are given some significant information for scientists and designers before decision making. 


\section{References}

Bayazitoglu, Y. (1986). Solar Energy Utilization, NATO ASI Series, Edited by Yuncu, H., Paykoc, E., Yener, Y., Series E: Applied Sciences, No 129.

Dincer, I. (2007). Exergetic and sustainability aspects of green energy systems. Clean, 35, (4), pp. 311-322.

Dincer, I. \& Rosen, M.A. (1998). A worldwide perspective on energy, environment and sustainable development. Int. J. Energy Res. 22, pp. 1305-1321.

Duffie, J. A. \& Beckman, W. A. (1991). Solar Engineering of Thermal Processes, John Wiley\&Sons, Inc.

Eskin, N. (1999). Transient performance analysis of cylindrical parabolic concentrating collectors and comparison with experimental results. Energy conversion and management, 40, pp. 175-191.

Goswami, D. Y., Kreith, F. \& Kreider, J. (1999). Principles of Solar Engineering. Taylor and Francis, New York.

Haught, A. P., (1984). Physical consideration of solar energy conversion. ASME journal of solar energy engineering. 106, pp. 3-15.

Hong-lei, L.; Ming-jun, J.; Wei-cheng, P.; Wen-xiang,Z. \& Da-zhen, J. (2006). Copper Promoted AdZnO-CuO Catalysts for Low Temperature Water-gas Shift Reaction. Chem. Res. Chinese, 22(1), pp 99-102.

Hua., N.; Wang, H.; Du, Y.; Shen, M. \& Yang, P. (2005). Ultrafine Ru and $\gamma-\mathrm{Fe}_{2} \mathrm{O}_{3}$ particles supported on $\mathrm{MgAl}_{2} \mathrm{O}_{4}$ spinel for water-gas shift reactions. Catalysis Communications, 6, pp. 491-496.

International Energy Agency (IEA), (2004). World Energy Outlook 2004

Kalogirou, S. A. (1997). Survey of solar desalination systems and system selection. Energy, 22, pp. 69-81.

Kodama, T. (2003). High-temperature solar chemistry for converting solar heat to chemical fuels. Progress in energy and combustion science. 29, pp. 567-597.

Kotas, T. J. (1985). The exergy method of thermal plant analysis. Printed and bound in Great Britain by Anchor Brendon Ltd.

Kreider, J.F. \& Kreith, F. (1975). Solar Heating and Cooling Engineering, Practical Design and Economics, Hemisphere Publishing Corporation, Washington, D.C.

Magal, B. S. (1994). Solar power engineering. Tata McGraw-Hill.

Mills, D. (2004). Advances in solar thermal electricity technology. Solar Energy, 76, 19-31.

Moran, M. J. (1989). Availability Analysis, ASME Press, New York.

Newsome, D. S. (1980). The water-gas shift reaction. Catal. Rev. Sci. Eng., 21 (2), pp. 275-381.

Petela, R. (2005). Exergy analysis of the solar cylindrical-parabolic cooker. Solar energy, 79, pp. 221-233.

Price, H.; Lupfert, E.; Kearney, D.; Zarza E.; Cohen, G., Gee, R.; \& Mahoney, R. M. (2002). Advances in parabolic trough solar power technology. Journal of Solar Energy Engineering, 124, (2), pp. 109-125.

Saying, A. A. M. (1979). Solar Energy Application in Buildings. Academic Press, New York.

Singh, N.; Kaushik, S. C. \& Misra, R. D., (2000). Exergetic analysis of a solar thermal power system. Renewable energy, 19, pp. 135-143.

Sorensen, B. (2004). Renewable energy: It's physics, engineering, use, environmental impacts, economy and planning aspects, 3rd edition. USA: Elsevier Inc. 
Spalding, F.R.; Harald, W. \& Stanford, M. (2005). Energy and the world summit on sustainable development. Energy Policy. (33), pp. 99-102.

Tiwari, G. N. (2003). Solar Energy Fundamentals, Design, Modelling and Applications. Alpha Science publication.

Trieb, F.; Lagni $\beta$, O. \& Klai $\beta$, H. (1997). Solar electricity generation - a comparative view of technologies, costs and environmental impact. Solar Energy, 59, pp. 89-99.

You, Y. \& Hu, E.J. (2002). A Medium-Temperature Solar Thermal Power System and Its Efficiency Optimization. Applied Thermal Engineering, 22, pp. 357-364. 


\title{
Economic analysis of large-scale wind energy conversion systems in central anatolian Turkey
}

\author{
Mustafa Serdar GENÇ \\ Erciyes Üniversitesi, Mühendislik Fakültesi, Enerji Sistemleri Mühendisliği Bölümü, \\ 38039, Kayseri \\ Turkey
}

\section{Introduction}

A political, economical and technological development is influenced by social events in all world. Increasing of industrial production and raising competitiveness is possible by development of technology. Countries which fail to develop a technology will be difficult to survive in the new world order and they will take place in the class of very populated, poor countries whose revenues do not increase. Today, the developing countries make research their own energy sources, particularly renewable and clean energy sources and develops their own technologies about energy conversion systems because of difficulties on energy in all over the world.

Not only the converting most efficiently an energy source into useable energy but also it is extremely important that this source is clean and sustainable energy. Clean and renewable energies obtaining from sunlight, wind or water around the earth do not make a net contribution of carbon dioxide to the atmosphere. Therefore, these energy sources should be used to protect our world, because of global warming and the injurious effects of carbon emissions.

Pressure and temperature differences occurring in the atmosphere because of solar energy, and the earth's rotation, and different forms of the earth's surface create wind. People has been used the wind for various purposes such as windmill, water pumping, etc. for centuries. Not only wind energy can be used as mechanical power but also mechanical energy of the wind through a generator can be converted into electrical energy. But, interest in wind energy have always been tied to oil prices. In the 1970s, oil prices raised suddenly and both this rising and the injurious effects of carbon emissions pushed people to seek alternative, clean and renewable energy sources.

Due to the fact that wind energy is a fuel-free, inexhaustible, and pollution-free source, the role of wind energy in electricity generation increased in the United States, Asia and Europe. In the past 25 years, use of wind energy in U.S.A. increased, and the wind energy price was 80 cents/kWh in 1980 and this price decreased to 4 cents/kWh in 2002 (Kakac, 2006). Although wind produces only about $1.5 \%$ of worldwide electricity use, it is growing rapidly, having doubled in the three years between 2005 and 2009 (World Wind Energy Association, 2010). In several countries it has a distribution, accounting for about $19 \%$ of electricity production in Denmark, $10 \%$ in Spain and Portugal, and 7\% in Germany and the Republic of Ireland in 2008. And Turkey is rather unsuccessful in using its potential and has $1002.35 \mathrm{MW}$ installed capacity (Electricity Market Regulatory Authority, 2010). Cumulative variation of installed 


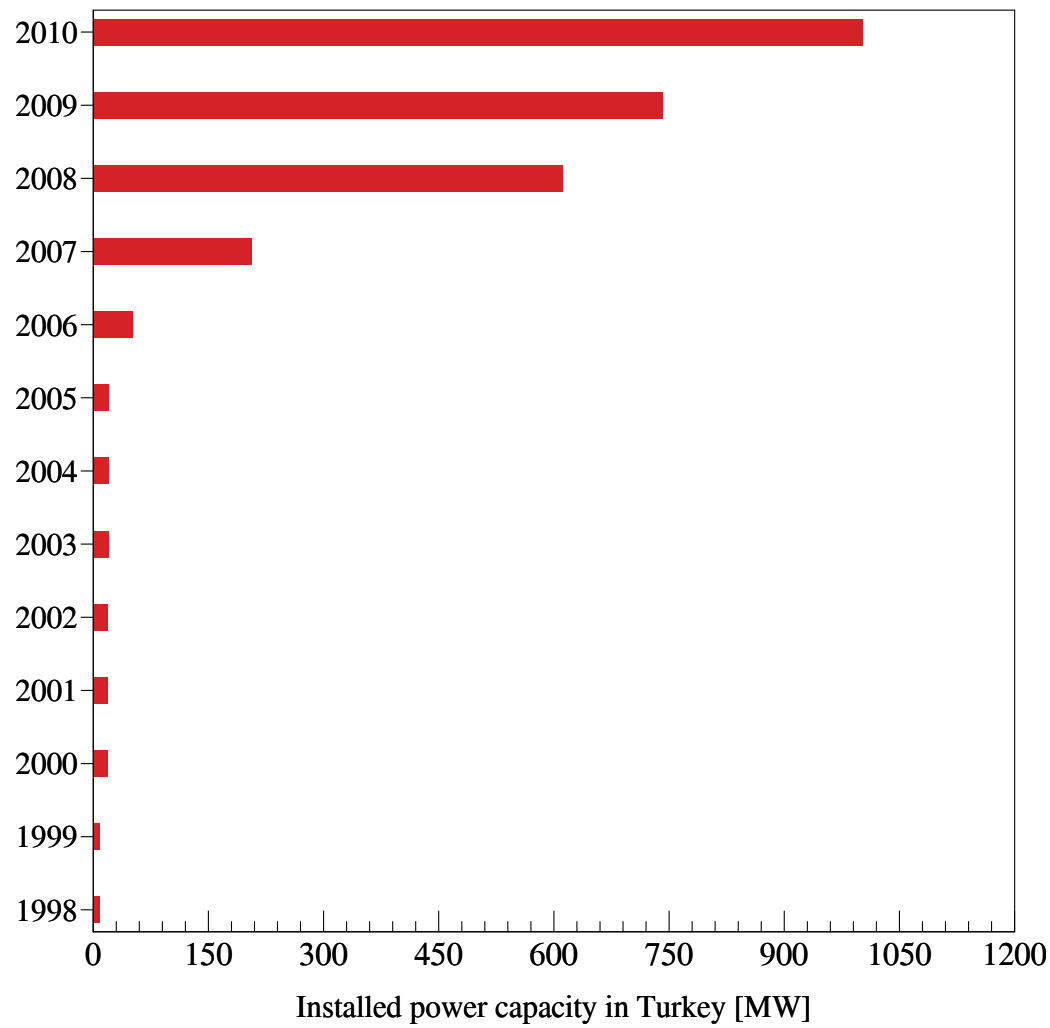

Fig. 1. Cumulative variation of wind power installed in Turkey

wind power in Turkey is shown in Fig. 1(Electricity Market Regulatory Authority, 2010). It is expected that the installed wind power capacity in Turkey will reach about $3500 \mathrm{MW}$ up to end of 2010 year.

Wind energy prices are based on local conditions and require to analyze for each country. The characteristics and the distribution of wind speeds of a site have to be investigated in detail for effective using this energy. When a wind energy conversion system will install in a site, many factors such as the wind speed, wind power, the generator type have to be taken into account and a feasibility study must be done. A lot of studies related to the wind characteristics and wind power potential have been made in many countries worldwide by researchers such as Rehman (2004), Ahmet Shata and Hanitsch (2006), Acker et. al (2007), Bagiorgas et al. (2007), Bouzidi et al. (2009), Nouni et al. (2007), Chang and Tu (2007), Ngalaa et al. (2007), Zhou et al. (2010) etc.

In Turkey, a lot of studies of the estimation of wind characteristics have been achieved by researchers. Bilgili et al. (2004) and Sahin et al. (2005) investigated the wind power potential for selected seven different sites (Antakya, Samandag, Karatas, Adana, Yumurtalýk, Dortyol and Iskenderun) in the Southern Anatolia. Their results show that the contours of constant wind speed and power potential could lead the private power developers to decide the locations of appropriate wind farms. Bilgili and Sahin (2009), and Sahin and Bilgili (2009) studied wind 
energy density in the southern and southwestern region of Turkey. The dominant wind directions, probability distributions, Weibull parameters, mean wind speeds, and power potentials were determined according to the wind directions, years, seasons, months, and hours of day, separately. It is obtained that these regions have a reasonable wind power potential and they are suitable for planting wind energy turbines. In addition, according to authors Belen-Hatay is the most promising and convenient site for production of electricity from wind power. Bilgili et al. (2010) and Bilgili and Sahin (2010) investigated statistically wind energy density of Akhisar, Bababurnu, Belen, Datca, Foca, Gelendost, Gelibolu, Gokceada and Soke districts which are located in the southern, southwestern and western region of Turkey. The Weibull and Rayleigh probability density functions, and the Wind Atlas Analysis and Application Program (WAsP) packet program were used to analyze the measured data collected by the General Directorate of Electrical Power Resources Survey Administration. They concluded that the Weibull probability density function and WAsP program provide better power density estimations than Rayleigh probability density function for all stations enjoying a reasonable wind power potential. They found that Gokceada and Gelibolu were the most promising and convenient sites to product the electricity from the wind energy. Furthermore, Bilgili and Sahin (2010) presented the electric power plants in Turkey and, their capacities and resources used in the electricity generation in order to update the electric energy statistics. The status of thermal, hydro, wind, and geothermal power plants in Turkey was classified according to the electricity utilities.

Kurban and Hocaoglu (2010) studied the possible wind energy potential in Eskisehir, Turkey using the data collected in the observation station established at Iki Eylul Campus of Anadolu University. And they (2010) investigated the wind statistics and energy calculations for Eskisehir region using the Wind Atlas Analysis and Application Program (WAsP) software. They selected suitable sites to locate wind turbines optimally according to the created wind power and wind speed maps. Eighteen different wind turbines with nominal powers between 200 and 2,000 kW are considered to product energy. Karsli and Gecit (2003) determined the wind power potential of the Nurdagi/Gaziantep district located in the south of Turkey using Weibull parameters of the wind speed distribution. Their results show that the district has a mean wind speed of $7.3 \mathrm{~m} / \mathrm{s}$ at $10 \mathrm{~m}$ height and mean power density of $222 \mathrm{~W} / \mathrm{m} 2$. Akpinar and Akpinar (2004) evaluated the wind energy potential of Maden-Elazig in eastern Turkey and obtained that the mean speed varies between 5 and $6 \mathrm{~m} / \mathrm{s}$ and yearly mean power density is $244.65 \mathrm{~W} / \mathrm{m} 2$. Kose (2004) and Kose et al. (2004) determined the possible wind energy potential at the Dumlupinar University-Kutahya main campus using their own observation station. Celik (2003) analyzed the wind energy potential of Iskenderun based on the Weibull and the Rayleigh models using 1-year measured hourly time-series wind speed data.

It can be generated more power from wind energy by selection of wind farm site with suitable wind electric generator and establishment of more number of wind stations. The selection and installing of suitable wind electric generator to produce electrical energy economically in the windy areas requires a number of activities that include the investigation of the source, feasibility assessment etc. Ozerdem et al. (2006) carried out both technical and economical feasibility study for a wind farm in Izmir-Turkey using three diverse scenarios for economical evaluation. It was shown that the generating cost per $\mathrm{kWh}$ and internal rate of return value for all three scenarios were promising. Celik (2007) analyzed economically suitable power generation using wind turbines which have nominal power range form 0.6 to $500 \mathrm{~kW}$. This study showed that Iskenderun was amongst the possible wind energy generation regions, 
and the lowest cost of electricity at $\$ 0.15$ per $\mathrm{kWh}$ was obtained in the wind turbine with 500 $\mathrm{kW}$.

Gökçek et al. (2007a, 2007b) studied wind energy potential and energy cost analysis of Kirklareli in the Marmara Region, Turkey. The results of their study indicated that Kirklareli enjoyed well enough wind energy potential and the wind turbine with $2300 \mathrm{~kW}$ rated power realized the highest annual energy production and the electrical energy cost per kWh was estimated as about 0.06 \$ for turbine specific cost as 700 \$/kW. Genç and Gökçek (2009), and Gökçek and Genç (2009) investigated the evaluation of wind potential, and electricity generation and cost of wind energy conversion systems in Central Anatolia Turkey. They has concluded that Pinarbasi among considered sites has a remarkable potential of wind energy for utilization and can be evaluated as marginal area for cost-effective electrical energy generation as the costs of wind energy conversion systems are lowered. Furthermore, according to the result of the calculations, it was shown that the wind energy conversion system of capacity $150 \mathrm{~kW}$ produce the energy output about 121 MWh per year in the Pinarbasi for hub height 30 $\mathrm{m}$ and also energy cost varies in the range of $0.29-30.0 \$ / \mathrm{kWh}$ for all wind energy conversion systems considered.

\section{Wind Characteristic}

\subsection{Wind Energy Meteorology}

The atmosphere of the earth absorbs solar radiation during the day. Then it delivers heat to space at a lower temperature at night time. In this process, the regions where the air pressure is temporarily higher or lower than average occur. This difference in air pressure causes air mass to flow from the region of higher pressure to that of lower pressure. This flow of air masses is called as wind.

Wind has two characteristics: wind speed and wind direction. Wind speed is the velocity of the air mass which travels horizontally through the atmosphere. Wind speed is often measured with an anemometer in kilometers per hour ( $\mathrm{kmph})$, miles per hour (mph), knots, or meters per second (mps) (Pidwirny, 2006). An anemometer (Fig. 2) consists of three open cups attached to a rotating spindle. Wind direction is called as the direction from where a wind comes from. Direction is measured by an instrument called a wind vane which is shown in Fig. 2. The wind vane instrument has a bullet shaped nose attached to a finned tail by a metal bar. The anemometer and wind vane are positioned in the atmospheric at a standard distance of 10 meters above the ground.

Information on the direction of wind can be presented in the wind roses. The wind rose is a chart which indicates the distribution of wind in different direction. Fig. 3 describes the sixteen principal directions of wind. Meteorology reports the wind direction using one of these sixteen directions. And aeronautical meteorology uses the degree concept based on the 360 degrees found in a circle for the wind direction, while climatological and synoptical meteorology uses the sixteen principal directions.

Wind always blows from high pressure region to low pressure region. High/low pressure region is a region whose pressure is higher/lower than its surroundings. The velocity of wind is based on pressure gradient force. If the pressure gradient force is greater, the faster wind will blow. If the isobars which are a line drawn through points of equal pressure on a weather map (Fig. 4) are closely spaced, a meteorologist can forecast wind speed to be high due to the fact that the pressure gradient force is great. In areas where the isobars are spaced widely apart, the pressure gradient is low and light winds normally exist. For example, when the low pressure region in the north of Black Sea in the surface weather chart taken from Turkish State 


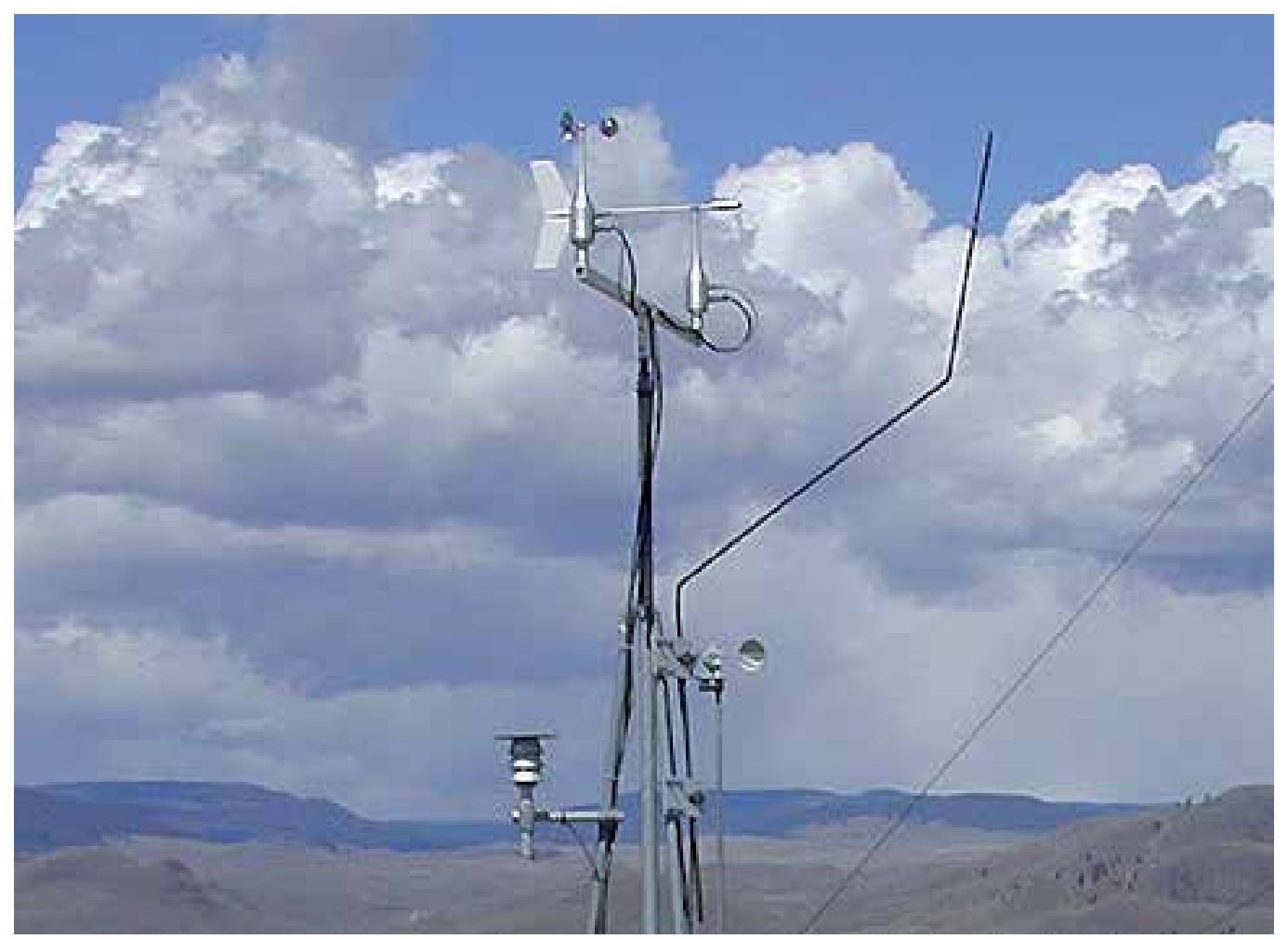

Fig. 2. Anemometer used to measure wind speed and direction (Pidwirny, 2006)

Meteorological Service (Turkish State Meteorological Service, 2010) is considered, the winds in the A region are faster than the winds in the B region. Because A region inside yellow circle has the four isobars while $B$ region inside brown circle enjoying same diameter with yellow circle has the two isobars.

There are three another forces acting on wind: coriolis force which the rotation of the Earth creates, centrifugal force which is directed towards the center of rotation and friction force which the Earth's surface creates. The coriolis force and centrifugal force only influence wind direction, while frictional force have a negative effect on wind speed and are limited to the lower one kilometer above the Earth's surface (Pidwirny, 2006).

\subsection{Wind Speed Distribution in Turkey}

Turkish Wind Atlas shown for open plains in Figure 5 was prepared using Wind Atlas Analysis and Application Program by Turkish State Meteorological Services and Electrical Power Resources Survey and Development Administration in 2002 (Dündar et al., 2002). In this study, the observations have been done for 96 meteorological stations distributed homogeneously over Turkey, and 45 of these observation stations were used for the preparation of the Wind Atlas. In this Wind Atlas, the legend for closed plains was given in Table 1. As shown in Figure 5 and Table 1, there are many suitable sites especially in coastal areas and central region (Pinarbasi) of Turkey to product electricity from wind energy. 


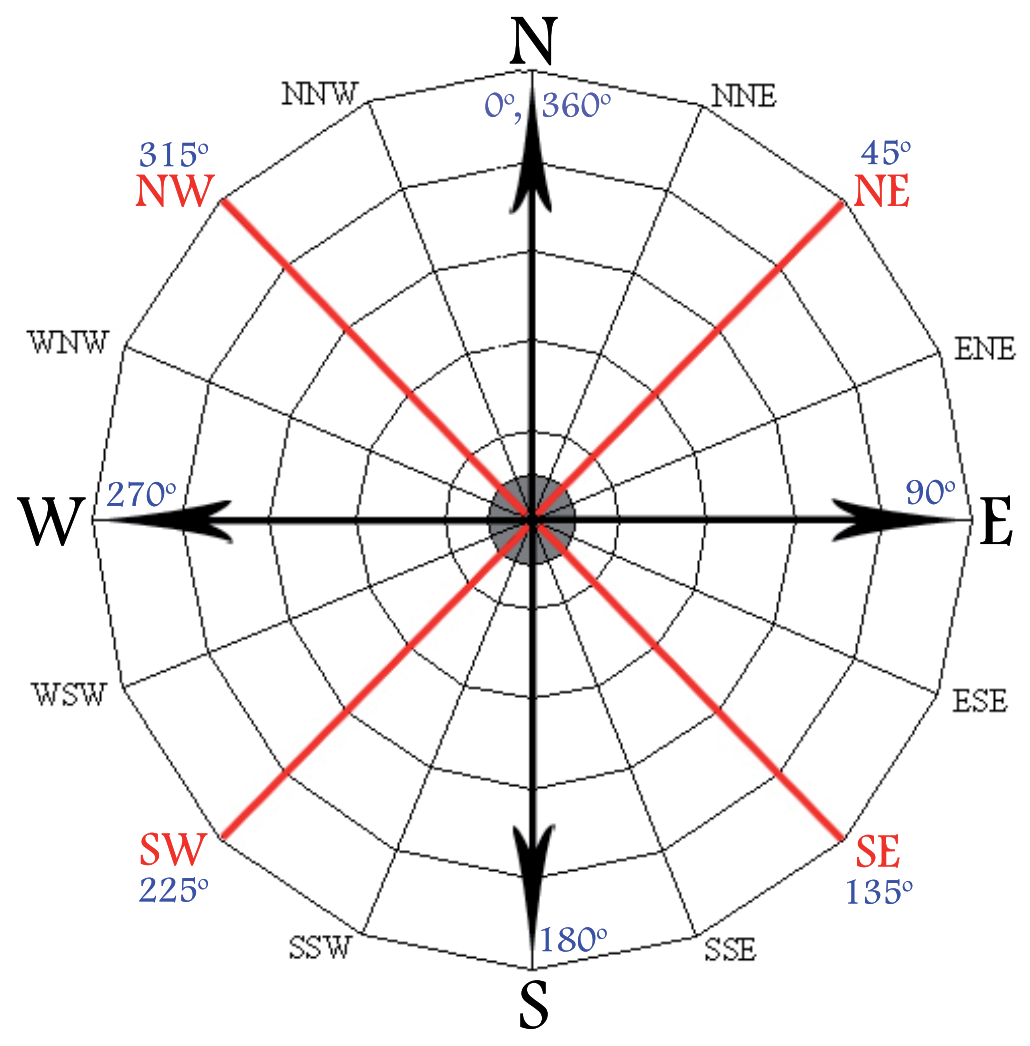

Fig. 3. Wind rose

\subsection{Wind Speed Variation With Height}

It is necessary that the wind data extrapolate for the turbine hub heights since the wind data are measured at $10 \mathrm{~m}$ height above ground. In order to calculate of wind speeds at any height, log law can be used. Log law boundary layer profile (Archer and Jacobson, 2003) incorporates a roughness factor based on the local surface roughness scale $z_{S}(\mathrm{~m})$,

$$
v=v_{0}\left(\frac{\ln \left(z / z_{s}\right)}{\ln \left(z_{0} / z_{s}\right)}\right)
$$

where $v$ is the wind speed to be determine for the desired height $(\mathrm{z}), v_{0}$ is the wind speed at recorded at standard anemometer height $\left(z_{0}\right)$. Surface roughness is based on land use category such as urban, cropland, grassland, forest, water, barren, tundra, etc. The land use category can be selected from the Engineering Sciences Data Unit (Engineering Sciences Data Unit, 2010).

\subsection{Weibull and Rayleigh Wind Speed Statistics}

In order to describe the wind speed frequency distribution, there are several probability density functions. The probability density functions point out the frequency distribution of wind speed, and which the interspace of the most frequent wind speed is, and how long a wind turbine is out and on of action. The Weibull and the Rayleigh functions are the two most 


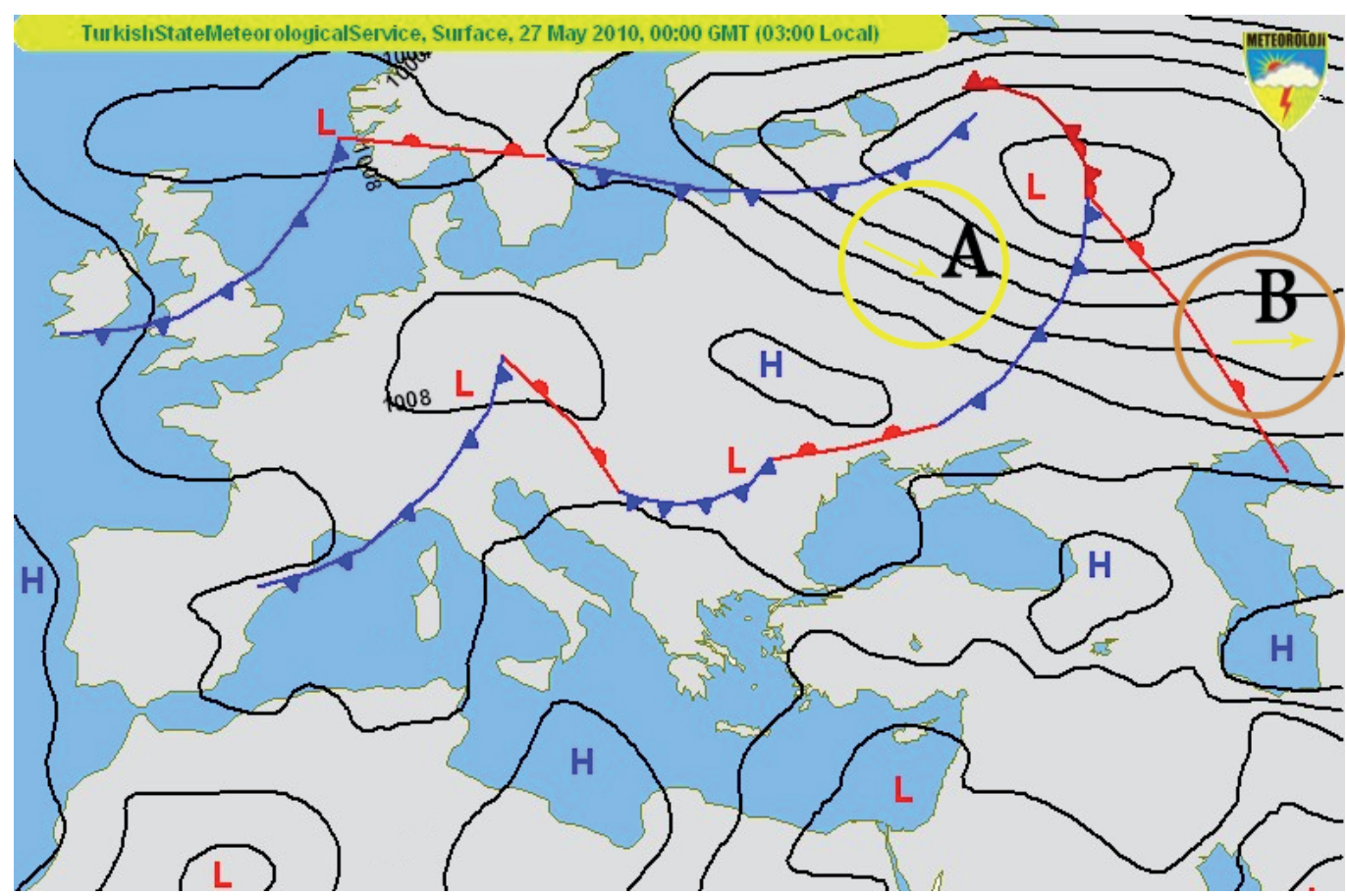

Fig. 4. The surface weather chart (Turkish State Meteorological Service, 2010)

\begin{tabular}{|l|c|c|}
\hline Color & Wind speed $(\mathrm{m} / \mathrm{s})$ & Wind power $\left(\mathrm{W} / \mathrm{m}^{2}\right)$ \\
\hline Dark blue & $>6.0$ & $>250$ \\
\hline Red & $5.0-6.0$ & $150-250$ \\
\hline Yellow & $4.5-5.0$ & $100-150$ \\
\hline Green & $3.5-4.5$ & $50-100$ \\
\hline Cyan & $<3.5$ & $<50$ \\
\hline
\end{tabular}

Table 1. The wind speed distributions for closed plains on Turkish Wind Atlas (Dündar et al., 2002)

known. The Weibull is a special case of generalized gamma distribution, while the Rayleigh distribution is a subset of the Weibull (Johnson, 2006). The Weibull is a two parameter distribution while the Rayleigh has only one parameter and this makes the Weibull somewhat more versatile and the Rayleigh somewhat simpler to use (Johnson, 2006). The Weibull distribution function is expressed as

$$
f_{w}(v)=\frac{k}{c}\left(\frac{v}{c}\right)^{k-1} \exp \left[-\left(\frac{v}{c}\right)^{k}\right]
$$

where $v$ is the wind speed, $c$ Weibull scale parameter in $\mathrm{m} / \mathrm{s}$, and $k$ dimensionless Weibull shape parameter. These parameters can be determined by the mean wind speed-standard deviation method (Justus et al., 1977) using Eqs. 3 and 4.

$$
k=\left(\frac{\sigma}{\bar{v}}\right)^{-1.086} \quad(1 \leq \mathrm{k} \leq 10)
$$




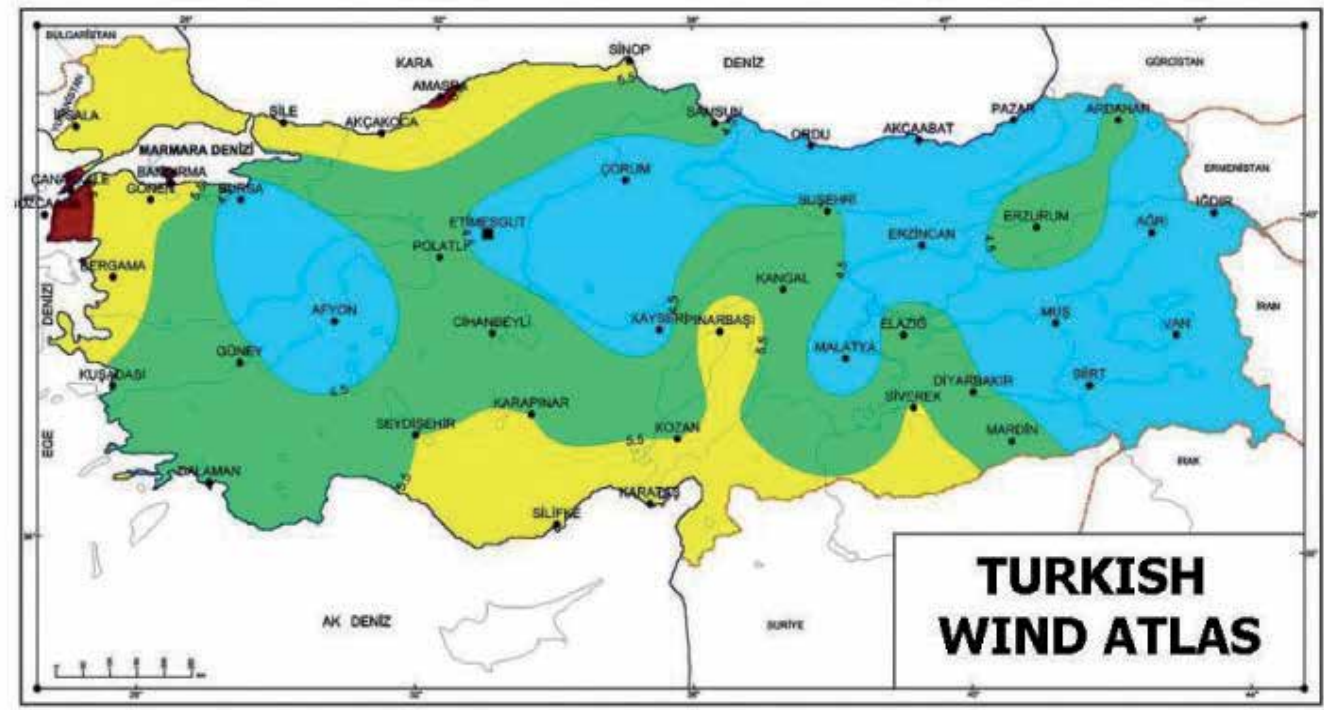

Wind resources at $50 \mathrm{~m}$ above ground level for open plains (roughness class 1)

\begin{tabular}{|l|c|c|c|c|c|}
\cline { 2 - 6 } \multicolumn{1}{c|}{} & & & & & \\
\hline $\mathrm{V}(\mathrm{m} / \mathrm{s})$ & $>7.5$ & $6.5-7.5$ & $5.5-6.5$ & $4.5-5.5$ & $<4.5$ \\
\hline $\mathrm{P}\left(\mathrm{W} / \mathrm{m}^{2}\right)$ & $>500$ & $300-500$ & $200-300$ & $100-200$ & $<100$ \\
\hline
\end{tabular}

Fig. 5. Turkish Wind Atlas (Dündar et al., 2002)

$$
c=\frac{\bar{v}}{\Gamma\left(1+\frac{1}{k}\right)}
$$

where $\bar{v}$ is the mean wind speed and $\sigma$ is the standard deviation. $\bar{v}$ is calculated using Eq. 5 and $\sigma$ using Eq. 6 (Zhou et al., 2006).

$$
\begin{gathered}
\bar{v}=\frac{1}{n}\left(\sum_{i=1}^{n} v_{i}\right) \\
\sigma=\left[\frac{1}{n-1} \sum_{i=1}^{n}\left(v_{i}-\bar{v}\right)^{2}\right]^{0.5}
\end{gathered}
$$

where $n$ is the number of hours in the period of the time considered such as month, season or year.

The dimensionless shape parameter, $k$ of Weibull distribution is assumed as 2 in Rayleigh distribution functions. The probability density function of the Rayleigh distribution is expressed as

$$
f_{R}(v)=\frac{\pi v}{2 \bar{v}^{2}} \exp \left[-\left(\frac{\pi}{4}\right)\left(\frac{v}{\bar{v}}\right)^{2}\right]
$$


The wind power density of any windy site per unit area based on any probability density function to estimate the wind power can be expressed as

$$
P_{m}=\frac{1}{2} \rho \int_{0}^{\infty} v^{3} f(v) d v
$$

where $\rho$ is the standard air density, $1.225 \mathrm{~kg} / \mathrm{m}^{3}$. When the Weibull function is chosen as distribution function $f(v)$, the average wind power density is calculated as

$$
P_{m w}=\frac{1}{2} \rho \bar{v}^{3} \frac{\Gamma(1+3 / k)}{[\Gamma(1+1 / k)]^{3}}
$$

\section{Electrical Power of Wind Energy Conversion System}

Annual wind energy output, Ewt for any windy site can be calculated using the time-series wind speed data of that site and the power curve of a wind turbine. In order to predict the wind energy output to be obtained from the wind turbine, an algebraic equation of degree $n$ according to the power curve of the wind turbine between cut-in and rated speed or cut-in speed and cut-out speed can be expressed as Eq. 10.

$$
P_{i}(v)=\left\{\begin{array}{ll}
0, & v<v_{c i} \\
\left(a_{n} v^{n}+a_{n-1} v^{n-1}+\ldots+a_{1} v+a_{0}\right), & v_{c i} \leq v<v_{R} \\
P_{R} & v_{R} \leq v<v_{c o} \\
\left(a_{n} v^{n}+a_{n-1} v^{n-1}+\ldots+a_{1} v+a_{0}\right), & v_{c i} \leq v<v_{c o} \\
0, & v \geq v_{c o}
\end{array} \quad\right. \text { or }
$$

where $a_{n}, a_{n-1}, a_{1}$ and $a_{0}$ are regression constants, $v_{c i}$ is the cut-in speed, $v_{R}$ is the rated speed, $v_{c o}$ is the cut-out speed and $P_{R}$ is the rated power and also $P_{i}(v)$ is the power generating in the related wind speed.

The total energy generated by the operational turbine over a period is calculated by adding up the energy output of all possible wind speeds. In this study, the energy output from a wind turbine was obtained with Eq. 11 using the hourly mean wind speeds.

$$
E_{w t}=\sum_{i=1}^{n} P_{i}(v) t
$$

where $n$ is the number of hours in the period of the considered time such as year, season or month, $t$ is one hour time duration.

Capacity factor, $C_{f}$ is an indicator of both the turbine type and the wind speed in a site considered. The capacity factor is important for assessing the performance of a wind turbine in a site considered (Sathyajith, 2006). Annual value of the capacity factor can be calculated as

$$
C_{f}=\frac{E_{w t}}{E_{\text {rated }}}
$$

\section{Energy Cost Analysis of Wind Energy}

The fuel of wind energy may be free, but the equipment necessary to use the wind energy can be expensive, so economic analysis of the wind energy is quite important. The wind turbine has to enjoy low operating cost. There are several factors affecting the unit energy cost of 
electricity produced in the wind turbines. These factors may vary from a country to another country.

The total capital investment and operating cost for wind electric generators have to been known to determine the unit cost of electricity. In general, the cost per unit energy is found by dividing the amount of energy produced to the total expenditures made along the certain time interval. All costs of acquiring, owning, and disposing of a system must be considered to make safely economic decisions. However, the value of money during the useful lifetime of wind energy conversion system considered should be taken into account in the cost analysis. The levelized cost of electricity method is one of the most important indicators for evaluating fiscal performance of power supply systems such as wind energy conversion system (Gökçek and Genç, 2009). The levelized cost of electricity method can be used to calculate the unit cost throughout the useful life of a system. The levelized cost of the wind energy conversion system is the ratio of the total annualized cost of the wind energy conversion system to the annual electricity produced by this system (Gökçek and Genç, 2009). The generation cost of the electrical energy of $1 \mathrm{kWh}$ using a wind turbine system using the levelized cost of electricity method can be defined as

$$
C_{e l}=\frac{C_{w t} F_{w t}+C_{i n} F_{i n}+C_{c i} F_{c i}+C_{b b} F_{b b}+C_{\text {misc }} F_{\text {misc }}+C_{(o m) e s c}}{E_{w t}} \quad[\$ / k W h]
$$

where $C_{e l}$ and $C_{(o m) e s c}$ are the cost of energy output and the cost of annual operation and maintenance escalated, respectively. And $F_{w t}, F_{i n}, F_{c i}, F_{b b}$ and $F_{m i s c}$ are the annual charge rate on capital for wind turbine, inverter, civil work and installation, battery bank and other miscellaneous equipments, respectively. The annual charge rate on capital and can be expressed by the following equation;

$$
F=\frac{r}{\left[1-(1+r)^{-n}\right]}
$$

where $n$ and $r$ are the useful system lifetime (year) and the discount rate, respectively. The total investment cost of a wind energy conversion system is given as;

$$
C_{w e c s}=C_{w t}+C_{b b}+C_{c i}+C_{i n}+C_{m i s c} \quad[\$]
$$

where $C_{w t}, C_{b b}, C_{c i}, C_{i n}$ and $C_{\text {misc }}$ are the cost of the wind turbine, the cost of battery bank, the cost of civil work and installation, the cost of the inverter and the cost of miscellaneous equipments (connecting cables, control panel and other components). Furthermore, while the a wind energy conversion system is being bought from a company, the total investment cost of the system, $C_{w e c s}$, can be also known as;

$$
C_{\text {wecs }}=I_{\text {wecs }} P_{r} \quad[\$]
$$

where $I_{\text {wecs }}$ and $P_{r}$ are the specific cost and rated power of the wind energy conversion system. A distribution of relative costs different components of a typical $5 \mathrm{~kW}$ wind energy conversion system is the wind machine $74 \%$, miscellaneous components $10 \%$, battery bank $9 \%$, civil work and installation $4 \%$, inverter $3 \%$ (Nouni et al. 2007). In this study, the evaluation of cost was considered as this cost break-up for all wind energy conversion systems. The total investment cost of any wind energy conversion system in terms of rated power was taken as mean of value read from Table 2 (Sathyajith 2006). And the costs of the wind turbine, battery bank, civil work and installation cost, inverter and miscellaneous equipments were calculated by using Eqs. 15 and 16 and used in Eq. 13. 


\begin{tabular}{|l|c|}
\hline Wind Turbine Size $(\mathrm{kW})$ & Specific Cost, $I_{\text {wecs }}(\$ / \mathrm{kW})$ \\
\hline $10-20$ & $2200-2900$ \\
\hline $20-200$ & $1500-2300$ \\
\hline $200>$ & $1000-1600$ \\
\hline
\end{tabular}

Table 2. Cost of wind turbines based on the rated power

The cost of operation and maintenance escalated, $C_{(o m) e s c}$, can be calculated as;

$$
C_{(o m) e s c}=\frac{C_{o m}}{r-e_{o m}}\left[1-\left(1+e_{o m}\right)^{n}(1+r)^{-n}\right] \quad[\$ / \text { year }]
$$

where $C_{o m}$ is the cost of operation and maintenance for the first year and $e_{o m}$ is ratio of escalation of the operation and maintenance. Of course, the cost of operation and maintenance of new wind energy conversion system is low. However, this cost will certainly increase as the time goes on. In addition, this cost is affected from the conditions of wind site, the quality of components and turbine design (Morthorst, 2004). The operation and maintenance cost, $\mathrm{C}_{o m}$ is generally considered as $15 \%$ of the annual cost of wind energy conversion system (Nouni et al., 2007).

\section{A Case Study: Energy Cost Analysis of Wind Energy in Central Turkey}

In this section, the energy cost analysis of wind energy of Pinarbasi, Develi, Nigde, Kirsehir and Sinop in Central Turkey was studied. In this study, energy costs of large-scale wind energy conversion systems at these observation stations considered were determined using the levelized cost of electricity method. In order to energy cost analysis, the estimation of wind characteristics and potential of Kayseri, Pinarbasi, Develi, Sariz, Tomarza, Kirikkale, Nigde, Nevsehir, Kirsehir, Yozgat, Bogazliyan, Corum and Sinop in Central Turkey were presented in previous studies (Genç and Gökçek, 2009; Gökçek and Genç, 2009; Genç, 2010). For these observation stations, wind data recorded using the cup anemometer for the years between 2000 and 2006 was taken from the Turkish State Meteorological Service. In the Turkish State Meteorological Service, the wind direction and wind speed are recorded by means of mechanical strip chart recorder on paper. The cup anemometer is placed over the observation building to be at a height of $10 \mathrm{~m}$ above the ground in all observation stations. The buildings around these observation stations are not too big to affect the wind speed and direction. Most of the meteorological observation stations of the Turkish State Meteorological Service in Turkey are located in almost-clear terrain and outside the city center and the big buildings. But Sinop observation station of the Turkish State Meteorological Service are near city center. The geographical specifications and wind characteristics of these observation stations at $10 \mathrm{~m}$ height from the ground are given (Genç and Gökçek, 2009; Gökçek and Genç, 2009; Genç, 2010) in Table 3.

As is shown in this table, at $10 \mathrm{~m}$ height the maximum annual mean wind speed, $\bar{v}$, is 3.67 $\mathrm{m} / \mathrm{s}$ in Pinarbasi, the maximum Weibull shape parameter, $k$, is 1.88 in Develi, the maximum Weibull scale parameter, $c$, is $4.09 \mathrm{~m} / \mathrm{s}$ in Pinarbasi, and the standard deviation, $\sigma$, is $2.56 \mathrm{~m} / \mathrm{s}$ in Pinarbasi. In Pinarbasi, both the mean wind speed and standard deviation is maximum. In other words, Pinarbasi has larger both wind speed and variance of wind speed. 


\begin{tabular}{|l|c|c|c|c|c|c|c|}
\hline Station & Latitude(N) & Longitude(E) & Altitude $(\mathrm{m})$ & $\bar{v}(\mathrm{~m} / \mathrm{s})$ & $\mathrm{k}$ & $\mathrm{c}(\mathrm{m} / \mathrm{s})$ & $\sigma$ \\
\hline Pinarbasi & $38^{\circ} 43^{\prime}$ & $36^{\circ} 24^{\prime}$ & 1500 & 3.67 & 1.49 & 4.09 & 2.56 \\
\hline Sinop & $42^{\circ} 01^{\prime}$ & $35^{\circ} 10^{\prime}$ & 32 & 3.02 & 1.21 & 3.22 & 2.54 \\
\hline Kirsehir & $39^{\circ} 09^{\prime}$ & $34^{\circ} 10^{\prime}$ & 1007 & 2.49 & 1.36 & 3.19 & 1.88 \\
\hline Nigde & $37^{\circ} 58^{\prime}$ & $34^{\circ} 41^{\prime}$ & 1211 & 2.48 & 1.64 & 2.76 & 1.58 \\
\hline Develi & $38^{\circ} 23^{\prime}$ & $35^{\circ} 30^{\prime}$ & 1180 & 2.60 & 1.88 & 2.97 & 1.48 \\
\hline Kirikkale & $39^{\circ} 51^{\prime}$ & $33^{\circ} 31^{\prime}$ & 747 & 2.16 & 1.43 & 2.38 & 1.56 \\
\hline Tomarza & $38^{\circ} 27^{\prime}$ & $35^{\circ} 48^{\prime}$ & 1347 & 2.24 & 1.20 & 2.42 & 1.92 \\
\hline Nevsehir & $38^{\circ} 35^{\prime}$ & $34^{\circ} 40^{\prime}$ & 1260 & 2.00 & 1.56 & 2.23 & 1.33 \\
\hline Bogazliyan & $39^{\circ} 12^{\prime}$ & $35^{\circ} 15^{\prime}$ & 1066 & 2.07 & 1.10 & 2.15 & 1.90 \\
\hline Yozgat & $39^{\circ} 49^{\prime}$ & $34^{\circ} 48^{\prime}$ & 1298 & 1.93 & 1.67 & 2.16 & 1.20 \\
\hline Corum & $40^{\circ} 33^{\prime}$ & $34^{\circ} 57^{\prime}$ & 776 & 1.71 & 1.11 & 1.78 & 1.55 \\
\hline Sariz & $38^{\circ} 29^{\prime}$ & $36^{\circ} 30^{\prime}$ & 1500 & 1.69 & 1.26 & 1.87 & 1.40 \\
\hline Kayseri & $38^{\circ} 44^{\prime}$ & $35^{\circ} 29^{\prime}$ & 1093 & 1.60 & 1.16 & 1.72 & 1.43 \\
\hline Sivas & $39^{\circ} 45^{\prime}$ & $37^{\circ} 01^{\prime}$ & 1285 & 1.30 & 1.35 & 1.42 & 0.99 \\
\hline
\end{tabular}

Table 3. Geographical specifications and wind characteristics of the observation stations at 10 $\mathrm{m}$ height on the ground
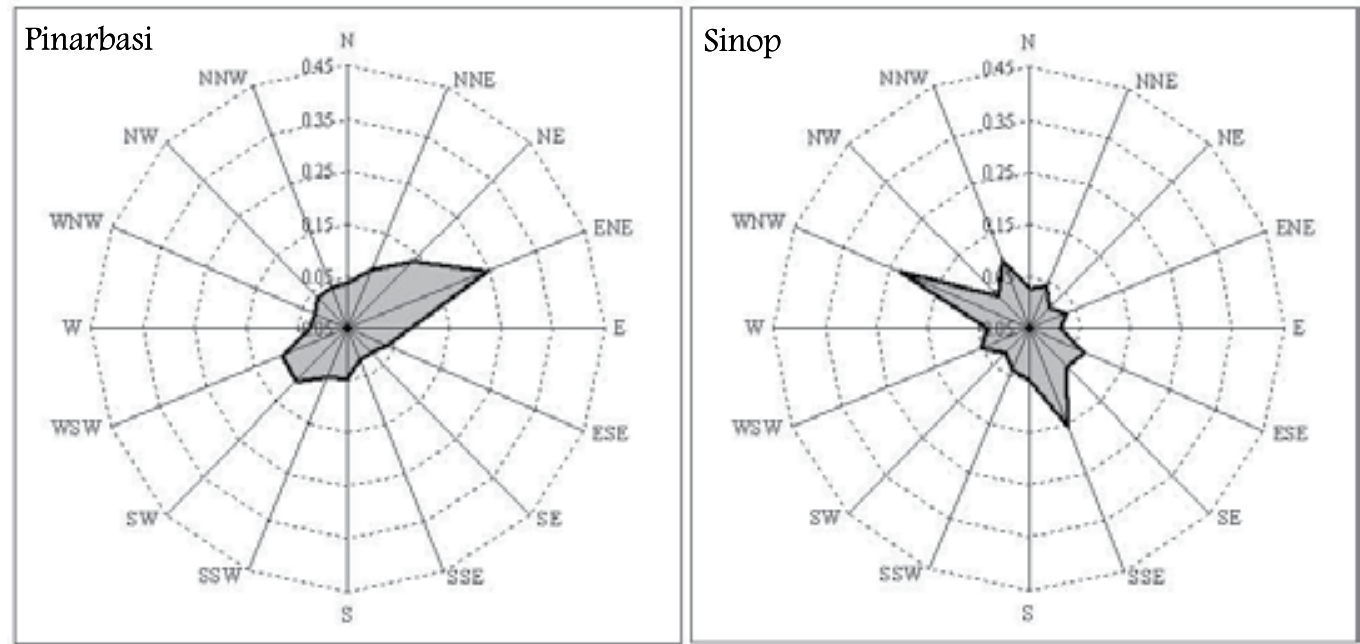

Fig. 6. The distribution of mean wind directions in Pinarbasi and Sinop

In order to calculate of wind speeds at any hub height, log law was used in this study. For $\log$ law, the local surface roughness scale $z_{S}$ was selected as in Table 4 for all observation station from the Engineering Sciences Data Unit (Engineering Sciences Data Unit, 2010). The wind speeds of these observation stations at $50 \mathrm{~m}$ hub height using log law were obtained by considering the land use category of the observation stations. It is shown that these obtained mean annual wind speeds are correspond to the values on Turkish Wind Atlas for closed plains (Table 1). Pinarbasi and Sinop are in yellow region where the mean annual wind speed is between $4.5 \mathrm{~m} / \mathrm{s}$ and $5.0 \mathrm{~m} / \mathrm{s}$ on Turkish Wind Atlas for closed plains (Table 1) and it is obtained that Pinarbasi has the wind speed of $5.08 \mathrm{~m} / \mathrm{s}$ and Sinop has the mean annual wind speed of $4.64 \mathrm{~m} / \mathrm{s}$ at $50 \mathrm{~m}$ hub height in this study. These obtained wind speeds are correspond 


\begin{tabular}{|l|l|c|c|}
\hline Station & Land use category & $z_{s}$ & Wind speed at $50 \mathrm{~m}(\mathrm{~m} / \mathrm{s})$ \\
\hline Pinarbasi & Savannah & 0.15 & 5.08 \\
\hline Sinop & Forest & 0.5 & 4.64 \\
\hline Kirsehir & Mixed shrubland/grassland & 0.3 & 3.63 \\
\hline Nigde & Mixed shrubland/grassland & 0.3 & 3.62 \\
\hline Develi & Savannah & 0.15 & 3.60 \\
\hline Kirikkale & Mixed shrubland/grassland & 0.3 & 3.15 \\
\hline Tomarza & Savannah & 0.15 & 3.10 \\
\hline Nevsehir & Mixed shrubland/grassland & 0.3 & 2.92 \\
\hline Bogazliyan & Savannah & 0.15 & 2.86 \\
\hline Yozgat & Mixed shrubland/grassland & 0.3 & 2.82 \\
\hline Corum & Mixed shrubland/grassland & 0.3 & 2.49 \\
\hline Sariz & Savannah & 0.15 & 2.34 \\
\hline Kayseri & Mixed shrubland/grassland & 0.3 & 2.33 \\
\hline Sivas & Urban & 1.0 & 2.21 \\
\hline
\end{tabular}

Table 4. Local surface roughness scales and wind speeds of the observation stations at $50 \mathrm{~m}$ height on the ground

to the values on Turkish Wind Atlas for closed plains (Table 1) except for Sivas and Sariz. The wind speeds of Sivas and Sariz are seen as less than the values on Turkish Wind Atlas, because Sivas observation station is in city center and Sariz observation station is on a plain between mountains. Finally, Pinarbasi and Sinop, can be characterized as marginal site (fairly good) in point of wind energy potential.

The direction of wind is an important factor for establishing the wind energy conversion system. If it is received the major share of the wind from a certain direction, it should be avoided any obstructions to the wind flow from this side. The distribution of the mean wind directions in Pinarbasi (Genç and Gökçek, 2009) and Sinop (Genç, 2010) which are marginal site is seen in Fig. 6. As is seen from this figure, the prevailing wind directions of Pinarbasi and Sinop are the east northeast $\left(\mathrm{ENE}, 67.5^{\circ}\right)$ and the west northwest $\left(\mathrm{WNW}, 270^{\circ}\right)$, respectively.

In this study, the wind speeds for all observation stations have been analyzed using the Weibull and Rayleigh probability density functions used to determine the wind potential of a site in a period of time. Figs. 7, 8 and 9 exhibits the actual, Weibull and Rayleigh distributions derived from observed the hourly wind data for the year 2003 regarding all observation stations considered. According to the probability density functions, the interspace which has the most frequent wind speed, and how long a wind turbine is out and on of action can be assessed. When it is looked at the Figs. 7, 8 and 9, it is seen that the distribution of wind speed of Pinarbasi, Sinop and Kirsehir is more widen than others. It means that their interspace which has the most frequent wind speed is more bigger than others and the wind energy capacity of these stations is more bigger. For example, the interspace of most frequent is between 0-10 $\mathrm{m} / \mathrm{s}$ for Pinarbasi, while it is between $0-5 \mathrm{~m} / \mathrm{s}$ for Kayseri. The Weibull distributions of Sinop, Kirsehir, Tomarza, Nevsehir, Bogazliyan, Corum, Sariz, and Sivas observation stations are in good agreement with actual data, whereas the Rayleigh distribution function is more accurate than the Weibull distribution function in the Pinarbasi, Nigde, Kirikkale, Yozgat and Kayseri wind observation stations. Furthermore, Fig. 10 shows the annual wind power density distributions in all observation stations for the year 2003. As showns in this figure, Pinarbasi has the maximum wind power $\left(125 \mathrm{~W} / \mathrm{m}^{2}\right)$ as actual, and the distributions of Weibull wind 

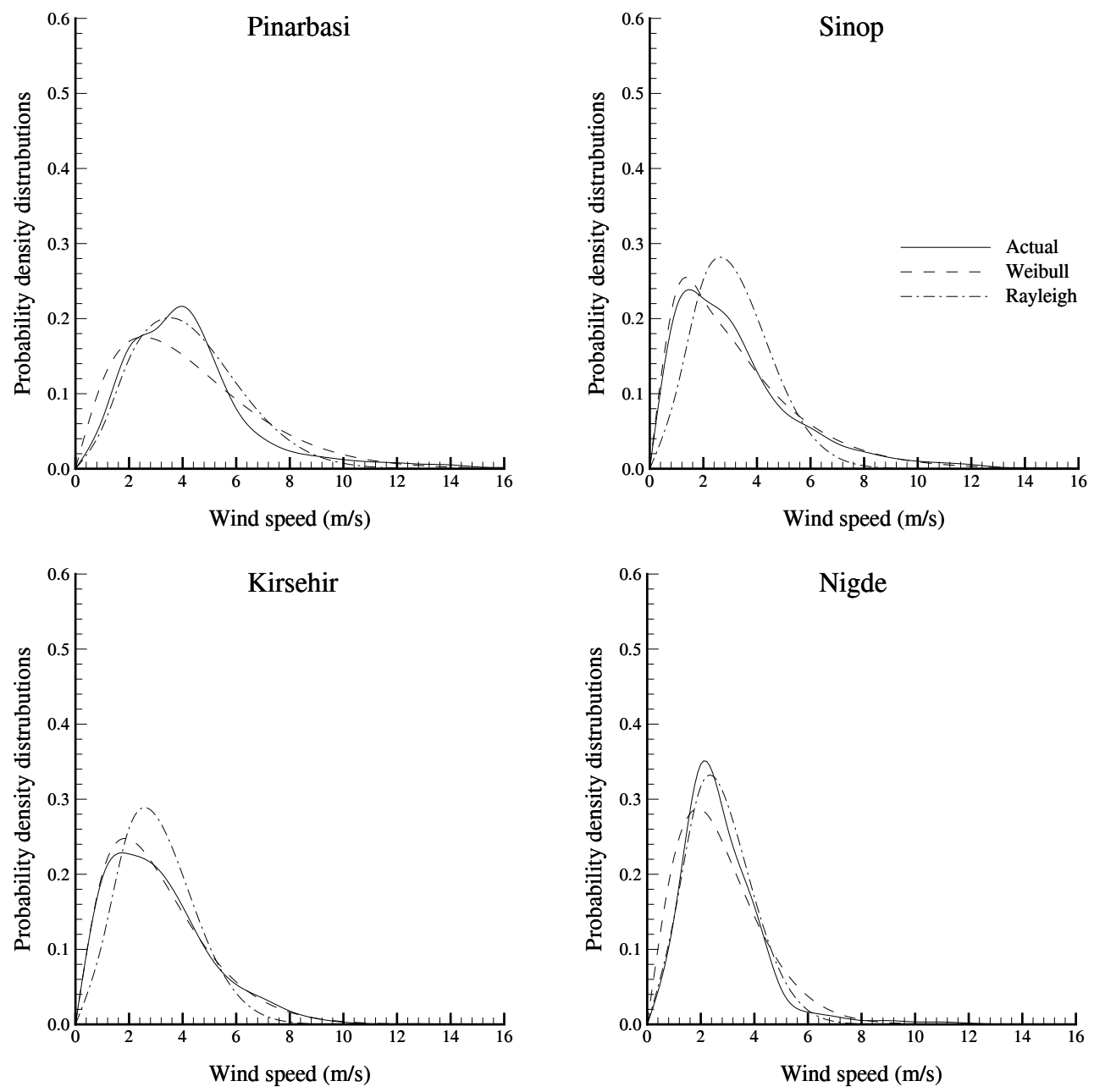

Fig. 7. Probability density distributions in Pinarbasi, Sinop, Kirsehir and Nigde for the year 2003

power of Yozgat, Bogazliyan, Sivas, Corum, Tomarza, Sariz, Nevsehir, Kirikkale and Kirsehir observation stations for year 2003 are in good agreement with actual data. 

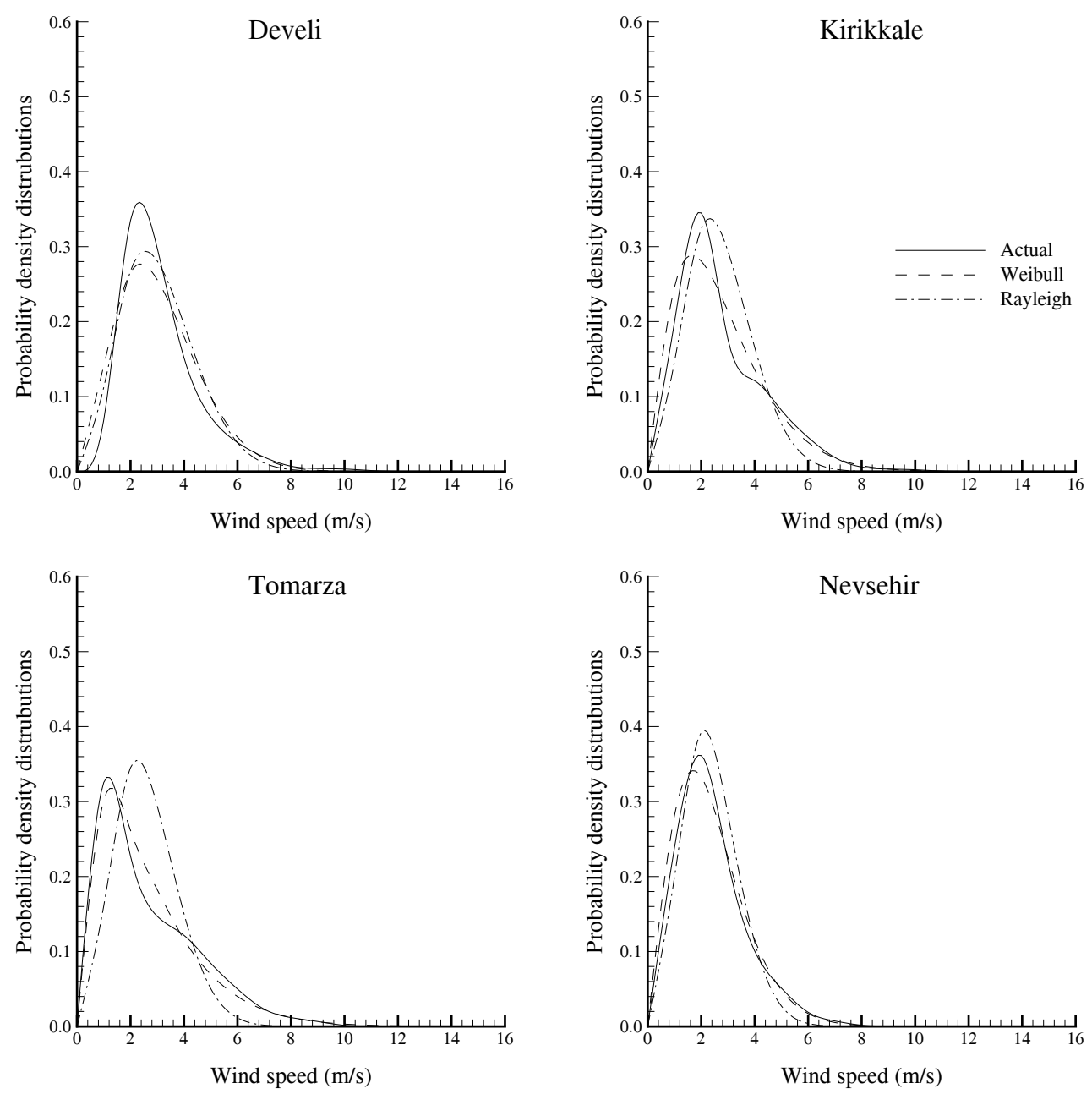

Fig. 8. Probability density distributions in Develi, Kirikkale, Tomarza and Nevsehir for the year 2003 

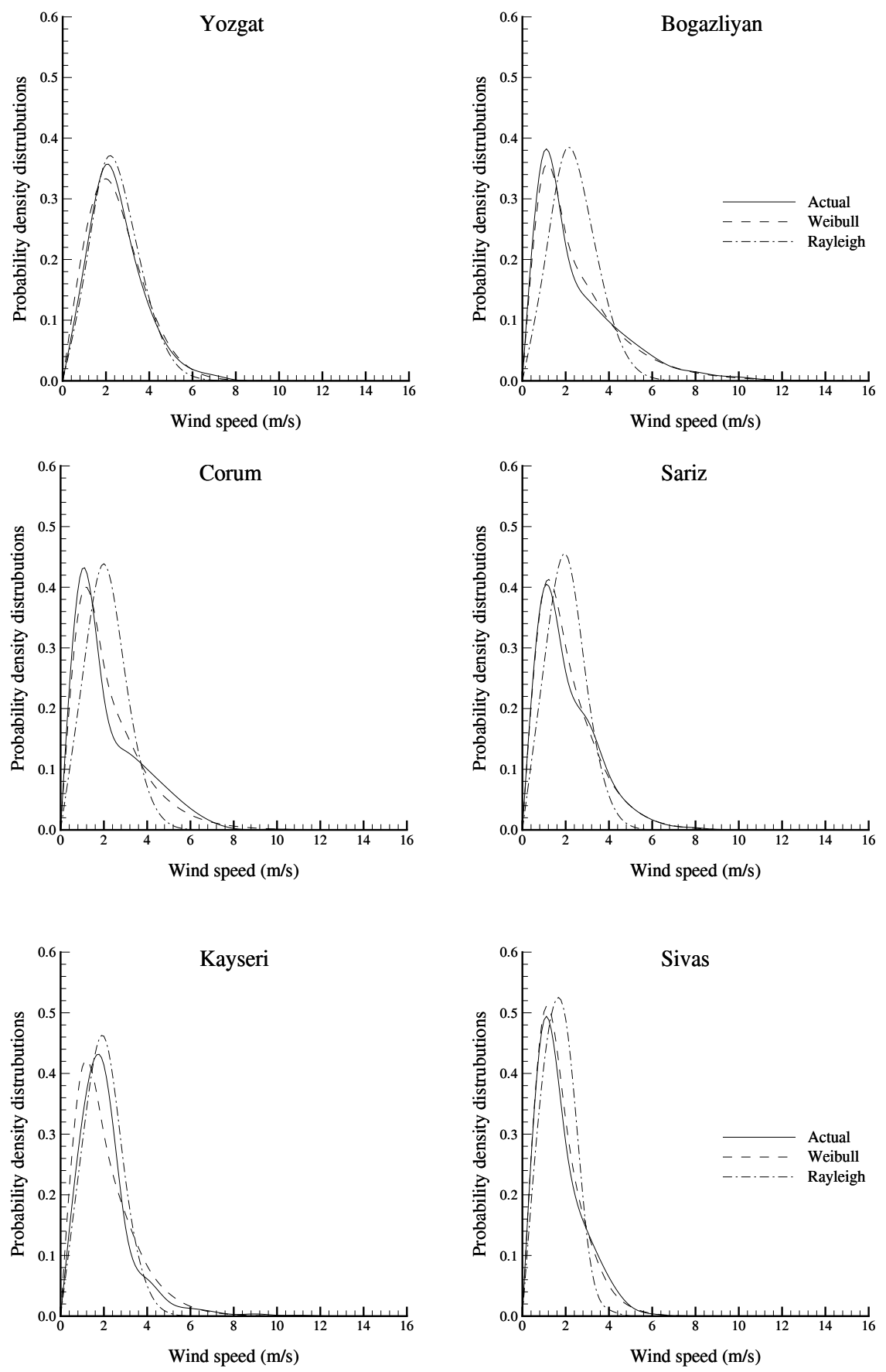

Fig. 9. Probability density distributions in Bogazliyan, Yozgat, Corum, Sariz, Kayseri and Sivas for the year 2003 


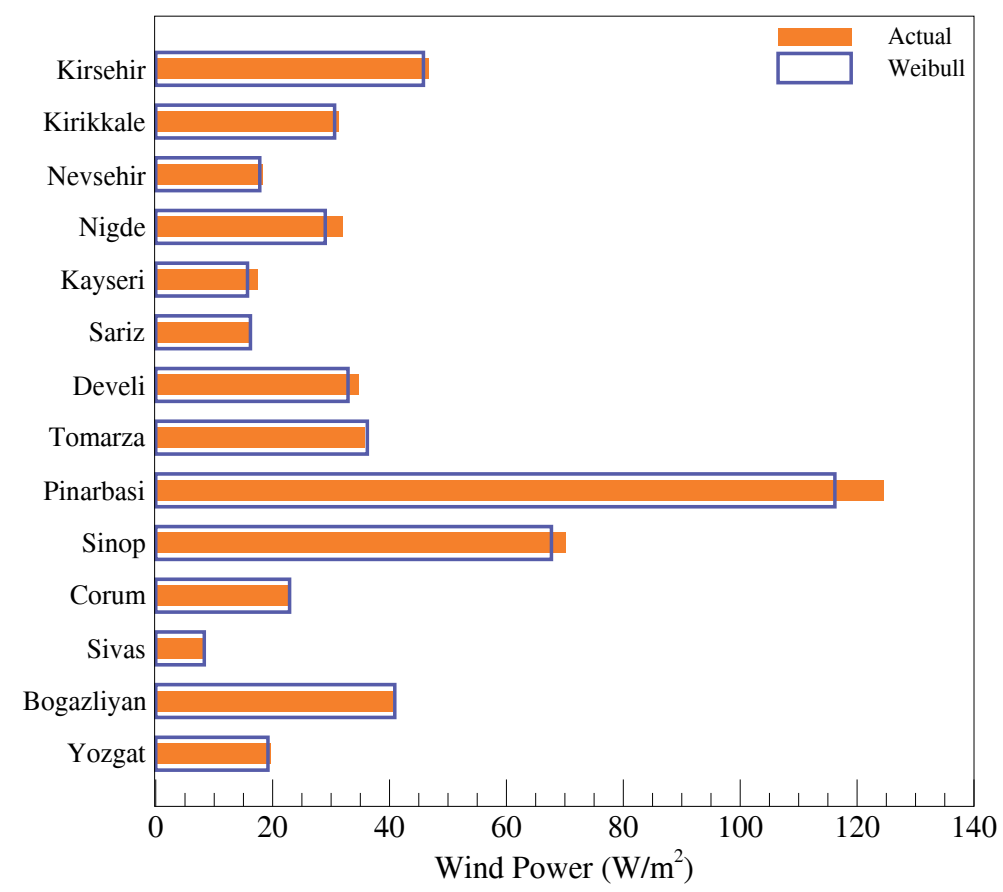

Fig. 10. Annual wind power density distributions in all observation stations for the year 2003

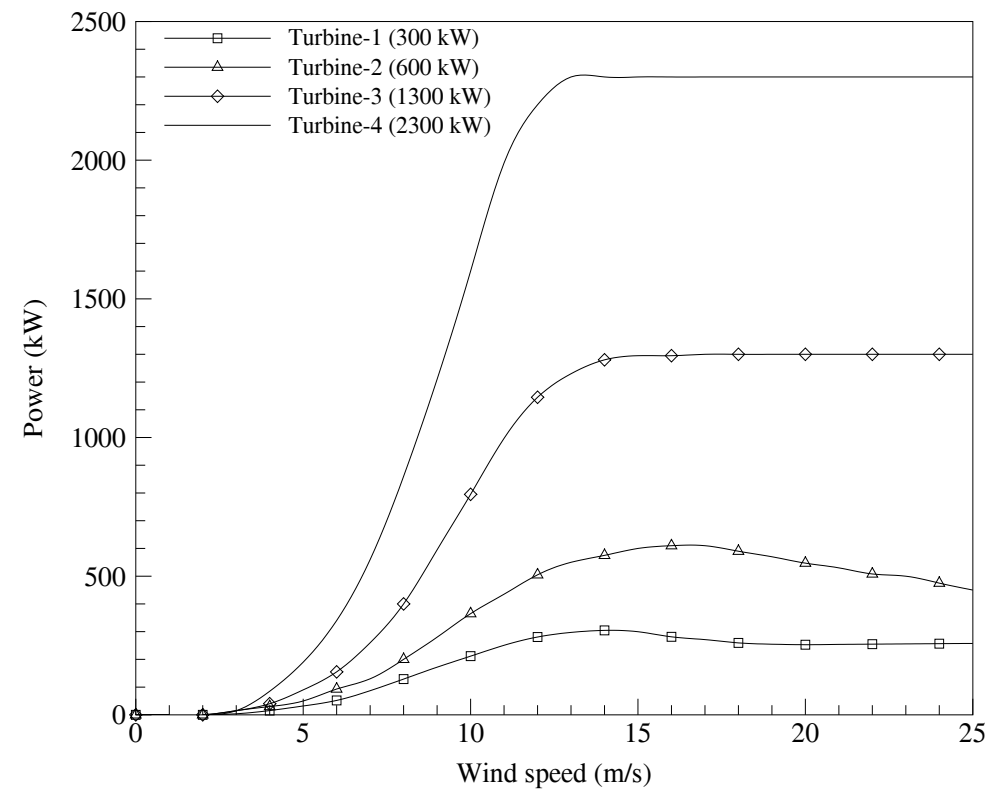

Fig. 11. Power curves of wind turbines selected 
The wind powered electrical energy is affected from the design characteristics of the turbine and the wind potential. Instead of designing a wind turbine for the site if a wind energy conversion system which is suitable for the site is selected, the energy cost of this system will be less. Because the designing a wind turbine for the site requires extra funds, so it should be chosen from the existing wind turbines suitable for the wind characteristics of the site in the market. And, the feasibility study and economic analysis of the system should be done to select the wind turbines suitable for the wind characteristics of the site. In this study, the economic analysis of wind energy conversion systems was carried out using the large scale wind energy conversion systems with different rated power. The power curves of the large scale $(200 \mathrm{~kW})$ wind turbines (named as Turbine-1 $(300 \mathrm{~kW})$, Turbine-2 $(600 \mathrm{~kW})$, Turbine-3 $(1300 \mathrm{~kW})$ and Turbine-4 $(2300 \mathrm{~kW}))$ considered in this study are given in Fig. 11. The technical specifications of these wind turbines are listed in Table 5 (Freris 1990, Pullen 2007).

\begin{tabular}{|l|c|c|c|c|}
\hline Characteristics & Turbine-1 & Turbine-2 & Turbine-3 & Turbine-4 \\
\hline Rated power $(\mathrm{kW})$ & 300 & 600 & 1300 & 2300 \\
\hline Hub height $(\mathrm{m})$ & 30 & 40 & 60 & 80 \\
\hline Rotor diameter $(\mathrm{m})$ & 33 & 44 & 62 & 90 \\
\hline Swept area $\left(\mathrm{m}^{2}\right)$ & 875 & 1520 & 2830 & 6362 \\
\hline Cut-in wind speed $\left(V_{c i}\right)(\mathrm{m} / \mathrm{s})$ & 3 & 3 & 3 & 4 \\
\hline Rated wind speed $\left(V_{R}\right)(\mathrm{m} / \mathrm{s})$ & 15 & 15 & 15 & 13 \\
\hline Cut-off wind speed $\left(V_{R}\right)(\mathrm{m} / \mathrm{s})$ & 25 & 25 & 25 & 25 \\
\hline
\end{tabular}

Table 5. Technical specifications of the wind energy conversion systems considered

Furthermore, in order to evaluate the costs of wind powered electrical energy $(\$ / \mathrm{kWh})$ using these wind energy conversion systems considered for Pinarbasi, Sinop, Kirsehir, Nigde and Develi whose mean annual wind speeds are higher than $3.5 \mathrm{~m} / \mathrm{s}$, some assumptions were agreed as follows :

- The lifetime of wind energy conversion system, $\mathrm{n}$ was considered as 25 years.

- The discount rate, $\mathrm{r}$ was assumed as $12 \%$.

- The operation and maintenance cost, $\mathrm{C}_{o m}$ was considered as $15 \%$ of the annual cost of wind energy conversion system (Nouni et al., 2007)

- The useful life of the battery bank was taken as 7 (Nouni et al., 2007)

- The useful life of the inverter was considered as 10 years (Nouni et al., 2007)

- The escalation ratio of operation and maintenance, battery bank and inverter were assumed as 3.5\% based on the annual average of twelve months of Producer Price Index of Turkish Statistical Institute (Turkish Statistical Institute, May 2010).

- Furthermore, it was assumed that the wind energy conversion system would produce same energy output in each year during its useful lifetime.

- The specific turbine cost was taken as $1000 \$ / \mathrm{kW}$ for large wind energy conversion systems in this study.

According to these assumptions, the annual energy outputs, capacity factors, the costs of energy output computed to estimate the performance of the different wind energy conversion systems in Pinarbasi, Sinop, Kirsehir, Nigde and Develi observation stations are given in Table 6. When it is looked at the Table 5, it is seen that the maximum annual energy output, 
$\left(E_{w t}\right)$ is 4058,143 MWh/year for Pinarbasi and 3330,763 MWh/year for Sinop produced from Turbine-4 enjoying $2300 \mathrm{~kW}$ rated power at $100 \mathrm{~m}$ hub height whereas the minimum annual energy output is 117,737 MWh/year produced from Turbine- 1 with $300 \mathrm{~kW}$ rated power in Nigde at $50 \mathrm{~m}$ hub height. It can be concluded that the annual power output of Turbine- 4 in Pinarbasi can supply the annual electricity consumption of 434 households which are $14 \%$ of 3051 households in Pinarbasi city center (Pinarbasi District, 2010) when it is considered the data of Wind and Hydropower Technologies Program, which is approximately $9360 \mathrm{kWh}$ per year (Wind and Hydropower Technologies Program, 2003).

\begin{tabular}{|c|c|c|c|c|c|c|c|}
\hline \multirow{2}{*}{\multicolumn{2}{|c|}{$\begin{array}{l}\text { WECS } \\
\text { Hub height (m) }\end{array}$}} & \multicolumn{3}{|c|}{ Turbine-1 (300 kW) } & \multicolumn{3}{|c|}{ Turbine-2 (600 kW) } \\
\hline & & 50 & 80 & 100 & 50 & 80 & 100 \\
\hline \multirow{3}{*}{ Pinarbasi } & $E_{w t}(\mathrm{kWh} /$ year $)$ & 441515 & 560086 & 620075 & 678387 & 832002 & 906448 \\
\hline & $C_{f}$ & 0.17 & 0.21 & 0.24 & 0.13 & 0.16 & 0.17 \\
\hline & $C_{\text {elc }}(\$ / \mathrm{kWh})$ & 0.13 & 0.10 & 0.09 & 0.17 & 0.14 & 0.13 \\
\hline \multirow{3}{*}{ Sinop } & $E_{w t}(\mathrm{kWh} /$ year $)$ & 330707 & 447390 & 507447 & 536381 & 710666 & 799973 \\
\hline & $C_{f}$ & 0.13 & 0.17 & 0.19 & 0.10 & 0.14 & 0.15 \\
\hline & $C_{e l c}(\$ / \mathrm{kWh})$ & 0.17 & 0.13 & 0.11 & 0.22 & 0.16 & 0.14 \\
\hline \multirow{3}{*}{ Kirsehir } & $E_{w t}(\mathrm{kWh} /$ year $)$ & 131787 & 176618 & 200303 & 235101 & 303945 & 339734 \\
\hline & $C_{f}$ & 0.05 & 0.07 & 0.08 & 0.04 & 0.06 & 0.06 \\
\hline & $C_{\text {elc }}(\$ / \mathrm{kWh})$ & 0.44 & 0.33 & 0.29 & 0.49 & 0.39 & 0.34 \\
\hline \multirow{3}{*}{ Nigde } & $E_{w t}(\mathrm{kWh} /$ year $)$ & 117737 & 159872 & 182154 & 219260 & 286161 & 320636 \\
\hline & $C_{f}$ & 0.04 & 0.06 & 0.07 & 0.04 & 0.05 & 0.06 \\
\hline & $C_{e l c}(\$ / \mathrm{kWh})$ & 0.49 & 0.36 & 0.32 & 0.53 & 0.40 & 0.36 \\
\hline \multirow{3}{*}{ Develi } & $E_{w t}(\mathrm{kWh} /$ year $)$ & 146338 & 198443 & 226924 & 248777 & 311527 & 3460873 \\
\hline & $C_{f}$ & 0.06 & 0.08 & 0.09 & 0.05 & 0.06 & 0.07 \\
\hline & $C_{\text {elc }}(\$ / \mathrm{kWh})$ & 0.39 & 0.29 & 0.25 & 0.46 & 0.37 & 0.33 \\
\hline \multicolumn{2}{|l|}{ WECS } & \multicolumn{3}{|c|}{ Turbine-3 $(1300 \mathrm{~kW})$} & \multicolumn{3}{|c|}{ Turbine-4 (2300 kW) } \\
\hline \multicolumn{2}{|c|}{ Hub height $(\mathrm{m})$} & 50 & 80 & 100 & 50 & 80 & 100 \\
\hline \multirow{3}{*}{ Pinarbasi } & $E_{w t}(\mathrm{kWh} /$ year $)$ & 1347479 & 1733873 & 1931328 & 2775982 & 3628222 & 4058143 \\
\hline & $C_{f}$ & 0.12 & 0.15 & 0.17 & 0.14 & 0.18 & 0.20 \\
\hline & $C_{\text {elc }}(\$ / \mathrm{kWh})$ & 0.19 & 0.14 & 0.13 & 0.16 & 0.12 & 0.11 \\
\hline \multirow{3}{*}{ Sinop } & $E_{w t}(\mathrm{kWh} /$ year $)$ & 997194 & 1387077 & 1595469 & 2046408 & 2886966 & 3330763 \\
\hline & $C_{f}$ & 0.09 & 0.12 & 0.14 & 0.10 & 0.14 & 0.17 \\
\hline & $C_{e l c}(\$ / k W h)$ & 0.25 & 0.18 & 0.16 & 0.22 & 0.15 & 0.13 \\
\hline \multirow{3}{*}{ Kirsehir } & $E_{w t}(\mathrm{kWh} /$ year $)$ & 391615 & 522453 & 593292 & 698218 & 992149 & 1153126 \\
\hline & $C_{f}$ & 0.03 & 0.05 & 0.05 & 0.03 & 0.05 & 0.06 \\
\hline & $C_{\text {elc }}(\$ / \mathrm{kWh})$ & 0.64 & 0.48 & 0.42 & 0.63 & 0.44 & 0.38 \\
\hline \multirow{3}{*}{ Nigde } & $E_{w t}(\mathrm{kWh} /$ year $)$ & 358206 & 481710 & 547622 & 565673 & 839912 & 991640 \\
\hline & $C_{f}$ & 0.03 & 0.04 & 0.05 & 0.03 & 0.04 & 0.05 \\
\hline & $C_{\text {elc }}(\$ / \mathrm{kWh})$ & 0.69 & 0.52 & 0.46 & 0.78 & 0.52 & 0.44 \\
\hline \multirow{3}{*}{ Develi } & $E_{w t}(\mathrm{kWh} /$ year $)$ & 424690 & 565792 & 641770 & 688535 & 1005863 & 1185565 \\
\hline & $C_{f}$ & 0.04 & 0.05 & 0.06 & 0.03 & 0.05 & 0.06 \\
\hline & $C_{e l c}(\$ / \mathrm{kWh})$ & 0.59 & 0.44 & 0.39 & 0.64 & 0.44 & 0.37 \\
\hline
\end{tabular}

Table 6. Annual energy outputs, the capacity factors and the costs of electrical energy produced using wind energy conversion systems considered for different hub heights

Capacity factor, $\mathrm{C}_{f}$ is not the same with the efficiency, and a higher capacity factor is not an indicator of higher efficiency or vice versa. Capacity factor is a factor in measuring the 
productivity of a wind energy conversion system. The large-scale wind turbines typically run at less than full capacity and operate in capacity factor of $20 \%$ to $40 \%$. As is seen from Table 6 , the maximum capacity factor was obtained in Pinarbasi with Turbine- 1 ( $300 \mathrm{~kW})$ at $100 \mathrm{~m}$ hub height as $24 \%$, meanwhile the minimum capacity factor is $3 \%$ being obtained from Turbine-3 $(1300 \mathrm{~kW})$ and Turbine-4 $(2300 \mathrm{~kW})$ at $50 \mathrm{~m}$ hub height in Kirsehir, Nigde and Develi.

According to the cost analysis, it is seen that the minimum cost of energy output is $0.09 \$ / \mathrm{kWh}$ in Pinarbasi and 0.11 \$/kWh in Sinop with Turbine-1 (300 kW) at $100 \mathrm{~m}$ hub height, while the maximum energy cost is $0.78 \$ / \mathrm{kWh}$ in Turbine-4 $(2300 \mathrm{~kW})$ at $50 \mathrm{~m}$ hub height in Nigde.

The minimum cost of energy output in Table 6 is $0.09 \$ / \mathrm{kWh}$ in Pinarbasi and $0.11 \$ / \mathrm{kWh}$ in Sinop with Turbine-1 (300 kW) enjoying the $100 \mathrm{~m}$ hub height, while the energy cost of Turbine-4 $(2300 \mathrm{~kW})$ at $50 \mathrm{~m}$ hub height in Nigde has been calculated as maximum cost $(0.78$ $\$ / \mathrm{kWh}$ ). According to renewable energy law, Turkey Energy Market Regulatory Authority determined mean wholesale trade price of electric as 13,32 Ykr $/ \mathrm{kWh}$ (about $0.09 \$ / \mathrm{kWh}$ ) in December 19th, 2009 (Turkey Energy Market Regulatory Authority, 2009). The buying price of electricity is $0.09 \$ / \mathrm{kWh}+\mathrm{Tax}=0.11 \$ / \mathrm{kWh}$. According to Turkey Energy Market Regulatory Authority, selling price should not be less than $0.11 \$ / \mathrm{kWh}$. As is seen in Table 6 , the minimum cost of energy output is $0.09 \$ / \mathrm{kWh}$ in Turbine- 1 at $100 \mathrm{~m}$ hub height in Pinarbasi. It is seen clearly that this price is lower than the minimum selling price of electricity determined by Turkey Energy Market Regulatory Authority. Moreover, the wind energy cost of Sinop is equal to the minimum selling price of electricity determined by Turkey Energy Market Regulatory Authority. And, these costs will be decreased as the costs of wind energy systems are lowered based on the development of wind energy technology. In this case, it seems that using of wind energy in Pinarbasi and Sinop is economical.

When the effect of hub height on the capacity factor, energy production, and unit energy cost are investigated for Turbine- $1(300 \mathrm{~kW})$ in Pinarbasi at three different hub heights $(50,80$, $100 \mathrm{~m}$ ) by helping Fig. 12, it can be seen that the capacity factor and annual energy output increase and the unit energy cost decreases due to fact that the mean wind speed increases, as hub height increases.

\section{Conclusion}

Clean and renewable energies obtaining from sunlight, wind or water around the earth do not make a net contribution of carbon dioxide to the atmosphere. Therefore, these energy sources should be used to protect our world, because of global warming and the injurious effects of carbon emissions. And so, it should be estimated the windy and sunny fields in Turkey, the unit cost of energy output of various wind and solar energy conversion systems. Today, wind energy seems to be reasonable due to the fact that the wind energy generating costs are lower than solar energy costs. Moreover, the wind energy has been experienced remarkably rapid growth in the last two decades because its energy generating cost decrease. In this study, it was presented the wind energy potential and characteristics, and the unit energy cost for the various wind energy conversion systems using the levelized cost of electricity method in different sites located in the Central Anatolia region of Turkey.

It is shown that the mean annual wind speeds obtained in this study are correspond to the values on Turkish Wind Atlas for closed plains. Pinarbasi and Sinop are in yellow region where the mean annual wind speed is between $4.5 \mathrm{~m} / \mathrm{s}$ and $5.0 \mathrm{~m} / \mathrm{s}$ on Turkish Wind Atlas for closed plains and it was obtained that Pinarbasi had the wind speed of $5.08 \mathrm{~m} / \mathrm{s}$ and Sinop had the mean annual wind speed of $4.64 \mathrm{~m} / \mathrm{s}$ at $50 \mathrm{~m}$ hub height in this study. Consequently, according to the mean annual wind speeds obtained in this study, Pinarbasi and Sinop can be 


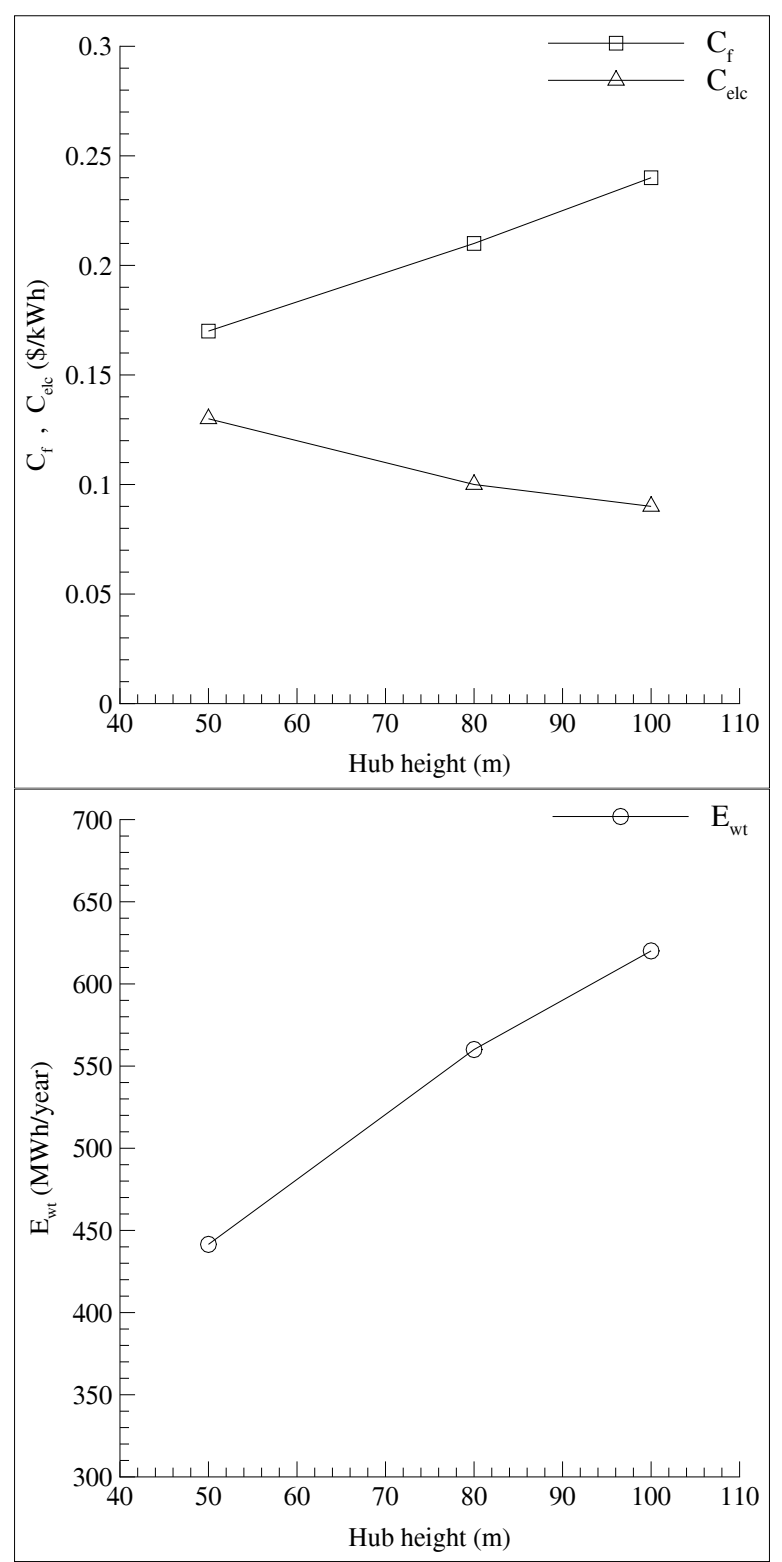

Fig. 12. Annual energy output, the capacity factor and the cost of electrical energy produced using wind energy conversion system with $300 \mathrm{~kW}$ rated power at different hub heights in Pinarbasi

characterized as marginal site (fairly good) in the Central Anatolia region of Turkey in point of wind energy potential.

Furthermore, it was found that the maximum annual energy output was 4058,143 MWh/year for Pinarbasi and 3330,763 MWh/year for Sinop produced from Turbine-4 enjoying $2300 \mathrm{~kW}$ rated power at $100 \mathrm{~m}$ hub height whereas the minimum annual energy output is 117,737 
MWh/year produced from Turbine- 1 with $300 \mathrm{~kW}$ rated power in Nigde at $50 \mathrm{~m}$ hub height. According to the cost analysis, it is seen that the minimum cost of energy output is $0.09 \mathrm{\$} / \mathrm{kWh}$ in Pinarbasi and 0.11 \$ $/ \mathrm{kWh}$ in Sinop with Turbine-1 $(300 \mathrm{~kW})$ at $100 \mathrm{~m}$ hub height, while the maximum energy cost is $0.78 \mathrm{\$} / \mathrm{kWh}$ in Turbine-4 $(2300 \mathrm{~kW})$ at $50 \mathrm{~m}$ hub height in Nigde. These wind energy cost of Pinarbasi and Sinop are lower than and equal to the minimum selling price of electricity determined by Turkey Energy Market Regulatory Authority. And, it seems that using of wind energy in Pinarbasi and Sinop is economical.

\section{References}

[1] Archer, C.L., Jacobson, M. Z. (2005). Evaluation of global wind power. Journal of Geophysical Research, Vol. 110, No. D12, pp. D12110.1-D12110.20.

[2] Acker, T.L., Williams, S.K., Duque, E.P.N., Brummels, G., Buechler, J. (2007). Wind resource assessment in the state of Arizona: Inventory, capacity factor, and cost. Renewable Energy, Vol. 32, pp. 1453-1466.

[3] Ahmet Shata, S. A., and Hanitsch, R. (2006). Evaluation of wind energy potential and electricity generation on the coast of Mediterranean Sea in Egypt. Renewable Energy, Vol. 31, pp. 1183-1202.

[4] Akpinar, E. K., and Akpinar, S. (2004). Determination of the wind energy potential for Maden-Elazig, Turkey. Energy Conversion and Management, Vol. 45, pp. 2901-2914.

[5] Bagiorgas, H.S., Assimakopoulos, M.N., Theoharopoulos, D., Matthopoulos, D., Mihalakakou, G.K. (2007). Electricity generation using wind energy conversion systems in the area of Western Greece. Energy Conversion and Management, Vol. 48, pp. 16401655.

[6] Bilgili, M., Sahin, B., Kahraman, A. (2004). Wind energy potential in Antakya and Ýskenderun regions, Turkey. Renewable Energy, Vol. 29, pp. 1733-1745.

[7] Bilgili, M., Sahin, B. (2009). Investigation of wind energy density in the southern and southwestern region of Turkey. J. Energy Engineering-ASCE, Vol. 135, pp. 12-20.

[8] Bouzidi, B., Haddadi, M., Belmokhtar, O. (2009).Assessment of a pumping system in the areas of the Algerian Sahara. Renewable and Sustainable Energy Review, Vol. 13, pp. 879-886.

[9] Burton T, Sharpe D, Jenkins N, Bossanyi E. Wind Energy Handbook. Chichester: John Wiley and Sons, Ltd.; 2001.

[10] Çelik, A. N. (2003). A statistical analysis of wind power density based on the Weibull and Rayleigh models at the southern region of Turkey. Renewable Energy, Vol. 29, pp. 593-604.

[11] Çelik, A.N. (2007). A techno-economic analysis of wind energy in southern Turkey. Int. J. Green Energy, Vol. 4, pp. 233-247.

[12] Chang, T.J., Tu, Y.L. (2007). Evaluation of monthly capacity factor of WECS using chronological and probabilistic wind speed data: A case study of Taiwan. Renewable Energy, Vol. 32, pp. 1999-2010.

[13] Dündar, C., Canbaz, M., Akgün, N., Ural, G., Türkiye Rüzgar Atlasi, EIEI and DMI, 2002.

[14] Freris, L. L. (1990). Wind energy conversion systems, Prentice-Hall Inc, Cambridge, UK.

[15] Genç, M.S., (2010). Economic Viability of Water Pumping Systems Supplied by Wind Energy Conversion and Diesel Generator System in North Central Anatolian, Turkey. J. Energy Engineering-ASCE, 10.1061/(ASCE)EY.1943-7897.0000033, in press. 
[16] Genç, M.S., Gökçek, M. (2009). Evaluation of wind characteristics and energy potential in Kayseri, Turkey. J. Energy Engineering-ASCE, Vol. 135, pp. 33-43.

[17] Gökçek, M., Genç, M.S. (2009). Evaluation of electricity generation and energy cost of wind energy conversion systems (WECSs) in Central Turkey. Applied Energy, Vol. 86, pp. 2731-2739.

[18] Gökçek, M., Bayülken, A., and Bekdemir, S. (2007). Investigation of wind characteristics and wind energy potential in Kirklareli, Turkey. Renewable Energy, Vol. 32, pp. 17391752.

[19] Gökçek, M., Erdem, H.H., Bayülken, A. (2007). A techno-economical evaluation for installation of suitable wind energy plants in Western Marmara, Turkey. Energy Exploration \& Exploitation, Vol. 25(6), pp. 407-428.

[20] Johnson G.L., Wind Energy Systems, Electronic Edition, Manhattan, KS, USA, October 2006.

[21] Justus, C. G., Hargraves, R., Mikhail, A., and Graber, D. (1977). Methods for estimating wind speed frequency distributions. J. Applied Meteorology, Vol. 17, pp. 350-353.

[22] Kakaç, S., Yenilenebilir Enerji Kaynaklari, Bugünü ve Yarini (in Turkish), TÜBA-Günce Dergisi, Vol. 34, May 2006.

[23] Karsli, V. M., and Geçit, C. (2003). An investigation on wind power potential of NurdagiGaziantep, Turkey. Renewable Energy, Vol. 28, pp. 823-830.

[24] Kose, R. (2004). An evaluation of wind energy potential as a power generation source in Kutahya, Turkey. Energy Conversion and Management, Vol. 45, pp. 1631-1641.

[25] Kose, R., Ozgur, M. A., Erbas, O., and Tugcu, A. (2004). The analysis of wind data and energy potential in Kutahya, Turkey. Renewable Sustainable Energy Review, Vol. 8, pp. 277-288.

[26] Morthorst PE. Cost and price, wind energy Ü the facts, Vol. 2, Brussels Ü Belgium: The European Wind Energy Association, 2004.

[27] Ngalaa, G.M., Alkalib, B., Ajia M.A. (2007). Viability of wind energy as a power generation source in Maiduguri, Borno state, Nigeria. Renewable Energy, Vol. 32, pp. 22422246.

[28] Nouni, M.R., Mullick, S.C., Kandpal, T.C. (2007). Techno-economics of small wind electric generator projects for decentralized power supply in India. Energy Policy, Vol. 35, pp. 2491-2506.

[29] Ozerdem, B., Ozer, S., Tosun, M. (2006). Feasibility study of wind farms: A case study for Izmir, Turkey. Journal of Wind Engineering and Industrial Aerodynamics, Vol. 94, pp. 725-743.

[30] Pullen, A. (2007). Global wind energy markets continue to boom-2006-Another record year, Global Wind Energy Council Press Release, Brussels, Belgium.

[31] Pidwirny, M. (2006). Forces Acting to Create Wind. Fundamentals of Physical Geography, 2nd Edition. Date Viewed. http://www.physicalgeography.net/fundamentals/7n.html

[32] Rehman S., El-Amin. I.M., Ahmad, F., Shaahid, S.M., Al-Shehri, A.M., Bakhashwain, J.M. (2007). Wind power resource assessment for Rafha, Saudi Arabia. Renewable and Sustainable Energy Review, Vol. 11, pp. 937-950.

[33] Saheb-Koussa, D., Haddadi, M., Belhamel, M. (2009). Economic and technical study of a hybrid system (wind-photovoltaic-diesel) for rural electrification in Algeria. Applied Energy, Vol. 86, pp. 1024-1030. 
[34] Sahin, B., Bilgili, M., and Akilli, H. (2005). The wind power potential of the eastern Mediterranean region of Turkey. Journal of Wind Engineering and Industrial Aerodynamics, Vol. 93, No.2, pp. 171-183.

[35] Sahin, B., Bilgili, M. (2009). Wind characteristics and energy potential in Belen-Hatay, Turkey. Int. J.Green Energy, Vol. 6, pp. 157-172.

[36] Sathyajith, M. (2006). Wind Energy Fundamentals, Resource Analysis and Economics, Springer-Verlag, Berlin Heidelberg, New York.

[37] Wind and Hydropower Technologies Program (2003) Small wind electric systems [electronic resource] - A Massachusetts consumer's guide, US Department of Energy, DOE/GO102003-1747, Washington, D.C.

[38] Republic of Turkey, Pinarbasi District (2010). http:/ / www.kayseripinarbasi.gov.tr.

[39] Turkey Energy Market Regulatory Authority (2010). http:/ /www.epdk.gov.tr.

[40] Turkish State Meteorological Service (TSMS) (2010). http:/ / www.meteor.gov.tr.

[41] Turkish Statistical Institute (TSI) (June, 2010). http:/ / www.turkstat.gov.tr.

[42] World Wind Energy Association (2010). http:/ / www.wwindea.org. 


\title{
Energy systems comparison and clean high tech evolution
}

\author{
Gustav R. Grob \\ Fellow of the Energy Institute F.EI, London (former F.IP) \\ Executive Secretary, International Sustainable Energy Organization ISEO \\ Chairman of ISO/TC203/WG3 Technical Energy Systems Analyses \\ President of the International Clean Energy Consortium ICEC
}

Energy investment decisions must be based on the full costing principle, including the external social cost and risks. The graph below shows the comparison of presently known energy systems. It is evident that conventional power plants cannot compete with clean, sustainable ones anymore.

Depending on the size, type and location of the energy system there is an operational cost range from the light blue minimum to the darker blue maximum. The green external cost comprise health cost due to pollution and damages to the environment and climate, whereby the cost of flooded islands and coastal regions from rising ocean levels due to global warming can hardly be quantified, as well as killed people by weather disasters or cancers from nuclear radiation. Affected agricultures and bio diversity by acid rains and draughts or noise are also external cost.

The risk factor of power plants is also part of the cost equation. No insurance company is covering the full risk of nuclear power, because of the infinite damages, accidents at such plants could cause, as was the case at Chernobyl with millions of contaminated people and biospheres. USA Professor Sternglass proved with official Department of Health statistics that around all nuclear power plants much higher health cancer rates were observed - see facts on www.radiation.org.

Based on the international standard ISO 13602-1 for energy systems analyses the true, total energy cost including all by-products, side effects and risks of energy systems can be calculated.

The oldest clean energies are the sun, biomass, wind and hydropower, complemented by ocean waves, tides and OTEC. They depend on varying weather conditions and seasonal cycles but are more and more competitive with non-renewable systems thanks to lower external cost and less dependency on the speculative fuels coal, petroleum, gas and uranium with their increasing cost. 


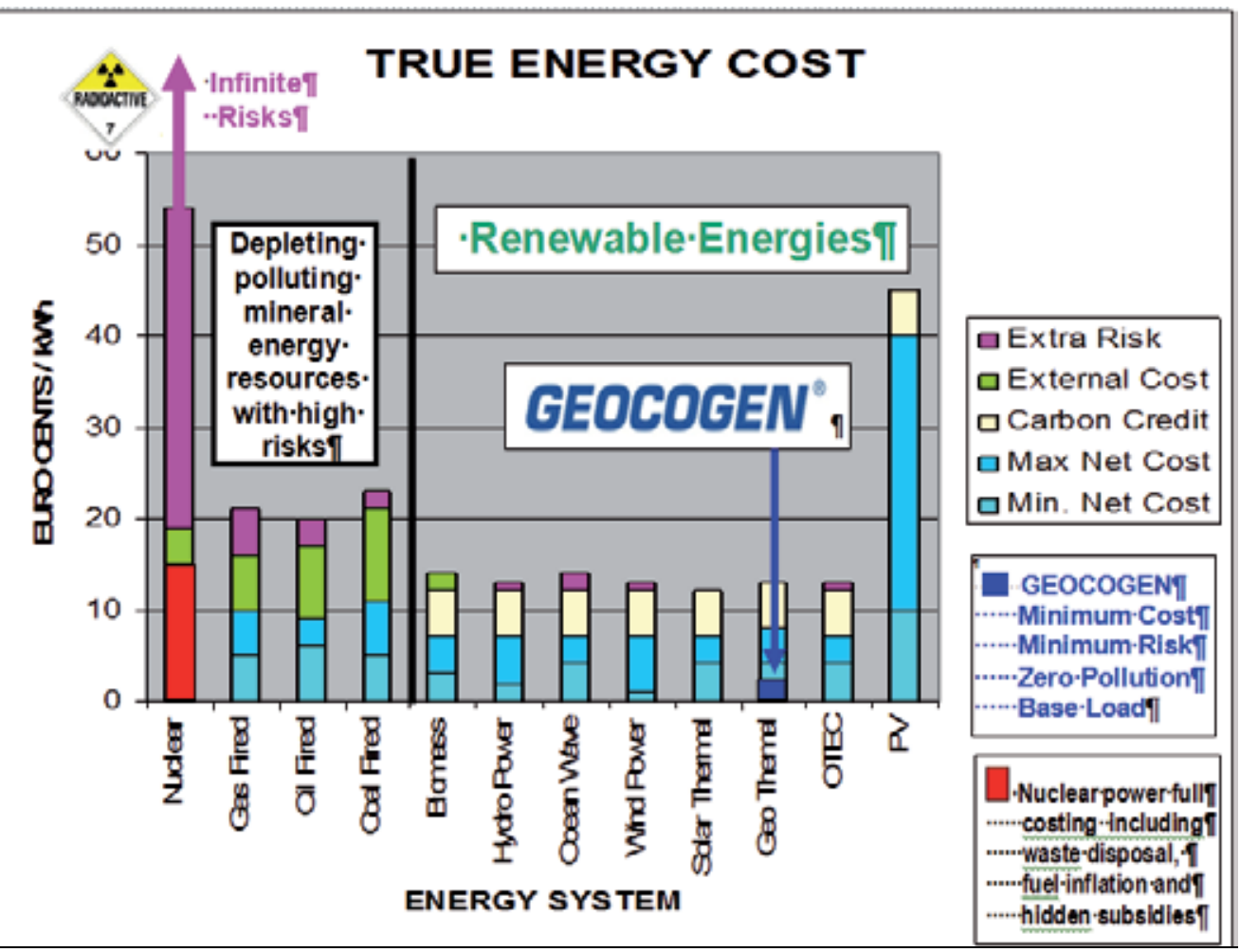

Fig. 1.

The world economy needs thousands of Giga Watt base load power in view of the modernization of life and a rapidly increasing number of electric vehicles which have to be recharged overnight.

Unlimited GW base load energy systems are the space-based solar power SBSP (space based solar power) transmitted to energy consumption areas on Earth and the $4^{\text {th }}$ generation deep-well hot rock GEOCOGEN (geothermal co-generation). Both can be built safely where energy is used, thus avoiding high transmission cost and losses from remote locations. International ISO-IEC standards are indispensable to implement energy systems.

\section{Energy History}

Cosmic nebula consist of overabundant energy. Our Earth and Moon sparked off in the solar system by immense power, full of geothermal energy, apparent by volcanic eruptions since millions of years. All life on Earth thrives from the solar energy, which is radiated into the atmosphere causing plants to grow, water to evaporate, wind and waves to move. The moon cycles drive the tidal movements, supplying abundant ocean energy onto the sea shores.

Energy and genius enabled the emergence of the human evolution in prehistoric times, which started off with the use of human muscle power for hiking, running, rowing, hunting and plant harvesting for food, using also dried biomass and dung for cooking and heating - 
thanks to the discovery of fire. But also geothermal springs and primitive solar food drying and heating were applied. Food was the source of this natural human bio-energy.

In ancient times man started to apply wind energy for sailing, pumping and milling, and made use of animal muscle power for farming, transport and other mechanical work. The "horsepower" (hp) denominated mechanical performance since the industrial revolution, which evolved from the bio, geo, wind and hydro energies to mineral energy sources, having started with the coal discovery for combustion in fire places, steam boilers and central heating systems.

The harnessing of petroleum reservoirs in the 20th century started the modern age with its incessantly rising mobility, industrialization, building comfort and communication technologies. The concept of combustion engines and thermal power plants culminated in modern nuclear technology - again using finite mineral resources, resulting in the peak phenomena within the millennium fraction of human technical history, as dramatically illustrated by following graph.

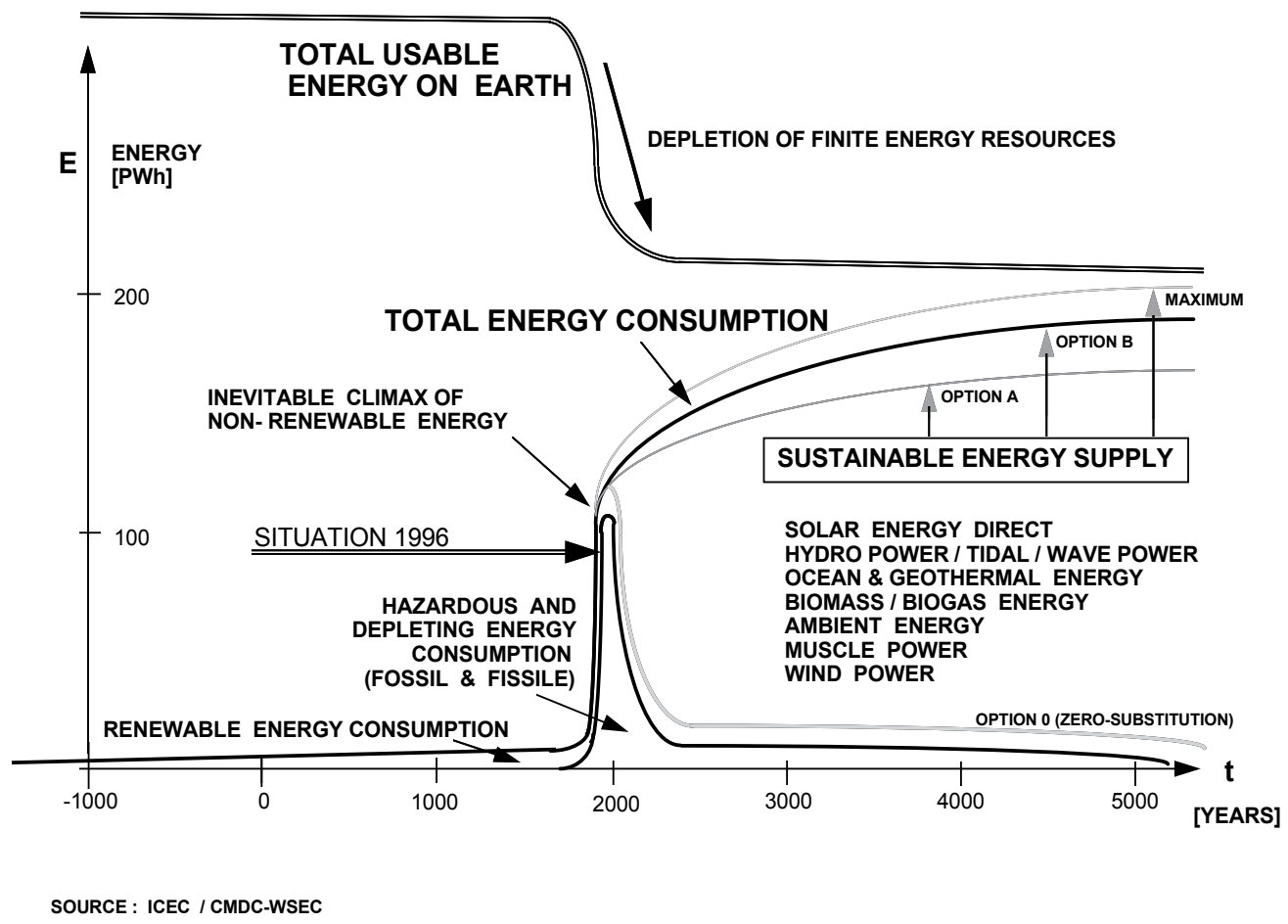

Fig. 2. Energy history and forecast

The fatal crux of the majority of energy systems over the last two centuries is the finite nature of their mineral sources and their catastrophic impacts on human health and on the natural climatic and biosphere cycles and balances, with incalculable risks in the case of nuclear fission and fusion energy, which insanely absorbed public and private funds of trillions of dollars. 
The calamity with most systems using finite energy resources is the fact, that engineers, physicists and chemists did not care about the holistic assessment of all side and after effects of their inventions. They did neither care about the environmental and health impacts of their use, nor about the resource depletion, nor about the consequences of the waste and safety hazards of such systems. The gasoline and Diesel engines are one typical example of such blindness - they would be prohibited by modern environmental and occupational health and safety laws - not to mention the heavy metal particle emissions by modern cars. Nuclear power, which originated from the development of weapons for mass destruction, is another shocking example, where neither material failures and human risks, nor the safe waste disposal, nor the wasteful Uranium mining with fossil fuel driven engines were put into a total cost and fallacy assessment.

Geologist Dr. Colin Campbell, publisher of the monthly ASPO reports about the world-wide oil and gas resource depletion, calls this fatal period in history the "The Age of Hydrocarbon Man" and foresees a collapse of the industrial age and the environment, if not enough is done fast enough to substitute mineral energy concepts by benign, sustainable energy systems.

\section{Future Energy Needs of Humanity}

All we need in future are energy services for better comfort, mobility, communication, work and leisure, which do not jeopardize our life basis with radiation risks, hazardous pollution, global warming, rising oceans, melting glaciers and further biosphere and ocean life deteriorations.

How can such clean energy services be provided to everybody in a sustainable manner - also to the billions of underprivileged people in the world, who could not enjoy the convenience of electricity, health care, hygienic habitat, basic education and modern mobility up to now?

The answer is simple: there is so much renewable energy available on Earth for thousands of years, that we can stop squandering mineral resources and conserve them for the chemical industry for many centuries, which would otherwise be depleted within one or two generations.

This future scenario is illustrated by the following graph, showing the gradual reduction of finite energy resource use to zero while increasing the renewable energy production drastically in order to satisfy development needs of the whole world, reflected in the $2 \%$ annual increase.

However, an annual energy consumption growth of merely $2 \%$ is only possible, if all conceivable energy efficiency measures are applied world-wide, which means the prohibition of all wasteful incandescent and halogen lamps, the substitution of all lowefficiency thermal engines in cars and power plants and the much better insulation of buildings and refrigerators.

The transition to a sustainable energy economy means in monetary terms the re-channelling of annually over one trillion USD from harmful subsidies and mineral energy investments to clean, sustainable energy systems. Another trillion could be re-channelled from exaggerated military budgets, since oil wars and other mineral resource disputes will be made superfluous. 


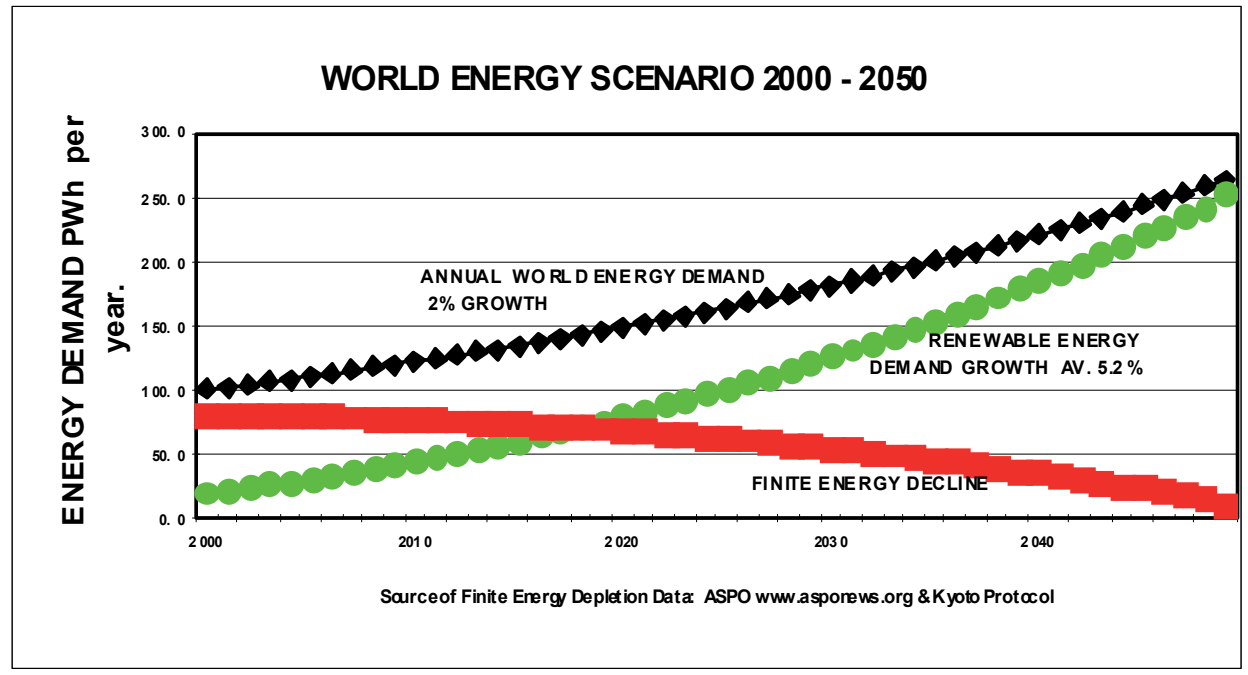

Fig. 3.

Some pessimists keep saying that energy consumption has to be reduced to less than half in industrialized nations, in order to allow the less developed countries an energy consumption increase. The term convergence is often used in this context: less for the affluent society and more for the poor, which sounds socially fair. The awkward term "2000 Watt Society" was coined for this austerity concept by somebody who confused the power unit $\mathrm{kW}$ with the legal energy units $\mathrm{kWh}$ or Joule, thus suggesting that there is not enough "power" available for the growing world population. With this utterly misleading terminology non-technical citizens get the wrong impression that merely $2 \mathrm{~kW}$ would be allocated to each of them, while their car and indispensable heating and cooking stoves have a multiple of this performance. What is really meant by this credo, is that all citizens on this planet shall limit their annual energy consumption to $2000 \mathrm{~W} \times 8760$ hours $=17^{\prime} 520 \mathrm{kWh}$ and thus must choose their preference and priorities whether to use this allocation for more comfort, mobility or for energy at their work.

Such pessimists are right in their conviction that too much energy is wasted nowadays with badly insulated houses and fridges, too heavy vehicles, inefficient combustion engines and light sources. But they are totally wrong in their believe that energy from mineral resources could be stretched forever merely by increased efficiency and that average people would forego some of the modern mobility pleasures, leisure gadgets, work aids, travel joys and living comforts. They grossly misjudge human nature with its desires and the temptations from modern technology!

What is absolutely right, is that energy emission impacts cannot any longer be paid by the victims in human society in terms of health cost, loss of environmental quality - resulting in a reduced quality of life, genetic damages from radiation, noise from inappropriate transport modes etc. - and that a more efficient use of energy is surely easing energy emission hazards. 
To make the polluters pay, total cost accounting must be enforced to make them accountable for the damage to the impaired. This is only possible with a world-wide tax reform, which re-directs hazard costs to cleaner, quieter and less risky energy systems. The technical committee ISO/TC203 (International Standards Organization in Geneva) has issued standard Nr. 13602-1, which allows the calculation of the total energy cost - including all external, social cost - by making all inputs and outputs of energy systems quantifiable in legal SI units. Thus all energy systems become economically and ecologically comparable, which have to be reflected in complete energy statistics and a better energy forecasting methodology, as also tackled by ISO.

\section{The Future Energy Solutions}

There is no lack of sustainable energy on Earth, making finite, polluting energy resources totally superfluous! The former Saudi Minister of Petroleum Sheikh Zaki Yamani has put it quite simple in saying that "the stone age did not come to an end, because of the lack of stones" and that similarly "the petroleum age will not be ended because of the lack of fossil fuels".

The sun is radiating daily about 10'000 times more solar energy to the surface of the Earth, than the total world energy consumption. The solar-induced bio-energy in nature and from energy crops could cover more than all present energy needs, if properly managed and utilized. The very economical hydro- and wind power electricity production can still be multiplied around the world to satisfy all electricity needs, complemented by geothermal energy and ocean energy, which are so abundant that they alone could again satisfy all energy demand, plus the direct solar energy on billions of roofs and along roads for electricity and heat which is able to grow by over $30 \%$ per annum, if economically mass produced and further optimised by more research. Space based solar power (SBSP) could be another modern base load electricity source in the GW class.

Hence, there is more sustainable energy available than humans ever need, which leads to the logic conclusion that all polluting energy systems can be replaced and no more such systems should be produced at all. They shall even be prohibited by international law and the United Nations to the benefit of a healthier, happier survival of life on planet Earth.

The energy supply infrastructure is undergoing a similar change like the computer technology:

from expensive central units to a decentralized, economic mix of interconnected small systems like solar panels and wind generators on the roofs, heat pumps and fuel cells in the basements and cogeneration units fuelled by local biomass instead of imported minerals. Evidently, the energy multinationals and large power producers do not like this trend, which makes them gradually lose their monopolistic grip on the energy business, the control over electricity grids and the fuel supply chains, when consumers will be covering their energy needs themselves.

To accelerate this overdue world-wide transition to the "Post-Mineral Energy Age, the International Sustainable Energy Organization ISEO was initiated by Swiss parliamentarians of all political parties in 2002 and got legally established in March 2003 in 
Geneva, the birthplace of the League of Nations, the Red Cross and the United Nations with its many economic and social council bodies, cooperating closely with relevant NGOs like ISO, to accomplish this global survival task of historic dimensions, thus allowing all nations and their people to develop their civilizations in a sustainable manner with equitable, clean and benign energy systems.

ISEO promotes the "Blueprint for the Clean, Sustainable Energy Age" with its "Geneva Declaration" as implementation guide for governments, academia and the private sector. Its web portal www.uniseo.org contains all necessary technical, legislative, educational and financial implementation tools, based on the heuristic "Global Energy Charter for Sustainable Development". Consequently oil wars will become superfluous and most nations can become energy self-sufficient without wasting their foreign exchange on hazardous energy imports, bringing drastically down health cost and environmental rehabilitation expenses in future.

\section{Mobility of the Future}

Mobility is one of the four main urges of human beings. It was kept in environmentally acceptable proportions, as long as only boots, horses, sledge dogs and sail ships were used. The steam engines with their coal firing did not make much leeway either, except for railway locomotives and ships until coal was replaced by the more convenient liquid fossil fuels.

The discovery and refining of crude oil, combined with combustion engines, changed the whole mobility concept, when modern vehicles and aeroplanes were developed and mass produced in the $20^{\text {th }}$ century. This mobility drive due to scattered habitats with more and more remote work places, food sources and holidays changed human habits fundamentally, to degenerate into one of the main nuisances to people and nature with its increasing pollution and noise.

The curse was the cheap fossil fuel supply and the low engine efficiency, which caused the depletion of over half of the economically viable energy resources within one century with now over one billion vehicles in service world-wide. The enormous expansion of air traffic for leisure, work and defence with its impact on the sensitive atmospheric strata worsened the situation.

Hydrogen seemed to be the clean answer to the dilemma of substituting about one third of the fossil energy consumption wasted in transport. Among the hydrogen drive concepts fuel cells look more promising than combustion engines, because of their much higher efficiency and silence. However, the clean production and storage of hydrogen is expensive and the fuel cell merely produces electricity, which necessities finally an electric drive system to turn the wheels.

By comparing the composite cost of hydrogen vehicles with the cost of electric vehicles with advanced batteries, one must conclude that the ultimate mobility solution are pure electric vehicles with safe high-density batteries, which are emerging now from intensive research and development. This ultimate concept costs less than half of any fuel solution and does neither cause emissions, nor engine noise, and does not necessitate an expensive fuel supply chain with its energy losses in transport and storage, and thus will satisfy people's expectations for their future individual mobility - similar to electric trains and buses for public transport. 


\section{Healthy Energy Job Creation and Avoided Uprooting}

All hazardous jobs in coal and uranium mines, on remote oil fields and offshore platforms and in hazardous mineral resource transportation with their too frequent disasters and oil spills will be eliminated by the clean, sustainable energy system production, requiring a multiple of workers compared with the resource intensive conventional energy jobs. The shift from concentrated, finite resource-intensive concepts to labour-intensive decentralized energy system production will provide enough jobs for everybody in their own countries, without necessitating migrations.

The danger of population displacements due to lost coastal zones and islands will also be banned as soon as the cause of rising oceans - manmade global warming - will slow down thanks to clean, sustainable energy systems.

And last but not least - the hitherto strangling health and accident insurance cost will be drastically reduced by the elimination of emissions from fossil energy combustion, minerals transport hazards, and nuclear radiation damages! There will also occur fewer sacrificed lives and less casualties and material losses from river floods, disastrous storms, land slides and rising oceans, as more and more frequently experienced in the last few decades of the fossil fuel frenzy, resulting in the unprecedented steep rise of man-made global warming and dramatic oil spills!

\section{Conclusions and Future Outlook}

Humanity can be confident to survive on planet Earth in good livelihood, because

1 - there is enough clean, sustainable energy available for centuries to come

2 - these clean, sustainable energy systems are competitive with finite polluting systems

3 - decentralized, clean sustainable energy conversion will be growing world-wide

4 - environmental impacts can be avoided with clean, sustainable energy systems

5 - mineral resources can be conserved for future generations and must not be burnt any more

6 - this huge historic task can be financed if governments and investors re-direct their money

7 - wars become totally superfluous and a gun-free global society can blossom peacefully

8 - the work can and must be done without further excuses and procrastinating conferences

\section{Artist's View of the Clean Energy Age by Hans Erni}

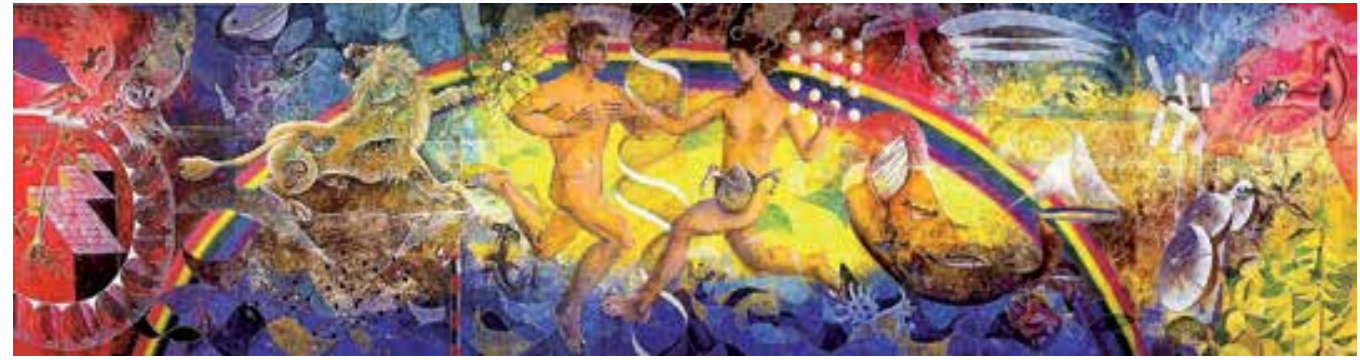

Fig. 4. 


\section{References}

Blueprint for the Clean, Sustainable Energy Age, 2000, Eco-Performance Verlag, ISBN 3909087-08-6

ISO 13'602-1 (2002-11-01), International Standards Organization, 1211 Geneva 20, www.iso.ch

ISO Standard 14'000-series on Environmental Management, www.iso.ch

Driving forces - Energy in ISO \& IEC, G.R. Grob, ISO Bulletin, Volume 28, No.4, April 1997, www.iso.ch

World Clean Energy Conference Proceedings, G.R. Grob, Geneva 4-7 November 1991, www.uniseo.org

World Energy Assessment, José Goldemberg et al, UNDP, New York, ISBN 92-1-126126-0, www.undp.org

The Global Energy Charter for Sustainable Development, CMDC \& ISEO Geneva, www.uniseo.org

ASPO Reports (monthly), the Association of Peak Oil and Gas; London, UK, www.asponews.org

The Coming Oil Crisis, C.J. Campbell, Multi-Science Publishing Co. UK, 1988, ISBN 0906522 110

Ein Planet wird geplündert, (Plundering of a Planet), Herbert Guhl, Fischer Verlag, Frankfurt am Main

Earth in the Balance, Senator Al Gore, 1992, Houghton Mifflin Co., New York, ISBN 0-39557821-3

WHO Report on the Panel on Energy, World Heath Organization, Geneva, 1992, www.who.org 


\title{
Zero emissions future city
}

\author{
Jan Gorski and Evgeny Yantovsky \\ AGH University of Sciences and Technology \\ Cracow, Poland \\ Independent Researcher \\ Aachen, Germany
}

\section{Introduction}

\subsection{Some principal questions}

It is necessary to reduce $\mathrm{CO} 2$ emissions against global warming, and the activities are expanding all over the world. As the world continues its reliance on fossil fuels to meet its growing energy demand, the associated environmental and climate change challenges must be adequately addressed. The world is undergoing the largest wave of urban growth in history and this process is mainly a domain of developing countries. In Europe over 70 percent of population is urban. In many developed countries this concentration is also creating its counterforce: decentralization, urban sprawl, dispersal and splintering of urban space. According to the United Nations reports, the growth in human population is largest in the developing world, with Africa's and Asia's urban population projected to double between 2000 and 2030. With approximately 3.4 billion people (in 2009), more than 50 percent of the world population living in cities and both human activities and the use of energy also concentrated in cities, the urban areas have become the root cause of orientating societies toward mass production, mass consumption and mass dumping of waste. In the world-wide urbanization process a particular significance have mega-cities (i.e. metropolises with more than 5 million people). According to the UN reports (Kraas, 2007), in the year 2015 more than 600 million people will be living in about 60 mega-cities worldwide, see Fig.1. While megacities have captured much public attention, most of the new growth will occur in smaller towns and cities, which have fewer resources to respond to the magnitude of the change. Urban areas sprawl deeply into regions surrounding cities and towns. Increased income and wealth has enabled extensive new construction of infrastructures and transportation within functional urban regions. 


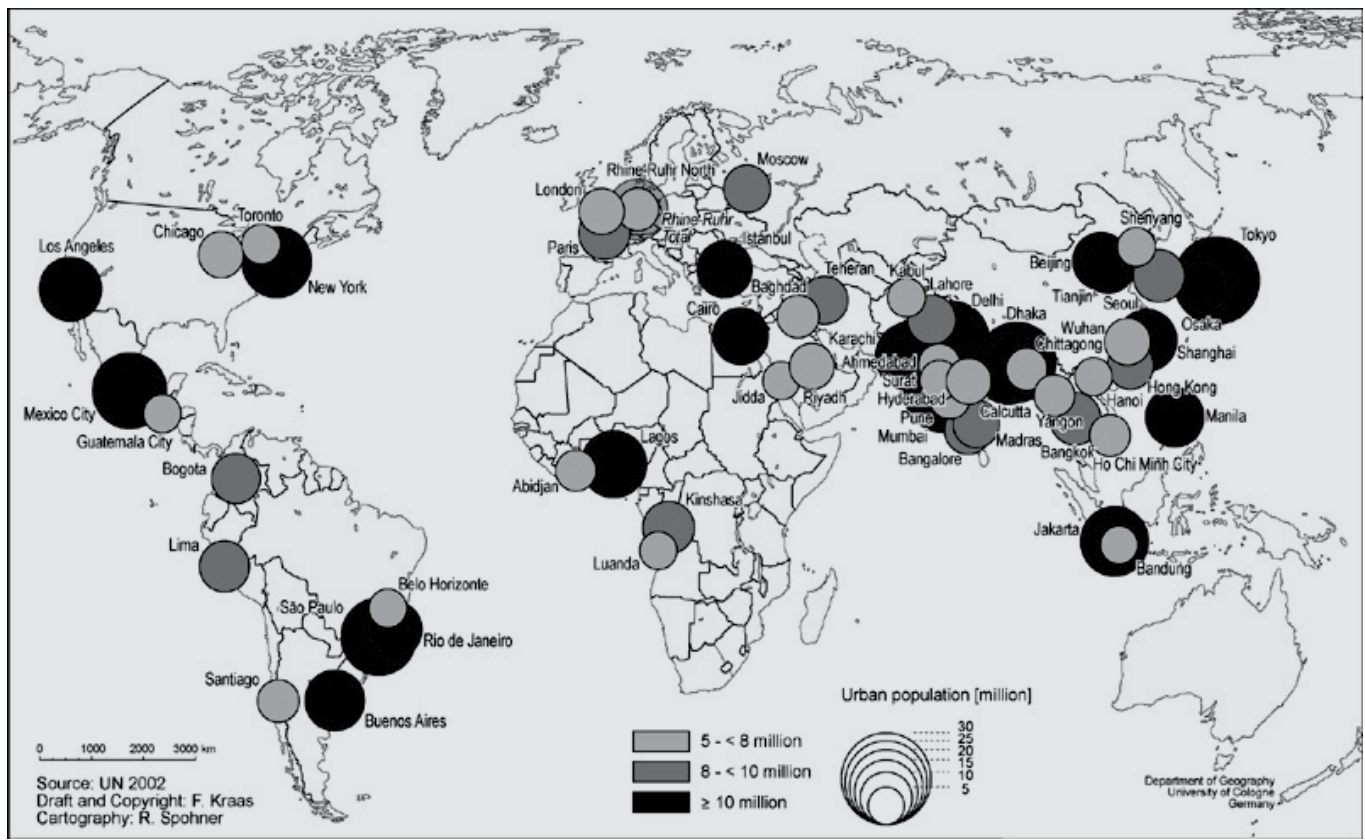

Fig. 1. World-wide urbanization: megacities in 2015

Since all sorts of human activities are concentrated in the city, it is essential to conduct such a reassessment from many viewpoints. This is why an interdisciplinary study approach has been expected, involving researchers in the fields of cultural and social sciences, to study the human and social aspects of local environmental changes such as human activities and lifestyles. In addition, researchers in the areas of natural science and engineering have been working to solve environmental problems and studying technical responses.

Many environmental problems have occurred in cities. The urban concentration of population, energy and information has expanded activities in cities beyond its limit. Because of this, the heavy car traffic in urban areas has brought about air pollution, noise and vibration. Attempts to make the most effective use of land have resulted in the cutting of trees and decreased open space. Rivers in the urban areas have been turned into culverts to secure safety and convenience in cities. A massive daily output of waste from city activities has been carried to neighboring municipalities or faraway places if required, because of the difficulty of finding sanitary landfills in the city areas.

\subsection{Sustainable Development Dilemmas}

In the Brundtland Report (WCED, 1987) alerted the world to the urgency of making progress toward economic development that could be sustained without depleting natural resources or harming the environment. Published by an international group of politicians, civil servants and experts on the environment and development, the report provided a key statement on sustainable development, defining it as: development that meets the needs of the present without compromising the ability of future generations to meet their own needs. This Report laid the groundwork for the convening of the Earth Summit in Rio de Janeiro five years later. There is no doubt about the necessity of improving our societies to sustainable ones in the 
beginning of this century. In order to build a sustainable world for the future, it will be necessary first to develop better models for cities, taking into account the multidimensional contributions of science and engineering, politics and social sciences, and many other fields for designing the improved cities of the future. City organization will have to drive our ecological efficiency as a species. Put simply, cities offer the best chance we have of minimizing our ecological impact.

In order to solve global environment problems such as global warming caused by human activities, it is necessary to change a society of heavy energy consumption to a recycling oriented society where thorough measures are implemented to save energy and resources. Founded in 2005, the European Technology Platform for Zero Emission Fossil Fuel Power Plants is a broad coalition of stakeholders united in their support for CO2 Capture and Storage (CCS) a key technology for combating climate change. Indeed, if implemented without delay, CCS can reduce CO2 emissions in the European Union by 400 million tonnes a year by 2030 even before its full potential is realized. CCS can be therefore the most effective measure for reducing European $\mathrm{CO} 2$ emissions after energy efficiency and renewables. These citations show the great plans of EU in the field of Zero Emission Power Plants (ZEPP) developments. Not less ambitious plans are in USA and worldwide. ZEPP creation is very important to prevent the global warming and climate change. But not less or even more important is the problem to eliminate emissions of other (disseminated) sources of atmospheric emissions. For that matter is needed a programme of a complex solution, the creation of Zero Emissions City (ZEC). The paper is aimed at describing of the main elements of such a program, bearing in mind all the air polluters of our cities. It might be solution to the problem of violation of our human right to breathe. Along with fuel-fired power plants such polluters are industry, vehicles, heating of dwellings and incinerators.

\section{Transportation Systems and Vehicles}

\subsection{Municipal Transportation}

Over the next three decades, virtually all of the world's population growth is expected to be concentrated in the high level population urban areas (so called "megacities") in the developing world. According to the World Bank data (2008), these urban agglomerations in most rapidly developing countries account for at least 50 percent of the GNP, but this economic growth tends to accelerate the urban transportation problems. Without any doubt, a well-managed transportation system of a thriving metropolis makes the city functional. It is also the critical link between productive activities and almost all the town services.

\subsection{Vehicles and Emissions}

The fleet of half billion of piston engine -driven vehicles is a big and dangerous polluter. In favour of ZEC the well known old vehicle- electrical car is now within sight. The first in the world electrical car has been demonstrated by Siemens in 1896. However the batteries of that time were too weak to compete with such genial invention of the same year - the diesel piston engine. In hundred years the diesel engine had changed insignificantly, its main elements now are the same as by invention. However gradual success in electrochemistry lets develop the very compact batteries on $\mathrm{NiCl}-\mathrm{Ni}$ process and even better the Li-ion accumulators. Many major automakers are demonstrated electrocars (Mercedes, Toyota, General Motors a.o.). 


\subsection{ZEMPES Concept}

If for any reason the electrical car use is impossible or not justified economically there exists a possibility to build a Zero Emission Membrane Piston Engine System (ZEMPES), see Fig.2 and Fig.3, (Yantovski et al, 2007, Ch.7). Here is used ordinary fuel, combusted in a piston engine just as in ZEPP in the mixture of oxygen and carbon dioxide. Oxygen produced from air, being separated from air in ceramic membrane reactor, whereas $\mathrm{CO}_{2}$ is stored onboard and discharged in a central big tank on filling station.

In the scheme, Fig.3 presented there is no supercharger as the power is increased without pressure elevation in the piston engine. The turbocompressor is actually used to feed the ITMR with compressed air, which enhances the oxygen flux. The total system consists of two loops: the main closed loop 1-2-4-5-6-7-1 and an auxiliary loop 18-19-23-24. Fuel enters the mixer at 11, air is taken from the atmosphere at 18 and oxygen is transferred from heated compressed air in the AMR to the mixer at 28 and 29. The combustible mixture at 1 enters a cylinder of $\mathrm{VM}$, is ignited by a spark and produces mechanical power. The auxiliary turbocompressor supplies compressed air to AMR and gives additional power through clutch KU. The sum is effective power $N_{\mathrm{e}}$. Carbon dioxide with dissolved contaminants is deflected from the cycle at 9 to be discharged at a filling station and then sequestered.

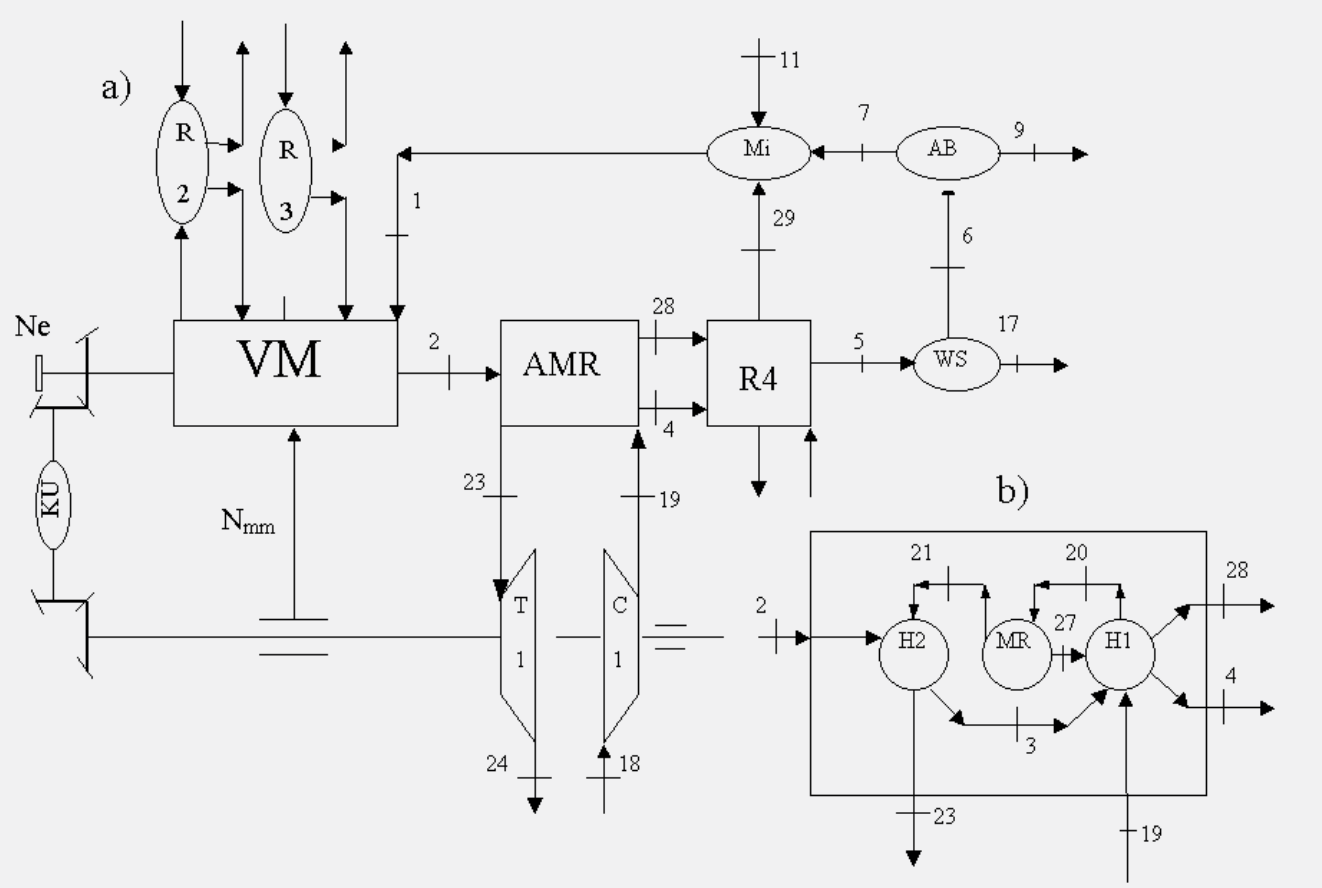

Fig. 2. Schematic of the ZEMPES with oxygen enrichment of an "artificial air" $\left(\mathrm{O}_{2}+\mathrm{CO} 2\right)$.

Symbols: AMR - ion transport membrane, VM - piston engine, $\mathrm{N}_{\mathrm{e}}$ - effective power, $\mathrm{R}$ radiator-cooler, WS - water separator, $\mathrm{AB}$ - splitter, $\mathrm{Mi}$ - mixer, $\mathrm{KU}$ - clutch, $\mathrm{N}_{\mathrm{mm}}$ - heat flow from mechanical losses of turbocompressor. /Numbers reflect the node points/. 


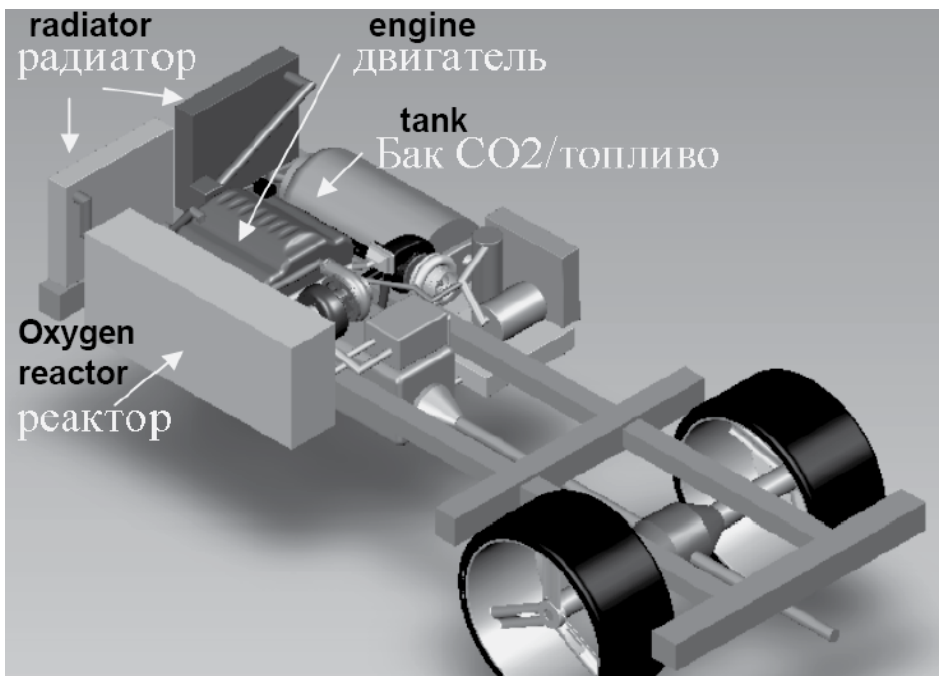

Fig. 3. ZEMPES outlook for a bus on compressed methane

This recently patented concept engine has been firstly proposed as a prime mover for an advanced "Zero emission bus" engine.

\section{Heating and Cooling of Dwellings}

\subsection{Building and Household Energy}

All buildings are individual from the energy consumption point of view. This is because each building has a unique combination of structure, occupation and local micro-climate conditions. Buildings account for 41 pereant of the EU's total energy use and are Europe's largest source of emissions, so improving their energy performance would help reach CO2 emission goals. The estimated potential of about 20 and 60 percent of the present energy consumption in this sector could be respectively saved by 2020 and 2050. To translate this potential into reduced energy consumption, the Energy Performance of Buildings Directive (EPBD) 2002/91/EC is intended to promote the improvement of energy performance of buildings. The same manner, the household sector, responsible for about 15 to 25 percent of primary energy use in OECD countries and for a higher share in many developing countries has been forced to an implementation of new rules for the energy labeling procedures. It should be added that our stock of household appliances is still far less energy efficient than would be economically optimal.

The major unknown factors in the space heating demands are the indoor temperatures used and national averages of hot water consumption. Based on the results of Ecoheatcool project (2005-2006), the most valuable measures to distinct the weather condition and average specific demands for the space heating and cooling in different regions of EU have been formulated. These two parameters: European Heating Index (EHI) and the European Cooling Index (ECI) are shown in the Figs.4a and 4b. A new European heating index (EHI) has been introduced in order to explain the geographical distribution of the average specific space heating demands in the European countries. 


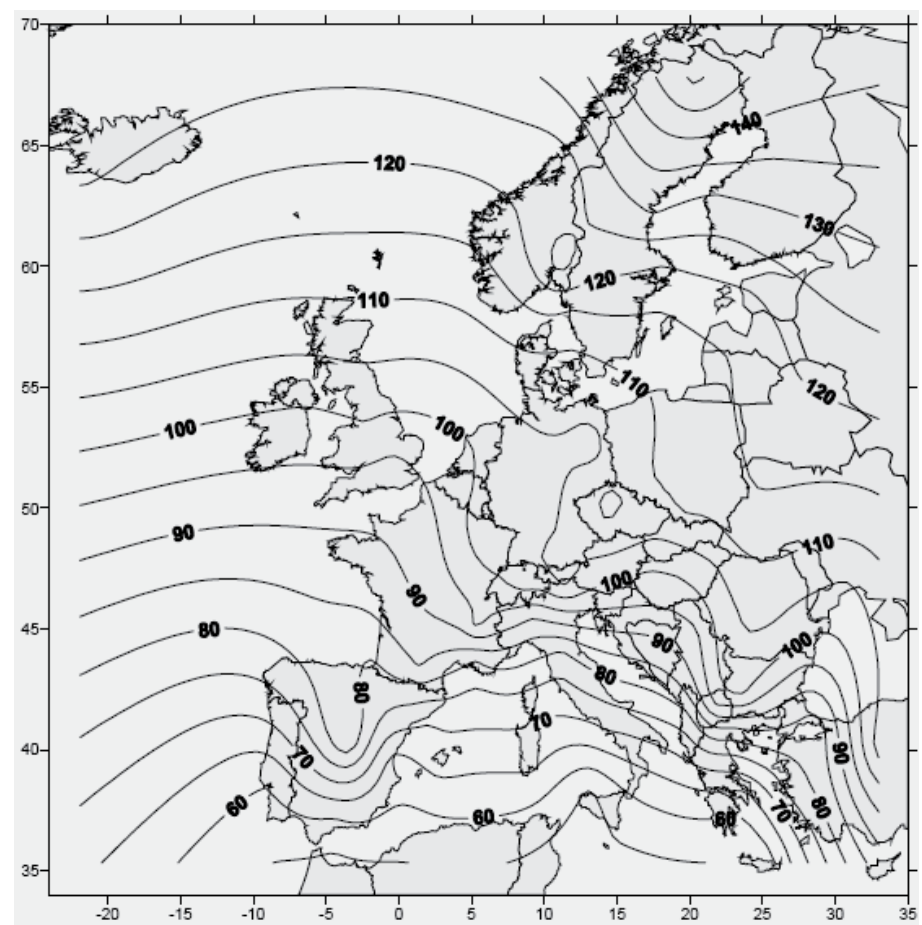

Fig. 4. a European heating index (EHI)

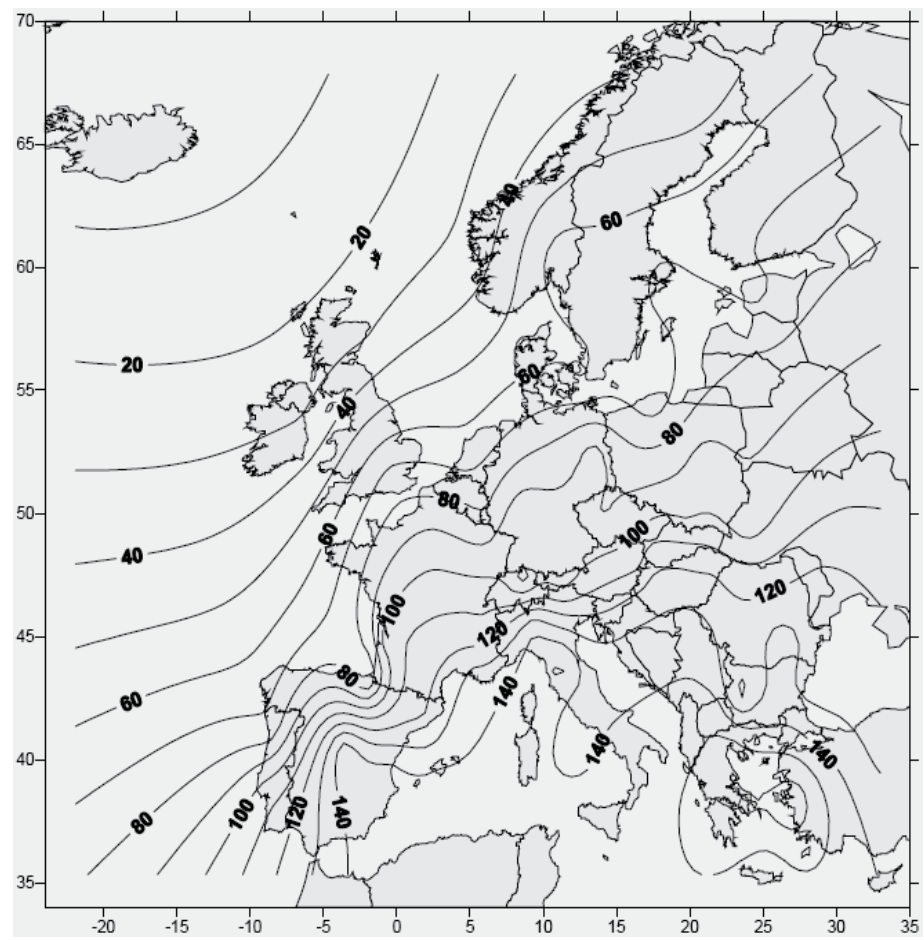

Fig. 4. b European cooling index (EHI) 
A market of heat supply systems was developing by many ages. The ancient Romans using "hypocausts" for distribution of flue gases below floors in buildings managed the first more organized space heating (see, WikipediA). In the middle of XIX century William Thomson (afterward Lord Kelvin) had claimed that he can heat our dwellings (even in rather cold Scotland) using only $3 \%$ of firewood by a "heat multiplier" in comparison with ordinary stove. He offered the use of machinery: to expand air with work production and air cooling below ambient air, then to heat this air by ambient air through appropriate heat exchanger, then to compress this air to the normal or slightly higher pressure by a compressor having temperature high enough for a dwelling. As work of compression exceeds the work of expansion the additional work is needed to drive compressor. But amount of this additional work so small that it is equal about $3 \%$ of energy income into dwelling due to much heat from ambient air.

This brilliant idea was considered as an unrealistic dream about half a century. Then it was materialized in the two large industrial branches: cooling machines and heating machines (the last are called "heat pumps", HP). The only change from the first idea was the use a special low-boiling fluid "Freon", instead of air in a closed loop. In some cases it might be the carbon dioxide either. Now in the world exist tens of millions small heat pumps, taking low-grade heat from ambient air (as it was mentioned by inventor) or from the ground, the layers some meters below the heated building. As usual their compressor is driven by an electric motor, which makes it very good for the ZEC concept. Due to accepted ambient heat the electrical energy is about $30 \%$ of the delivered heat to dwelling. If to use direct electric heat for the same matter the $100 \%$ of electrical energy is needed. That is why the direct electrical heating of dwellings is considered as barbarism and is admitted in rare special cases. If a ZEC prefers the district heating, there the heat pump stations (HPS) should be used with powerful HP of about hundred megawatts, taking heat from a near water basin, like a sea or river. An example is one of many Swedish HPS, taking heat from Botany Bay (2 ${ }^{0} \mathrm{C}$ in the winter).

\subsection{District Heating and Cooling}

Typically a district energy system provides thermal energy in the form of hot water or steam from a central heat-generating plant, distributing the energy through the pipe system to the end-users. District energy systems are retrofitted to comply with the new country and EU regulations. These systems have a big potential to be important part of evolving strategies for global climate change. Projections of district energy future are possible with the use of energy consumption forecasts and trend setting concepts involving: cogeneration and trigeneration, geothermal and waste heat systems, renewable energies, gas turbines, fuel cells, chillers, and carbon capture.

In the next Fig.5 (IEA-DHC, 2002) is presented the recent approach how to use heat pumps technology to adaptation to cool dwellings, if needed. In European climate this equipment is in work all year-round, replacing many small air conditioners and boilers . 


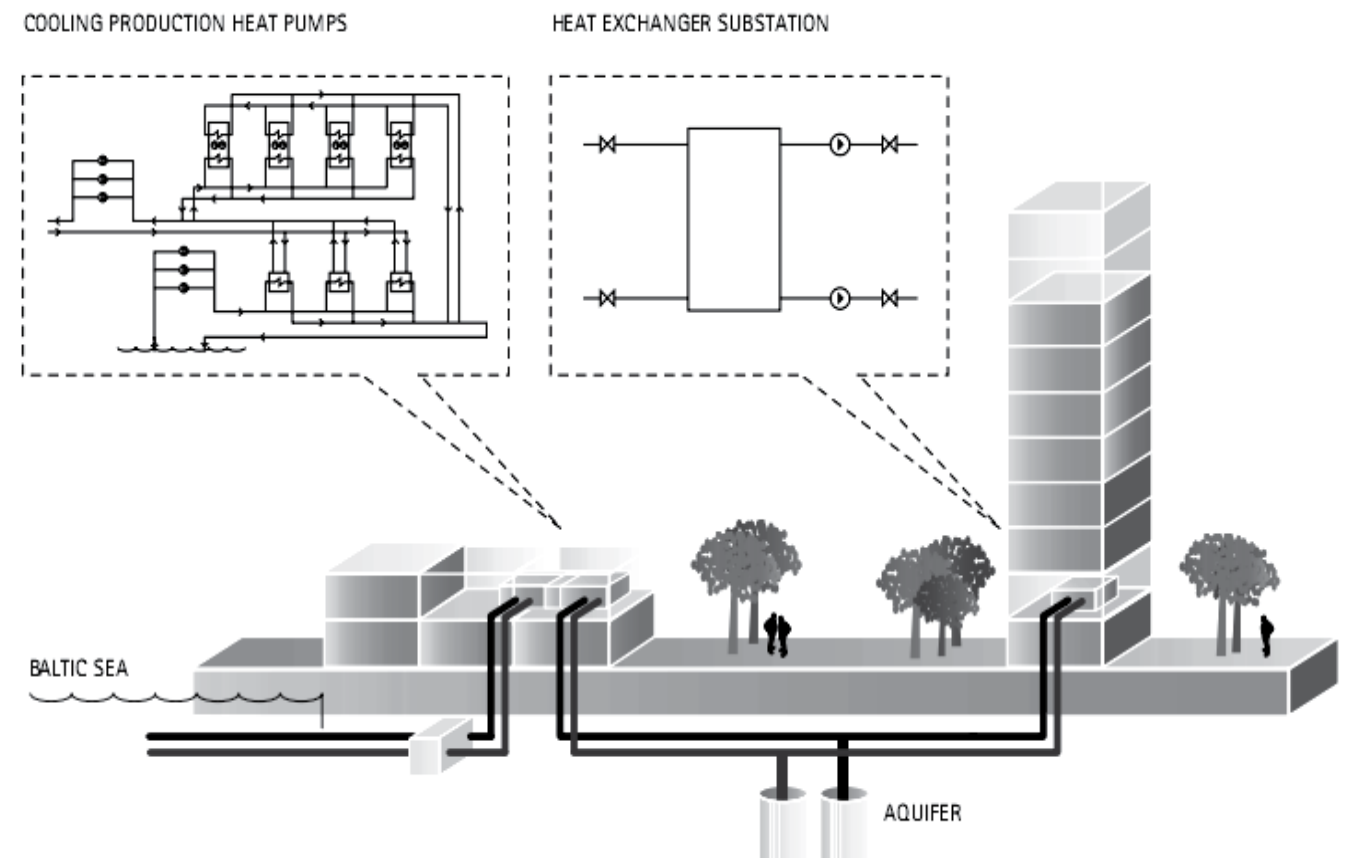

Fig. 5. District heating and cooling (DHC) heat pump station

This modern district heating and cooling (DHC) system is operating by using water of Baltic Sea as low-grade heat source and gives an example of efficient zero emissions climatization in large cities near to the shore heat pump station. It should be mentioned, that an input of secondary and renewable resources to the district heating and cooling systems can replaces mainly fossil primary energy supply (coal and oil). Hence, more district heat in the European energy system will generate more electricity in CHP plants, extend the use of renewable resources, and reduce the final demand of natural gas and fuel oil.

\subsection{Zero Emissions Power Plants}

The domination of fossil fuels in the energy supply of this Century is seen from the World Energy Forecasts of International Energy Agency (IEA, 2004). Only to the very end of the Century might be implemented Renewable energy in massive scale. The ZEPP are unavoidable for many decades as a bridge to that time.

Among many schematics, including the first one by C. Marchetti (1979) the most popular is "Oxy-fuel" one, with combustion of arbitrary fuel in the artificial air, the mixture of oxygen and carbon dioxide, recirculated to be mixed to oxygen from an air separation unit. First experiments of combustion of coal powder in CO2 and oxygen belongs to A. Wolsky (1985) in Argonne National Lab., see Foy and Yantovsky (2006). The first in the world brown coal-fired ZEPP of $30 \mathrm{MW}$ commissioned 9-th October 2008 by Vattenfall in Germany. Due to successful test it in a year (Rolland, 2008), it is worth to be depicted in Fig.6. 


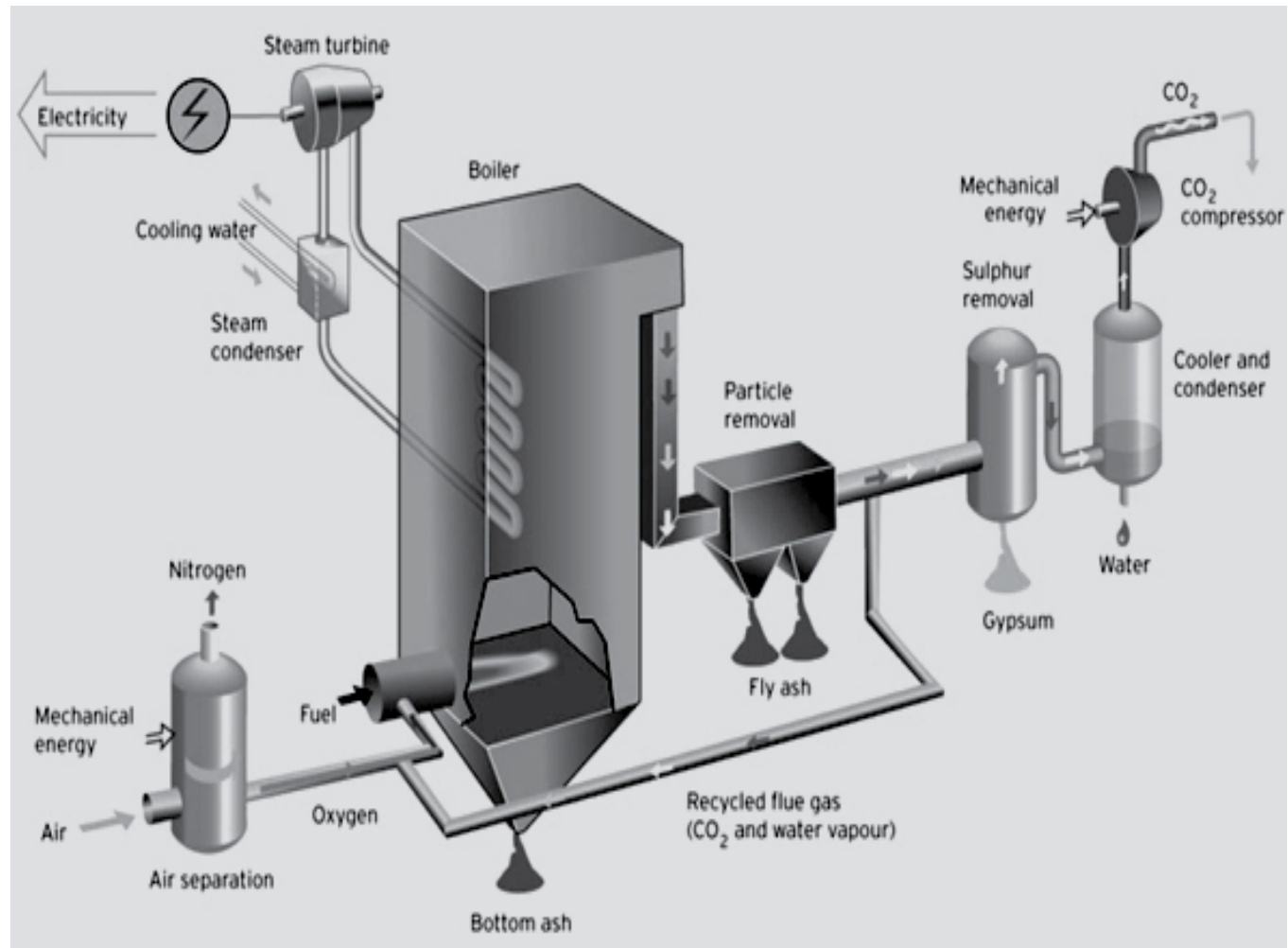

Fig. 6. Schematics of the first ZEPP coal-fired power plant of $30 \mathrm{MW}$ by Vattenfall

\section{Municipal Wastes Treatment}

\subsection{Solid Wastes Incineration}

Worldwide population growth, urbanization, technological development and grooving up economic activity generate large quantities of waste. Since the waste streams contain sometimes the raw material and energy resources, waste management decisions must be tied to their conservation, recovery and utilization issues (recycling). Space for landfills has been plentiful in the past, but is becoming harder to find in large urban areas. Recycling programs have reduced the amount of matter going into landfills, but combustion may become more viable in some urban areas where the landfill sites become scarce or if energy prices make combustion more economically viable. The combustion of municipal wastes is extremely detrimental for atmosphere due to very dangerous combustion products. Some wastes contain the plastic materials with Chlorine, heavy metals and others; giving poisonous exhaust gases with very toxic dioxins and furans. Hovever, burning waste at extremely high temperatures also destroys chemical compounds and disease-causing bacteria. Even after many stages of cleaning the discharge of incinerators into atmosphere is harmful and the problem of Zero Emission Incinerator (ZEI) is still very urgent and difficult. The best way seems to be the combining of an incinerator and ZEPP, proposed by Yantovsky (1998). Well known are incinerators with rotary kiln, see Fig.7. 


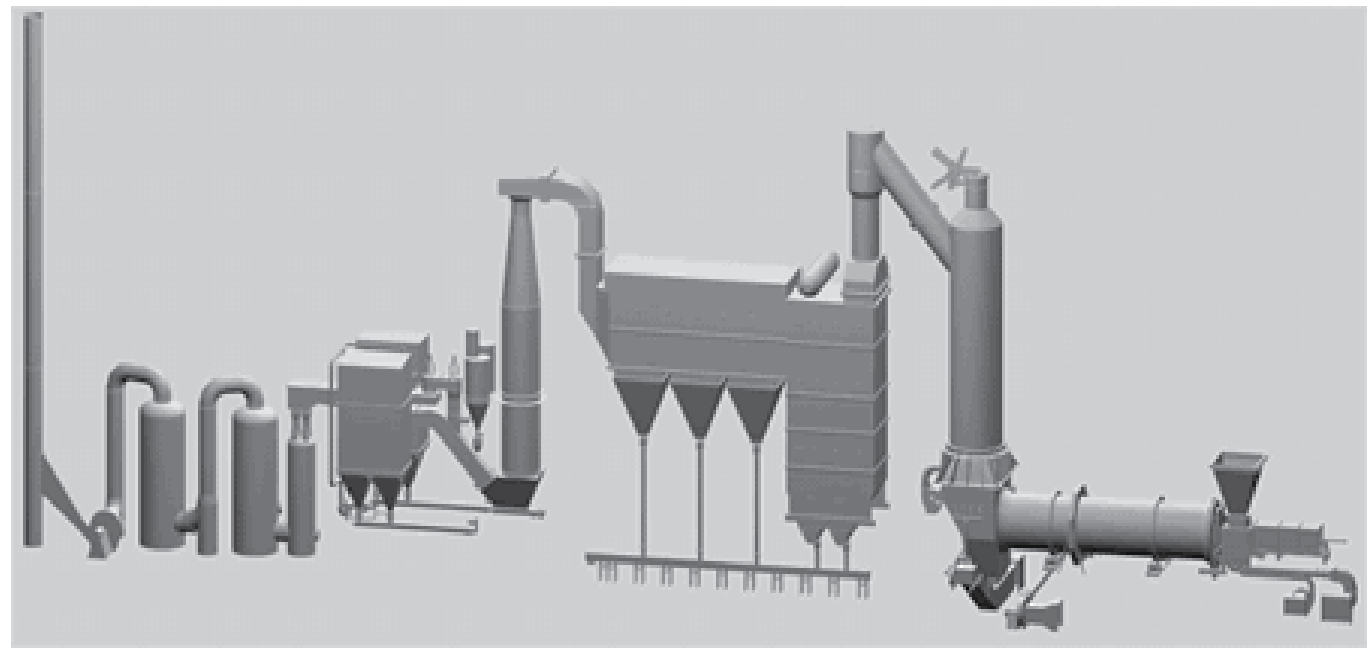

Fig. 7. Schematics of a rotary kiln incinerator

Rotary kilns provide long retention, good thermal isolation, and because of the rotation excellent bed rollover. All systems are configured for continuous operation and can have many types of waste streams such as: boxed, containers, drum, and shredded. In this schematics the total flow goes from right to the left, rotating kiln is almost horizontal cylinder, and after some cleaning reactors the exhaust gases are going through a vertical stack upward into atmosphere. Just this is a sore point, inadmissible for ZEC. Looking at a coal-fired ZEPP (Fig.7) we see that if combustion in rotary kiln is in "artificial air", (a mixture of recirculated gases with oxygen), the incinerator might become Zero Emissions just like coal-fired power plant. It is a possible matching, giving ZEI. Rotary kiln here plays the role of combustion chamber of the boiler of power station. This equipment, with corresponding post-combustion chamber is a universal unit, a proven and versatile process for the incineration of solid "hazardous waste". All the poisonous contaminants of exhaust gases are dissolved in the liquefied carbon dioxide and sequestered in depth without harm.

\section{Energy System of Zero Emissions City}

\subsection{Environmentally Sustainable Society}

Without any doubts we can tell, that for humans to live sustainably, the Earth's resources must be used at a rate at which they can be replenished. From the global point of view the sustainability is a state of balance between resource and the regenerative capacity of the earth.

An environmentally sustainable society satisfies the basic needs of its people without depleting or degrading its natural resources and thereby preventing current and future generations of humans and other species from meeting their basic needs. During the preparatory meetings for the URBAN21 Conference (Berlin, July 2000) the following definition was developed to define sustainable urban development: "Improving the quality of life in a city, including ecological, cultural, political, institutional, social and economic components without leaving a burden on the future generations. A burden which is the result of a reduced natural capital and an excessive local debt. Our aim is that the flow principle, that is based on an equilibrium 
of material and energy and also financial input/output, plays a crucial role in all future decisions upon the development of urban areas." However, many more definitions can be very easy found in the all open sources.

\subsection{Zero Carbon Future Town}

Many scientists and politics now throw around the terms "zero-carbon economy" or "lowcarbon society", not explaining the tools and introducing not well-defined conditions to achieve these goals.

As problems of industry and incineration are not still elaborated enough, here is presented schematics for a city without them, see Fig.8. The main energy system of this "Zero Emission City" will be operating with the carbon dioxide capture and sequestration at the Oxyfuell ZEPP. The public city-bus transportation is equipped with modern and ultra-low emissions engines (ZEMPES), small electrical/fuel-cell cars. It will be mentioned that the oxy-fuel combustion takes place in ZEPP and ZEMPES with nearly zero emissions. In Fig.8 (see, Yantovsky and Gorski, 2008) the only emission is water vapour from cooling tower. Any stack is absent.

Individual domestic heating systems should apply the geothermal or water/air heat pumps, biomass boilers and solar panels (thermal and PV's), depending on the local weather conditions and resources. Each house represents the highest level of EPDB class and displays its zero-carbon energy certificate.

All household appliances and electric lighting bulbs are energy-save systems (A++ units) and can be connected to the central control processor, integrating the internal system operation (especially for cold and hot water closed loops, and the ventilating air circulation with the heat recovery).

The urban-drainage and sewage systems are capable for selection of recoverable liquid components and catch some poisoning substances. All solid wastes and garbage are initially segregated, and partially incinerated or recycled.

Local travel, as a principle is covered by public bus and light tram transportation network, bicycle paths and walkways (close to riverside). Te majority of private cars and taxis are electric. The community centre with the offices, sport and cultural halls will be easy and fast accessible by public routes.

The long-distance land travelling (for example between megacities and provinces) will be reorganized in order to extend the very fast continental networks with magnetic levitating ("Maglev") technology railways. It should cover a main needs for future connection needs.

In 2006, 15-17 May in Stockholm there was the European conference for local governments on climate protection, energy efficiency and the promotion of renewable energy under a motto: "A Future with Zero CO2 Emissions". There are erroneously no one word on carbon capture and sequestration (CCS), only prayers on efficiency increase and coal elimination. It is a sharp contrast to policy of European Union, formulated in the beginning of Introduction. 


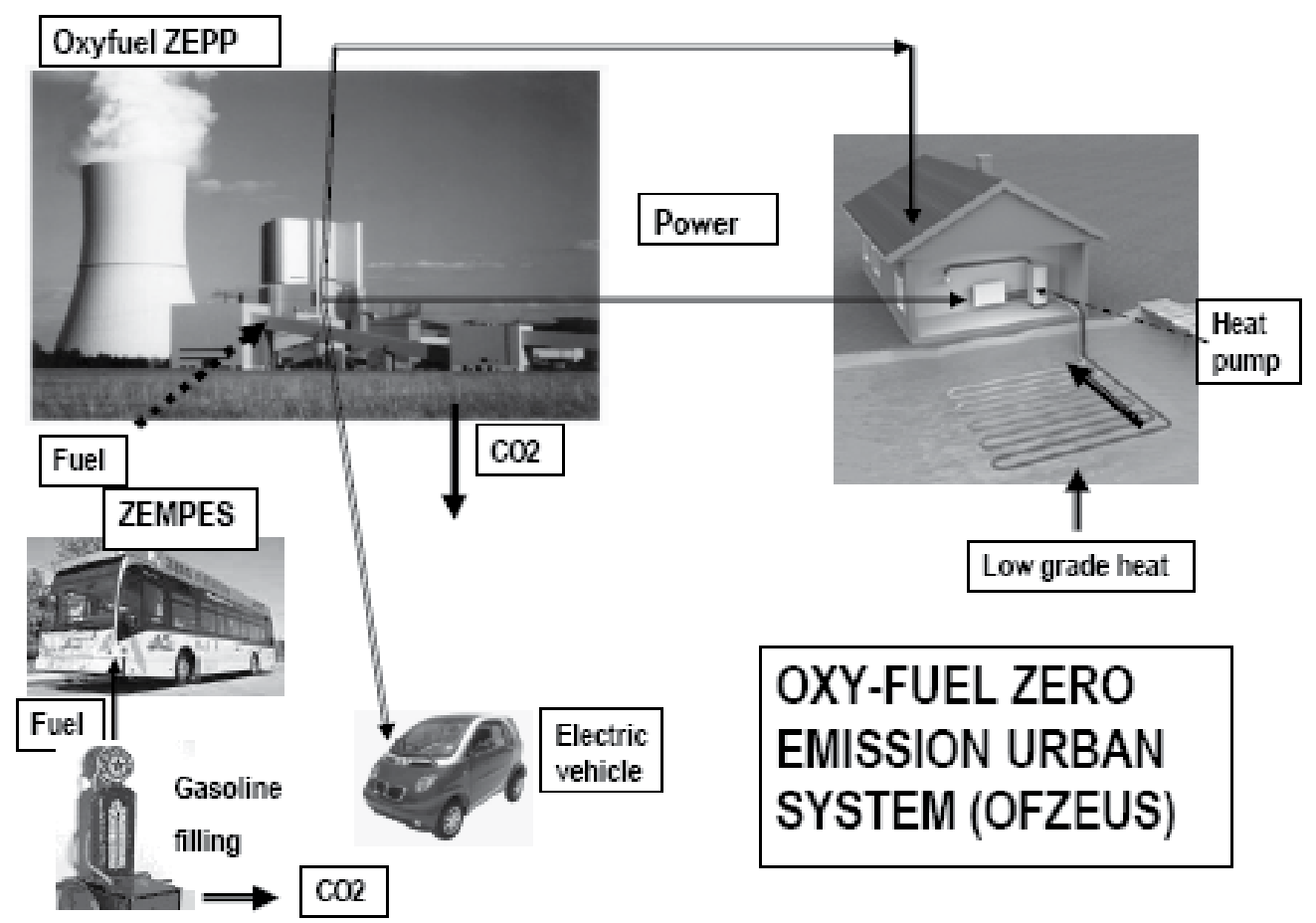

Fig. 8. Energy system of "Zero Emission City"

\section{Concluding Remarks}

In 2007 the IPCC climate scientists concluded that there was at least a 90\% probability that the atmospheric increase in $\mathrm{CO} 2$ was human-induced - essentially due to fossil fuel combustion and, to a lesser extent, the $\mathrm{CO} 2$ released from changes in land use. Projections for the end of 21-st century indicate that a minimum of $500 \mathrm{ppm}$ can be expected. Stabilizing the world's climate will require high income countries to reduce their emissions by $60-90 \%$ over 2010 levels by 2050. This should stabilize atmospheric carbon dioxide levels at 450-650 ppm from the current level of about 392 ppm (April 2010). Above this level and temperatures would probably rise by more than 2 Centigrade to produce "catastrophic" climate change. Reduction of current $\mathrm{CO} 2$ levels must be achieved against a background of global population increase and developing countries aspiring to the energy-intensive and high consumption lifestyles.

The human consumption should be related to the biologically productive land needed to provide the resources, and absorb the wastes of the average global citizen. The sustainability goal is to raise the global standard of living without increasing the use of resources beyond globally sustainable levels; that is, to not exceed "one planet" consumption. This requires us to change the way we design, produce, use and dispose of the goods at a very constrained world.

The main questions today concerning urban space energy systems are their economical and environmental impacts. Conversion of a city into zero emission one seems to be possible using known and recently developing technologies. Even without industry and incineration 
(so far require a number of improvements), amount of cities is quite enough to begin with. The price of dwellings in such cities might be higher than in cities with polluted air. The consumption of oil will be drastically reduced, which is essential in view of world oil decline. Major or alternative energy supply is to be from coal-fired ZEPP. These combined power plants will assure an alternative way for supplying the heat and electricity based on still popular solid fuels and avoid large $\mathrm{CO} 2$ emissions associated to the classical combustion technologies. The described zero emissions coal-electrical energy system of an eco-city with Oxy-fuel ZEPP should attract attention of the World Mayors Council on Climate Change.

In the long run, the development and widespread adoption of new technologies can greatly ameliorate what, in the short run, sometimes appear to be overwhelming conflicts between economic well-being and environmental quality. With existing technology, problems such as emissions of green-house gases and disposal of hazardous wastes pose difficult choices between potentially irreversible damage to the environment and high economic costs of control. But if history is any guide, we know that over a period of decades changes in technology can alter dramatically the nature of these tradeoffs. Therefore, the effect of public policies on the development and spread of new technologies may, in the long run, be among the most important determinants of success or failure in environmental protection (Kneese \& Schultz, 1978).

\section{References}

Annon. (2002) District Cooling Stockholm City, www.iea-dhc.org/0400.html , www.energy.rochester.edu/idea/cooling/1995/stockholm.htm - opis www.friotherm.com/downloads/vaertan_e008_uk.pdf (accessed March 7th 2010)

Annon, (2009). Rinspeed iChange. www.rinspeed.com/pages/content/frames_e.htm (accessed March 8th 2010)

Annon, (2004). Call for urgent and decisive policy responses. IEA Press Releases, 04(21) Oct. 26, www.iea.org/press/pressdetail.asp?press_rel_id=137 (accessed May 2nd 2010)

Annon, (2010). Rotary Incineration. www.metso.com/miningandconstruction/mm_pyro. nsf/WebWID/WTB-041116-2256F-3B3FA, (accessed March 10 th 2010)

Ecoheatcool and Euroheat \& Power (2005-2006) www.euroheat.org/Files/Filer/ ecoheatcool/download.htm (accessed March 11 th 2010)

Foy, K. \& Yantovsky, E. (2006). History and state-of-the-art of fuel-fired zero-emissions power cycles, Int. Journal of Thermodynamics, Vol. 9, No. 2 (June 2006), 37-64, ISSN 1301-9724

Hall, P. \& Pfeiffer, U. (2000). Urban Future 21. A Global Agenda for Twenty-First Century Cities, E\&F Spon, Berlin, Proc. of Urban Future Conference, ISBN 0-415-24075-1

Kraas, F. (2007). Megacities and Global Change in East, Southeast and South Asia, ASIEN Journal, Vol. 103 (April 2007), pp. 9-22, Ed. DGA, ISSN 0721-5231

Kneese, A.V. \& Schultz, C.L. (1975). Pollution, prices and public policy (The Brookings Institute, Washington, DC). 
Rolland, W. (2008). Entwicklung der CCS Technologie bei Vattenfall. Sächsisch-ungarischer Wirtschaft-kongress, 14/15 Oct. 2008, Budapest, www.ahkungarn.hu/fileadmin/user _upload/Dokumente/Bereich_HF/Dienstleistungen/Kooperationsboersen/Rolland.pdf, (accessed March 10th 2010)

Toporov, D. et al., (2008). Detailed investigation of a pulverised fuel swirl flame in CO2/O2 atmosphere, Combustion \& Flame, Vol. 155, No. 4, 605-618, ISSN: 0010-2180

Yantovski, E. (1998). Zero emissions power plant as an incinerator. Fuel and Energy Abstracts, Vol. 39, No. 3 (May 1998), 232-232, ISSN 0140-6701

Yantovsky, E. (2009). Author's photo. At the Energy Kongress, 10th Febr., Essen

Yantovsky, E.; Gorski, J. \& Shokotov, M. (2009). Zero Emissions Power Cycles, CRC Press, ISBN 978-1-4200-8791-8, Boca Raton

Yantovsky, E. \& Gorski, J. (2008). Zero Emissions Urban Power, Lectures presented at the Conf. COST23: Low Carbon Urban Built Environments (LCUBE), 24/25 Sept., Munich

WCED (1987): Our Common Future, Oxford Univ. Press (1987), ISBN: 0-19-282080-X 



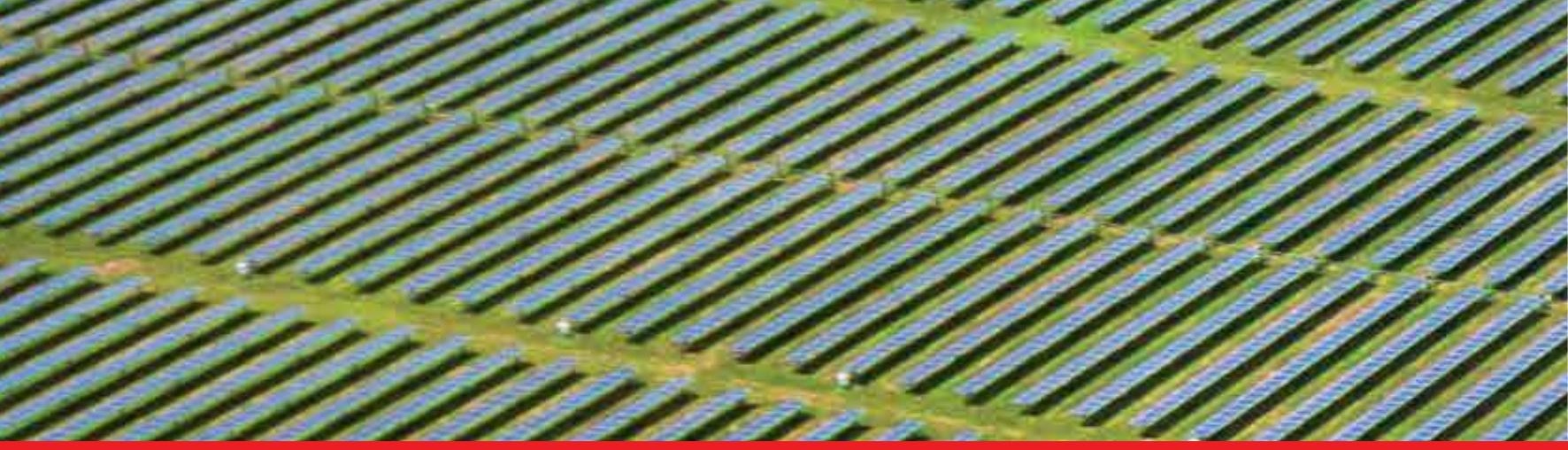

\section{Edited by Kei Eguchi}

This book reports the latest developments and trends in "clean energy systems and experiences". The contributors to each chapter are energy scientists and engineers with strong expertise in their respective fields. This book offers a forum for exchanging state of the art scientific information and knowledge. As a whole, the studies presented here reveal important new directions toward the realization of a sustainable society.

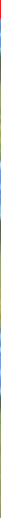

